Pontifícia Universidade C $_{\text {atólica }}$

Jean Michel da Silva Pereira

Efeitos Causados Pelo Impacto de Íons de MeV em Meteoritos do tipo Condrito Ordinário: Intemperismo Espacial

Tese apresentada como requisito parcial para obtenção do grau de Doutor pelo Programa de Pós-Graduação em Física da PUC-Rio.

Orientador: Prof. Enio Frota da Silveira

Co-orientador: Prof. Daniele Fulvio 


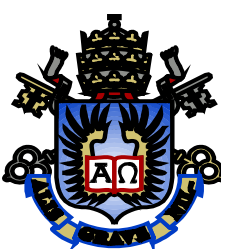

Jean Michel da Silva Pereira

\section{Efeitos Causados Pelo Impacto de Ílons de MeV em Meteoritos do tipo Condrito Ordinário: Intemperismo Espacial}

Tese apresentada como requisito parcial para obtenção do grau de Doutor pelo Programa de Pós-Graduação em Física do Centro Técnico Científico da PUC-Rio. Aprovada pela Comissão Examinadora abaixo

Prof. Enio Frota da Silveira Orientador Departamento de Física - PUC-Rio

Prof. Daniele Fulvio Co-orientador Departamento de Física - PUC-Rio

Prof. Marcelo Martins Sant'Anna UFRJ

Prof. Omar Ginoble Pandoli Departamento de Química - PUC-Rio Prof. Jorge Marcio Ferreira Carvano Observatório Nacional - ON

Prof. Leandro José Raniero UniVap 
Todos os direitos reservados. É proibida a reprodução total ou parcial do trabalho sem autorização da universidade, do autor e do orientador.

\section{Jean Michel da Silva Pereira}

Graduou-se em licenciatura em física pelo Instituto Federal do Rio de Janeiro (2012). É mestre em Física pela Pontificia Universidade Católica - PUC-Rio (2015). Atualmente atua com professor de educação básica, técnica e tecnólogica no IFRJ Campus Volta Redonda.

Ficha Catalográfica

Pereira, Jean Michel da Silva

Efeitos Causados Pelo Impacto de Íons de MeV em Meteoritos do tipo Condrito Ordinário: Intemperismo Espacial / Jean Michel da Silva Pereira; orientador: Enio Frota da Silveira; co-orientado: Daniele Fulvio. - Rio de Janeiro: PUCRio, Departamento de Física, 2019.

v., $166 \mathrm{f}$ : il. color. ; $30 \mathrm{~cm}$

Tese (doutorado) - Pontifícia Universidade Católica do Rio de Janeiro, Departamento de Física, 2019.

Inclui bibliografia

1. Física - Tese. 2. Meteorito; Condrito Ordinário; 3. UVVIS-NIR; Raman; 4. Irradiação por íons; 5. Intemperismo Espacial

I. da Silevira, Enio Frota. II. Fulvio, Daniele. III. Pontifícia Universidade Católica do Rio de Janeiro. Departamento de Física. IV. Título. 


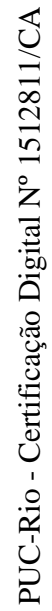

Ao professor Enio Frota da Silveira 


\section{Agradecimentos}

Ao professor Enio Frota da Silveira por me abrir as portas, por toda paciência e dedicação durante a orientação do trabalho.

Ao professor Daniele Fulvio pela sugestão de tema e pelas inúmeras contribuições durante todo o processo.

À Cassia, em especial, pelo incentivo no início de tudo.

À professora Maria Elizabeth Zucolotto do Museu Nacional-UFRJ, por disponibilizar as amostra utilizadas.

Aos professores Fernando Lázaro Freire Junior e Marcelo Eduardo Huguenin Maia da Costa, por disponibilizar o espectrômetro Raman sempre que necessário, bem como aos colegas Cesar Augusto Diaz Mendoza, André Nascimento e Neileth Johanna Stand Figueroa por sempre estarem dispostos a ajudar a operá-lo.

Ao professor Marco Cremona por disponibilizar o espectrômetro UV-VIS-NIR.

Aos professores do Departamento de Engenharia Química e de Materiais (DEQM/PUCRio), Rodrigo F. M. de Souza pelas simulações termodinâmicas e Natasha Midori Suguihiro pela ajuda nas discussões e por indicar experimentos complementares.

Aos amigos de pós-graduação Cíntia Pires da Costa e Felipe Ptak Lemos por tornarem o caminho um pouco menos árduo. À Cíntia, em especial, por estar sempre disposta a ajudar com medidas e conselhos. Sem as contribuições dela esta tese não seria possível.

Aos colegas de grupo, Rodrigo Pereira e Pablo Ramón Oliveira por ajudarem na realização de algumas medidas.

À minha esposa Dalva por estar sempre ao meu lado.

À minha família.

Aos técnicos e funcionários do Laboratório Van de Graaff por sempre estarem dispostos a ajudar.

Aos professores do Departamento de Física.

Ao IFRJ por permitir minha licença para finalizar o doutorado.

O presente trabalho foi realizado com apoio da Coordenação de Aperfeiçoamento de Pessoal de Nível Superior - Brasil (CAPES) - Código de Financiamento 001 


\section{Resumo}

Da Silva Pereira, Jean Michel: da Silveira, Enio Frota (orientador). Efeitos Causados Pelo Impacto de Íons de MeV em Meteoritos do tipo Condrito Ordinário: Intemperismo Espacial. Rio de Janeiro, 2019. 166p. Tese de Doutorado - Departamento de Física, Pontifícia Universidade Católica do Rio de Janeiro.

Corpos relativamente pequenos do sistema solar não possuem atmosfera (ou muito rarefeita, chamada exosfera) e nem campo magnético: encontram-se praticamente desprotegidos da influência do ambiente espacial no qual estão inseridos. Tais corpos (como a maioria dos asteroides, luas e cometas distantes do Sol), estão sujeitos aos efeitos do chamado intemperismo espacial. Com o objetivo de simular e estudar este fenômeno em laboratório, três amostras de meteoritos do tipo condrito ordinário foram irradiadas por feixes de $\mathrm{H}^{+}$com energia de 1,0 MeV. Uma das amostras foi, também, irradiada por feixe de $\mathrm{N}^{+}$de 2,0 MeV. Os efeitos da irradiação foram monitorados por espectroscopias Raman e UV-VIS-NIR. Os resultados Raman mostram variações sistemáticas do número de onda, da intensidade e da largura das bandas vibracionais estudadas, evidências de modificações estruturais. As seções de choque de destruição das ligações $\mathrm{Si}-\mathrm{O}$ presentes nas estruturas cristalinas foram determinadas. A espectroscopia UV-VIS-NIR por refletância de esfera integrada foi usada para monitorar as modificações nas características espectrais. Os espectros obtidos mostram escurecimento e avermelhamento progressivos das amostras irradiadas; a amplitude destas modificações depende do conteúdo inicial de ferro na estrutura. É proposto que o avermelhamento observado com o aumento da fluência (ou dose) da irradiação deve-se ao aumento do coeficiente de absorção na faixa azul que, por sua vez, decorre da diminuição do gap óptico do material. Estes resultados são relevantes para a modelagem da evolução físico-química de asteroides expostos ao vento solar.

\section{Palavras - chave}

Meteorito; condrito ordinário; irradiação por íons de MeV; Espectroscopia UV-VIS-NIR; Espectroscopia Raman. 


\section{Abstract}

Da Silva Pereira, Jean Michel: da Silveira, Enio Frota (Advisor). Effects produced by MeV Ion Impact on ordinary chondrite Meteorites: Spatial Weathering. Rio de Janeiro, 2019. 166p. Tese de Doutorado Departamento de Física, Pontifícia Universidade Católica do Rio de Janeiro.

Relatively small bodies in the solar system have no atmosphere (or very thin, called the exosphere) and no magnetic field: they are virtually unprotected from the influence of the space environment in which they are inserted. Such bodies (like most asteroids, moons, and comets far from the sun), are subject to the effects of so-called space weathering. To simulate and study this phenomenon in the laboratory, three samples of ordinary chondrite meteorites were irradiated by $\mathrm{H}^{+}$beams with $1.0 \mathrm{MeV}$ energy. One of the samples was also irradiated by a 2.0 $\mathrm{MeV} \mathrm{N}^{+}$beam. The effects of irradiation were monitored by Raman and UVVIS-NIR spectroscopies. The Raman results show systematic variations in the wavenumber, intensity, and width of the studied vibrational bands, evidence of structural modifications. The shock sections of the destruction of Si-O bonds present in the crystalline structures were determined. Integrated sphere reflectance UV-VIS-NIR spectroscopy was used to monitor changes in spectral characteristics. The obtained spectra show progressive darkening and reddening of the irradiated samples; The extent of these modifications depends on the initial iron content in the structure. It is proposed that the redness observed with the increase of irradiation creep (or dose) is due to the increase in the absorption coefficient in the blue band, which, in turn, results from the decrease of the optical gap of the material. These results are relevant for modeling the physicochemical evolution of asteroids exposed to the solar Wind.

\section{Keywords}

Meteorite; ordinary chondrite; $\mathrm{MeV}$ ion irradiation; UV-VIS-NIR Spectroscopy; Raman Spectroscopy. 


\section{Sumário}

1 Introdução 23

1.1 Motivação do trabalho 24

1.2 Objetivos gerais 26

$\begin{array}{ll}1.3 \text { Objetivos específicos } & 26\end{array}$

$\begin{array}{ll}1.4 \text { Estrutura da tese } & 27\end{array}$

2 Space weathering e astrofísica experimental 28

2.1 O que é o SpWe e por que estudá-lo 28

2.2 Space weathering em laboratório 31

2.2.1 Experimentos com silicatos 31

2.2.2 Experimentos com meteoritos 32

2.3 Raios cósmicos e vento solar: simulações em laboratório 36

2.3.1 Raios cósmicos e vento solar 36

2.3.2 Intaração íon-matéria 38

3 Técnicas experimentais $\quad 41$

3.1 As amostras: meteoritos condritos ordinários 41

3.1.1 Meteorito Parambu $\quad 42$

3.1.1 Meteorito Putinga $\quad 42$

3.1.3 Meteorito Gail $\quad 43$ 
3.3 Parâmetros de irradiação

3.4 Realização do experimentos 
4.2.3 Mudanças espectrais induzidas pela irradiação com nitrogênio

5.2.1 Refletância no visível e profundidade de banda à 1 micrômetro 110 


\section{Lista de figuras}

Figura 2.1 - à esquerda um esquema dos efeitos da incidência de partículas carregadas e de poeira cósmica; a direita a imagem de microscopia eletrônica de transmissão mostra a presença de nano partículas de ferro.

Figura 2.2 - Comparação entre os espectros de refletância solar do asteroide 6 Hebe e do meteorito OC Averege H6. (Gaffey e Gilbert, 1998).

Figura 2.3 - Fluxo de partículas do vento solar na região próxima a órbita da Terra (a) e dos raios cósmicos galácticos (b).

Figura 2.4 - Esquema representando a incidência de um projétil sobre um sólido (esquerdo); resultado da passagem e interação do projétil com os átomos que formam a estrutura do alvo e a emissão de partículas secundárias (direito).

Figura 3.1 - Fotografias do ímã $90^{\circ}$ que deflete os íons da vertical para horizontal e do switching que dirige os íons horizontalmente para uma das linhas de trabalho. Adaptado de Garcia, 2006.

Figura 3.2 - (a) Representação esquemática do porta-amostras utilizado; (b) exemplo de região irradiada da amostra de meteorito.

Figura 3.3 - (a) Representação esquemática do porta-amostras utilizado; (b) exemplo de região irradiada da amostra de meteorito.

Figura 3.4 - Representação de diferentes interações da radiação incidente com a superfície da amostra.

Figura 3.5 - Representação das interações usadas no modelo de Kubelka-Munk. 
Figura 3.6 - Esquema de medida da esfera integradora: (a) medida de referência; (b) medida de refletância da amostra; (c) Espectrômetro UV-VIS-NIR da PUC-Rio; (d) esfera integradora que pode ser acoplada a ele para medidas de reflexão integrada.

Figura 3.7 - Esquema indicando a área onde a amostra foi irradiada e a região onde a medida do espectro de reflexão é feita.

Figura 3.8 - Exemplo de espectro de refletância obtido no espectrômetro UV-VIS-NIR com a esfera integradora.

Figura 3.9 - Transições responsáveis pela absorção de infravermelho e pelos espalhamentos Rayleigh e Raman. No processo Rayleigh, o fóton espalhado tem mesma energia do incidente. No processo Raman (Stokes), o fóton é espalhado com energia menor que a do fóton incidente. A linha tracejada corresponde a um estado proibido por transição direta do estado fundamental.

Figura 3.10 - Parâmetros Raman e as informações que fornecem. Adaptado de Zongwei X, et. al. 2018.

Figura 3.11 - Representação esquemática da incidência de um faixe de laser de um espectrômetro Raman sobre uma amostra.

Figura 3.12 - Exemplo de espectro Raman do meteorito Putinga.

Figura 3.13 - Foto do espectrômetro Raman utilizado nesse trabalho. Ao lado encontra-se a foto do laser.

Figura 4.1 - Espectros Raman obtidos para 10 pontos diferentes em torno do centro da amostra para o meteorito Parambu ainda não irradiado.

Figura 4.2 - (a) espectro Raman de uma amostra pura de Olivina; (b) espectro Raman de uma amostra pura de diopsita, um tipo de pirixênio; espectros Raman de dois pontos (c) (ponto 2) e (d) 
(ponto 7) do meteorito Parambu para evidenciar a presença de quatro picos de interesse.

Figura 4.3 - Espectros Raman obtidos para 14 pontos diferentes em torno do centro da amostra para o meteorito Putinga, ainda não irradiado.

Figura 4.4 - Espectros Raman de dois pontos (ponto 5 no lado esquerdo e ponto 10 no lado direito) do meteorito Putinga para evidenciar a presença de quatro picos de interesse.

Figura 4.5 - Espectros Raman obtidos para 6 pontos diferentes em torno do centro da amostra para o meteorito Gail, ainda não irradiado.

Figura 4.6 - Espectro Raman do ponto 6 feito no meteorito Gail para evidenciar a presença de dois picos de interesse.

Figura 4.7- Exemplo de ajuste Lorentz feito nos picos para obtenção dos parâmetros Raman.

Figura 4.8 - Parâmetros Raman como função da fluência para o meteorito Parambu; (a) Xc do pico 1; (b) w do pico 1; (c) Xc do pico 2; (d) w pico 2; (e) Xc pico 3; (f) w pico 3; (g) Xc pico 4; (h) w pico 4.

Figura 4.9 - Parâmetros Raman como função da fluência para o meteorito Putinga; (a) Xc do pico 1; (b) w do pico 1; (c) Xc do pico 2; (d) w pico 2; (e) Xc pico 3; (f) w pico 4; (g) Xc pico 4; (h) w pico 4.

Figura 4.10 - Parâmetros Raman como função da fluência para o meteorito Gail; (a) Xc do pico 3; (b) Xc do pico 4; (c) w do pico 3.

Figura 4.11 - (a) intensidade do pico 1 normalizada como função da fluência; (b) intensidade do pico 2 normalizada como função da fluência. Ambos os gráficos são para irradiação com $\mathrm{H}^{+}$. 
Figura 4.12 - (a) intensidade do pico 3 normalizada como função da fluência; (b) intensidade do pico 4 normalizada como função da fluência. Ambos os gráficos são para irradiação com $\mathrm{H}^{+}$.

Figura 4.13 - Comparação entre os espectros de refletância (normalizados a 0,6 micron) dos meteoritos Parambu (LL), Putinga (L) e Gail (H). Todos os espectros medidos antes da irradiação.

Figura 4.14 - (a) Exemplo de como obter a profundidade de banda de absorção em 1 micrometro. $\mathrm{O}$ espectro mostrado pertence ao meteorito Putinga. (b) Resultado após a divisão do espectro original pelo gráfico da reta mostrada em (a).

Figura 4.15 - Comparação entre as profundidades de banda para os três meteoritos.

Figura 4.16 - Espectros de refletância do meteorito Putinga (L), virgem e após 5 pontos de irradiação.

Figura 4.17 - Gráfico das refletâncias, visível e infravermelho, como função da fluência da irradiação.

Figura 4.18 - Profundidade de banda em $1 \mu \mathrm{m}$ como função da fluência.

Figura 4.19 - Espectros normalizados a $\lambda=6 \mu \mathrm{m}$ do meteorito Putinga após vários pontos de irradiação.

Figura 4.20 - Comparação entre as inclinações BI dos espectros normalizados virgem e adiquirido após a última fluência de irradiação.

Figura 4.21 - Relação entre os valores da inclinação espectral para cada ponto de irradiação em função do valor da fluência.

Figura 4.22 - (a) espectros de reflexão do meteorito Parambu, virgem e após quatro pontos de irradiação; (b) os mesmos espectros mas normalizados em $0,6 \mu \mathrm{m}$. 
Figura 4.23 - (a) relação entre os albedos na região do visível e do infravermelho como função da fluência; (b) variação da profundidade de banda em $1 \mu \mathrm{m}$ como função da fluência.

Figura 4.24 - Inclinação BI como função da fluência para o meteorito Parambu.

Figura 4.25 - (a) espectros de reflexão do meteorito Gail, virgem e após quatro pontos de irradiação; (b) os mesmos espectros mas com refletância normalizada em $0,6 \mu \mathrm{m}$.

Figura 4.26 - (a) Refletância, visível e infravermelho, como função da fluência; (b) profundidade de banda em $1 \mu \mathrm{m}$ como função da fluência.

Figura 4.27 - Relação entre a inclinação BI do meteorito Gail e a fluência.

Figura 4.28 - (a) espectros de reflexão do meteorito Gail, virgem e após quatro pontos de irradiação; (b) os mesmos espectros, mas com refletância normalizada em $0,6 \mu \mathrm{m}$.

Figura 4.29 - (a) Refletância, visível e infravermelho, como função da fluência; (b) Relação entre a inclinação BI do meteorito Gail e a fluência.

Figura 4.30 - Os valores de inclinação da banda BI obtidos na irradiação por $\mathrm{N}+$ formam reescalados (divididos por 3). $\mathrm{O}$ resultado é que ele se sobrepõe ao gráfico das inclinações BI obtidos a apartir da irradiação com prótons.

Figura 5.1 - (1) Espectro Raman do meteorito Putinga mostrando os picos 1, 2, 3 e 4; (2) Representação esquemática de modos vibracionais de estiramento simétrico e deflexão da ligação Si-O. (3) Esquerda: imagem de uma olivina terrestre pura; Direita: estrutura do mineral olivina. Os pontos vermelhos representam 
átomos de oxigênio que se localizam no vértice do tetraedro cujo centro é ocupado por átomos de silício.

Figura 5.2 - Ajuste exponencial feito dos números de onda Xc observados em função da fluência $\mathrm{F}$ de irradiação. Lado esquerdo (a): valores Xc do meteorito Parambu; lado direito (b): Xc do meteorito Putinga.

Figura 5.3 - (1) Espectro Raman do mineral diopsita mostrando os picos 3 e 4. (2) Representação esquemática de modos vibracionais de estiramento simétrico e flexão da ligação O-Si-O. (3) Esquerda: imagem de uma diopsita terrestre pura. Direita: estrutura do mineral diopsita. Os tetraedros formam uma cadeia na qual cada tetraedro compartilha um dos átomos de oxigênio com o vizinho. Os pontos verdes representam íons que podem ser $\mathrm{Fe}^{2+}, \mathrm{Mg}^{2+}$ ou $\mathrm{Ca}^{2+}$ que conectam a cadeia de tetraedros.

Figura 5.4 - (a) relação entre a variação total do número de onda e (b) das seções de choque de deslocamento, em função da concentração relativa (\%) de ferro de cada amostra de meteorito.

Figura 5.5 - Poder de frenamento eletrônico e nuclear em função da profundidade de penetração na amostra. No mesmo gráfico, intensidade do laser utilizado no espectrômetro Raman em função da profundidade da amostra. As escalas dos três gráficos foram modificadas para que a comparação fosse possível.

Figura 5.6 - Seção de choque de destruição obtida em experimentos de irradiação da proteína L-Valina por diferentes feixes (da Costa, C. A. P. (2016)). Seções de choque de destruição de olivina e piroxênio foram inseridos no mesmo gráfico. As retas tracejadas representa a função $\sigma_{\mathrm{d}}=\mathrm{aSe}^{\mathrm{n}}$.

Figura 5.7 - (a) As refletâncias no visível nos espectros do meteorito Putinga, virgem e após último ponto de irradiação. A linha tracejada vertical mostra o comprimento de onda de $0,7 \mu \mathrm{m}$ 
para o qual o valor de refletância foi escolhido; (b) As profundidades de banda BI nos espectros do meteorito Putinga, virgem e após o término da irradiação. A linha tracejada vertical mostra a diferença de profundidade de banda.

Figura 5.8 - Relação entre a variação total sofrida i) pela profundidade de banda à 1 micron e ii) pela refletância no visível como função da abundância de ferro em cada amostra de meteorito.

Figura 5.9 - Inclinação da banda BI como função do número de deslocamentos causados pelas colisões nucleares dos íons de $\mathrm{H}+\mathrm{e}$ $\mathrm{N}+$ por unidade de área.

Figura 5.10 - Transformação de um espectro de refletância (a) em um espectro de absorbância (b). Abaixo (c) é mostrado o espectro de absorbância de olivina obtido experimentalmente, Shankland et. at. (1979).

Figura 5.11 - Comparação entre os espectros de absorção do meteorito Putinga, virgem e após o último ponto de irradiação. Ambos foram normalizados a $1,5 \mu \mathrm{m}$.

Figura 5.12 - Tauc plot obtido a partir da conversão do espetro de refletância do meteorito Putinga.

Figura 5.13 - Tauc plot utilizado para determinar as modificações nas energias de gap dos meteoritos (a) Putinga (L) e (b) Parambu (LL)

Figura 5.14 - Tauc plot utilizado para determinar as modificações nas energias de gap do meteorito Gail (a) irradiado por $\mathrm{H}+$ de 1,0 $\mathrm{MeV}$; e (b) irradiado por $\mathrm{N}^{+}$de $2,0 \mathrm{MeV}$

Figura 5.15 - Relação entre os valores obtidos para as energias de gap em função da fluência para os meteoritos (a) Parambu (LL); (b) Putinga (L) 
Figura 5.16 - Relação entre os valores obtidos para as energias de gap em função da fluência para o meteorito Gail (H) (a) e (b) irradiado por $\mathrm{N}^{+}$de $2,0 \mathrm{MeV}$

Figura 5.17 - Diagrama de níveis de energia para as bandas de energia de $\mathrm{Mg}_{2} \mathrm{SiO}_{4}$ e $\mathrm{MgO}$ com níveis gerados por defeitos e impurezas. Adaptado de Morin et. al. (1977)

Figura 5.18 - Esquerda: inclinação espectral em função da energia de gap para cada ponto de irradiação; Direita: mesmas inclinações, porém em função da fluência

Figura 5.19 - Relação entre a seção de choque de avermelhamento com a porcentagem de Ferro de cada amostra de meteorito

Figura 5.20 - Dependência linear da variação da energia de gap como função do conteúdo de ferro

Figura A.1 - Bandas de energia em um sólido. (a) átomo isolado; (b) sistema de alguns átomos; (c) um mol de átomos

Figura A.2 - Exemplo de um espectro de absorção

Figura A.3 - Esquema representando: diagrama de energia, densidade de estados, distribuição de Fermi-Dirac e concentração de portadores de carga de semicondutores (a) tipo $\mathrm{n}$ e (b) tipo p. Adaptado de Barros (2018)

Figura A.4 - Esquema representando transições diretas (esquerda) e indiretas (direita) ocorrendo entre a banda de valência e a banda de condução em uma região próxima da borda fundamental. Adaptado de Barros (2018)

Figura A.5 - Função dielétrica como função da energia do fóton incidente sobre uma amostra de Ge. Entre $0,22 \mathrm{eV}$ e 0,12 eV há uma banda de absorção de uma transição fundamental. Para 
energias menores que $0,1 \mathrm{eV}$ uma cauda mostra que a absorção, nesta região aumenta rapidamente. Tauc (1966).

Figura A.6 - Gráfico de hv $\varepsilon 1 / 2$ como função de hv. O gráfico apresenta um regime linear que ao ser extrapolado fornece o valor da energia de gap do material. Tauc (1966)

Figura B.1 - Decomposição térmica de $\mathrm{Fe}_{2} \mathrm{SiO}_{4}$ e as composições de equilíbrio formadas em função da temperatura

Figura B.2 - Decomposição térmica de $\mathrm{Mg}_{2} \mathrm{SiO}_{4}$ e as composições de equilíbrio formadas em função da temperatura

Figura B.3 - Decomposição térmica de $\mathrm{Fe}_{2} \mathrm{O}_{3}$ e as composições de equilíbrio formadas em função da temperatura

Figura B.4 - Decomposição térmica de $\mathrm{Fe}_{2}\left(\mathrm{SO}_{4}\right)_{3}$ e as composições 


\section{Lista de tabelas}

Tabela 2.1 - Trabalhos realizados sobre irradiação de meteoritos por feixe de íons produzidos em aceleradores.

Tabela 4.1- Seções de choque obtidas dos ajustes da intensidade dos picos 1 e 2 em função da fluência. Irradiação por feixe de $\mathrm{H}+$ com energia de $1,0 \mathrm{MeV}$

Tabela 4.2 - Seções de choque obtidas dos ajustes da intensidade dos picos 3 e 4 em função da fluência. Irradiação por feixe de $\mathrm{H}+$ com energia de $1,0 \mathrm{MeV}$

Tabela 4.3 - Valores obtidos para os parâmetros espectrais, albedo e profundidade de banda

Tabela 4.4 - Valores das fluências usadas em cada ponto de irradiação e os respectivos valores do slope

Tabela 4.5 - Comparação entre as seções de choque de avermelhamento obtidas para cada meteorito

Tabela 4.6 - Comparação entre as seções de choque de avermelhamento obtidas para cada meteorito

Tabela 5.1 - Taxa de sputtering (Y) dos elementos majoritários contidos nas amostras. Simulação feita no programa SRIM

Tabela 5.2 - Relação entre os valores dos números de onda dos picos 3 e 4 e a porcentagem de Ferro de cada amostra de meteorito 
Tabela 5.3 - Comparação entre as seções de choque de deslocamento dos picos 3 e 4 das três amostras de meteorito utilizadas. A abundância relativa inicial de ferro de cada amostra é também apresentada

Tabela 5.4 - Comparação entre características dos feixes iônicos utilizados nos experimentos deste trabalho e da literatura. Para cada projétil iônico atravessando a olivina é mostrado: a energia, o poder de frenamento nuclear, o poder de frenamento eletrônico e a penetração. Simulações feitas com o SRIM

Tabela 5.5 - Valores das fluências usadas em cada ponto de irradiação e os respectivos valores da energia de gap obtidos do espectro

Tabela 5.6 - Comparação entre a porcentagem de ferro inicial, valor do número de onda (espectro Raman), seções de choque de deslocamento (tabela 5.3), energia de gap inicial, seções de choque de variação das energias de gap e seção de choque de avermelhamento do espectro de reflexão, obtidas para cada meteorito 
"O que torna belo o deserto é que ele esconde o poço em algum lugar" 


\section{Introdução}

Corpos pequenos e de médio porte do sistema solar não possuem atmosfera (ou muito rarefeita, chamada exosfera) e nem campo magnético: encontram-se praticamente desprotegidos da influência do ambiente espacial no qual estão inseridos. Tais corpos (como a maioria dos asteroides, várias luas e cometas distantes do Sol), estão sujeitos aos efeitos do chamado intemperismo espacial, a superfície dos corpos em questão está continuamente exposta à ação de agentes externos. Os principais agentes externos são: i) poeira cósmica; ii) radiação e partículas carregadas provenientes direta ou indiretamente do vento solar e iii) íons oriundos dos raios cósmicos galácticos. Este processo pode levar à progressiva alteração na coloração dos objetos presentes nessas regiões, fazendo com que sua superfície torne-se cada vez mais escurecida enquanto seu espectro de refletância solar pode sofrer avermelhamento ${ }^{1}$ (veja, por exemplo, Hapke, 2001). Todos os processos mencionados atuam sobre a superfície concomitantemente. A esse conjunto de processos dá-se o nome de Erosão Espacial, Intemperismo Espacial ou ainda Space Weathering (SpWe). Uma definição mais concisa do termo é dada pela enciclopédia de astrobiologia: "Space Weathering descreve todos os efeitos causados pela interação entre a superfície dos corpos sem atmosfera ou sem campo magnético e o ambiente espacial”.

Desde muitos anos, os efeitos do fenômeno SpWe vêm sendo estudados por diversos pesquisadores em todo o mundo. Tanto esforço empregado na compreensão desse problema se justifica pelo fato de que tais efeitos geram modificações nas propriedades físicas, químicas e mineralógicas de corpos menores do sistema solar. Estas modificações influenciam as propriedades óticas, dificultando e limitando o processo de estudo e caracterização dos citados corpos.

\footnotetext{
${ }^{1}$ O processo conhecido como avermelhamento do espectro será discutido em detalhes no capítulo de discussão, pois é justamente esse efeito que será estudado na tese.
} 
A pesquisa de objetos menores do sistema solar é feita, em grande parte, via observações astronômicas. Isso quer dizer que, o que permite tal estudo é a capacidade do alvo observado de refletir a luz solar que atinge sua superfície. E os efeitos de SpWe interferem nessa capacidade, modificando assim os resultados e as interpretações dos dados observacionais obtidos. Assim, para se compreender de forma adequada os resultados das observações, é preciso entender, a fundo, as consequências do SpWe.

Apesar de muito esforço já ter sido empregado no estudo dos efeitos do SpWe, muitas são as questões que ainda continuam em aberto. A revisão de literatura mostra que a explicação física para os efeitos observados ainda é questão de debates. A maioria dos trabalhos concorda com Hapke (2001) que propôs uma explicação baseada na formação de nanopartículas de ferro neutro como causadoras dos efeitos de escurecimento e avermelhamento. Uma única explicação alternativa é dada por Brunetto e Strazzulla (2005) baseada em processos de colisões elástica entre projéteis usados e núcleos do alvo.

O número de meteoritos estudados, em experimento com irradiação por feixe de íons, é outro aspecto da pesquisa em SpWe a ser levado em conta. No capítulo 2 é mostrado que são poucos os trabalhos. E, quando se considera a pesquisa com condritos ordinários (OCs), apenas dois artigos foram encontrados. Isto mostra a carência em pesquisas dos efeitos de $\mathrm{SpWe}$ sobre esses meteoritos.

\section{1}

\section{Motivação do trabalho}

Em geral, os trabalhos dedicados ao estudo dos efeitos do SpWe sobre a superfície de asteroides apresentam dois grandes objetivos em comum:

(a) quantificar os efeitos espectrais da incidência do vento solar e dos raios cósmicos sobre a superfície de possíveis corpos parentais dos meteoritos e

(b) identificar os prováveis corpos parentais. 
Certos artigos incluem ainda um terceiro objetivo: entender quais processos físicos decorrem da interação dos íons do vento solar e dos raios cósmicos com a superfície dos asteroides e como esses processos influenciam nas mudanças espectrais observadas. A formação de nanopartículas de ferro comumente é considerada como responsável pelos efeitos observados (Hapke (2001), Loeffler (2009), Gaffey (2010)), porém até o momento, o Space Weathering continua sendo pouco compreendido e a falta de experimentos dedicados a esse proposito precisa ser preenchida.

A revisão dos artigos evidencia, também, os seguintes fatos:

(i) a variedade de classes de meteoritos estudadas é muito pequena em comparação ao grande número de meteoritos catalogados;

(ii) ainda há poucas informações a respeito dos efeitos da irradiação com íons sobre amostras de uma mesma classe;

(iii) a formação de nanopartículas de ferro é comumente considerada como responsável pelos efeitos observados, mas não há consenso sobre qual mecanismo físico que induz as modificações espectrais observadas.

Sabe-se que no modelo das nanopartículas de ferro, o que ocorre é uma mistura do espectro de reflectãncia do material original com o espectro de reflectância dessas nanopartículas. Como o albedo do material original é maior que o das nanoparticulas, o efeito vai ser uma diminuição do albedo resultante. Mas, se o albedo do material original for menor, o resultado final será um aumento de albedo (Clark et. al., 2002). Porém, o que as nanopartículas de ferro fazem, efetivamente, no material para modificar suas propriedades reflexivas ainda é espaço de debate.

Baseado nessas constatações fica claro que ainda existem tópicos a serem investigados. As amostras, para simulação de SpWe, devem ser escolhidas de forma a possibilitar a investigação proposta pelos itens (i) e (ii). Em especial, no caso dos meteoritos OCs, a seleção de amostras pertencentes a cada um dos subgrupos H, L e LL (caracterizados por suas proporções diferentes de ferro, como mostrado no capítulo 3, seção 3.1) ajudará a obter dados com os quais será 
possível investigar, sistematicamente, se o subgrupo químico da amostra influencia nos efeitos da irradiação, resultado que pode ajudar na interpretação de dados observacionais de asteroide tipo $\mathrm{S}$ que apresentem espectros de refletância diferentes.

Conforme supracitado, existem ainda questões em aberto na pesquisa envolvendo o fenômeno SpWe. Uma delas é que a diversidade de meteoritos estudados é, muito pequena em comparação à grande variedade existente (das 21 classes existentes, apenas 7 formam estudadas). Logo, há pouca informação acerca da influência dos efeitos induzidos pelo $\mathrm{SpWe}$ na classificação desses objetos. De acordo com a tabela 2.1 somente dois meteoritos do tipo OCs foram estudados. E ambos do subtipo H. Visando contribuir para a diminuição dessa lacuna as amostras escolhidas para este trabalho (que serão apresentadas no capítulo 3) todas elas foram selecionadas entre as do tipo OCs, uma de cada subtipo $^{2}$.

\section{2}

\section{Objetivos gerais deste trabalho}

- Irradiar três amostras de meteoritos do tipo condrito ordinário com feixe de íons, na faixa de $\mathrm{MeV}$, produzido pelo acelerador Van de Graaff da PUC-Rio a fim de compreender quais mecanismos físicos estão por trás dos efeitos observados. Com isso, pretende-se simular os efeitos espectrais da incidência de vento solar e de raios cósmicos sobre a superfície de asteroides.

\section{3}

\section{Objetivos específicos deste trabalho}

1. Preparar três amostras de meteoritos condritos ordinários dos subgrupos $\mathrm{H}$, L e LL;

\footnotetext{
${ }^{2}$ Para uma melhor compreensão sobre os tipos de meteoritos existentes veja o apêndice D.
} 
2. Irradiar com diferentes fluências as amostras com feixes de íons $\mathrm{H}^{+}$com energia de $1 \mathrm{MeV}$ e de íons de $\mathrm{N}^{+}$com energias de $2 \mathrm{MeV}$ para induzir modificações físico-químicas e espectrais em suas superfícies;

Os íons de hidrogênio serão usados devido ao fato de o vento solar e os raios cósmicos serem compostos majoritariamente por eles.

3. Acompanhar as alterações espectroscópicas via espectroscopia UV-VISNIR. A principal técnica do trabalho por permitir a comparação dos dados de laboratório como os observacionais.

4. Comparar os efeitos da irradiação para cada um dos grupos de meteoritos e verificar se existe dependência entre os efeitos observados e o conteúdo de ferro de cada amostra;

5. Realizar medidas adicionais utilizando espectroscopia Raman para obter informações mais completas a respeito dos processos físico-químicos resultantes da irradiação;

6. Confirmar ou propor uma explicação complementar, e mais fundamental do ponto de vista físico do processo, às já feitas na literatura para as variações observadas nos espectros de refletância após irradiação;

\section{4}

\section{Estrutura da tese}

Este trabalho foi desenvolvido para contribuir no entendimento de algumas das questões supracitadas. Ele foi organizado em seis capítulos contando com o presente. $\mathrm{O}$ capítulo 2 apresenta uma revisão dos tópicos básicos sobre o SpWe e também uma discussão geral de como estudos sobre o tema podem ser feitos em laboratório. O capítulo 3 descreve o esquema de funcionamento do acelerador de partículas usado, a rotina experimental empregada e os fundamentos das técnicas experimentais aplicadas. No quarto capítulo são apresentados os resultados experimentais obtidos. A discussão destes resultados é apresentada no capítulo 5. É no sexto, e último capítulo, que as conclusões obtidas a partir da discussão dos resultados experimentais obtidos são apresentadas de forma sumária. 


\section{2}

\section{Space Weathering e astrofísica experimental}

\section{1}

\section{O que é o SpWe e por que estudá-lo}

O processo de SpWe está presente em todo o sistema solar, atuando de forma diferenciada sobre cada corpo celeste. Um exemplo interessante de seus efeitos pode ser observado na atmosfera de Mercúrio. Observações realizadas durante diferentes dias mostraram que lá existe uma grande concentração de sódio, e que essa concentração varia a uma alta taxa num intervalo de alguns dias. Como explicação para essa observação Killen et. al. (2001) propuseram que a alta taxa de variação poderia ser devida à incidência de íons do vento solar que causa sputtering das partículas de sódio, da crosta, lançando-as à atmosfera.

Historicamente, o estudo dos efeitos do SpWe começou devido a uma discrepância observada ao se comparar medidas do espectro de refletância da superfície da Lua com espectros medidos em laboratório das amostras trazidas pela missão Apollo. Ficou evidente a grande diferença entre os espectros nos dois casos (McCord e Johnson, 1970) e (McCord e Adans, 1973). Essa discrepância foi atribuída a efeitos de SpWe na superfície lunar. As amostras trazidas pela missão Apollo não apresentaram o mesmo grau de exposição ao SpWe porque, para analisá-las em laboratório, elas foram trituradas, esse procedimento de preparo de amostras gerou uma mistura do material da superfície (processado) com o material interno (virgem). O resultado foi a preparação de amostras que, do ponto de vista espectral, tiveram suas superfícies menos expostas ao SpWe. Para verificar como a incidência dos íons do vento solar e raios cósmicos afetam a superfície de alguns corpos celestes, Hapke (1973) utilizou feixe de prótons para irradiar amostras de rochas terrestres e lunares. Foi observado que como consequência da exposição à 
iraradiação as amostras sofriam escurecimento (diminuição do albedo ${ }^{3}$ ) e seu espectro de refletância sofria avermelhamento. O autor atribuiu essas alterações espectrais observadas ao sputtering de átomos de oxigenio $\left(\mathrm{O}^{2-}\right)$ que, inicialmente, estariam fazendo parte da ligação com o ferro ferroso $\mathrm{Fe}^{2+}$ formando o sistema $\mathrm{Fe}^{2+}-\mathrm{O}^{2-}$ nos silicatos que constituem as amostras. $\mathrm{O}$ ferro que permaneceu na superfície da amostra forma as chamadas nano partículas de ferro (nanophase $\mathrm{Fe}^{0}$ ou $\mathrm{npFe}^{0}$ ), processo muitas vezes chamado de metalização da superfície. Posteriormente, Pieters et.al. (2000) examinaram o produto dos efeitos da exposição ao SpWe sobre amostra do solo lunar via microscopia eletrônica de transmissão e observaram que a superfície encontrava-se encoberta de nano partículas de ferro neutro, ferro no estado metálico, cuja origem eles atribuíram a combinação dos efeitos de sputtering (introduzido pela irradiação por vento solar) com a deposição de vapor de ferro (gerado pelo bombardeio por poeira cósmica) (Figura 2.1). Nesse mesmo trabalho foi mostrado que as propriedades ópticas da superfície (escurecimento e avermelhamento) são fortemente dependentes do acúmulo de nano partículas de ferro. Este resultado é de extrema importância, e será utilizado como referência para a interpretação dos resultados obtidos em trabalhos posteriores.

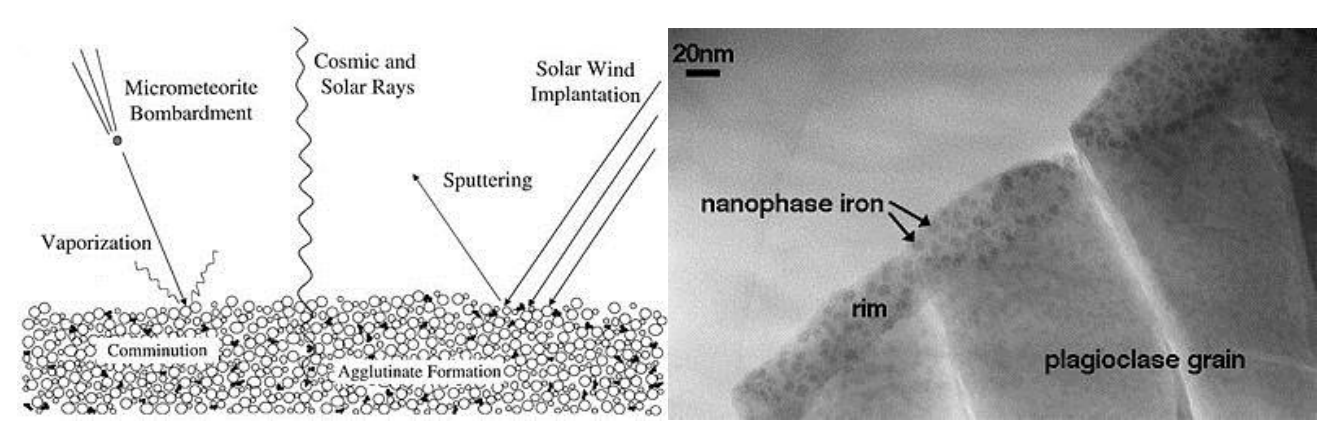

Figura 2.1 - a esquerda um esquema dos efeitos da incidência de partículas carregadas e de poeira cósmica; a direita a imagem de microscopia eletrônica de transmissão mostra a presença de nano partículas de ferro. Hapke (2001)

\footnotetext{
3 - Razão entre a quantidade de radiação (luz) refletida pela atmosfera ou pela superfície de um corpo celeste e a quantidade de luz incidente. Objetos com alto albedo refletem grande parte da luz do Sol que incide sobre eles.
} 
Os meteoritos condritos ordinários ${ }^{3}$ (COs) integram a classe de meteoritos mais comum, aproximadamente $70 \%$ dos meteoritos pertencem a essa classe (por esse motivo o nome "ordinário"), por essa razão, foram feitos esforços na tentativa de identificação de seus possíveis corpos parentais (asteroide do qual cada meteorito fez parte no passado). É natural pensar que a classe de meteoritos mais abundante deveria ter sua origem na região do cinturão principal onde há a maior abundância de asteroides, cujas características espectrais se assemelham as dos COs. Surpreendentemente, os asteroides no cinturão principal que, por considerações de natureza dinâmica, são as fontes mais prováveis de meteoritos pertencentes à classe taxonômica $\mathrm{S}$, cujos espectros são muito semelhantes aos da Palasitos, um tipo muito raro de meteoritos. Essa discrepância recebeu o nome de "paradoxo dos condritos ordinários". Uma proposta de explicação para o fenômeno citado acima foi que os efeitos do SpWe seriam responsáveis pela diferença observada e, com isso, o estudo dos efeitos do SpWe sobre a superfície de asteroides foi intensificado. O que se observa, em geral, é que os asteroides tipo S apresentam espectro de refletância mais avermelhado, bandas de absorção mais estreitas e menor albedo em comparação com os espectros de meteoritos COs, como o exemplo da figura 2.2 que exibe espectros do asteroide 6 Hebe e do CO Averege (Gaffey e Gilbert, 1998). Os resultados observados em amostras lunares foram imediatamente invocados como explicação para as inconsistências entre os espectros dos asteroides tipo S e dos meteoritos COs. Então, para que a interpretação correta dos espectros de refletância dos mesmos possa ser feita, tornou-se imprescindível conhecer e entender os mecanismos e resultados das interações entre os agentes causadores de SpWe e a superfície dos asteroides.

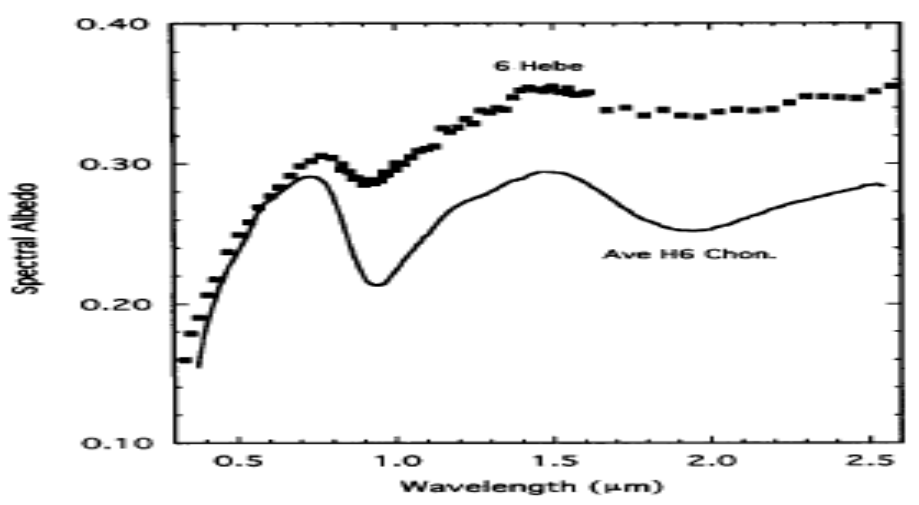

Figura 2.2 - Comparação entre os espectros de refletância solar do asteroide 6 Hebe e do meteorito OC Averege H6. (Gaffey e Gilbert, 1998). 


\section{2}

\section{Space weathering em laboratório}

Para determinar o estado da arte relativo ao estudo do SpWe em laboratório (astrofísica experimental) foi feito um levantamento dos artigos publicados que continham como tema simulação do efeito de SpWe, por feixe de íons, em laboratório. O resultado desse levantamento é apresentado a seguir.

\subsection{1}

\section{Experimentos com silicatos}

No caso dos análogos, os experimentos têm se restringido no estudo dos efeitos da irradiação sobre amostras de silicatos, geralmente olivina, piroxênio entre outros. Um mineral que recebeu atenção em diversos trabalho devido a sua importância na composição de asteroides e meteoritos é a olivina (cuja formula química é $\left.(\mathrm{Mg}, \mathrm{Fe})_{2} \mathrm{SiO}_{4}\right)$. Dukes et. al. (1999) submeteram esse mineral à irradiação por prótons e por íons de hélio. Foi observada que grande quantidade de ferro superficial transformou-se em ferro na forma metálica, o que em termos de espectro significa uma redução na profundidade de banda de absorção que é característica do ferro. Já Yamada et. al. (1999) realizaram experimentos com o objetivo de estudar os efeitos da implantação de íons de hidrogênio na estrutura da olivina e de outro mineral, também muito comum em asteroides, chamado piroxênio. Eles observaram alterações muito discretas em ambos os espectros.

Experimentos utilizando íons mais pesados também foram realizados. Brunetto e Strazzulla (2005) irradiaram amostras de silicatos com $\mathrm{H}^{+}, \mathrm{He}^{+}, \mathrm{Ar}^{+} \mathrm{e}$ $\mathrm{Ar}^{++}$para diversas energias variando desde 60 até $400 \mathrm{keV}$. A análise foi feita via espectroscopia Raman, que detectou mudança nas propriedades óticas na região da amostra próxima à superfície, e por espectroscopia UV-VIS-NIR ${ }^{4}$ com a qual foi observado um avermelhamento no espectro e o escurecimento da amostra. A partir dos dados obtidos, os autores estimaram que o processo de avermelhamento do espectro de refletância levaria um escala de tempo da ordem de $10^{4}$ a $10^{6}$ anos

\footnotetext{
4 - Técnica espectroscópica que estuda interação da amostra com a radiação nas faixas do ultravioleta, visível e do infravermelho próximo.
} 
na região próxima a órbita terrestre. Como a idade do sistema solar é de aproximadamente 4,5 bilhões de anos, já se passou tempo suficiente para que todos os asteroides dessa região tivessem sofrido total processamento devido ao SpWe. No entanto, observam-se asteroides com diferentes graus de processamento. Isso indica que existe um processo inverso aos efeitos do SpWe que age no sentido de rejuvenescer as superfícies alteradas contrabalanceando o avermelhamento. Acredita-se que o processo de rejuvenescimento da superfície possa ser explicado pelo impacto com outros corpos, que causa uma mistura do material da superfície (já processado pelo $\mathrm{SpWe}$ ) com o material não alterado das camadas mais internas. Ainda com relação a esse trabalho, foi sugerido que outro mecanismo físico também influencia as mudanças espectrais observados. Os autores atribuem tais mudanças ao deslocamento de átomos do alvo, causado pela colisão elástica entre os íons do feixe e os núcleos de átomos da amostra. Porém é enfatizado que esse mecanismo não se contrapõe ao mencionado anteriormente (formação de nano partículas de Fe), pois cada um dos mecanismos é importante para diferentes regimes de fluência.

\section{2 .2}

\section{Experimentos com meteoritos}

A outra opção para esse tipo de trabalho é estudar os efeitos da irradiação sobre a superfície de amostras que no passado fizeram parte do asteroide. Essas amostras seriam os meteoritos que são fragmentos de corpos sólidos do sistema solar, como asteroides, cometas, etc.

A tabela 2.1 lista os artigos dedicados a esse tipo de estudo, indicando o meteorito (e sua classe) estudado, os parâmetros de irradiação e as técnicas de análise. É interessante notar que esse tipo de trabalho é relativamente recente (o mais antigo data de 2005) e que poucas amostras diferentes de meteoritos (apenas 11) foram estudadas até o momento. A escolha da classe do meteorito a ser estudado depende de se saber (ou assumir) a qual tipo de asteroide ele pode ser relacionado. Estudando-os, espera-se chegar a informações que ajudem na interpretação dos dados conhecidos para esse asteroide. Acredita-se, por exemplo, que os meteoritos diogenitos e euclitos sejam fragmentos do asteroide 4 Vesta. Nesse contexto, Fulvio et. al. (2007) irradiaram amostras dos meteoritos Bereba 
(euclito) e Tatahoine (diogenido), da classe HED, a fim de compreender quais os efeitos da exposição ao SpWe sofre a superfície dessa família de asteroides. Utilizaram íons leves ( $\mathrm{H} \mathrm{e} \mathrm{He}$ ) e pesados (Ar) com diferentes energias. Foram observados os já conhecidos efeitos de avermelhamento do espectro e a diminuição do albedo; a escala de tempo foi estimada como sendo da ordem de $10^{5}$ anos. O espectro observacional de 4 Vesta não apresenta esse grau de processamento por SpWe indicando que possua um campo magnético que o protege da incidência de íons ou que sua superfície sofreu algum processo de rejuvenescimento (Vernazza et. al, 2006). Posteriormente outro estudo foi feio em complemento a este. Fulvio et. al. (2012) irradiaram amostras do meteorito Dar al Gani (HED) e compararam os resultados com os obtidos para o Bereba (HED), mostrando que os efeitos ocorriam de forma diferente para cada um deles. Já Vernazza et. al (2009) estudaram os efeitos da exposição ao processo de SpWe para meteoritos das classes enstatitos (meteorito Eagle) e mesosideritos (Vaca Muerta) via espectroscopia VIS-NIR. Para o primeiro foi observada pouca variação espectral, indicando que ele é pouco afetado pela incidência de íons e que seu espectro deve ser muito similar ao de seu corpo parental. O Vaca Muerta, no entanto, apresentou o mesmo efeito de avermelhamento e escurecimento do espectro visto em experimento feitos com silicatos (Strazzulla et. al., 2005), condritos ordinários (Brunetto et. al., 2004) e HED (Fulvio et. al., 2007). Os espectros de antes e depois da irradiação foram comparados com os de aproximadamente 400 asteroides do cinturão principal.

Há apenas dois artigos sobre irradiação por feixe de íons de meteoritos da classe dos condritos ordinários, ambos referentes ao subtipo $\mathrm{H}$. $\mathrm{O}$ primeiro descreve os experimentos que Strazzulla et. al. (2005) realizaram para simular os efeitos da incidência de vento solar sobre o meteorito Epinal (H5). Íons de $\mathrm{H} \mathrm{e} \mathrm{Ar}$ foram utilizados e as modificações monitoradas por espectroscopia VIS-NIR. Foi observado avermelhamento do espectro similar ao observado para asteroides tipo S e estimou-se que a escala de tempo para o total processamento é da ordem de $10^{4}-10^{6}$ anos. A passagem do $\mathrm{H}^{+}$não causou alterações relevantes no espectro, pois apenas atua causando ionização e excitação dos átomos das amostras. Ao contrário, $\mathrm{o}{ }^{+}$foi o responsável pelo avermelhamento observado. Atribuiu-se que tais mudanças ocorreram devido à interação entre o íon e os núcleos do alvo 
(colisão elástica) causando deslocamento dos átomos (o que resulta em amorfização da amostra).

O segundo trabalho dedicado ao estudo de condritos ordinários foi realizado por Kanuchova et. al. (2015). A irradiação foi feita sobre o meteorito Kocise (H5) com íons de Ar e as modificações monitoradas tanto por espectroscopia VIS-NIR quanto por ultravioleta próximo (Near UV ou NUV; de 200 a $400 \mathrm{~nm}$ ). O diferencial desse trabalho é que os autores associam o avermelhamento do espectro (tão conhecido na faixa VIS-NIR) com um segundo efeito chamado de "azulamento" do espectro NUV e mostram que os efeitos são interdependentes. Ambos os efeitos são atribuídos à formação de nano partículas de ferro. Os autores destacam que o efeito observado no espectro NUV pode ajudar a elucidar muitas questões ainda em aberto e afirmam a importância de incluir a faixa NUV em trabalhos futuros (experimentais e observacionais).

Há também trabalhos de SpWe sobre a superfície de meteoritos do tipo carbonáceo. Vernazza et. al. (2013) irradiaram o meteorito Tagish Lake com o objetivo de identificar uma possível correlação entre este meteorito e asteroides do cinturão principal ou dos troianos ${ }^{5}$ de Júpiter. Foi observado o avermelhamento do espectro em acordo com os demais experimentos, no entanto, percebeu-se um aumento do albedo. A comparação com o espectro dos asteroides indica que origem mais provável do Tagish Lake é o cinturão externo. Uma análise detalhada foi feita por Brunetto et. al. (2014) sobre outro meteorito carbonáceo: o Allende. A irradiação foi feita com íons de $\mathrm{He}$ e $\mathrm{Ar}$ e seus efeitos monitorados via espectroscopia visível, infravermelho e Raman. Na faixa VIS-NIR foi observado o avermelhamento e o escurecimento (diminuição do albedo, resultado que contrapõe o obtido por Vernazza et al. (2013) indicando que os efeitos são dependentes da composição). No caso do Raman, observou-se que o conteúdo orgânico da amostra é altamente afetado pela irradiação. Mais recentemente Lantz et. al. (2015) estudaram os efeitos da irradiação sobre outro meteorito condrito carbonáceo, o Murchison. A irradiação com íons de He e Ar foi monitorada via espectroscopia na faixa indo do visível ao infravermelho médio e via

\footnotetext{
${ }^{5}$ - Grupo de asteroides que orbitam em torno do Sol na mesma órbita de Júpiter.
} 
espectroscopia Raman. Observaram alterações na banda atribuída ao silicato que foram interpretadas como resultado da perda de átomos de $\mathrm{Mg}$ por sputtering. Foi visto avermelhamento, porém também foi observado aumento do albedo (como no caso do Tagish Lake (Vernazza et. al., 2013)).

Tabela 2.1 - Trabalhos realizados sobre irradiação de meteoritos por feixe de íons produzidos em aceleradores.

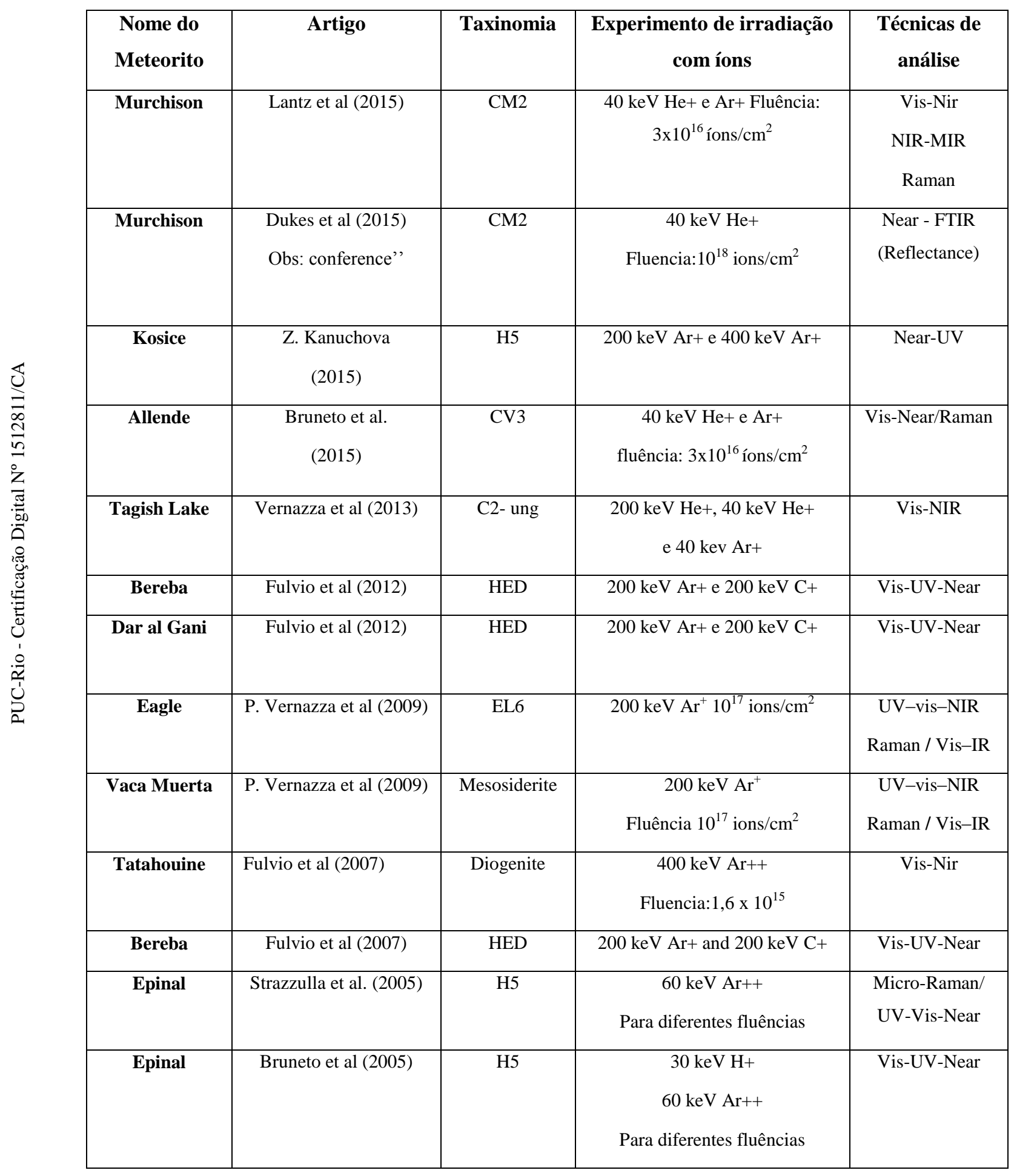




\section{3}

\section{Raios cósmicos e vento solar: simulações em laboratório}

Conforme mencionado, os agentes externos causadores de efeitos de $\mathrm{SpWe}$ podem ser íons do vento solar ou dos raios cósmicos, poeira cósmica e fótons solares. O presente trabalho pretende contribuir para um melhor entendimento do processo de SpWe quando causado por raios cósmicos e vento solar sobre a superfície de asteroides.

\subsection{1}

\section{Raios cósmicos e vento Solar}

Inicialmente, é preciso caracterizar os raios cósmicos e o vento solar. Eles são fluxos de partículas carregadas que se deslocam pelo espaço com certa distribuição de velocidades. Na verdade, ambos são constituídos pelas mesmas partículas, embora com distribuições de abundâncias e de velocidades (módulos e direções) diferentes. Ambos os aspectos dependem da fonte do fluxo. Com relação à origem das partículas, os raios cósmicos são classificados em três grupos: i) estelar; ii) galáctico e iii) extragaláctico. O estelar, como o nome diz, tem como fonte uma estrela. Trata-se da emissão continua de íons provenientes da corona ${ }^{4}$ estelar. Um exemplo é o vento solar, que é a emissão de um fluxo de partículas carregadas oriundas da corona do Sol. As partículas do vento estelar são em maioria formadas por prótons (aproximadamente 90\%) de baixa energia (menor que $10 \mathrm{keV}$ ) e cujo fluxo é radial e decai com $1 / \mathrm{r}^{2}$ onde $\mathrm{r}$ é a distância ao centro do Sol. O fluxo do vento solar é ordens de grandeza superior ao raios cósmicos no interior do sistema solar. Já os raios cósmicos galácticos são produzidos por explosão de supernovas, e por esse motivo, as partículas emitidas são muito mais energéticas do que as do vento estelar, com energias que vão desde $100 \mathrm{keV}$ até $\mathrm{EeV}$ (exaelétron-volt; exa corresponde a $10^{18}$ ). São constituídos tanto por íons leves (como hidrogênio e hélio) como por mais pesados (chegando até o ferro). Seu fluxo é baixo e isotrópico (é o mesmo fluxo em qualquer parte do sistema solar). Os raios cósmicos extragalácticos, por sua

\footnotetext{
${ }^{4}$ A corona é um vasto halo de gás em emissão. O gás coronal é muito quente (temperaturas da ordem de um milhão de graus) e ao ser expelido forma o vento estelar.
} 
vez, são compostos basicamente por prótons com energias extremamente altas, maiores do que o EeV, embora seu fluxo seja baixo. No caso do vento solar, o fluxo é máximo para energias de aproximadamente $1 \mathrm{keV} / \mathrm{u}$. A figura 2.3 apresenta o fluxo de partículas como função da energia por nucleon para: (a) vento solar próximo a orbita da Terra e (b) e raios cósmicos galácticos.

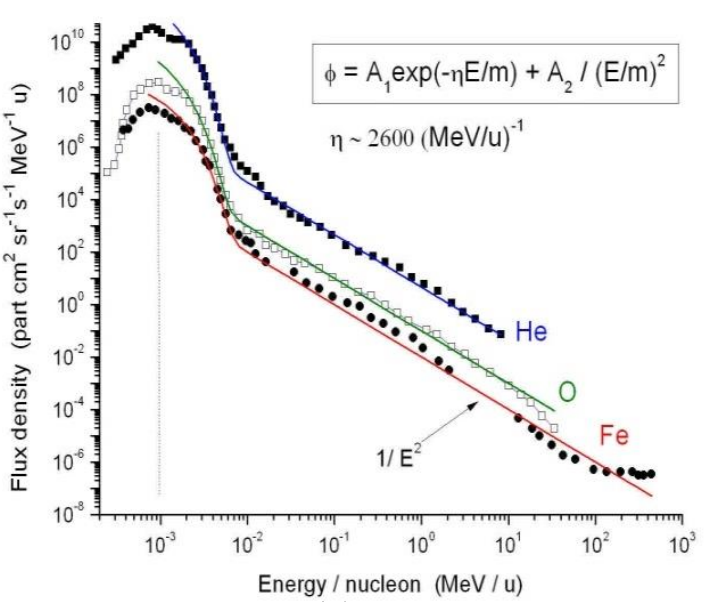

(a)

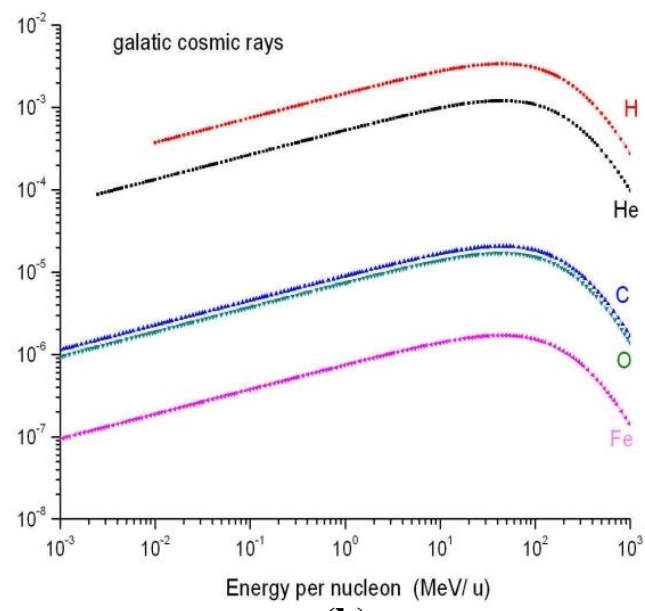

(b)

Figura 2.3 - Fluxo de partículas do vento solar na região próxima a órbita da Terra (a) e dos raios cósmicos galácticos (b).

Com base no exposto, para simular raios cósmicos em laboratório se faz necessário uma maneira de produzir um fluxo de íons rápidos. Aceleradores de partículas foram desenvolvidos para esse fim, e nas últimas décadas eles têm sido empregados no estudo dos efeitos dos raios cósmicos e do vento solar sobre a superfície de materiais de interesse astrofísico como silicatos, gelos astrofísicos, materiais carbonáceos e até mesmo amostras vindas diretamente do espaço como meteoritos e grãos coletados por missões. O trabalho de Hapke (1973), já citado, analisa o efeito simulado do SpWe sobre silicatos e rocha lunares. Há também trabalhos que focam no efeito do SpWe sobre a superfície de objetos do sistema solar externo. Como nessa região as temperaturas são muito mais baixas formamse camadas de gelos. Brunetto et. al. (2006) irradiaram amostras de metanol, metano e benzeno com feixes de próton e hélio. Os efeitos da irradiação foram estudados via espectroscopia VIS-NIR para que se pudessem comparar os dados com as observações. Como conclusão, os autores afirmam que sobre a superfície 
de alguns objetos do sistema solar exterior pode ter crescido um manto de irradiação gerada pela incidência de raios cósmicos.

\subsection{2}

\section{Interação íon-superfície}

A interação de um íon que incide sobre a superfície de um sólido pode gerar alterações físico-químicas no projétil, no sólido e ainda induzir emissões secundárias de partículas e fótons. As modificações sofridas pelo íon podem ser perda de energia ou alterações no seu estado de carga (captura ou perda de elétrons). Além disso, o sólido pode sofrer alguma mudança proveniente desta interação, como por exemplo, amorfização de sua estrutura, reações químicas ou, até mesmo, a formação do efeito denominado traço (track, do inglês). Pode ainda ocorrer, devido à interação, emissão de partículas secundárias da superfície do sólido, como fótons, elétrons e aglomerados moleculares e íons. A Figura 2.4 mostra uma representação esquemática.
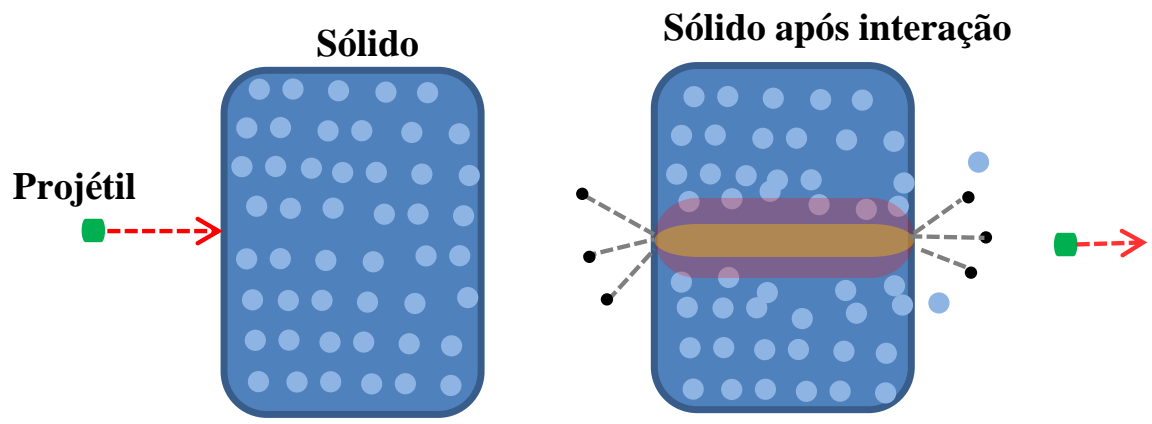

Figura 2.4 - Esquema representando a incidência de um projétil sobre um sólido (esquerdo); resultado da passagem e interação do projétil com os átomos que formam a estrutura do alvo e a emissão de partículas secundárias (direito).

\section{(i) Efeitos no projétil}

A Figura 2.4 representa um projétil que incide sobre a superfície de um sólido. O projétil pode ser constituído por um átomo, molécula ou íon. Estes íons podem ser produzidos por aceleradores de partículas de forma que suas características, como a massa, carga e a energia, por exemplo, sejam conhecidas. 
Ao penetrar no alvo, o íon será freado ao interagir com os átomos e moléculas do alvo, transferindo parte de sua energia para os constituintes do sólido. Esta transferência de energia pode ocorrer por duas vias.

Uma delas é por meio de colisões elásticas com os núcleos dos átomos que compõem a amostra. Este tipo de interação também é denominado de colisões nucleares, pois o projétil transfere parte de sua energia cinética à energia cinética de recuo dos núcleos dos átomos com os quais colide. $\mathrm{O}$ resultado deste processo é uma grande perda de energia por parte do íon, que também tem sua trajetória desviada, e uma consequente desordem na rede cristalina do sólido devido ao deslocamento que seus átomos colididos experimentam.

A outra forma de interação entre o íon e os átomos do sólido é através das colisões inelásticas, ou eletrônicas. Neste tipo de interação, a transferência de energia do íon ocorre por meio de ionização e/ou excitação atômica. $\mathrm{Na}$ ionização, um ou mais elétrons são liberados por átomo. Estes elétrons são chamados de elétrons secundários. A característica deste tipo de processo é que há uma menor perda de energia por parte do projétil em cada interação devido à diferença de massa dos elétrons do alvo em comparação à do íon mas, no entanto, o número de colisões é muitas vezes maior.

O que decidirá qual dos dois tipos de interação será a predominante em termos de transferência de energia do íon para o sólido é a velocidade relativa do projétil em relação ao átomo alvo.

A taxa de perda de energia (E) sofrida pelo projétil por unidade de comprimento (S) é denominada poder de frenamento (stopping power, do inglês) que irá depender das características do íon e do sólido. Como as energias perdidas são aditivas, o stopping power é dado pela soma das perdas de cada processo:

$$
\frac{\mathrm{dE}}{\mathrm{dS}}=\left(\frac{\mathrm{dE}}{\mathrm{dS}}\right)_{\mathrm{e}}+\left(\frac{\mathrm{dE}}{\mathrm{dS}}\right)_{\mathrm{n}}
$$

onde $\mathrm{S}_{\mathrm{e}}=(\mathrm{dE} / \mathrm{dS})_{\mathrm{e}}$ é o stopping power eletrônico e $\mathrm{S}_{\mathrm{n}}=(\mathrm{dE} / \mathrm{dS})_{\mathrm{n}}$ o stopping power nuclear.

$\mathrm{O}$ tipo de interação dominante reflete-se nos valores $S_{\mathrm{e}}$ e $S_{\mathrm{n}}$. Na irradiação da olivina (mineral majoritário das amostras estudadas), o valor de $\mathrm{S}_{\mathrm{e}}$ para prótons 
de energia de $1 \mathrm{MeV}$ é de $56 \mathrm{keV} / \mu \mathrm{m}$, muitas vezes superior ao de valor de $S_{\mathrm{n}}$ que é de $0,042 \mathrm{keV} / \mu \mathrm{m}$. Isso significa que o projetil irá perder energia para a amostra, predominantemente, através de interações eletrônicas.

\section{(ii) Efeitos da interação entre íon e sólido}

As consequências da interação entre íon e sólido, no sólido, dependem dos valores de cada stopping power parcial. Se o valor $S_{n}$ for muito maior que o eletrônico, a interação predominante será por médio de colisões elásticas entre o projétil e os núcleos dos átomos do alvo provocando deslocamento dos núcleos atômicos. O resultado pode ser amorfização da estrutura da amostra.

Já se o valor de $S_{\mathrm{e}}$ for dominante, então as interações ocorrerão por meio de excitações e ionizações. Ao longo de sua trajetória no interior da amostra, o próton excita e ioniza átomos do material, causando modificações cristalinas e químicas durante a passagem. Esta região modificada (Figura 2.4) é caracterizada pelo traço nuclear. O traço não é apenas uma linha que representa a trajetória pelo íon, e sim todo o volume cilíndrico que foi modificado pela passagem dele. Os elétrons emitidos pela passagem do íon são chamados de elétrons secundários e têm uma distribuição angular com simetria de revolução em relação à direção da trajetória do projétil: Colisões frontais levam os elétrons para frente, enquanto que direções distantes dispersam os elétrons na direção perpendicular (radial) a essa trajetória. Após a passagem do íon, a parte central do traço (infra-traço) permanece positivamente carregada e atrai os elétrons secundários, que iniciam o retorno. Como a olivina é um material semicondutor, o retorno dos elétrons não é imediato e permite ao infra-traço gerar uma repulsão coulombiana entre os átomos e moléculas do traço. Este fenômeno é denominado explosão coulombiana e tem uma consequência importante que é a amorfização/cristalização em torno do traço; para fluências suficientemente altas, este fato acarreta uma estrutura de equilíbrio amorfização/cristalização em toda a região irradiada do sólido.

- A explosão coulombiana, quando acontece próximo à superfície da amostra, dá origem a outro fenômeno chamado sputtering que é a dessorção causada pelo impacto de íons. Dessorção, por sua vez, é a emissão de material (que podem ser íons, aglomerados iônicos ou átomos neutros). 


\section{3}

\section{Técnicas Experimentais}

\section{1}

\section{As amostras: meteoritos condritos ordinários}

Neste trabalho foram analisados meteoritos da classe COs. Esta classe é comumente associada a alguns asteroides do tipo $\mathrm{S}$, devido a semelhante constituição mineralógica, constituída basicamente por silicatos (como a olivina e o piroxênio). Ela apresenta as seguintes características gerais: o conteúdo relativo de todo o ferro nesses meteoritos é usado como critério para sua subdivisão em três grupos: H (High), de 25\% a 30\%; L (Low), de 20\% a 25\%; e LL (Low-Low) de $18 \%$ a $20 \%$ de ferro em massa do total da massa da amostra do meteorito analisado. Vale ressaltar que existem dois trabalhos de irradiação iônica que utilizaram condritos ordinários do tipo H (Strazzulla et al (1005) e Bruneto et. al. (2005)) e não há trabalho algum para os subtipos L e LL até este momento. Este fato evidencia a necessidade de mais estudos sobre as consequências do SpWe sobre a superfície dessas classes de meteoritos, estudo este que é um dos objetivos deste trabalho.

Os meteoritos COs cujas amostras foram estudadas no presente trabalho foram:

- Parambu (LL);

- Putinga (L);

- Gail (H).

As amostras foram cedidas pela curadora da Coleção de Meteoritos do Museu Nacional ${ }^{7}$ (Quinta da Boa Vista - Rio de Janeiro), Professora Maria Elizabeth Zucolotto. O fato relevante da classificação apresentada acima é que os

\footnotetext{
7 - Amostra obtidas antes do incêndio de 2 de setembro de 2018 que destruiu parte considerável do acervo do Museu Nacional.
} 
três meteoritos são condritos ordinários, porém cada um deles pertence a um dos subgrupos químicos/mineralógicos que essa classe de meteoritos compreende. Isso permite que possa ser feito um estudo sistemático de como a variação no conteúdo de ferro dos meteoritos influencia os efeitos espectrais da irradiação.

\subsection{1}

\section{Meteorito Parambu}

O Parambu (CO, LL) é um meteorito que caiu na cidade de Parambu, no Estado do Ceará (Br), em 24 de julho 1967. Ele é classificado como um meteorito condrito ordinário do subtipo LL e grupo petrológico 5. Condrito por apresentar côndrulos ${ }^{8}$ em uma matriz de grãos finos. Sua estrutura é brechada. Sua classificação química (LL) se deve ao fato de apresentar um conteúdo total de ferro que corresponde a $18,96 \%$ de sua massa total, sendo apenas $0,5 \%$ na forma de ferro metálico ${ }^{9}$ (Levi-Donati e Sighinolfi, 1974). Seu grupo petrológico indica que este meteorito experimentou alto grau de metamorfismo (processo geológico no qual o mineral sofre modificações em sua natureza), a ponto de homogeneizar a olivina e o piroxênio (Meteoritical Bulletin ${ }^{10}$ ).

Sua composição mineralógica compreende diferentes tipos de olivina $(\mathrm{Fe}, \mathrm{Mg})_{2} \mathrm{SiO}_{4}$, além de orto e clinopiroxênios, plagioclastos, cromita, trolita, e imenita e seu alto grau de metamorfismo é uma grande evidência de choques mecânicos (Levi-Donati e Sighinolfi, 1974).

\subsection{2}

\section{Meteorito Putinga}

O meteorito Putinga (CO, L) foi encontrado no município de Putinga no estado do Rio Grande do Sul (Br) no ano de $1966^{11}$. Sua classificação completa é condrito ordinário do grupo químico L e grupo petrológico 6. Sua classificação

\footnotetext{
8 - São inclusões que foram totalmente ou parcialmente formadas antes ou durante o período de acreção que levou a formação dos condritos (Hutchison, 2004). Os côndrulos são pequenos elementos quasi-esféricos, formados principalmente de silicatos, com diâmetros que variam entre 1 $\mu \mathrm{m}$ e $5 \mathrm{~cm}$.

9 - Trata-se de ferro em sua forma elementar.

10 - É um database que contêm informações sobre todos os meteoritos catalogados no mundo.

11 - Curiosamente a cidade havia sido fundada apenas três anos antes, em 1963.
} 
neste grupo químico se justifica pelo fato de apresentar um conteúdo total de ferro correspondendo à $23,3 \%$ de sua massa. É condrito pelas mesmas razões que o Parambu. Sua estrutura mineralógica apresenta côndrulos, em uma matriz de grãos finos composta predominantemente por cristais de olivina. Apresenta alguns cristais de piroxênio, além da presença de alguns poucos grãos de metal. Outros minerais como feldspato, kamacita, taenita e trolita são também observados em sua estrutura (Symes e Hutchison, 1970). O tipo petrológico indica que experimentou alto grau de metamorfismo o que pode ter sido suficiente para converter piroxênio rico em $\mathrm{Ca}$ em ortopiroxênio. $\mathrm{O}$ metamorfismo também alterou os contornos dos côndrulos (Meteoritical Bulletin).

\subsection{3}

\section{Meteorito Gail}

O Gail é um meteorito condrito ordinário, do tipo químico $\mathrm{H}$ com classificação petrológica 4. Ele foi encontrado no Texas, Estados Unidos, no ano de 1948. Cerca de 4,6 kg foram recuperados. Sua estrutura contém abundantes côndrulos inseridos em uma matriz de grãos fino que foi recristalizada devido ao metamorfismo. Sua classificação química se dá pelo fato de conter cerca de $26 \%$ de ferro. Sua composição mineralógica apresenta olivina, como mineral mais abundante, piroxênio com baixo teor de cálcio, ferro-níquel metálico, trolita e plagioclásio (Ehlmann e Keil, 1985).

\section{2}

\section{O acelerador VDG e o feixe de íons}

Neste trabalho as amostras de meteoritos foram irradiadas por feixe de prótons e nitrogênio com energia de $\mathrm{MeV}$. O feixe de íons foi produzido no acelerador eletrostático linear Van de Graaff (construído pela High Voltage Engineering corp.), modelo KN400, que está localizado no prédio Pe. Roser no Departamento de Física da PUC-Rio. Este acelerador é capaz de gerar potenciais elétricos de até $4 \mathrm{MV}$.

Os projéteis utilizados são produzidos por uma fonte de íons que por radiofrequência ioniza o gás introduzido no interior de uma ampola de quartzo. Os íons produzidos são extraídos da ampola para o tubo acelerador onde parâmetros, 
como focalização, corrente e energia do feixe, são otimizados pelo operador de acordo com as necessidades.

Para levar o feixe de íons até a câmara de análise, os íons acelerados são defletidos da direção vertical para a horizontal pelo ímã analisador de $90^{\circ}$ (Figura 3.1 (a)) que possui a função de selecionar o feixe cuja energia é a que se deseja trabalhar. Já na horizontal o feixe passa por um quadrupolo magnético utilizado na focalização do feixe e chega a outro ímã (Figura 3.1 (b)), que tem a função de distribuí-lo para uma das 7 linhas disponíveis. Este ímã distribuidor (o switching magnet) é capaz de direcionar o feixe horizontalmente em ângulos desde $-45^{\circ}$ até $+45^{\circ}$ com intervalos angulares de $15^{\circ}$ entre as linhas. A linha utilizada na irradiação das amostras deste trabalho é a localizada a $-15^{\circ}$.

Todo o sistema é mantido em alto vácuo, com pressão menor que $10^{-6} \mathrm{mbar}$, por um conjunto de bombas mecânicas, difusoras e turbo moleculares, distribuídas ao longo da canalização que forma o caminho do feixe até as câmaras de irradiação. A região de alto vácuo inicia-se no tubo acelerador e vai até uma válvula pneumática, a partir da qual, inicia-se a região de ultra alto vácuo. Para proteção da câmara de irradiação contra contaminação por vapor óleo residual das bombas, uma armadilha de nitrogênio líquido foi colocada imediatamente antes da válvula pneumática ${ }^{12}$. Logo após a mesma, foi colocada uma folha de carbono no caminho do feixe com a função de impedir a passagem de moléculas de gás residual das bombas que não foram capturadas pela armadilha de nitrogênio líquido. A linha conta ainda com uma bomba iônica usada para evitar contaminações de óleo das bombas difusoras da região de alto vácuo.

Antes de chegar à câmara de irradiação, o feixe de íons passa ainda por um segundo quadrupolo que pode ser utilizado para ajustes óticos no feixe antes dele finalmente incidir na amostra.

12 - A válvula pneumática, controlada remotamente, tem a função de interromper o caminho do feixe para que se possa fazer alguma alteração na câmara de irradiação, como tirar o $\mathrm{KBr}$ da direção de irradiação e colocar a amostra, por exemplo. Tem também a função de interromper o feixe na fluência desejada. 

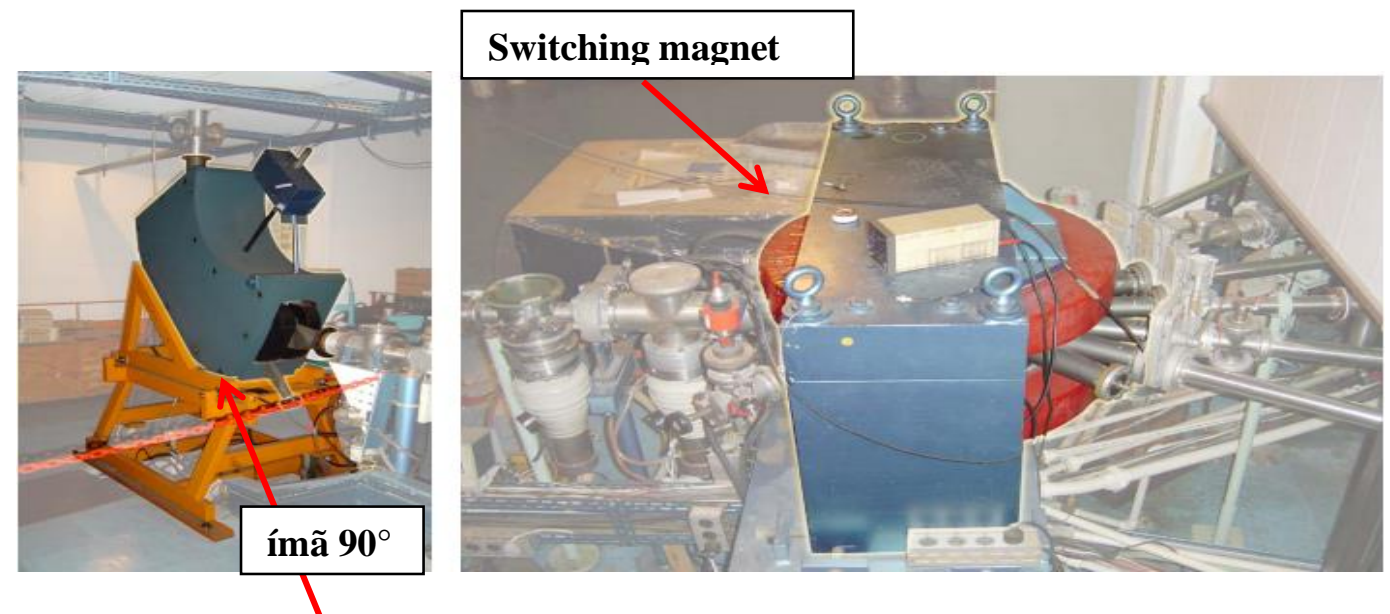

Figura 3.1 - Fotografias do ímã $90^{\circ}$ que deflete os íons da vertical para horizontal e do switching que dirige os íons horizontalmente para uma das linhas de trabalho. Adaptado de Garcia, 2006.

\section{3}

\section{Parâmetros de irradiação}

Um porta-amostra à temperatura ambiente foi empregado neste trabalho. Ele pode ser movimentado por três micrometros ortogonais para que pudesse ser variada manualmente a posição do centro das amostras nas três dimensões (direções x, y e z) com precisão de $1 \mu \mathrm{m}$. As amostras podiam ser inseridas em até três posições na direção vertical, conforme Figura 3.2. Na posição 1 foi colocada uma pastilha de $\mathrm{KBr}$ puro; na posição 2 está a amostra; e na posição 3 um copo de Faraday. Os valores das posições nas direções x, y e z foram anotados porque as amostras precisaram ser retiradas da câmara para medidas de espectroscopia e deveriam, ao retornarem ser recolocadas na mesma posição para que a nova dose de irradiação fosse feita sobre a anterior. Uma máscara foi acoplada à frente do porta-amostra para nele fixar a amostra e o KBr.

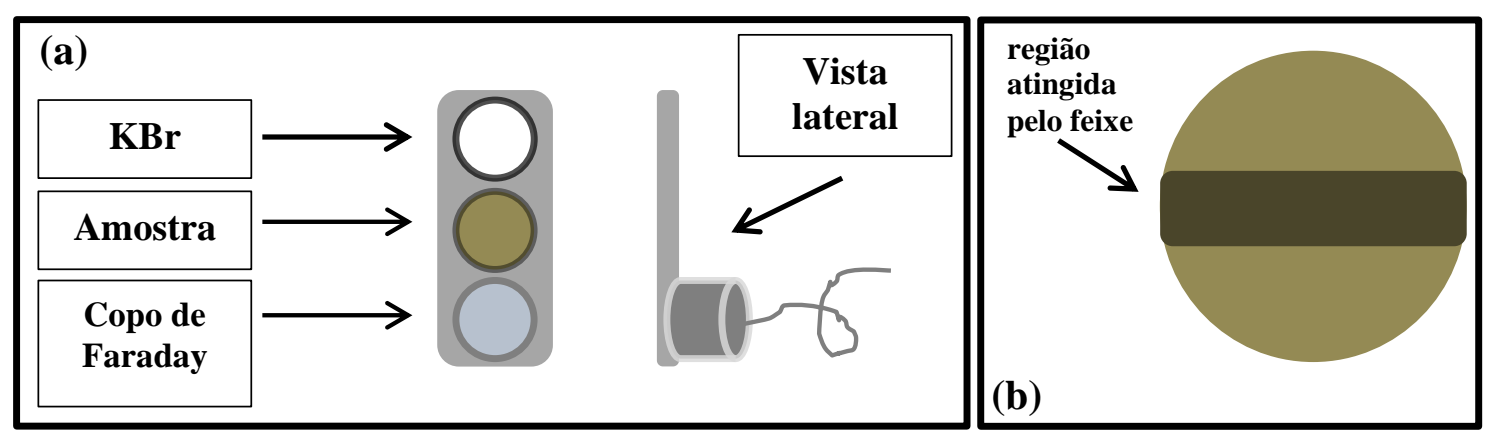

Figura 3.2 - (a) Representação esquemática do porta-amostras utilizado; (b) exemplo de região irradiada da amostra de meteorito. 


\section{(i) $\mathrm{KBr}$}

Na primeira posição foi colocada uma pastilha constituída de $\mathrm{KBr}$ puro. A função desta pastilha é auxiliar a determinação das dimensões do feixe e da posição de irradiação. $\mathrm{O} \mathrm{KBr}$ luminesce ao ser atravessado pelo feixe de prótons. A região irradiada pode então ser visualizada, o que permite determiná-la. Isto precisou ser feito com cautela para garantir que as medidas no o espectrômetro UV-VIS-NIR fossem realizadas somente na região irradiada, isto é uma área de 32 $\mathrm{mm}^{2}$ (Fig. 3.2 (b)).

\section{(ii) Copo de Faraday}

Como as amostras utilizadas são uma mistura de diferentes minerais isolantes e semicondutores, não foi possível medir de forma direta a carga depositada nela pelo feixe (utilizando um nanoamperímetro conectado à amostra). Um método de medida alternativo da corrente do feixe precisou ser empregado.

$\mathrm{Na}$ terceira posição foi instalado um copo de Faraday, isolado eletricamente do porta-amostras. Sua função é medir a carga elétrica que chega à amostra durante a irradiação, ou seja, a fluência do feixe de íons. O copo é conectado ao exterior da câmara por um cabo ligado a um passador. Um fio externo liga o passador em série com uma fonte DC (um conjunto de baterias que geram uma d.d.p equivalente de aproximadamente $105 \mathrm{~V}$ ) e um nanoamperímetro. A função da fonte DC é polarizar o copo positivamente para que o mesmo atue como uma armadilha para os elétrons secundários ${ }^{13}$ emitidos quando a amostra é irradiada; já o nanoamperímetro mede a corrente elétrica $i_{a}$ que circula entre o copo e a Terra. Um contador, conectado ao amperímetro faz a integração da carga total depositada.

Um anel colimador, conectado a um segundo nanoamperímetro, coleta a corrente $i_{c}$ que não chega a amostra. Este valor de corrente é usado como uma referência para a determinação da que de fato irradia a amostra.

Para a medida da corrente na amostra adotou-se os seguintes procedimentos:

\footnotetext{
${ }^{13}$-Um feixe de íons, ao incidir sobre uma superfície sólida, faz com que a mesma emita elétrons secundários. Estes elétrons emitidos introduzem erros na medida da corrente na amostra. Por esse motivo é importante recaptura-los, atraindo-os respectivamente para o copo de Faraday e colimador, ambos polarizados.
} 
1. Após centralizar do feixe no $\mathrm{KBr}$ e otimizar suas dimensões, utilizase o manipulador do porta-amostras para variar sua posição na direção z, até que o copo de Faraday seja colocado na posição de irradiação;

2. Duas correntes de feixe de íons são medidas simultaneamente: aquela que chega ao copo de Faraday e aquela que é interceptada pelo colimador; com estes dois valores determina-se a razão K entre a intensidade da corrente no alvo $\left(i_{a}\right)$ e no colimador $\left(i_{c}\right)$;

Este procedimento é feito irradiando-se o copo e o colimador por um intervalo de tempo (usualmente 1 minuto) e medindo-se as correntes em seguida. $\mathrm{O}$ procedimento é repetido algumas vezes para atestar a estabilidade do feixe. Se o valor de K variar entre os procedimentos, deve-se melhora as condições do feixe no painel de comandos.

Uma vez determinado o valor de $\mathrm{K}$ não se deve mais variar os parâmetros de controle do feixe, tal como focalização, pois isto altera o valor de $\mathrm{K}$.

3. De posse do valor de $\mathrm{K}$ deve-se colocar a amostra na posição de irradiação. Para isso, o caminho do feixe é interrompido fechando-se a válvula pneumática. A amostra é então movimentada na direção z até a posição correta. A válvula pneumática é aberta e a experiência é iniciada. Durante a irradiação da amostra, a medida da corrente no colimador é feita concomitantemente. Esta medida informa o operador sobre a estabilidade do feixe de íons além de permitir o cálculo da fluência na amostra.

4. Terminada a irradiação, o valor total da carga depositada no colimador é multiplicada por K para se obter o valor da carga depositada na amostra.

\section{4}

\section{Realização dos experimentos}

Nesta seção serão descritos:

I. o procedimento empregado para o preparo das amostras; 
II. a rotina experimental durante a irradiação;

III. a sequência de medidas;

IV. os métodos analíticos usados.

\subsection{1}

\section{Preparo de amostras}

As amostras estudadas no presente trabalho foram fornecidas em pequenos pedaços brutos. Elas precisaram ser trituradas com o auxílio de um almofariz de ágata para que adquirissem a forma de pequenos grãos. Uma precaução tomada foi a de utilizar somente partes internas do pedaço de meteorito. Esse cuidado é importante porque as partes externas ficaram muito tempo expostas ao contato com a atmosfera, com o solo, com a mão das pessoas ou outros ambientes e certamente encontram-se contaminadas.

Uma vez obtidos os grãos, pastilhas são confeccionadas. Para isto utiliza-se um empastilhador e uma prensa. Como não é possível fazer pastilhas de meteorito puro, uma vez que os grãos de meteorito obtidos não apresentam consistência suficiente, foi utilizado como substrato o brometo de potássio $(\mathrm{KBr})$ (Tanto a irradiação quanto a medida de refletância foram realizadas na posição vertical. Por esse motivo optou-se por utilizar pastilhas com $\mathrm{KBr}$ como substrato, uma vez que sem este substrato não seria possível medir os grãos nesta posição). A seguinte rotina foi empregada no preparo das amostras:

i) inicialmente $0,6 \mathrm{~g}$ de $\mathrm{KBr}$ foram colocados no empastilhador e levados à prensa onde foram submetidos a 2 toneladas-força por $2 \mathrm{~min}$.

Essa quantidade foi escolhida, pois se observou, após algumas tentativas e erros, que uma quantidade menor fornecia pastilhas muito frágeis. Dada a complexidade na rotina experimental de colocar e retirar amostras da câmara de vácuo e do espectrômetro, tal fragilidade pode se tornar um problema; por outro lado, colocar uma quantidade maior do que 0,6 g gera pastilhas muito grossas, uma inconveniência no momento de prendê-las no porta-amostras.

ii) abre-se então o empastilhador sem retirar o $\mathrm{KBr}$; 
iii) coloca-se $0,1 \mathrm{~g}$ de meteorito sobre a pastilha de $\mathrm{KBr}$ dentro do empastilhador. Deve-se colocá-lo de forma a cobrir toda a superfície do KBr. Essa quantidade é suficiente para isso;

iv) Leva-se então o empastilhador novamente à prensa e aplica-se 3 toneladas-força por $5 \mathrm{~min}$. Assim se obtém uma pastilha de meteorito $+\mathrm{KBr}$, estável o suficiente para ser colocada no porta-amostras da câmara de irradiação e para análise no espectrômetro UV-VIS-NIR. O procedimento descrito é similar ao utilizado em grande parte dos trabalhos existentes. O resultado é uma amostra como esquematizada na Fig.3.3.

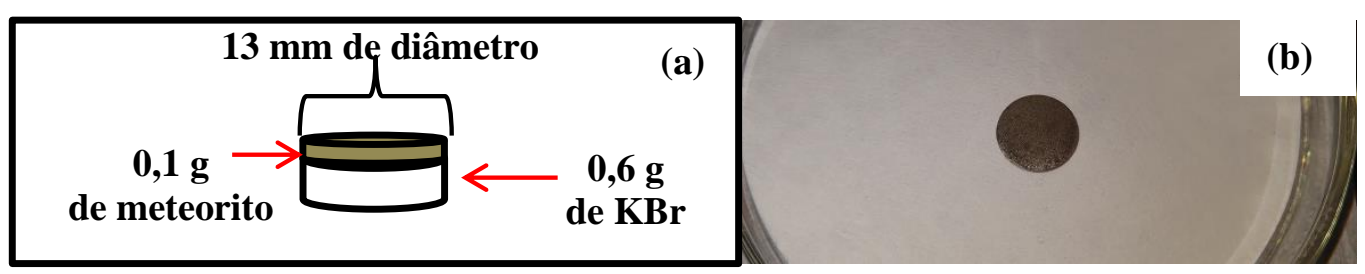

Figura 3.3 - (a) Representação da pastilha feita de amostra de meteorito prensada sobre KBr. (b) Foto tirada de cima da pastilha pronta do meteorito Parambu.

\section{4 .2}

\section{Rotina experimental e sequência de medidas}

Todas as medidas realizadas durante a execução desta tese são "ex-situ", pois foram feitas em aparatos analíticos que não são conectados com a câmara onde o processo de irradiação ocorreu: após a medida, a pastilha é retirada do porta-amostras e transportada para o aparato analítico (espectrômetro UV-VISNIR ou Raman).

Para a análise das três amostras foram seguidos os procedimento abaixo:

- Caracteriza-se a amostra, antes da irradiação, com o espectrômetro UV-VIS-NIR; este será o espectro da amostra virgem;

A amostra é colocada no porta-amostras especialmente projetado para este espectrômetro. Como a medida é realizada "ex-situ” é necessário garantir que a pastilha seja sempre colocada na mesma posição dentro do porta-amostras e, também, que o porta-amostras seja disposto sempre na mesma posição em relação ao 
espectrômetro. Para isso, marcações que permitam recolocar ambos na mesma posição de antes foram feitas.

- Caracteriza-se a amostra por espectroscopia Raman.

- A pastilha é transportada de volta ao laboratório do acelerador e colocada na câmara de irradiação.

- Fecha-se a câmara de irradiação e liga-se o sistema de bombas para baixar a pressão no interior da mesma. A pressão de trabalho deve ter ser inferior a $10^{-6}$ mbar.

- São feitas as medidas de caracterização do feixe, como sua corrente. O copo de Faraday é utilizado para isso.

- Inicia-se a irradiação até atingir o valor de fluência desejado quando a irradiação é, então, interrompida, quebra-se o vácuo e a câmara de irradiação é aberta.

- A pastilha é retirada e levada novamente para análise nos espectrômetros UV-VIS-NIR e Raman.

- O procedimento descrito acima é repetido até que a fluência desejada na amostra seja alcançada e a última medida UV-VIS-NIR seja feita.

\section{5}

\section{Técnicas de análise}

Para analisar as modificações induzidas pela irradiação com íons na superfície das amostras, as seguintes técnicas analíticas foram utilizadas:

i) Espectroscopia UV-VIS-NIR - espectroscopia na faixa do ultravioleta, visível e infravermelho próximo $(0,2-2,5 \mu \mathrm{m})$. A espectroscopia é feita na modalidade "reflexão integrada" utilizando-se uma esfera integradora acoplada ao espectrômetro UV-VIS-NIR. Espera-se acompanhar o avermelhamento dos espectros e escurecimento das amostras, associando mudanças físico-químicas e mineralógicas com o conteúdo de ferro existente nos meteoritos.

Essa é a técnica mais importante para o presente trabalho, pois as medidas observacionais de asteroides são feitas nessa faixa de espectro 
eletromagnético. Logo, essa técnica possibilita a comparação direta entre os espectros de laboratório e aqueles obtidos por observação.

ii) Espectroscopia Raman - É empregado com o objetivo de acompanhar as modificações estruturais e mineralógicas na amostra, permitindo acompanhar, por exemplo, efeitos que causem amorfização. A técnica é também aplicada no estudo da dissociação de espécimes química.

\subsection{1}

\section{Espectroscopia de refletância difusa}

A espectroscopia de refletância difusa, na faixa UV-VIS-NIR, é empregada no estudo e obtenção de informações espectroscópicas de moléculas.

Optou-se pelo uso da espectroscopia na faixa do ultravioleta (200 a 400 $\mathrm{nm}$ ), do visível (400 a $700 \mathrm{~nm}$ ) e do infravermelho próximo (700 a $2500 \mathrm{~nm}$ ) devido às grandes variações de refletância apresentadas pelos materiais dos meteoritos nestas faixas de comprimento de onda. A radiação direcionada sobre a superfície da amostra, após interagir com ela, sofre reflexão que pode ser especular ou difusa dependendo das características topológicas da amostra. No caso das amostras analisadas nesta tese, a reflexão é predominantemente difusa devido ao alto grau de rugosidade dos grãos que compõem as amostras.

Para entender o que é a reflexão difusa, imagine uma superfície totalmente branca sobre a qual incide luz solar. Se a reflexão for difusa, independentemente do ângulo que se olha a superfície, ela irá parecer igualmente iluminada, pois a radiação que incide sobre ela é (igualmente) refletida em diferentes ângulos. A reflexão difusa pode ser definida, então como aquela em que a radiação é isotropicamente refletida em diferentes direções independente do ângulo da radiação incidente.

O fenômeno da interação luz-matéria, especificamente no caso da reflexão difusa, é altamente complexo o que torna difícil o tratamento teórico. Isso porque, quando a radiação eletromagnética incide sobre a amostra e interage com a mesma, a radiação refletida no final é uma combinação de três fenômenos óticos que ocorrem simultaneamente: reflexão imediata, refração e espalhamento (Figura 3.4), além de outros como absorção e polarização. Fótons, ao interagir com a matéria, causam diferentes efeitos dependendo da energia (frequência). 


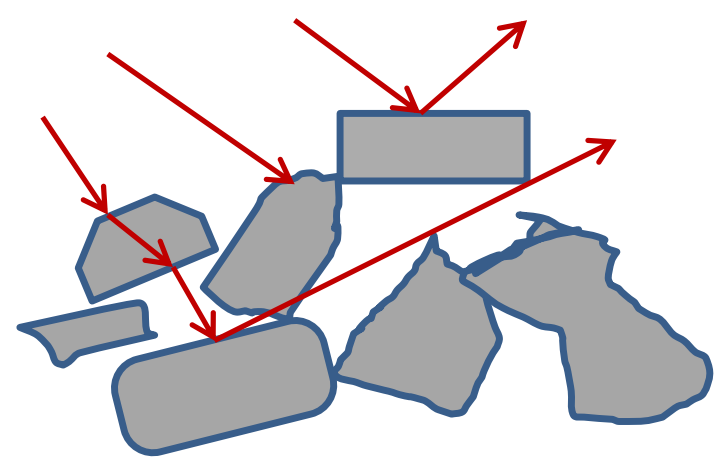

Figura 3.4 - Representação de diferentes interações da radiação incidente com a superfície da amostra.

Uma amostra deve, então, ser considerada, simultaneamente, como um meio espalhador e absorvedor de radiação.

Um tratamento teórico para reflexão difusa muito bem estabelecido e confirmado por experimentos é a teoria de Kubelka-Munk (K-M) para reflexão difusa (Blitz, 1998). Nesta teoria, a amostra sólida recebe a radiação incidente $\mathrm{I}_{0} \mathrm{e}$ responde refletindo a radiação com intensidade $\mathrm{J}_{0}$. A radiação penetra no sólido na direção $\mathrm{x}$, reduzindo de intensidade devido a processos de absorção $\mathrm{e}$ espalhamento. O sólido é modelado por uma sucessão de pequenas camadas muito finas e homogêneas de espessura dx. Ao incidir sobre a camada dx, na posição dx, a intensidade da radiação, I(x), é menor que a incidente. Ao penetrar no pedaço $\mathrm{dx}$, uma parte da radiação sofre absorção de valor kIdx, sendo k o coeficiente de absorção, e a outra parte sofre espalhamento sIdx, onde s é o coeficiente de espelhamento efetivo da amostra. Parte da radiação espalhada pela camada retorna à superfície com uma intensidade $\mathrm{J}(\mathrm{x})$. Um esquema é mostrado na Figura 3.5.

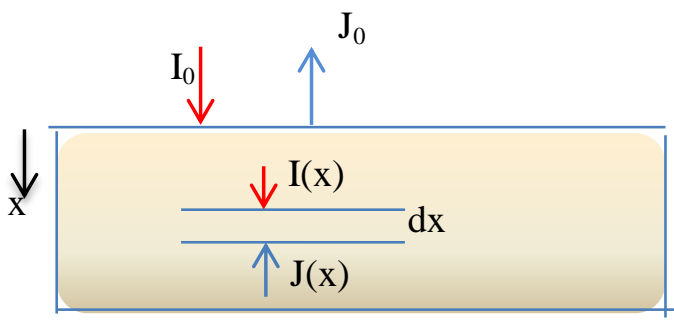

Figura 3.5 - Representação das interações usadas no modelo de Kubelka-Munk.

Os processos citados acima podem ser modelados pelo conjunto de equações diferenciais: 


$$
\begin{gathered}
\frac{\mathrm{dI}}{\mathrm{dx}}=-(\mathbf{k}+\mathbf{s}) \mathbf{I}(\mathbf{x})+\mathbf{s} \mathbf{J}(\mathbf{x}) \\
\frac{\mathbf{d J}}{\mathrm{dx}}=(\mathbf{k}+\mathbf{s}) \mathbf{J}(\mathbf{x})-\mathbf{s} \mathbf{I}(\mathbf{x})
\end{gathered}
$$

Cujas soluções gerais são:

$$
\begin{aligned}
& \mathbf{I}(\mathbf{x})=\mathbf{A}(\mathbf{1}-\mathbf{b}) e^{a x}+B(1+b) e^{-a x} \\
& \mathbf{J}(\mathbf{x})=\mathbf{A}(1-\mathbf{b}) e^{a x}+B(1+b) e^{-a x}
\end{aligned}
$$

Onde A e B são duas constantes e a e b correspondem a seguintes substituições:

$$
\begin{gathered}
\mathbf{a}=\sqrt{\mathbf{k}(\mathbf{k}+2 \mathbf{s})} \\
\mathbf{b}=\sqrt{\mathbf{k} /(\mathbf{k}+2 \mathbf{s})}
\end{gathered}
$$

As soluções particulares das equações 3.3 com condição de contorno: i) inicial $\mathrm{x}=0 \mathrm{I}(\mathrm{x}=0)=\mathrm{I}_{0}$ (onde $\mathrm{x}=0$ é a superfície da amostra) e ii) final $\mathrm{J}(\mathrm{x} \rightarrow \infty)=$ $\mathrm{I}(\mathrm{x} \rightarrow \infty)=0$ (onde $\mathrm{x} \rightarrow \infty$ representa um sólido infinitamente espesso) são:

$$
\begin{gathered}
\mathbf{I}=\mathbf{I}_{\mathbf{0}} \mathbf{e}^{-\mathbf{a x}} \\
\mathbf{J}=\frac{(1-\mathbf{b})}{(1+\mathbf{b})} \mathbf{e}^{-\mathbf{a x}}
\end{gathered}
$$

Em medidas de refletância, o que se deseja medir é o valor da refletância da amostra como função do comprimento de onda da radiação. Este parâmetro é definido como sendo razão entre a intensidade da radiação que retorna da amostra $(\mathrm{J}(\mathrm{x}=0))$ pelo valor de uma intensidade de referência. A intensidade de referência é a medida da refletância de uma amostra padrão que, no caso ideal, não absorveria nenhuma porcentagem da radiação que sobre ela incida (o equivalente a ter $\mathrm{k}=0$ na segunda equação 3.4$)$. Ou seja, 


$$
\mathbf{R}=\frac{\mathbf{k}+\mathbf{s}-\sqrt{\mathbf{k}^{2}+2 \mathbf{k s}}}{\mathbf{s}}
$$

A refletância é uma combinação de efeitos de espalhamento e absorção de radiação eletromagnética.

Ainda neste mesmo modelo teórico, Kubelka e Munk definiram a chamada função K-M, f(R), como sendo a razão entre os coeficientes de absorção e espalhamento.

$$
\mathbf{f}(\mathbf{R})=\frac{\mathbf{k}}{\mathbf{s}}
$$

Razão essa que será maior quanto mais radiação a amostra absorver, e menor quanto mais ela espalhar. Manipulando as equações (3.5) e (3.6) obtém-se a seguinte relação entre $f(R)$ e R:

$$
\mathbf{f}(\mathbf{R})=\frac{\left(1-R^{2}\right)}{4 R}
$$

que relaciona os coeficientes de absorção e espalhamento com o valor da refletância para cada comprimento de onda. No capítulo de resultados (4), esta teoria, em especial a relação 3.7 , será empregada para obter a conversão do gráfico de refletância em um gráfico de absorbância.

\subsubsection{1}

\section{Espectrômetro UV-VIS-NIR}

O espectrômetro UV-VIS-NIR é um aparelho de análise utilizado neste trabalho para obtenção de espectros óticos no modo reflexão. Um espectrômetro deste tipo é composto por um conjunto de elementos ópticos, como filtros, monocromadores, atenuadores e janelas; duas lâmpadas são usadas como fonte de radiação, uma com filamento de tungstênio e outra contendo gás de deutério (2D lamp). A radiação emitida por ambas as lâmpadas percorre o interior do aparelho até incidir sobre a superfície da amostra. Em sua versão completa este aparelho realiza medidas nas modalidades transmissão e absorção; este não era o caso da unidade existente no Departamento e, para que fosse possível utilizá-lo no modo reflexão, uma esfera integradora de $150 \mathrm{~mm}$ de diâmetro foi adquirida. 
A esfera integradora é uma ferramenta que permite fazer medidas mais eficientes de refletância de uma amostra, pois seu interior é revestido por material refletor que direciona toda luz refletida difusamente pela superfície da amostra para o detector, conforme esquematizado na Fig. 3.6. Obtêm-se assim, uma gama mais rica de informações. A esfera apresenta quatro acessos ao seu interior, dois para entrada dos feixes de luz e dois outros para posicionamento da amostra e dos dois padrões de medidas conforme a Figura 3.7 (a) e (b). Antes de medir a refletância da amostra, é necessário calibrar a medida e estabelecer o valor da refletância que o aparelho entenderá como 100\%. Para isso utiliza-se um padrão de referência composto de sulfato de bário $\left(\mathrm{BaSO}_{4}\right)$ que apresenta alto grau de refletividade. Com os dois padrões de $\mathrm{BaSO}_{4}$ posicionados nas entradas, conforme Figura 3.6 (a), o espectrômetro é acionado e a medida da referência é feita. Dois feixes de luz entram pelos dois acessos desocupados. Cada feixe incide perpendicularmente sobre cada um dos padrões e com isso, o aparelho grava em sua memória o valor de refletância equivalente a 100\%. Após este passo, troca-se um dos padrões de $\mathrm{BaSiO}_{4}$ pela amostra mantendo o outro padrão no lugar (Figura 3.6 (b)). Ele funcionará como referência durante toda a medida, e a refletância da amostra será medida em relação à refletância do padrão. A luz de medida incide sobre a superfície da amostra e é espalhada difusamente para o interior da esfera que em sucessivas reflexões incide no detector que se encontra na base da esfera integradora (Fig. 3.7).

Para as medidas de refletância das amostras, uma máscara contendo um orifício de $4 \mathrm{~mm}$ foi acoplada à esfera integradora na porta de entrada da luz de medida. Isso foi feito para reduzir as dimensões do feixe de luz que chega à superfície da amostra. Com um feixe de luz de seção transversal menor, a área a ser irradiada também se reduz.

A consequência é a diminuição do tempo de irradiação por feixe de prótons, pois para uma área menor de irradiação é possível atingir valores de fluência desejados com maior rapidez. O diâmetro do feixe de luz medido na superfície da amostra foi de cerca de $30 \mathrm{~mm}^{2}$, menor do que a área irradiada. 


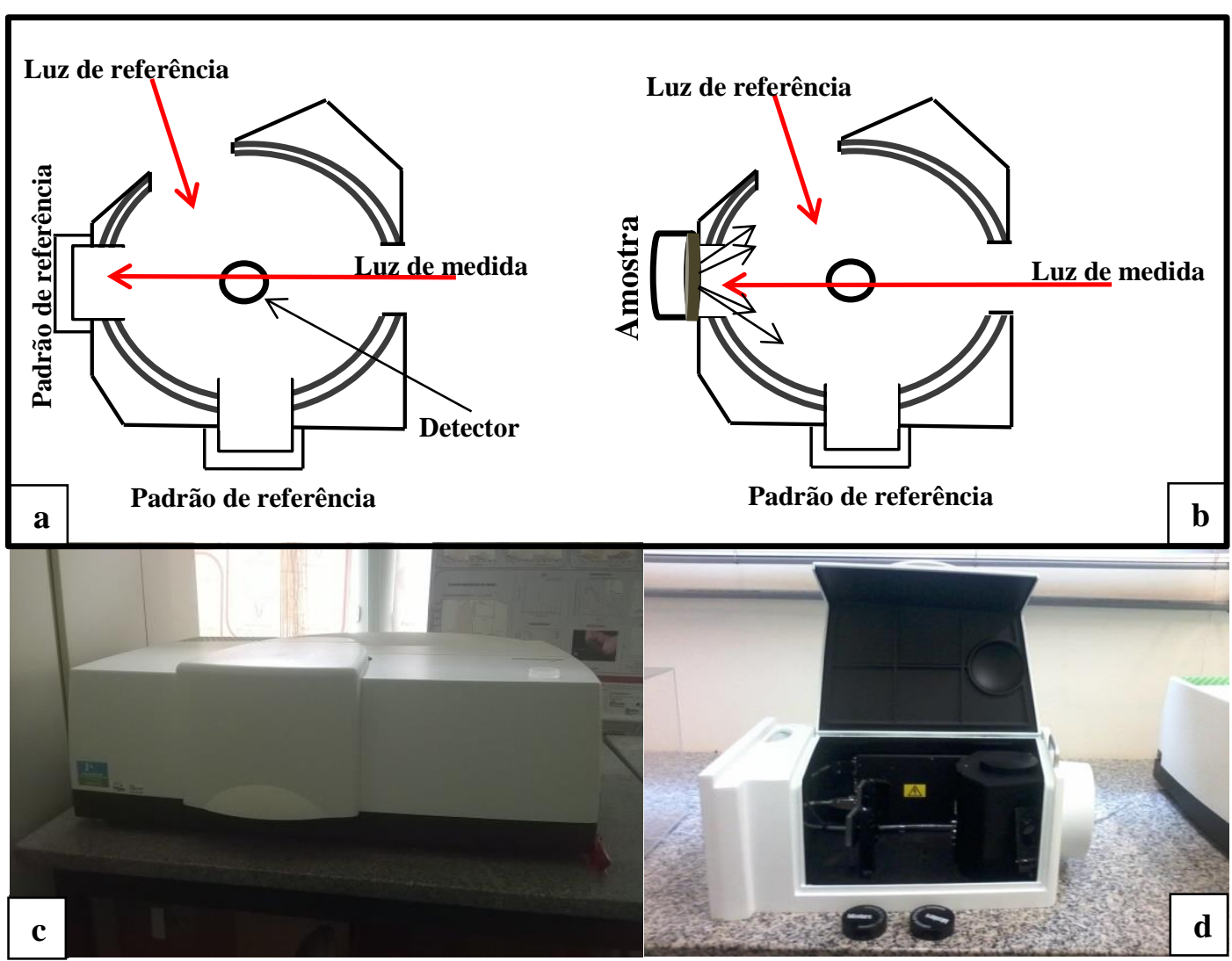

Figura 3.6 - Esquema de medida da esfera integradora: (a) medida de referência; (b) medida de refletância da amostra; (c) Espectrômetro UV-VIS-NIR da PUC-Rio; (d) esfera integradora que pode ser acoplada a ele para medidas de reflexão integrada.

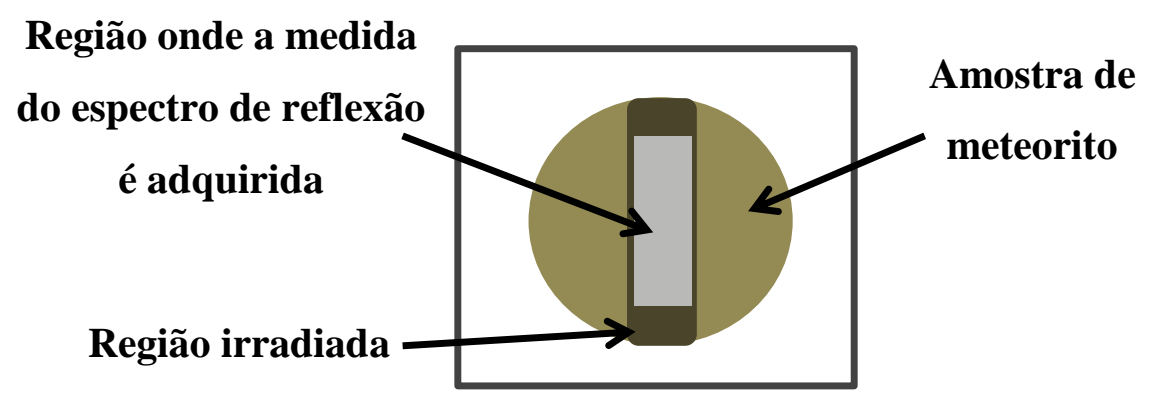

Figura 3.7 - Esquema indicando a área onde a amostra foi irradiada e a região onde a medida do espectro de reflexão é feita.

A intensidade da radiação eletromagnética que, após sucessivas reflexões, chega ao detector, é medida e os dados são enviados para um software em um computador acoplado ao espectrômetro. O software Labview produz um espectro de reflexão que é um gráfico da refletância detectada como função do comprimento de onda da radiação. Um espectro de reflexão do meteorito Putinga é mostrado na Figura 3.8. 


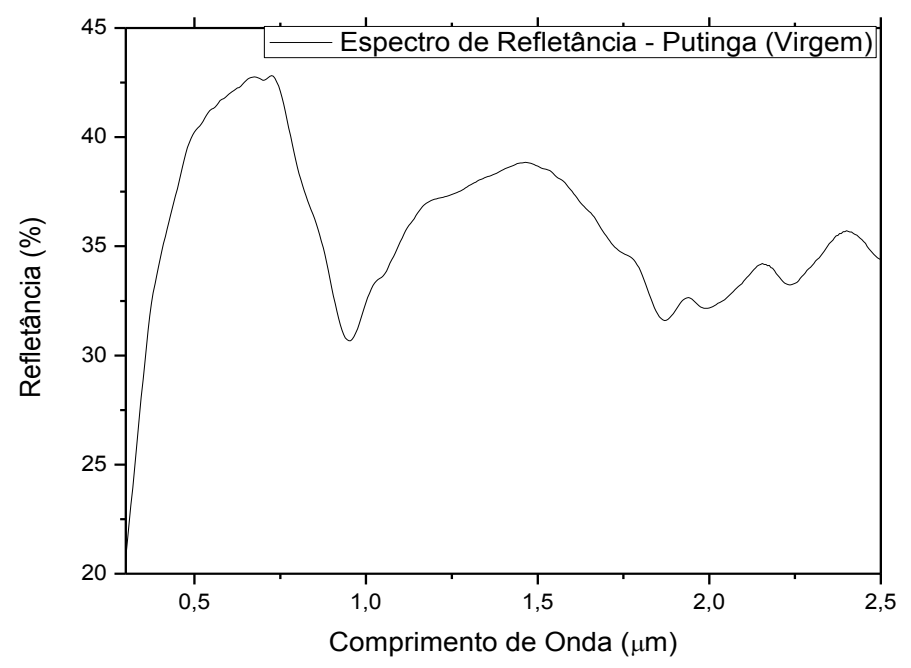

Figura 3.8 - Exemplo de espectro de refletância obtido no espectrômetro UV-VIS-NIR com a esfera integradora.

Para as medidas deste trabalho foi utilizado um espectrômetro Perkin-Elmer do modelo Lambda 950, que atua na faixa do ultravioleta, visível e infravermelho próximo $(0.2-2.5 \mu \mathrm{m})$. Uma esfera integradora também da Perkin-Elmer, de 150 mm de diâmetro foi acoplada a ele.

As medidas forma feitas no modo reflexão com resolução de $5 \mathrm{~nm}$, pois resoluções menores não revelavam novos detalhes e obrigavam o tempo de medida aumentar muito. O intervalo de comprimento de onda utilizado foi de 200 $\mathrm{nm}$ a $2500 \mathrm{~nm}$.

\section{5 .2}

\section{Processos de espalhamento Raman}

A espectroscopia Raman é um fenômeno de espalhamento de luz por moléculas, que envolve dois fótons cuja diferença de energias corresponde à energia da transição molecular. É um processo de espalhamento inelástico em que o fóton incidente, com energia muito maior do que a diferença de energias dos estados moleculares vibracionais, é absorvido causando uma transição para um estado molecular virtual; em seguida, uma nova transição ocorre, gerando a emissão de um novo fóton com energia inferior ao primeiro. O fóton emitido é detectado e analisado, e a diferença de frequências entre fóton incidente e o fóton espalhado é calculada. Na espectroscopia Raman, pelo fato de se tratar de 
transição para estados virtuais, a interação entre a luz incidente e a amostra é uma condição não ressonante que envolve polarizabilidade da molécula (Mendoza, 2014).

Historicamente, o fenômeno de que uma pequena fração da radiação espalhada por certos tipos de moléculas possui comprimento de onda diferente da do feixe incidente recebeu o nome de espalhamento Raman, em homenagem ao cientista que o descreveu C. V. Raman (1923). Ele observou o seguinte: i) os comprimentos de onda dos fótons incidente e espalhado estavam na faixa do visível, ii) a diferença entre estes comprimentos de onda estava no infravermelho e iii) a intensidade do feixe espalhado depende fortemente da estrutura da molécula responsável pelo processo.

A teoria do espalhamento Raman mostra que o fenômeno é resultado dos mesmos tipos de mudanças nos níveis de energia vibracionais quantizados das moléculas associadas a espectros de infravermelho. Entretanto, apesar de o espectro Raman estar na mesma faixa do infravermelho médio, ele apresenta uma vantagem importante sobre a espectrometria por infravermelho. A presença de água não causa interferência nos resultados, pois na espectroscopia Raman as vibrações das ligações de uma molécula de água não são ativadas. A radiação espalhada pode ser de três tipos: espalhamento Stokes, espalhamento anti-Stokes e espalhamento Rayleigh. O último é caracterizado pela radiação espalhada apresentar o mesmo comprimento de onda da radiação de excitação. O diagrama da Figura 3.9 ilustra os processos responsáveis pelo espalhamento Raman em comparação com a absorção direta no infravermelho. A primeira seta representa a mudança de nível de energia vibracional de uma molécula que absorve um fóton com energia no infravermelho. $\mathrm{O}$ incremento de energia é exatamente igual a energia do fóton. As duas setas do meio representam as transições responsáveis pelo espalhamento Rayleigh. Como não há perda de energia, o espalhamento Rayleigh é considerado como o resultado de uma colisão elástica entre o fóton e a amostra. As setas à direita representam as transições responsáveis pelas emissões Stokes. 


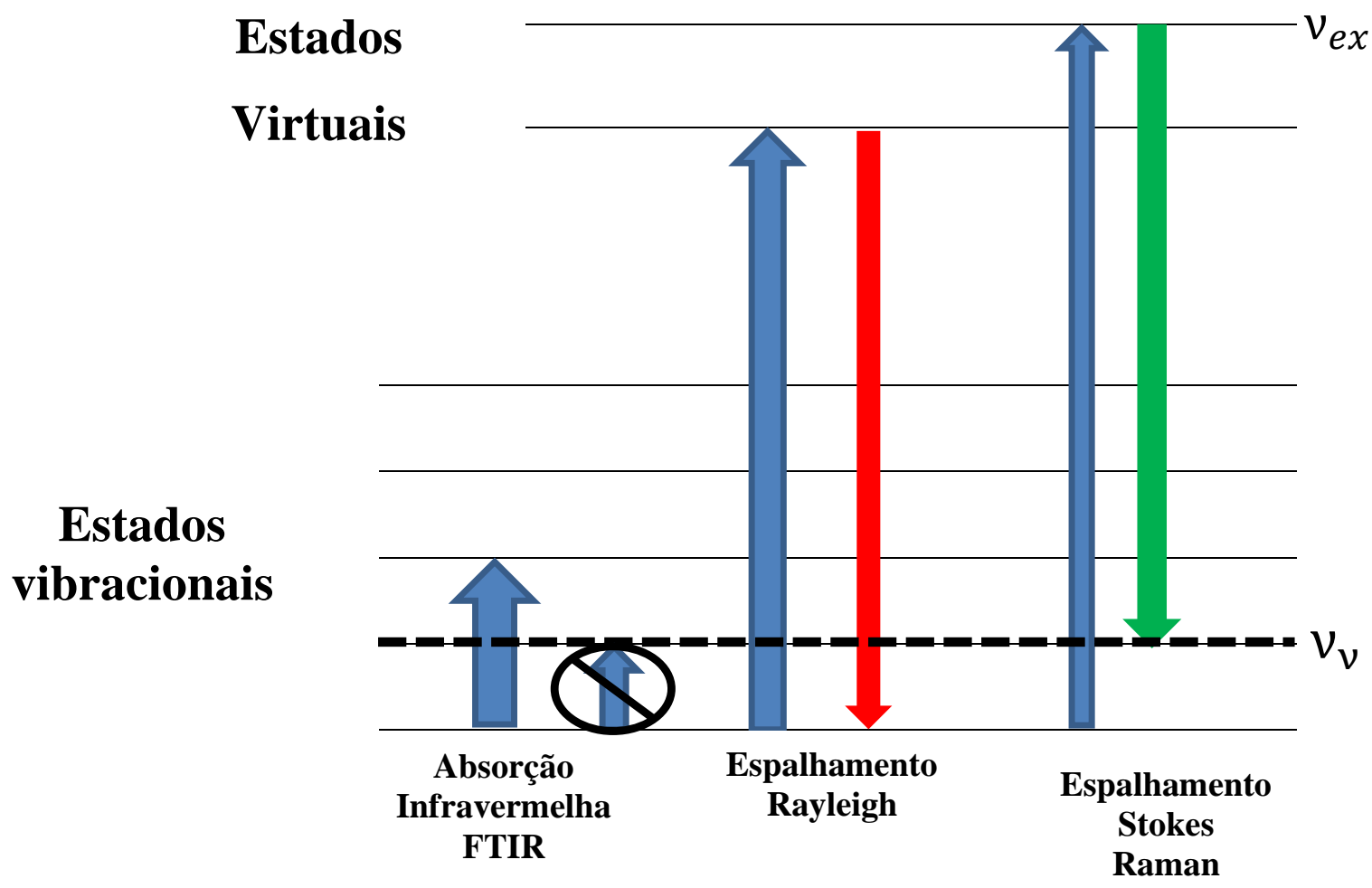

Figura 3.9 - Transições responsáveis pela absorção de infravermelho e pelos espalhamentos Rayleigh e Raman. No processo Rayleigh, o fóton espalhado tem mesma energia do incidente. No processo Raman (Stokes), o fóton é espalhado com energia menor que a do fóton incidente. A linha tracejada corresponde a um estado proibido por transição direta do estado fundamental.

Quando a radiação de excitação incide sobre a amostra, seu campo elétrico induz nas moléculas da amostra um momento de dipolo $\overrightarrow{\mathrm{P}}$, dado por:

$$
\overrightarrow{\mathbf{P}}=\boldsymbol{\alpha} \overrightarrow{\mathbf{E}}
$$

Em que $\alpha$ é a polarizabilidade das ligações e $\vec{E}$ é o campo elétrico da radiação incidente. Sendo $v_{e x}$ a frequência da radiação de excitação, o módulo do campo elétrico pode ser descrito por:

$$
E=E_{0} \cos \left(2 \pi v_{e x} t\right)
$$

Substituindo o valor dado pela equação 3.9 na equação 3.8 , encontra-se que o módulo do momento de dipolo é:

$$
P=\alpha E_{0} \cos \left(2 \pi v_{e x} t\right)
$$

Para que haja atividade Raman, as vibrações moleculares precisam causar variação da polarizabilidade. 
A polarizabilidade das ligações químicas varia em função das distâncias entre os núcleos dos átomos de acordo com:

$$
\alpha=\alpha_{0}+\left(\mathbf{r}-\mathbf{r}_{\text {eq }}\right)(\mathbf{d} \alpha / \mathbf{d r})
$$

em que $\alpha_{0}$ é a polarizabilidade das moléculas na posição de equilíbrio e $\left(\mathrm{r}-\mathrm{r}_{\mathrm{eq}}\right)$ é a separação internuclear.

A mudança na distância internuclear varia periodicamente com uma frequência de oscilação $v_{v}$,

$$
r-r_{e q}=r_{m} \cos \left(2 \pi v_{v} t\right)
$$

$\mathrm{r}_{\mathrm{m}}$, a amplitude de oscilação, é definida como o afastamento máximo da posição de equilíbrio. Substituindo-se a eq. 3.12 na eq. 3.11 e esta na eq. 3.10, e lembrando que $\cos a \cos b=[\cos (a+b)+\cos (a-b)] / 2$, tem-se que o momento de dipolo induzido é:

$$
\begin{gathered}
P=\alpha_{0} E_{0} \cos \left(2 \pi v_{e x} t\right)+\frac{E_{0} r_{m}}{2} \cos \left[2 \pi\left(v_{e x}+v_{v}\right) t\right] \frac{d \alpha}{d r} \\
+ \\
+\frac{E_{0} r_{m}}{2} \cos \left[2 \pi\left(v_{e x}-v_{v}\right) t\right] \frac{d \alpha}{d r}
\end{gathered}
$$

O primeiro termo da equação 3.13 representa o espalhamento Rayleigh, que ocorre na mesma frequência da radiação de excitação $v_{\mathrm{ex}}$. Os dois últimos termos correspondem ao espalhamento Raman; o segundo termo corresponde ao espalhamento anti-Stokes $\left(v_{\mathrm{ex}}+v_{v}\right)$, no qual o meio espalhador cede energia a radiação espalhada; o terceiro termo refere-se ao espalhamento Stokes $\left(v_{\mathrm{ex}}-v_{v}\right)$, onde a radiação incidente cede energia ao meio espalhador. Ambas as radiações são espalhadas com frequência modulada pela frequência de excitação (Rodrigues e Galzerani, 2012). A partir da equação 3.13, observa-se que uma condição importante para que ocorra espalhamento Raman é que a polarizabilidade varie como função da distância entre os átomos; tal variação necessita ser intensa para que se observe o espectro Raman. 
São muitas as informações que podem ser obtidas a respeito da amostra a partir de um espectro Raman. A Fig. 3.10 lista os parâmetros Raman e as respectivas informações que fornecem.

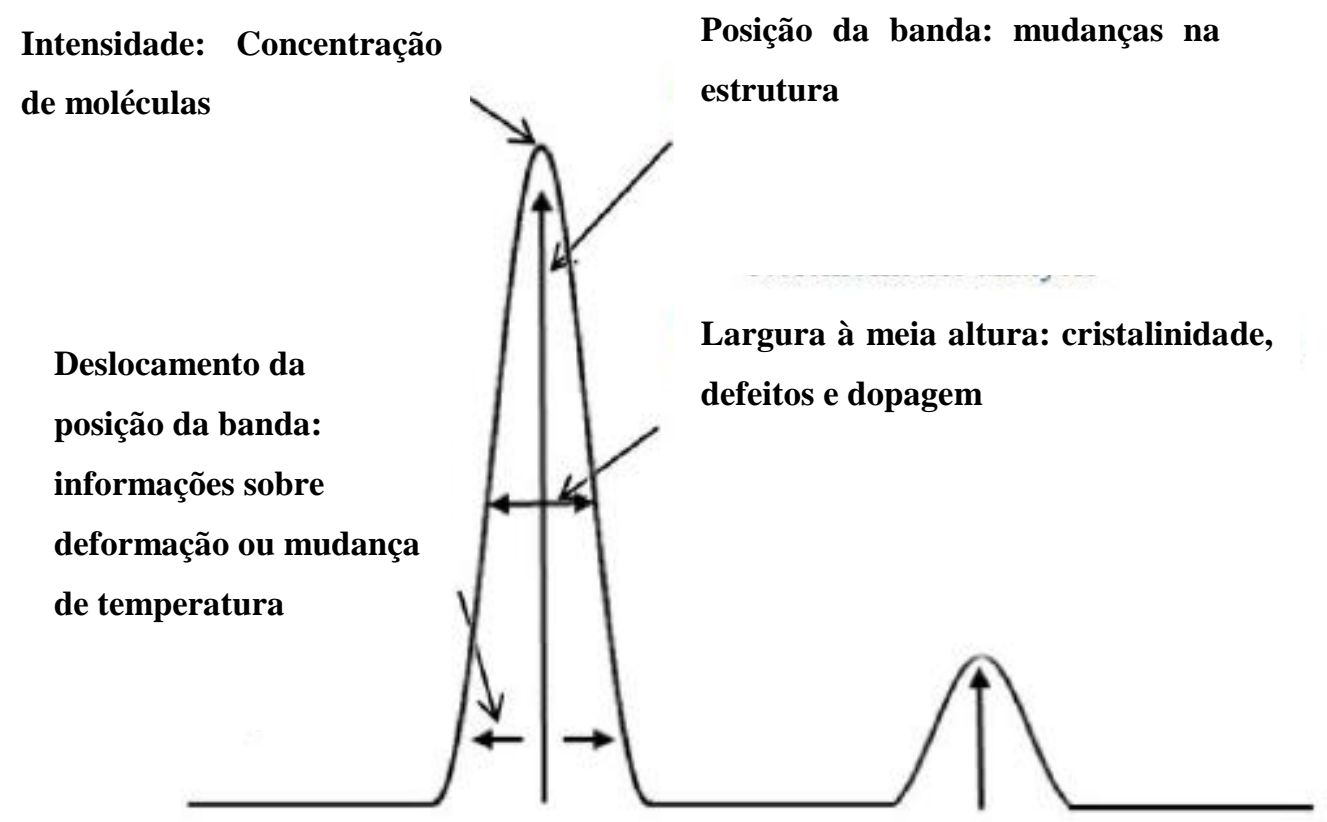

Figura 3.10 - Parâmetros Raman e as informações que fornecem. Adaptado de Zongwei X, et. al. 2018.

A intensidade da radiação espalhada $\left(\mathrm{I}_{\mathrm{e}}\right)$ é proporcional ao número de moléculas espalhadoras na região atravessada pelo feixe luminoso (n) e à da seção de choque de espalhamento Raman $\left(\sigma_{e}\right)$ segundo a equação abaixo (Zongwei X, et. al. 2018):

$$
I_{e}=I_{0} n \sigma_{e} \Omega d f(T)
$$

onde $\Omega$, d são respectivamente o ângulo sólido de espalhamento da radiação e o caminho percorrido pelo laser; $\mathrm{f}(\mathrm{T})$ é um parâmetro, dependente da temperatura $\mathrm{T}$, que determina a eficiência da óptica de detecção do sistema.

Após atravessar sua superfície, o laser penetra na amostra algumas dezenas de nanômetros de profundidade, conforme ilustrado na Fig. 3.11. 


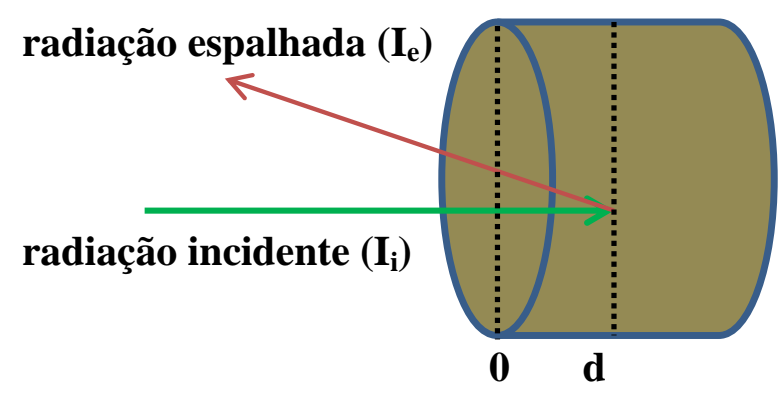

Figura 3.11 - Representação esquemática da incidência de um feixe de laser de um espectrômetro Raman sobre uma amostra.

A intensidade da radiação incidente desde a superfície da amostra até a profundidade d pode ser calculada pela seguinte relação:

$$
\mathbf{I}_{\mathrm{i}}=\frac{\mathbf{I}_{0}}{2 \alpha} \sigma_{\mathrm{e}} e^{-2 \alpha d}
$$

onde $\alpha$ é a coeficiente de absorção e d a distancia entre a superfície da amostra e a profundidade onde a radiação chega.

\subsubsection{1}

\section{Espectroscopia Raman}

O espectro de espalhamento Raman é obtido incidindo-se sobre a amostra um feixe de laser monocromático potente, na faixa do visível ou do infravermelho próximo. Durante a irradiação, o espectro da radiação é espalhado em ângulo bem diferente da direção de incidência. Para permitir uma comparação com a transição direta (proibida ou não) do estado fundamental ao vibracional, o espectro Raman é apresentado como um gráfico da intensidade da radiação espalhada em função da diferença entre os números de onda incidente e espalhado, $\Delta \mathrm{k}$.

A espectroscopia Raman possui as relevantes características de: i) permitir a análise de níveis vibracionais cuja excitação é proibida em $1^{\mathrm{a}}$ ordem e ii) possuir grande eficiência na identificação da presença de carbono em um material. Um espectro Raman do meteorito Putinga é apresentado na figura 3.12. 


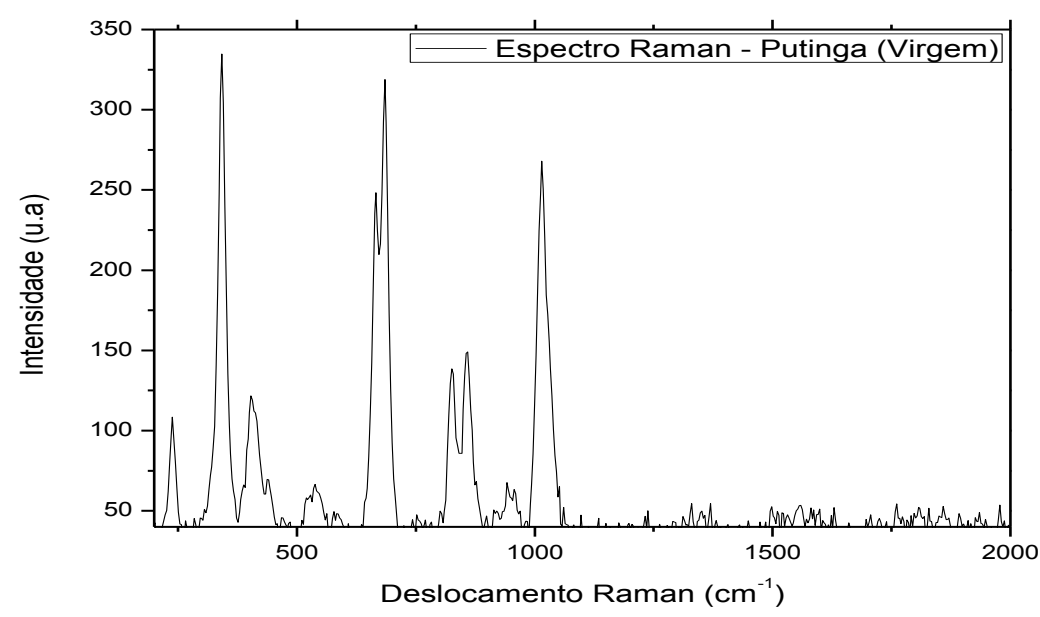

Figura 3.12 - Exemplo de espectro Raman do meteorito Putinga.

\subsubsection{2}

\section{Dissociação química e medidas de seção de choque}

No processo de espalhamento Raman, as moléculas que compõem a amostra interagem com a radiação do laser e uma parte é espalhada. A equação 3.14 relaciona a intensidade (I) da banda Raman, atribuído a determinado modo de vibração, com a quantidade de moléculas (n) que vibram nesse modo e que se encontram no caminho ótico do feixe do laser. É conveniente introduzir neste formalismo a densidade de coluna $(\mathrm{N})$, que é o número de moléculas presentes em uma coluna da amostra cuja área transversal tem valor unitário. A partir dos espectros Raman, pode-se acompanhar a evolução da densidade de coluna como função da fluência utilizada.

Conforme o processo de irradiação por feixe de íons ocorre, o impacto de cada íon provoca variação do número de ligações químicas presentes em seu caminho. A taxa de variação da densidade de coluna, dN, em função da variação da fluência, $\mathrm{dF}$, deve ser proporcional ao número total de moléculas na coluna. A proporcionalidade entre estes valores é dada pela seção de choque de destruição (ou de dissociação), $\sigma_{\text {d. }}$ Assim, temos a seguinte equação para modelar o problema de destruição de espécies químicas (Prawner, S. et. al, 1995):

$$
\frac{\mathbf{d N}}{\mathbf{d F}}=-\boldsymbol{\sigma}_{\mathbf{d}} \mathbf{N}(\mathbf{F})
$$


A densidade de coluna depende da fluência e o sinal negativo significa que ela diminui com a irradiação.

A equação 3.16 pode ser rearranjada como:

$$
\frac{\mathbf{d N}}{\mathbf{N}}=-\boldsymbol{\sigma}_{\mathbf{d}} \mathbf{d F}
$$

Cuja solução é

$$
\mathbf{N}(\mathbf{F})=\mathbf{N}_{\mathbf{0}} \mathbf{e}^{-\boldsymbol{\sigma} \mathbf{F}}
$$

Onde $\mathrm{N}_{0}$ corresponde ao valor da densidade de coluna antes da irradiação. Ou seja, $\mathrm{N}(\mathrm{F}=0)=\mathrm{N}_{0}$.

A equação (3.17) será empregada no capítulo de resultados para obtenção das seções de choque de destruição de ligações Si-O cujos picos são observados nos espectros Raman.

\subsubsection{3}

\section{Espectrômetro Raman}

Em um espectrômetro Raman, uma fonte de laser emite um feixe geralmente na faixa do visível; este passa por um sistema de lentes e filtros para focalizá-lo e colimá-lo. Um filtro, eficiente na mesma faixa de comprimentos de onda, é utilizado para controlar a potência do laser. Uma lente objetiva, próxima à amostra, focaliza o feixe do laser nesta. A fração da radiação incidente espalhada a um ângulo de $180^{\circ}$ é coletada através de um microscópio e atravessa em seguida um divisor de feixe onde parte dela é refletida para o sistema de detecção.

O espectrômetro Raman utilizado do Laboratório do Acelerador Van de Graaff foi fabricado pela Bruker (figura 3.13). Ele é do tipo confocal (permite maior resolução espacial das medidas) acoplado a um microscópio de força atômica, modelo NT-DTM, NTEGRA SPECTRA, equipado com um detector CCD e um microscópio óptico. O sistema de detecção, modelo MS5004i, apresenta distância focal de $540 \mathrm{~nm}$, uma rede de difração e um CCD, que converte o sinal luminoso em sinal digital e o envia ao computador. $\mathrm{O}$ 
comprimento de onda do laser é de $473 \mathrm{~nm}$ (corresponde a luz azul) e a potência é de $0,12 \mathrm{~mW}$. Para cada irradiação iônica foi medido de 10 a 15 pontos em torno do centro da amostra. O tempo de medida de cada ponto foi de 100 segundos. Os espectros foram obtidos com resolução de $2 \mathrm{~cm}^{-1}$.

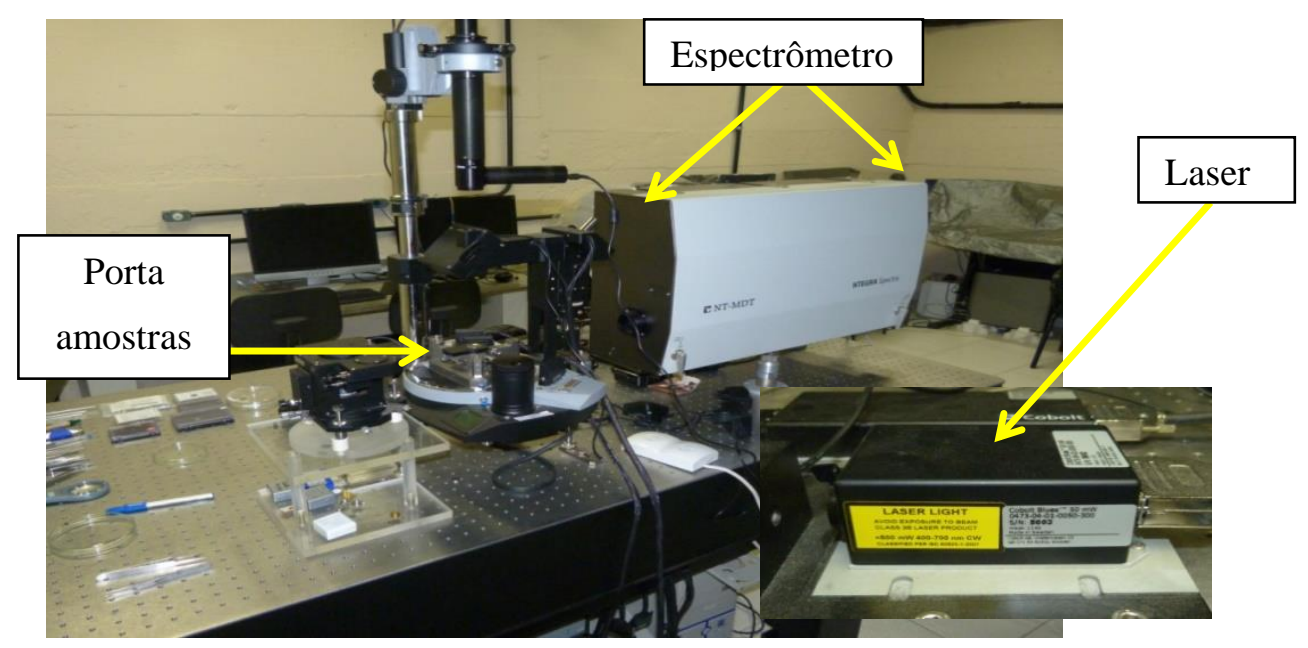

Figura 3.13 - Foto do espectrômetro Raman utilizado nesse trabalho. Ao lado encontra-se a foto do laser. 


\section{Resultados}

\section{1}

\section{Espectroscopia Raman}

\subsection{1}

\section{Análise comparativa entre espectros Raman}

O objetivo da presente seção é apresentar a análise comparativa entre os espectros Raman dos três meteoritos estudados nesta tese, Parambu (LL), Putinga (L) e Gail (H). Uma comparação foi inicialmente feita para os espectros Raman das amostras ainda não irradiadas, a fim de evidenciar as diferenças observadas entre eles devido às características físicas, químicas e mineralógicas de cada um.

Conforme descrito no capítulo 3, foram obtidos de 10 a 15 espectros Raman para cada ponto de irradiação, e os foram utilizados os valores médios dos parâmetros Raman de interesse: a posição do centro do pico, Xc, e a largura a meia altura do pico, w, (FWHM (do inglês Full Width at Half Maximum)). Para o meteorito Parambu foram feitas 10 medidas em diferentes pontos do centro da amostra. Todos os espectros obtidos são mostrados na Figura 4.1.

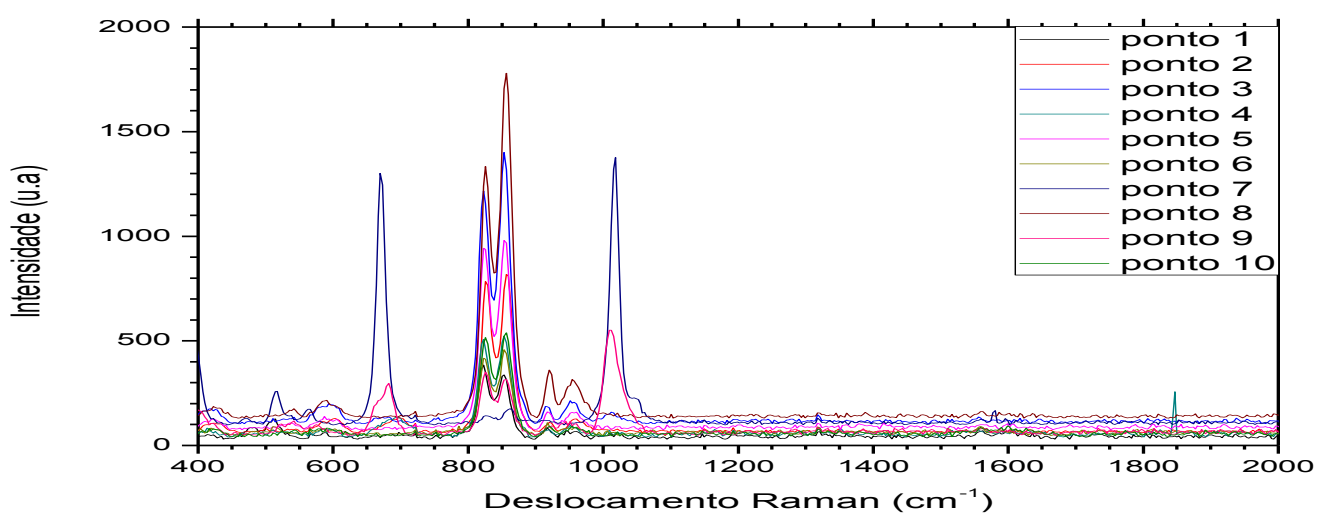

Figura 4.1 - Espectros Raman obtidos para 10 pontos diferentes em torno do centro da amostra para o meteorito Parambu ainda não irradiado. 
Na Figura 4.1 pode-se observar vários picos de interesse para o meteorito Parambu. Como são muitos os picos presentes, foram selecionados os quatro picos que mais se destacam em relação aos demais picos. A Figura 4.2 mostra apenas os espectros do ponto 2 e do ponto 7 para que os picos analisados fiquem em destaque.
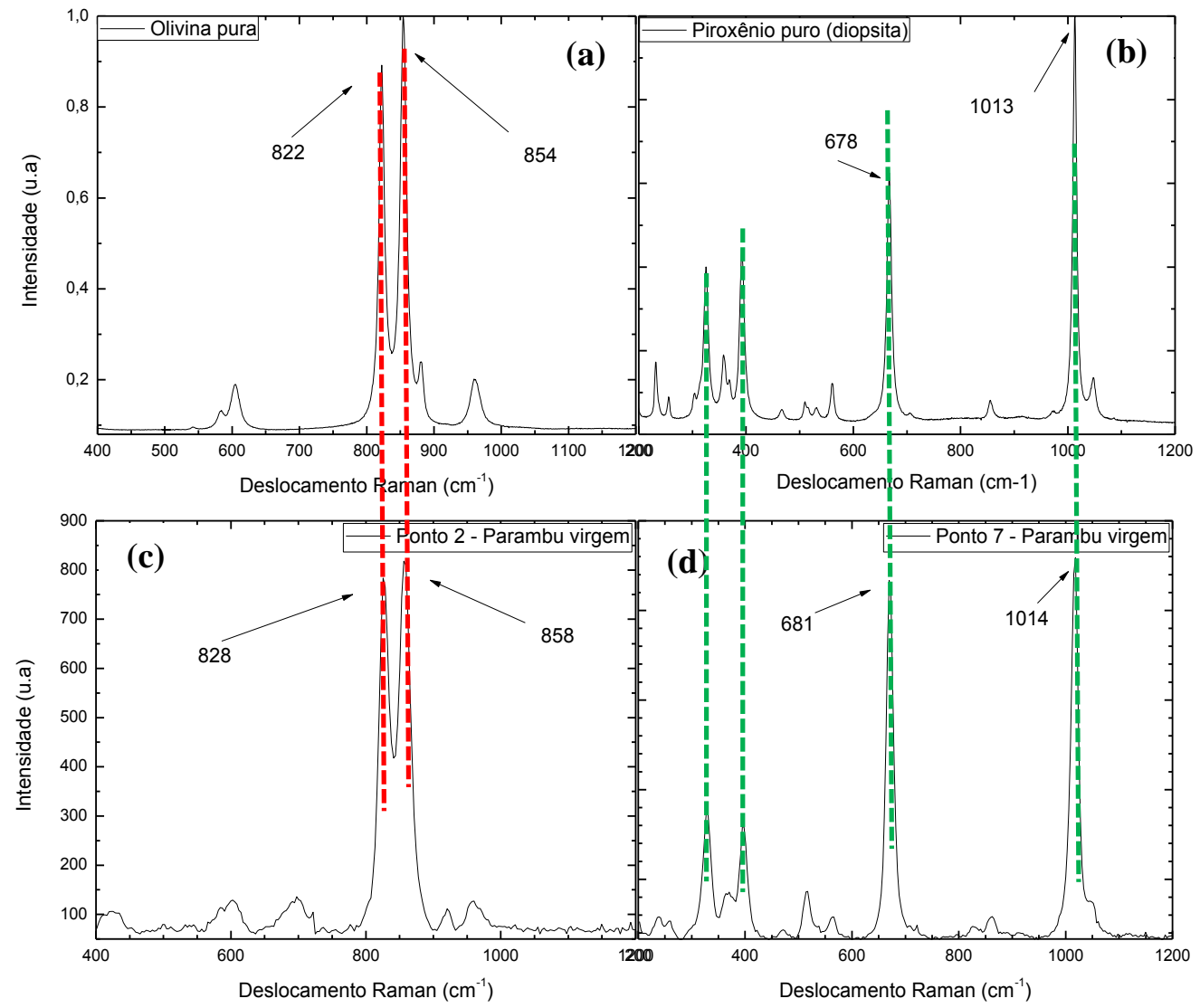

Figura 4.2 - (a) espectro Raman de uma amostra pura de Olivina; (b) espectro Raman de uma amostra pura de diopsita, um tipo de pirixênio; espectros Raman de dois pontos (c) (ponto 2) e (d) (ponto 7) do meteorito Parambu para evidenciar a presença de quatro picos de interesse.

Os picos que foram analisados são os que apresentam valores de Xc em torno de $828 \mathrm{~cm}^{-1}$ e $858 \mathrm{~cm}^{-1}$, (Fig. 4.2 (c)), que correspondem à presença de olivina na estrutura do meteorito, e $681 \mathrm{~cm}^{-1}$ e $1014 \mathrm{~cm}^{-1}$ (Fig. 4.2 (d)) que estão relacionados à presença de piroxênio. Como mostra o apêndice $\mathrm{B}$, esse dois minerais são majoritários nesse meteorito.

Uma metodologia semelhante foi empregada no estudo do meteorito Putinga. Foram obtidas 14 medidas em diferentes pontos do centro da amostra 
ainda não irradiada. Os espectros Raman de cada ponto são apresentados na Figura 4.3.

Os quatro picos destacados no caso do meteorito Parambu (Fig. 4.2) também estão presentes nos espectros Raman do meteorito Putinga. De fato, existe uma grande similaridade entre esses dois meteoritos em termos de picos presentes no espectro Raman. Isso indica que esses dois meteoritos apresentam estrutura mineralógica muito parecida, ambos contendo, majoritariamente, olivina e piroxênio.

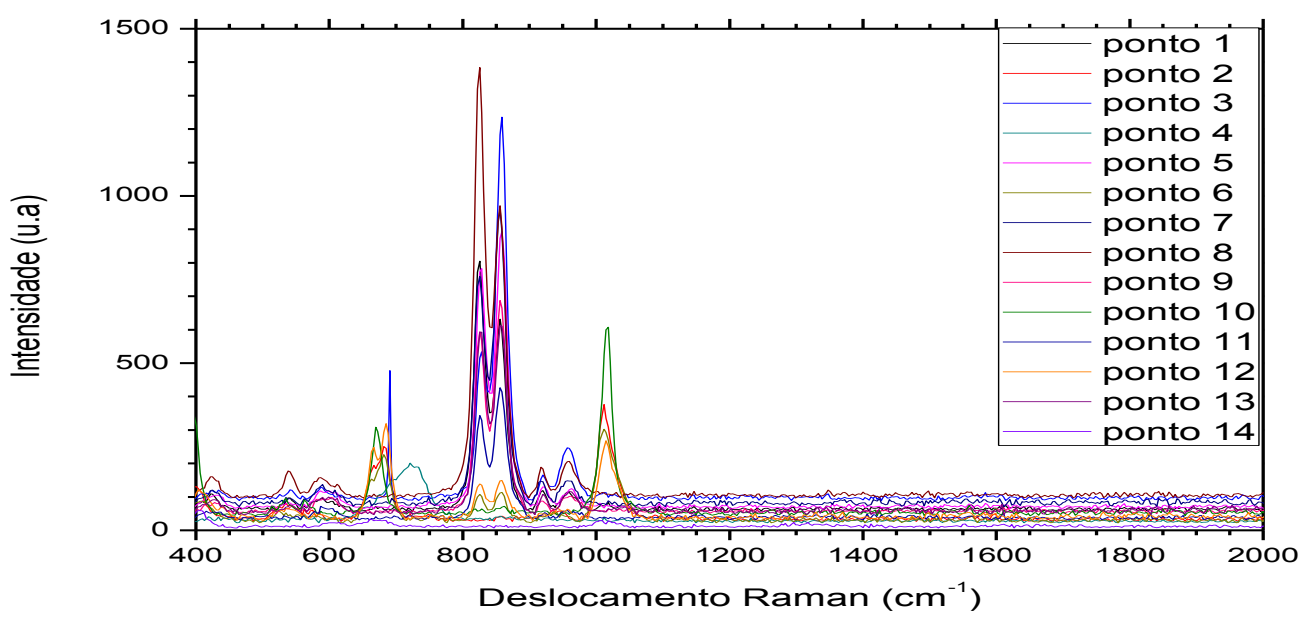

Figura 4.3 - Espectros Raman obtidos para 14 pontos diferentes em torno do centro da amostra para o meteorito Putinga, ainda não irradiado.

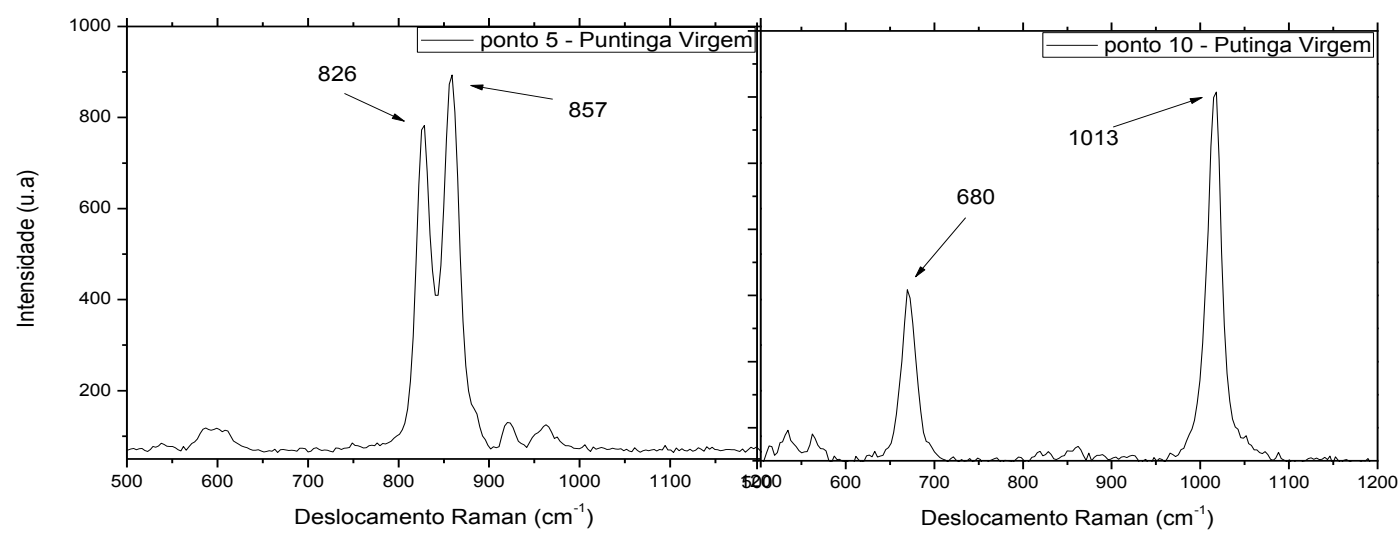

Figura 4.4 - Espectros Raman de dois pontos (ponto 5 no lado esquerdo e ponto 10 no lado direito) do meteorito Putinga para evidenciar a presença de quatro picos de interesse.

O meteorito Gail (H) apresenta espectros Raman diferentes dos obtidos para Parambu e Putinga. A começar, os picos que indicariam a presença de olivina não aparecem no espectro virgem conforme indica a Figura 4.5. Embora as referências 
sobre esse meteorito mostrem olivina em sua composição, os picos Raman atribuídos a esse mineral não foram observados em nossos espectros.

Um dos pontos medidos (ponto 6) mostrou picos com valores $821 \mathrm{~cm}^{-1} \mathrm{e}$ $851 \mathrm{~cm}^{-1}$. Esses dois picos indicam a presença do mineral ringwoodita $\left((\mathrm{Mg}, \mathrm{Fe})_{2} \mathrm{SiO}_{4}\right.$-spinel) presente em meteoritos que experimentaram choques extremos. A ringwoodita é formada tendo como precursor o mineral olivina que sofre metamorfismo devido ao choque com outros corpos (Walton e McCarthy, 2016). Porém, de todas as medidas Raman realizadas sobre esse meteorito, apenas um único ponto mostrou esses picos. Isto mostra que a quantidade relativa deste mineral contida no meteorito Gail deve ser muito pequena.

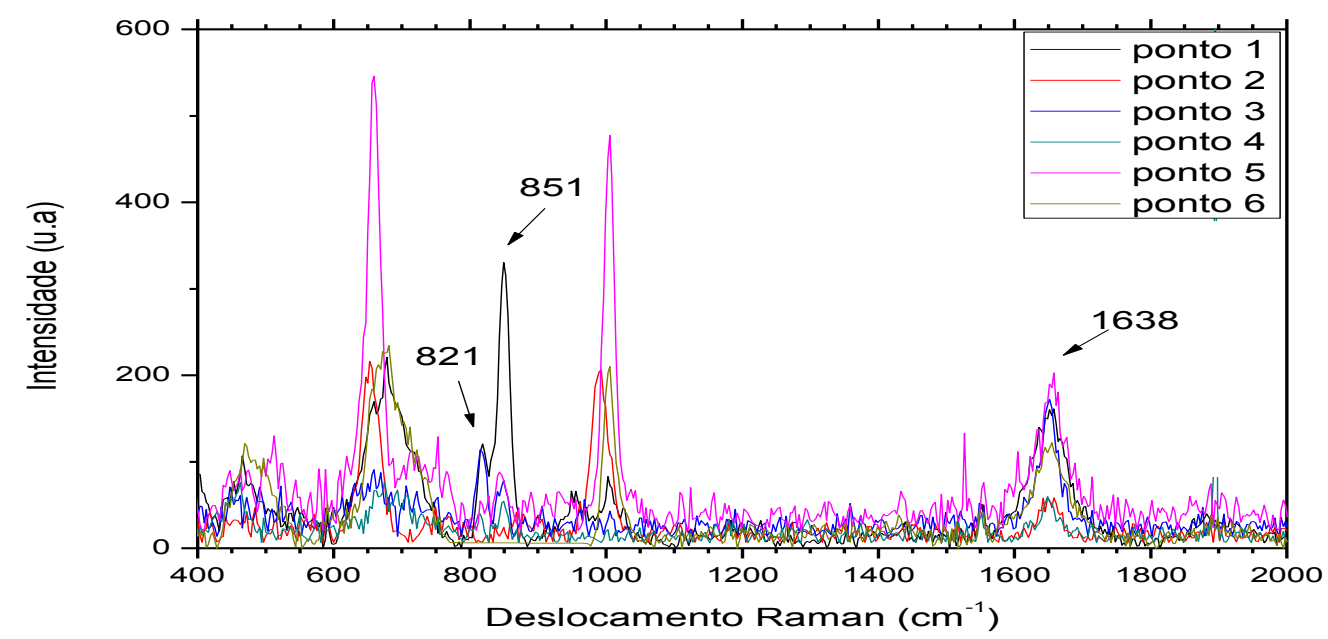

Figura 4.5 - Espectros Raman obtidos para 6 pontos diferentes em torno do centro da amostra para o meteorito Gail, ainda não irradiado.

A Figura 4.6 destaca os picos de interesse no espectro Raman do meteorito Gail. Estes dois picos também são visíveis nos espectros Raman dos meteoritos apresentados anteriormente. Como citado, eles indicam a presença de piroxênio na estrutura mineralógica da amostra.

Além desses dois picos, os espectros Raman também apresentam outro pico em torno $1638 \mathrm{~cm}^{-1}$, que pode ser atribuído à ligação $\mathrm{C}=\mathrm{O}$ do grupo hidroxila. Porém, isso provavelmente se deve a algum tipo de contaminação, não sendo esta banda encontrada comumente nesta classe de meteoritos. 


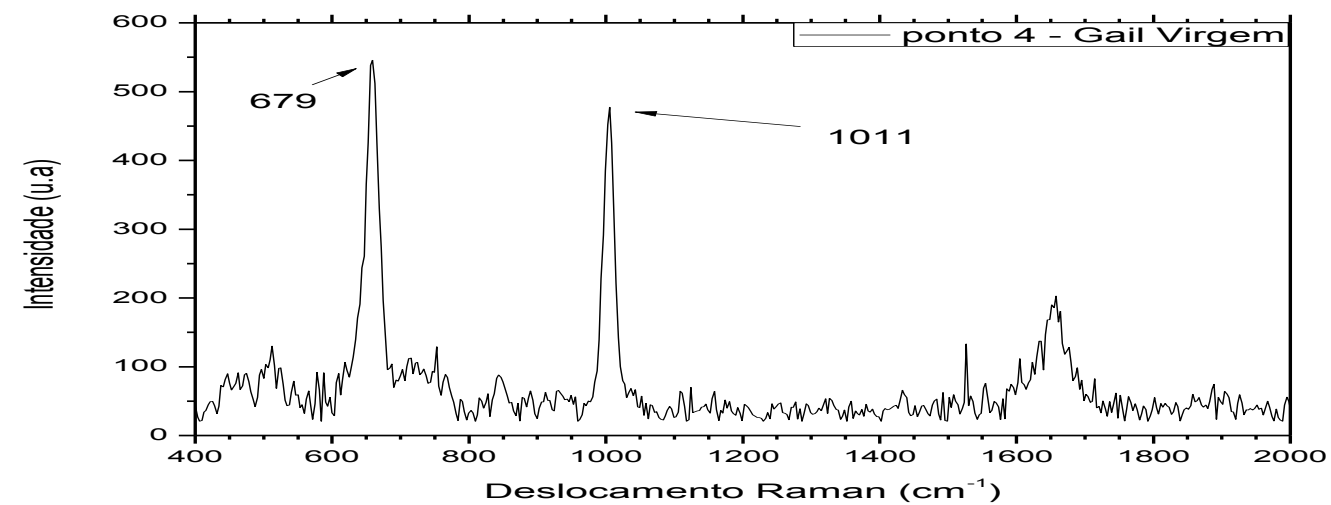

Figura 4.6 - Espectro Raman do ponto 6 feito no meteorito Gail para evidenciar a presença de dois picos de interesse.

\subsection{2}

\section{Variações induzidas pela irradiação}

Nesta seção são apresentados os resultados obtidos para os três meteoritos, antes a após o processo de irradiação com prótons. As mudanças no espectro Raman, especialmente nos picos destacados na seção anterior, são mostradas bem como as diferenças observadas entre os efeitos em cada meteorito. $\mathrm{O}$ meteorito Gail foi, também, irradiado por feixe de nitrogênio.

Conforme mencionado, a presente análise se concentra nas quatro bandas indicadas nas Fig. 4.2, 4.4 e 4.6. As mudanças induzidas nos parâmetros Raman dessas quatro bandas podem fornecer informações relevantes a respeito dos efeitos de SpWe sobre esses meteoritos. Para cada pico foi feito um ajuste lorenziano para extrair os parâmetros Raman de interesse, conforme o exemplo abaixo:

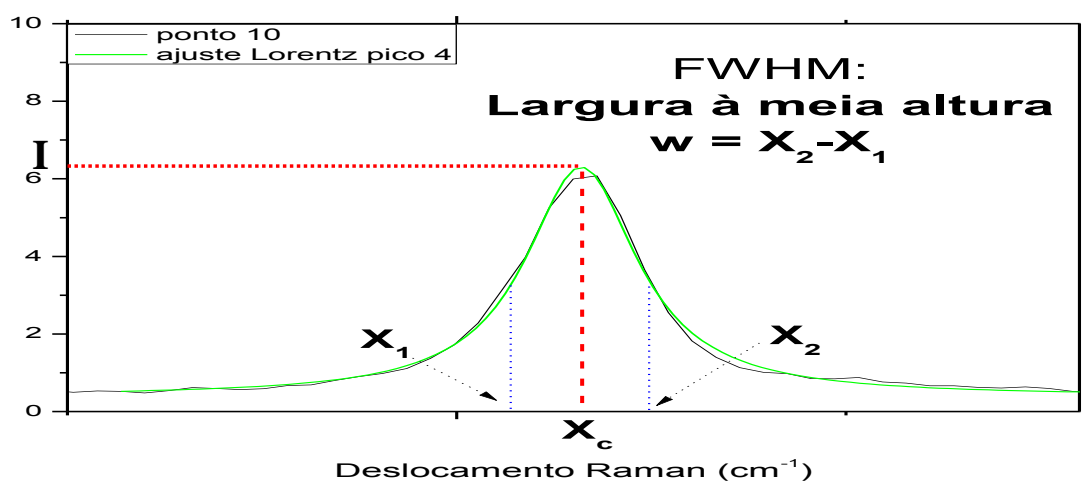

Figura 4.7 - Exemplo de ajuste Lorentz feito nos picos para obtenção dos parâmetros Raman. 
Para facilitar a identificação os picos atribuídos como sendo devido da olivina serão chamados de pico 1 (pico em torno de $827 \mathrm{~cm}^{-1}$ ) e pico 2 (pico em torno de $857 \mathrm{~cm}^{-1}$ ) e os picos atribuídos ao piroxênio serão chamados de pico 3 $\left(680 \mathrm{~cm}^{-1}\right)$ e pico $4\left(1013 \mathrm{~cm}^{-1}\right)$.

A Figura 4.8 mostra a variação dos parâmetros $\mathrm{Xc}$ e w, do meteorito Parambu, como função da fluência. Por esses gráficos pode-se observar que os parâmetros Xc, tanto no pico 1 (a) como no pico 2 (b) sofreram uma leve diminuição conforme a irradiação foi sendo feita. No caso dos picos 3 (e) e pico 4 (f) um efeito similar é observado. A posição, Xc, desses picos, também, sofre uma leve redução como consequência da irradiação. Já o parâmetro w quase não se modifica. As Figuras 4.7 (c), (d), (g) e (h) mostram um aumento pouco pronunciado nesse parâmetro para os quatro picos analisados.

Uma análise semelhante à empregada para os espectros Raman do meteorito Parambu foi usada para os meteoritos Putinga e Gail, conforme mostrado nas Figuras 4.9 e 4.10, respectivamente. No caso do meteorito Putinga (Fig. 4.9) o que se observa em relação ao parâmetro Xc é que seu valor sofre diminuição conforme a superfície deste meteorito recebe doses maiores de irradiação. Isso também é observado no caso do Parambu, conforme visto anteriormente, porém esse deslocamento no número de onda ocorre a uma fluência levemente maior. Com relação à largura a meia altura, w, o que se observa é que como efeito da irradiação esse parâmetro sofre um leve aumento de valor. Não é possível saber como esses mesmos picos (picos da olivina) se comportam no caso do Gail pelo fato de os espectros Raman desse meteorito não apresentarem os grupos funcionais.

Os números de onda dos picos 3 e 4 também apresentam redução para esses dois meteoritos, Putinga (Fig. 4.9 (e) e (f)) e Gail (Fig. 4.10 (a) e (b)), conforme uma fluência maior é usada. Já as larguras a meia altura dos picos 3 e 4, no caso do Putinga, ocorre um leve decrescimento, resultado contrário ao visto no caso do Parambu. Infelizmente, devido ao fato dos espectros Raman irradiados do meteorito Gail se mostrarem muito ruidosos, somente a largura a meia altura do pico 3 pode ser obtida. Esse parâmetro, no caso do Gail, concorda com o observado para o Putinga. Também é possível observar um crescimento do seu valor como efeito da irradiação por feixe de prótons. 

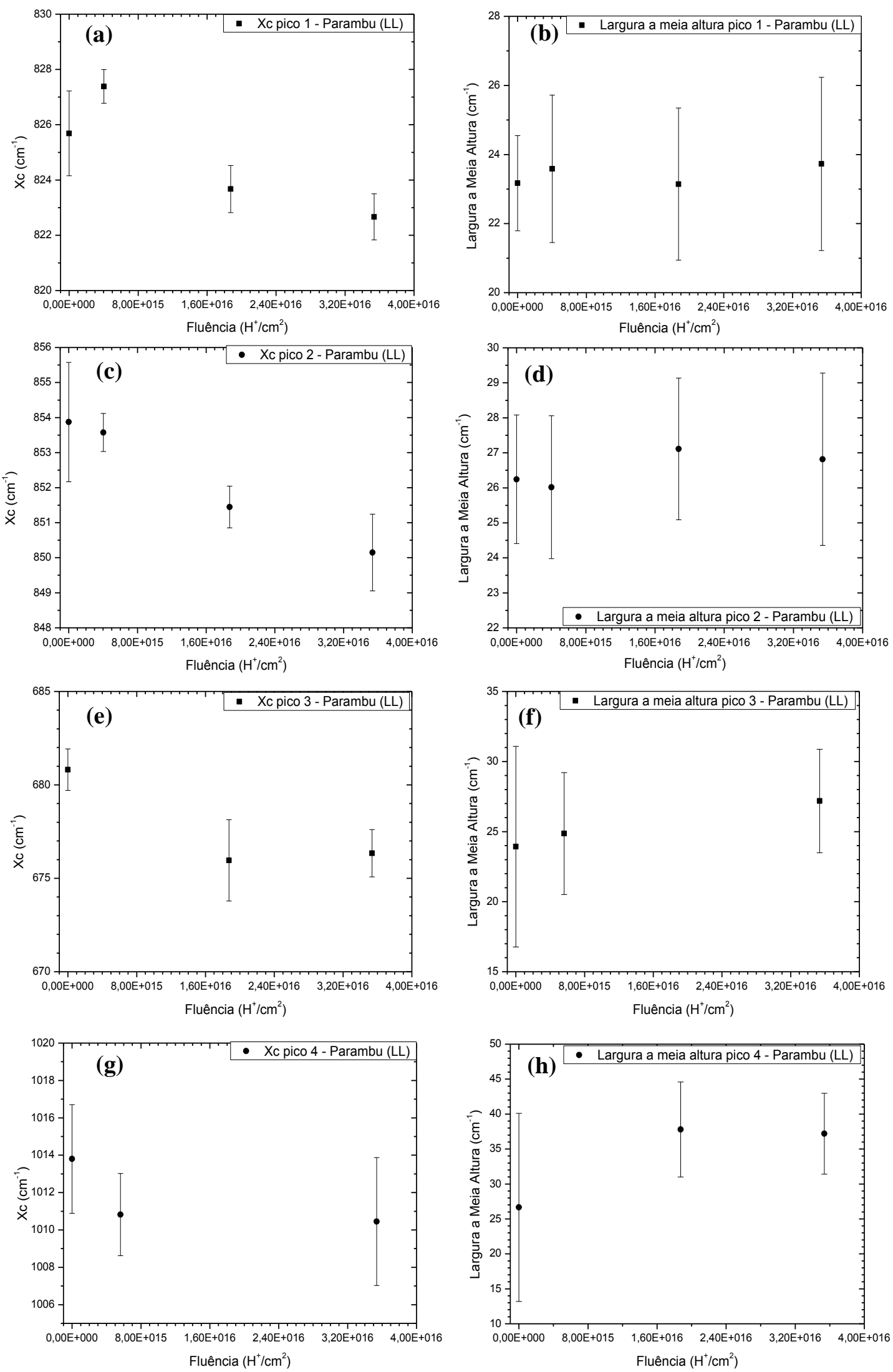

Figura 4.8 - Parâmetros Raman como função da fluência para o meteorito Parambu; (a) Xc do pico 1; (b) w do pico 1; (c) Xc do pico 2; (d) w pico 2; (e) Xc pico 3; (f) w pico 3; (g) Xc pico 4; (h) w pico 4. 

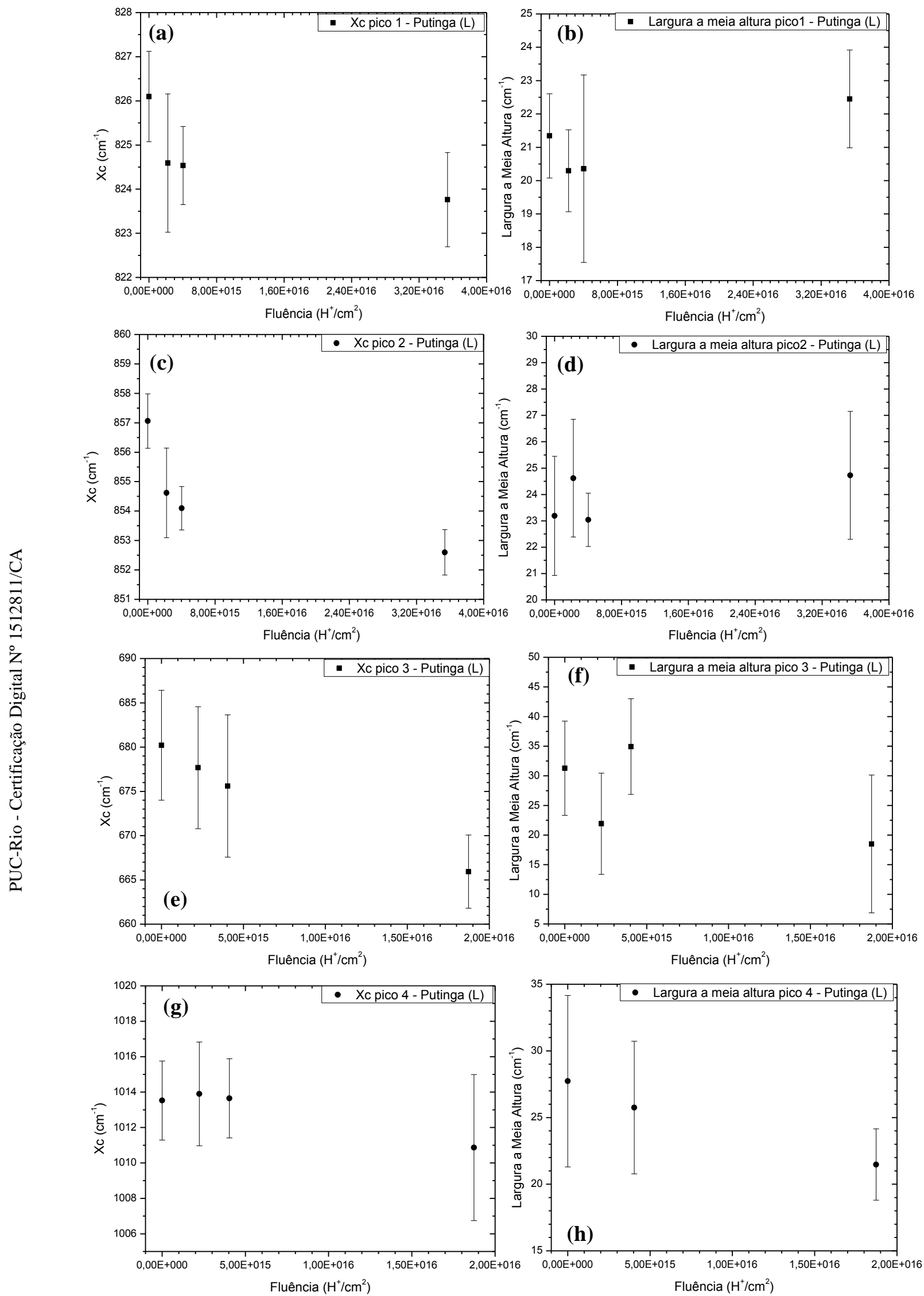

Figura 4.9 - Parâmetros Raman como função da fluência para o meteorito Putinga; (a) Xc do pico 1; (b) w do pico 1; (c) Xc do pico 2; (d) w pico 2; (e) Xc pico 3; (f) w pico 4; (g) Xc pico 4; (h) w pico 4. 

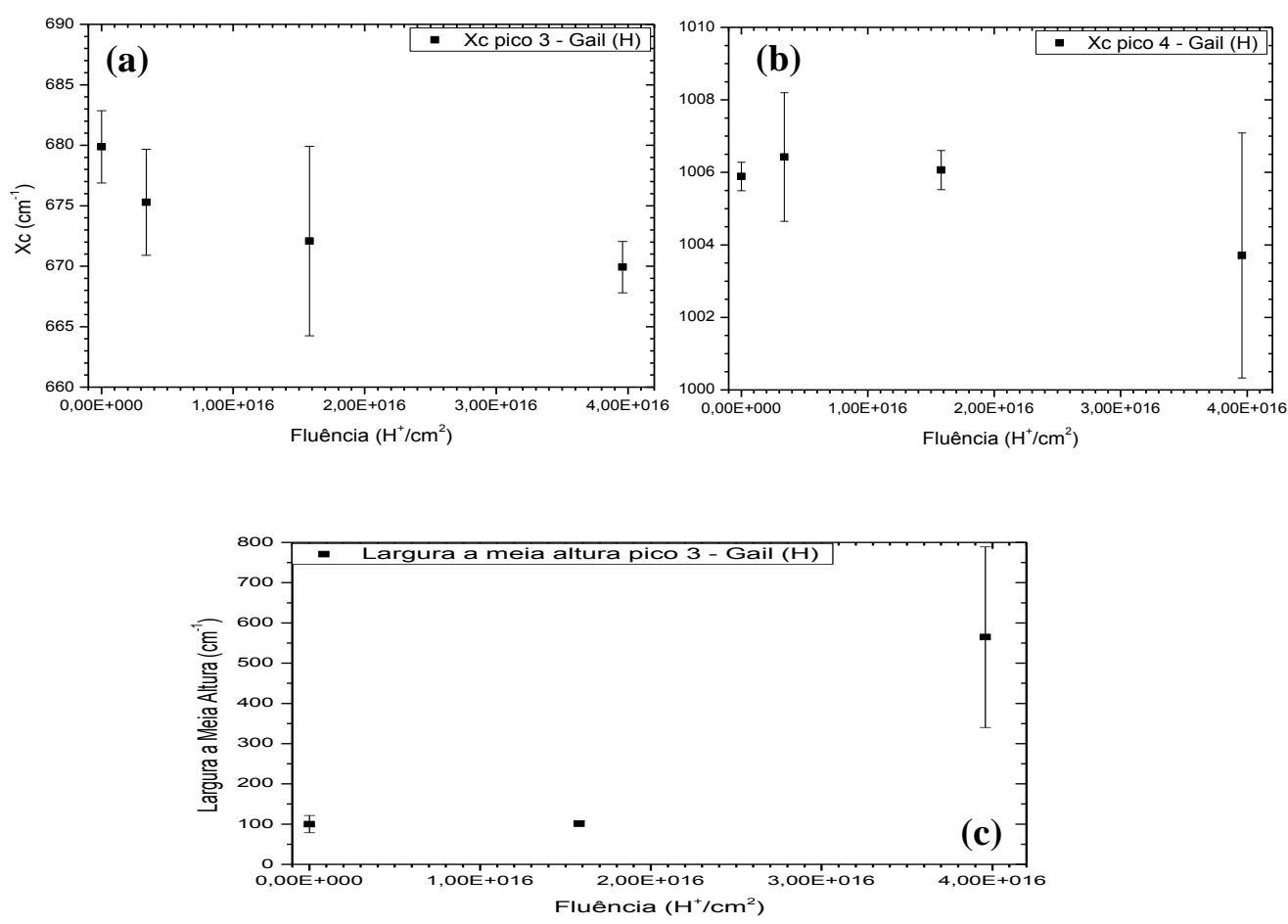

Figura 4.10 - Parâmetros Raman como função da fluência para o meteorito Gail; (a) Xc do pico 3; (b) Xc do pico 4 ; (c) w do pico 3.

\subsection{3}

\section{Variação da intensidade dos picos Raman e densidade de coluna}

Os picos Raman nomeados de 1, 2, 3 e 4 (apresentados nas seções anteriores) representam diferentes modos vibracionais da ligação Si-O, conforme já citado. No capítulo 3 (seção 3.5.2) é mostrado que a intensidade (I) de um pico Raman é proporcional ao número (n) de moléculas espalhadoras (equação 3.14). Desta forma, quanto menor a densidade de moléculas espalhando a radiação que incide sobre a superfície da amostra, menor será a intensidade do pico que caracteriza a ligação.

A partir do ajuste lorenziano feito nos picos Raman, conforme Fig. 4.7, foram obtidos os valores da intensidade de cada pico estudado. Assim como no caso dos outros parâmetros Raman $\left(\mathrm{X}_{\mathrm{c}} \mathrm{e} \mathrm{w}\right)$, a intensidade de cada pico foi obtidas a partir de uma análise estatística. $\mathrm{O}$ valor utilizado para a intensidade do pico 1 , por exemplo, é a média simples das intensidade de todos os picos obtidos em cada medida. 
A Fig. 4.11 (a) mostra a variação do logaritmo da intensidade (normalizada para a intensidade do pico da amostra ainda virgem) do pico 1, que é atribuído ao modo de estiramento simétrico (ES) da ligação Si-O, como função da fluência. $\mathrm{Na}$ Fig. 4.11 (b) é apresentado o mesmo para o modo de estiramento assimétrico (EAS) da mesma ligação. O que se observa é que conforme a irradiação ocorre e uma fluência maior é utilizada a intensidade do pico vai sofrendo redução. Isto é consequência da redução do número de moléculas espalhadoras.
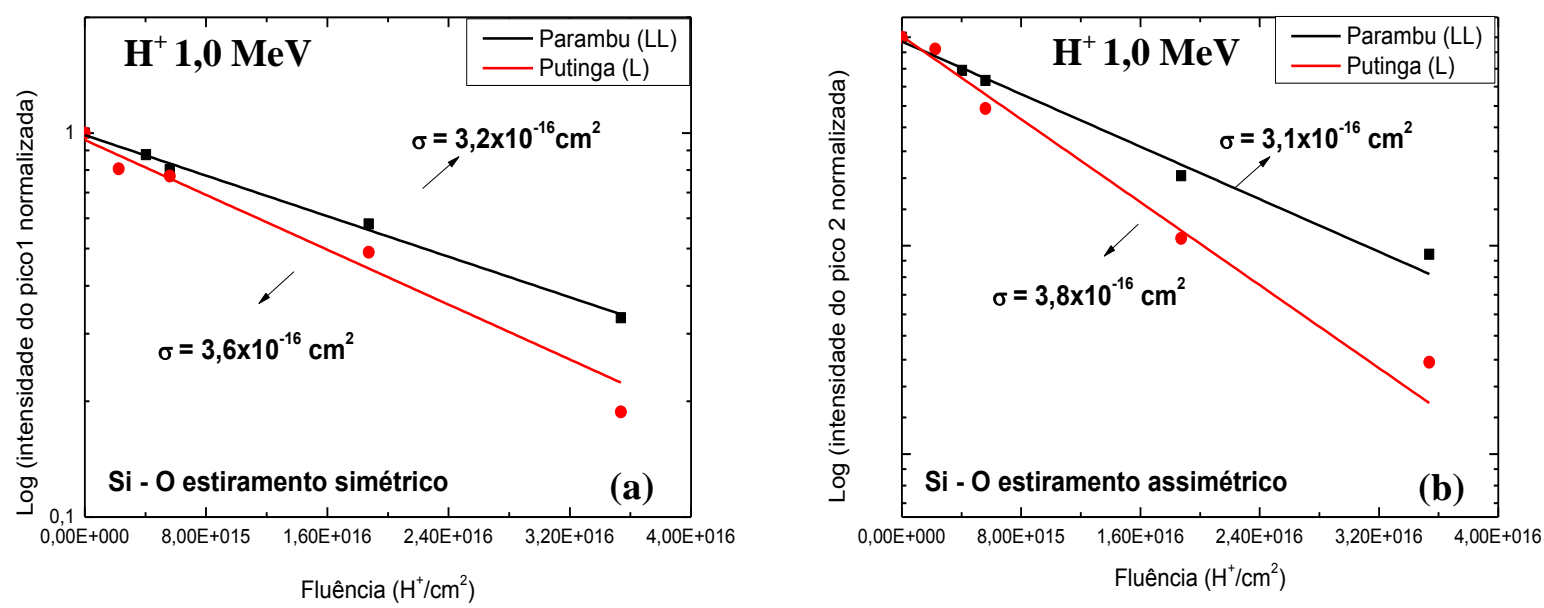

Figura 4.11 - (a) intensidade do pico 1 normalizada como função da fluência; (b) intensidade do pico 2 normalizada como função da fluência. Ambos os gráficos são para irradiação com $\mathrm{H}^{+}$.

Em cada gráfico obtido foi possível fazer um ajuste exponencial dos pontos experimentais e a equação obtida é

$$
\log \left(\frac{\mathbf{I}(\mathbf{F})}{\mathbf{I}_{\mathbf{0}}}\right)=-\boldsymbol{\sigma}_{\mathbf{d}} \mathbf{F}
$$

onde $\mathrm{I}(\mathrm{F})$ é a intensidade do pico para uma dada fluência, $\mathrm{I}_{0}$ é a intensidade do pico para a medida ainda virgem e $\sigma_{d}$ é a seção de choque que dissociação da ligação. A equação, obtida do ajuste, é exatamente a equação (3.17) apresentada no capítulo 3 que relaciona a densidade de coluna com o valor da fluência e permite determinar o valor das seções de choque para a ligação Si-O.

A partir do ajuste feito foram obtidos os valores de seção de choque para cada amostra. Os valores são apresentados na tabela 4.1. 
Tabela 4.1 - Seções de choque obtidas dos ajustes da intensidade dos picos 1 e 2 em função da fluência. Irradiação por feixe de $\mathrm{H}^{+}$com energia de $1,0 \mathrm{MeV}$.

\begin{tabular}{|c|c|c|}
\hline \multirow{2}{*}{ Meteorito } & \multicolumn{2}{|c|}{ Seção de choque $\left(\mathbf{1 0}^{-16} \mathrm{~cm}^{2}\right)$} \\
\cline { 2 - 3 } & Pico 1 & Pico 2 \\
\hline Parambu (LL) & $\mathbf{3 , 2} \pm \mathbf{0 , 5}$ & $\mathbf{3 , 1} \pm \mathbf{0 , 3}$ \\
\hline Putinga (L) & $\mathbf{3 , 6} \pm \mathbf{0 , 3}$ & $\mathbf{3 , 8} \pm \mathbf{0 , 4}$ \\
\hline
\end{tabular}
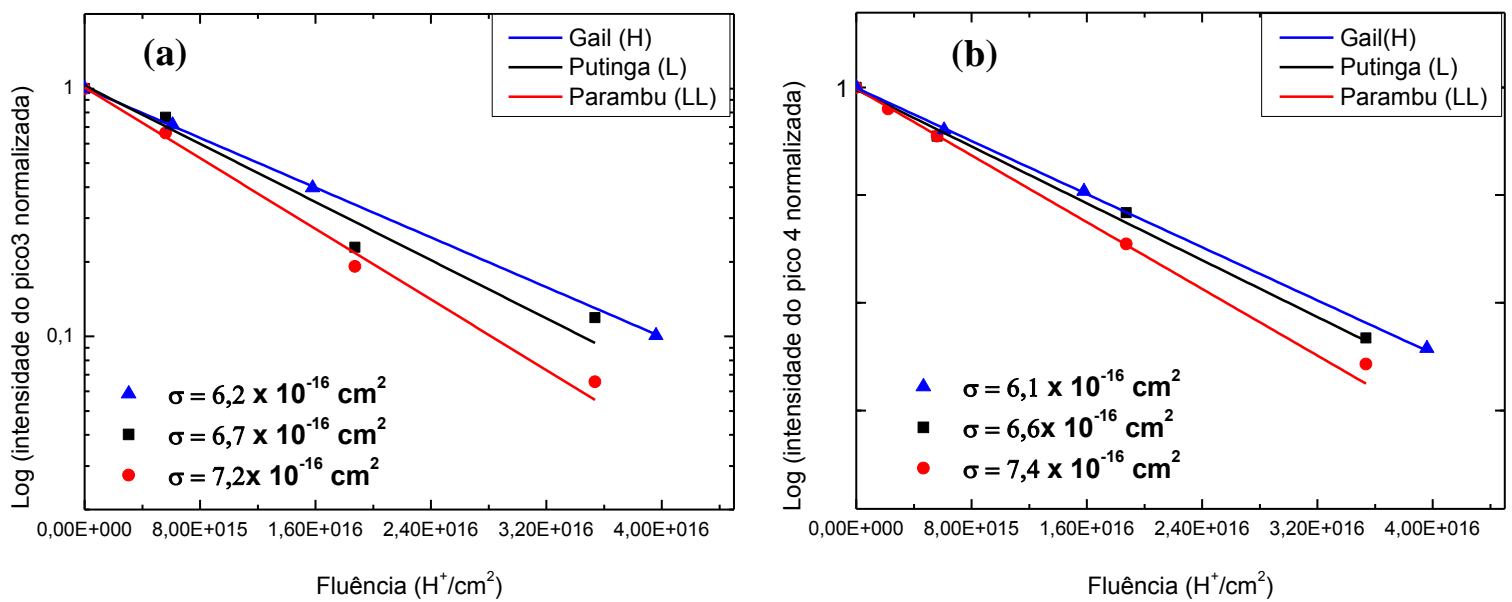

Figura 4.12 - (a) intensidade do pico 3 normalizada como função da fluência; (b) intensidade do pico 4 normalizada como função da fluência. Ambos os gráficos são para irradiação com $\mathrm{H}^{+}$.

Análise similar foi empregada para os picos 3 e 4, conforme mostra a Fig. 4.12. Como o meteorito Gail apresenta estes picos em seu espectro, ele foi incluso na análise.

Como antes, foi possível fazer o ajuste exponencial para os gráficos em logaritmo, e mais uma vez foi encontrada a equação:

$$
\log \left(\frac{\mathbf{I}(\mathbf{F})}{\mathbf{I}_{\mathbf{0}}}\right)=-\boldsymbol{\sigma}_{\mathbf{d}} \mathbf{F}
$$


possibilitando a obtenção das seções de choque de dissociação. Os valores obtidos para as seções de choque, bem como as respectivas incertezas são mostrados na tabela 4.2.

Tabela 4.2 - Seções de choque obtidas dos ajustes da intensidade dos picos 3 e 4 em função da fluência. Irradiação por feixe de $\mathrm{H}^{+}$com energia de 1,0 MeV.

\begin{tabular}{|c|c|c|}
\hline \multirow{2}{*}{ Meteorito } & \multicolumn{2}{|c|}{ Seção de choque $\left(\mathbf{1 0}^{-16} \mathrm{~cm}^{2}\right)$} \\
\cline { 2 - 3 } & Pico 3 & Pico 4 \\
\hline Parambu (LL) & $\mathbf{7 , 2} \pm 0,1$ & $7,4 \pm 0,2$ \\
\hline Putinga (L) & $\mathbf{6 , 2} \pm \mathbf{0 , 4}$ & $\mathbf{6 , 1} \pm \mathbf{0 , 3}$ \\
\hline Gail (H) & $\mathbf{6 , 7} \pm 0,3$ & $6,6 \pm 0,6$ \\
\hline
\end{tabular}

\section{2}

\section{Espectroscopia UV-VIS-NIR}

Os resultados de espectroscopia UV-VIS-NIR obtidos do estudo das três amostras utilizadas no presente trabalho são apresentados a seguir.

\subsection{1}

\section{Condritos ordinários: considerações preliminares}

Nessa seção serão feitas considerações iniciais a respeito das características espectrais observadas para cada amostra.

Como foi descrito no capítulo 3, as amostras estudadas pertentem ao mesmo grupo classificatório, condritos ordinários, porém pertencentes a subgrupos distintos (LL, L e H) cuja diferença básica é a quantidade de ferro contida em sua estrutura mineral. A fim de comparação e obtenção de informações qualitativas a respeito da influência da característica supracitada, os espectros dos três meteoritos, ainda não irradiados, são mostrados (Fig. 4.13). 


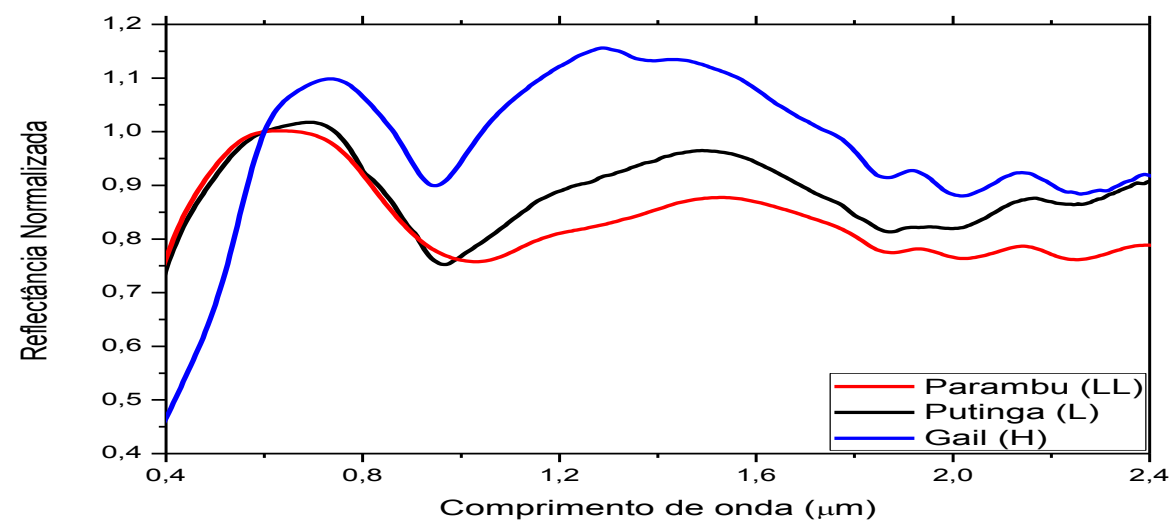

Figura 4.13 - Comparação entre os espectros de refletância (normalizados a 0,6 micron) dos meteoritos Parambu (LL), Putinga (L) e Gail (H). Todos os espectros medidos antes da irradiação.

À primeira vista, os três espectros se mostram muito parecidos, quando comparados entre si. Este fato é esperado, sendo a composição mineralógica destes três meteoritos muito parecida. As diferenças, que são poucas, estão presentes.

A tabela 4.3 mostra a relação entre dois importantes parâmetros espectrais observados: refletância e profundidade de banda. A refletância é a capacidade de um dado corpo celeste de refletir a radiação solar e pode ser obtida diretamente do espectro de refletância. Foram determinadas as refletâncias da região UV-VIS e da região infravermelho próximo, separadamente. Para isso, dois valores de comprimento de onda fixos (um em cada região) são escolhidos e a refletância nesse ponto é obtida. Foram escolhidos os comprimentos em 0,7 micrometros (VIS) e 2,4 micrometros (Infravermelho). A profundidade de banda pode ser obtida utilizando a técnica de análise de espectros de refletância chamada de remoção do contínuo (Breunig et. al., 2007). Para obter esse parâmetro uma função linear é ajustada sobre o espectro UV-VIS-NIR de forma que tangencie os dois máximos da banda característica de absorção em torno de 1 micron, conforme mostra a Figura 4.14 (a).

Após inserir a reta sobre o espectro, basta dividir, para cada comprimento de onda, o valor da refletância do espectro pelo valor da refletância obtido pela função linear. Ao refazer o gráfico, após divisão, obtem-se um espectro com os dois máximos sem a inclinação mostrada antes. O resultado é mostrado na Figura 4.14 (b). A profundidade de banda fica muito mais evidente e agora podemos comparar este parâmetro obtido em espectros diferentes. Praticamente, a 
profundidade é calculada como $\mathrm{P}=1-\mathrm{R}_{\min }$, onde $\mathrm{R}_{\min }$ é o valor de refletância no ponto de mínimo da banda a 1 micron.
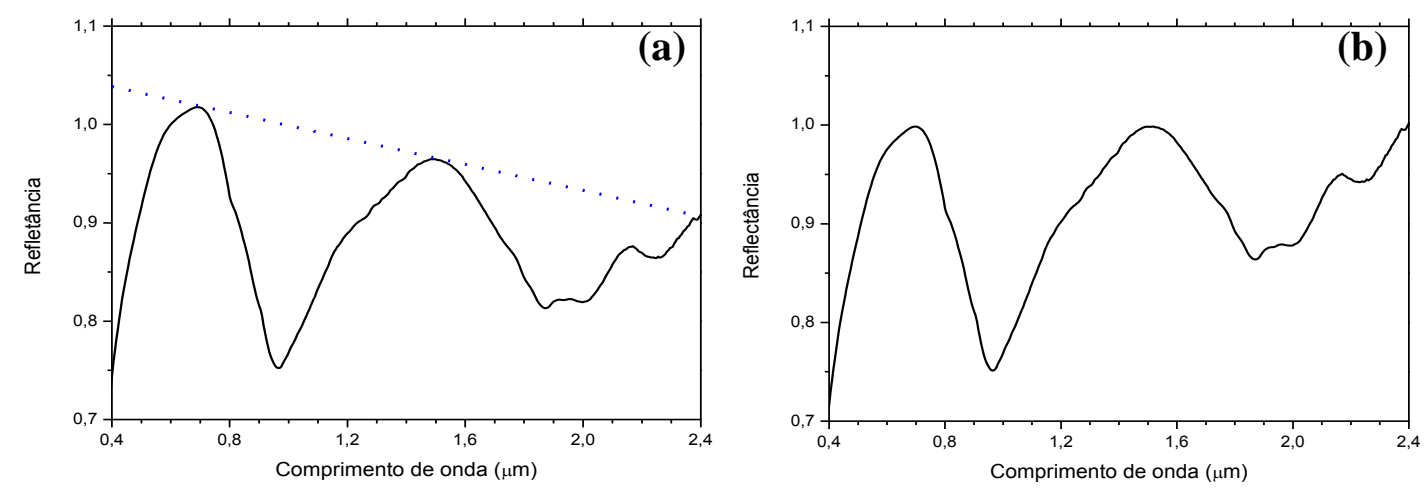

Figura 4.14 - (a) Exemplo de como obter a profundidade de banda de absorção em 1 micrometro. O espectro mostrado pertence ao meteorito Putinga. (b) Resultado após a divisão do espectro original pelo gráfico da reta mostrada em (a).

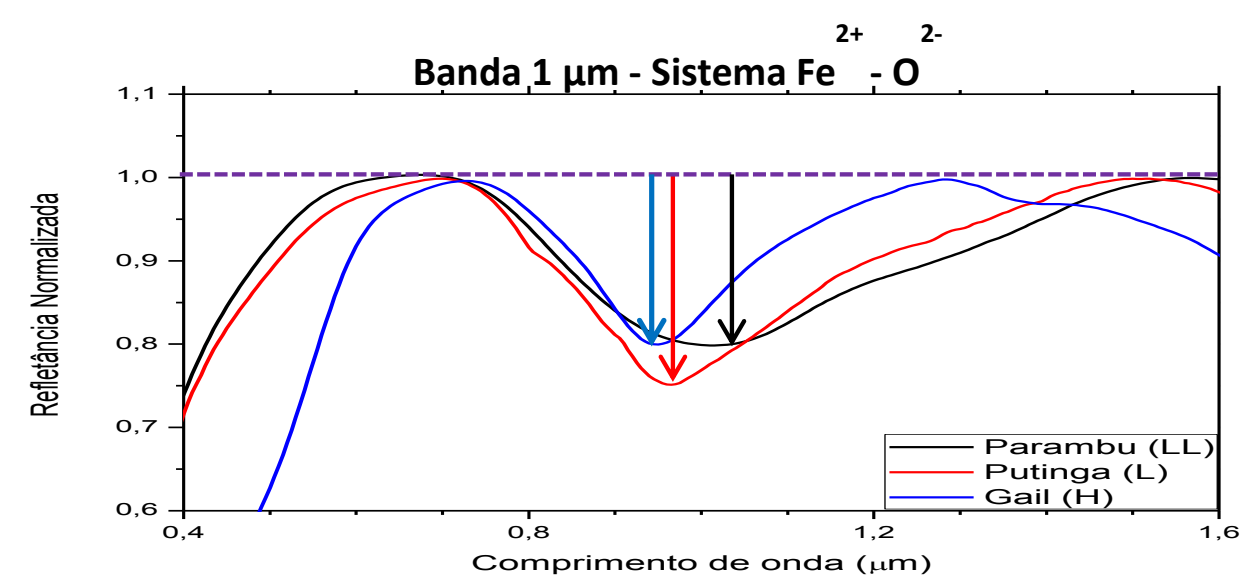

Figura 4.15 - Comparação entre as profundidades de banda para os três meteoritos.

A Figura 4.15 mostra a comparação entre as profundidades da banda de 1 micrometro $^{14}$ (que também é comumente chamada de banda BI, onde I é o número 1 em algarismo romano) para cada uma das amostras. É possível notar

14 - O termo "banda de 1 micrometro" é utilizado para designar a banda referente ao ligação $\mathrm{Fe}^{2+}$ - $\mathrm{O}^{2-}$. Ela recebe esse nome por ser em torno de 1 micron não significando que seu mínimo corresponde exatamente a este valor. 
uma semelhança entre os resultados para os meteoritos Parambu e Gail, tendo o Putinga a maior profundidade inicial.

Tabela 4.3 - Valores obtidos para os parâmetros espectrais, albedo e profundidade de banda.

\begin{tabular}{|l|c|c|c|}
\hline Parâmetro & $\begin{array}{c}\text { Parambu } \\
(\mathbf{L L})\end{array}$ & $\begin{array}{c}\text { Putinga } \\
(\mathbf{L})\end{array}$ & $\begin{array}{c}\text { Gail } \\
(\mathbf{H})\end{array}$ \\
\hline Refletância no Visível & 0,98 & 1,02 & 1,09 \\
\hline Refletância no Infravermelho & 0,79 & 0,90 & 0,92 \\
\hline $\begin{array}{l}\text { Profundidade de Banda em 1 } \\
\text { micron }\left(\mu \mathrm{m}^{-1}\right)\end{array}$ & 0,21 & 0,25 & 0,21 \\
\hline
\end{tabular}

A tabela 4.3 mostra que para a refletância (tanto no visível quanto no infravermelho) parece haver uma dependência com o subtipo do meteorito. Nos dois casos, a refletância tende a aumentar com o conteúdo de ferro. Já a profundidade de banda não mostra, a principio, nenhuma dependência com essa característica das amostras.

Outro parâmetro espectral de extrema relevância no estudo de corpos celestes, com particular importância na pesquisa sobre os efeitos induzidos devido ao SpWe, é a chamada de inclinação da banda de BI (BI slope, do inglês. O I significa 1 em romano, neste caso). Considerando, novamente, a reta traçada sobre o espectro do Puting (figura 4.14 (a)), observamos que a mesma possuí uma dada inclinação (coeficiente angular da reta) que depende da refletância dos ombros nos quais a reta é tangente. A reta terá uma equação $\mathrm{y}=\mathrm{a}+\mathrm{b} * \mathrm{x}$ onde $\mathrm{x}=$ comprimento de onda e y = refletância. Nesta equação, $b=$ inclinação da reta. Justamente essa inclinação é a inclinação da banda BI o do espectro, que relevante na discussão das consequências da exposição à irradiação. Os valores das inclinações obtidos para Parambu, Putinga e Gail, são respectivamente, $-0,15 \mu \mathrm{m}^{-}$ ${ }^{1},-0,13 \mu \mathrm{m}^{-1}$ e $0,01 \mu \mathrm{m}^{-1}$. Já aqui se pode observar que pode existir influência da composição do meteorito. 


\section{2 .2}

\section{Mudanças espectrais induzidas pela irradiação}

Nosso próximo objetivo é estudar os efeitos produzidos pela irradiação sobre os vários meteoritos aqui considerados. Foram usados feixes de prótons, cuja energia foi de 1,0 MeV, e o objetivo principal foi verificar se a quantidade de ferro da amostra influencia as mudanças espectrais induzidas pela irradiação. Para todos os experimentos os meteoritos foram preparados na forma de pastilha (conforme descrito no capítulo 3) e os espectros de reflexão na faixa do UV-VisNIR foram adquiridos, antes e após várias fluências de irradiação. Medidas complementares foram realizadas utilizando íons de nitrogênio com energia de 2,0 $\mathrm{MeV}$ para irradiar apenas o meteorito Gail $(\mathrm{H})$. O objetivo, nesse caso, era comparar os efeitos produzidos por cada um dos projéteis $\left(\mathrm{H}^{+}\right.$e $\left.\mathrm{N}^{+}\right)$sobre a superfície desta amostra de meteorito.

\subsubsection{1}

\section{Meteorito L: Putinga}

O meteorito Putinga é um condrito ordinário do subtipo L. A Figura 4.16 mostra os espectros obtidos via espectroscopia UV-VIS-NIR para este meteorito. São mostrados os resultados da medida anterior à irradiação ("virgem”) e após cinco pontos de irradiação por prótons (ou seja, cinco fluências crescentes), cuja energia era de 1,0 MeV. A comparação mostra que a irradiação resultou em mudança nas propriedades físico-químicas e mineralógicas do material do qual esse meteorito é composto, pois seu espectro de refletância (sensível a tais propriedades) sofre variações progressivas. Observa-se, a partir desta comparação, que todos os parâmetros espectrais apresentados na seção 4.2.1 sofrem modificações devido à irradiação. A amostra sofre o chamado "escurecimento" (em inglês, “darkening”), ou variação da refletância que diminui progressivamente na região do visível e permanece quase constante na região do infravermelho próximo, conforme o gráfico da figura 4.17. 


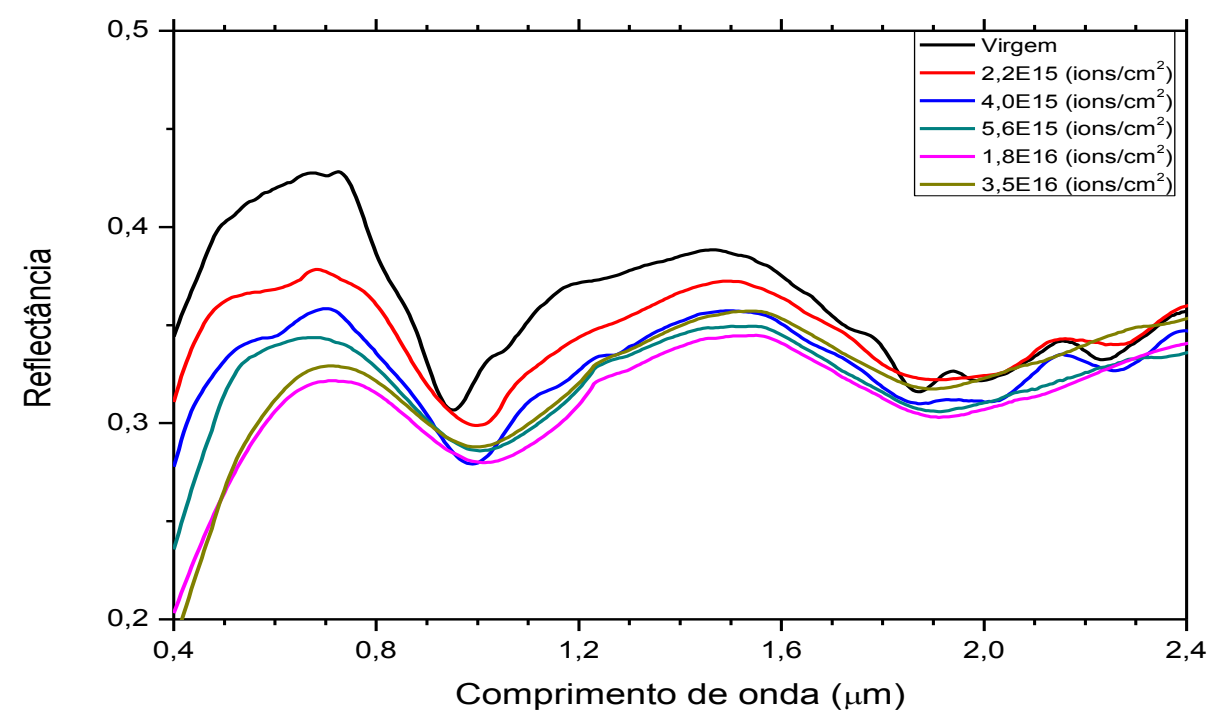

Figura 4.16 - Espectros de refletância do meteorito Putinga (L), virgem e após 5 pontos de irradiação.

A refletância foi normalizada ${ }^{15}$ para o valor do espectro virgem (Fig. 4.17) de modo a permitir uma comparação entre os resultados. O que se observa na Figura 4.17 é que a refletância sofre uma considerável diminuição na região do visível $(\lambda=0,7 \mu \mathrm{m})$ enquanto que quase não se modifica na região do infravermelho. Isso indica que as modificações provocadas pela irradiação, em primeira aproximação, afetam, preferencialmente, as propriedades espectrais relacionadas à absorção e reflexão de radiação na faixa do UV-VIS e de forma menor aquelas na faixa do NIR.

15 - Todos os valores de refletância utilizados foram divididos pelo valor da refletância retirado do espectro da amostra ainda virgem. 


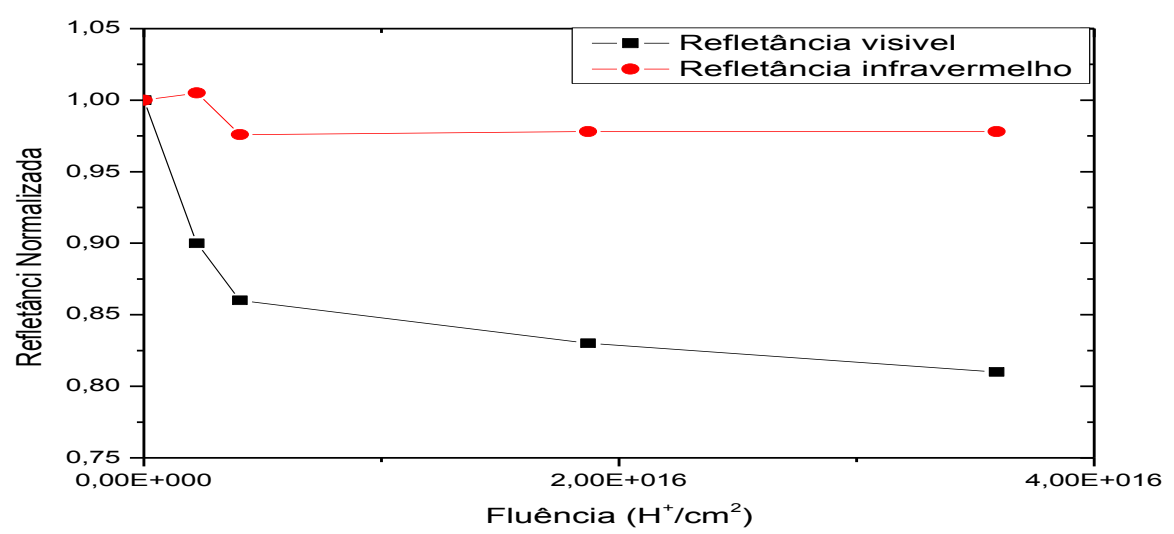

Figura 4.17- Gráfico das refletâncias, visível e infravermelho, como função da fluência da irradiação.

Foi feito, também, o estudo das modificações induzidas pelo feixe de prótons, sobre a profundidade de banda BI, conforme mostra a Figura 4.18. Nela é possível observar que esse parâmetro espectral também sofre diminuição progressiva conforme vai sendo irradiado pelo feixe de prótons. Como dito anteriormente, esta banda esta relacionada com a capacidade deste material em análise de absorver e refletir radiação nessa faixa de comprimento de onda. Logo, mudanças espectrais desta banda indicam que variações físicas, químicas e mineralógicas aconteceram para que o meteorito passasse a absorver uma menor quantidade de radiação eletromagnética que chega nele.

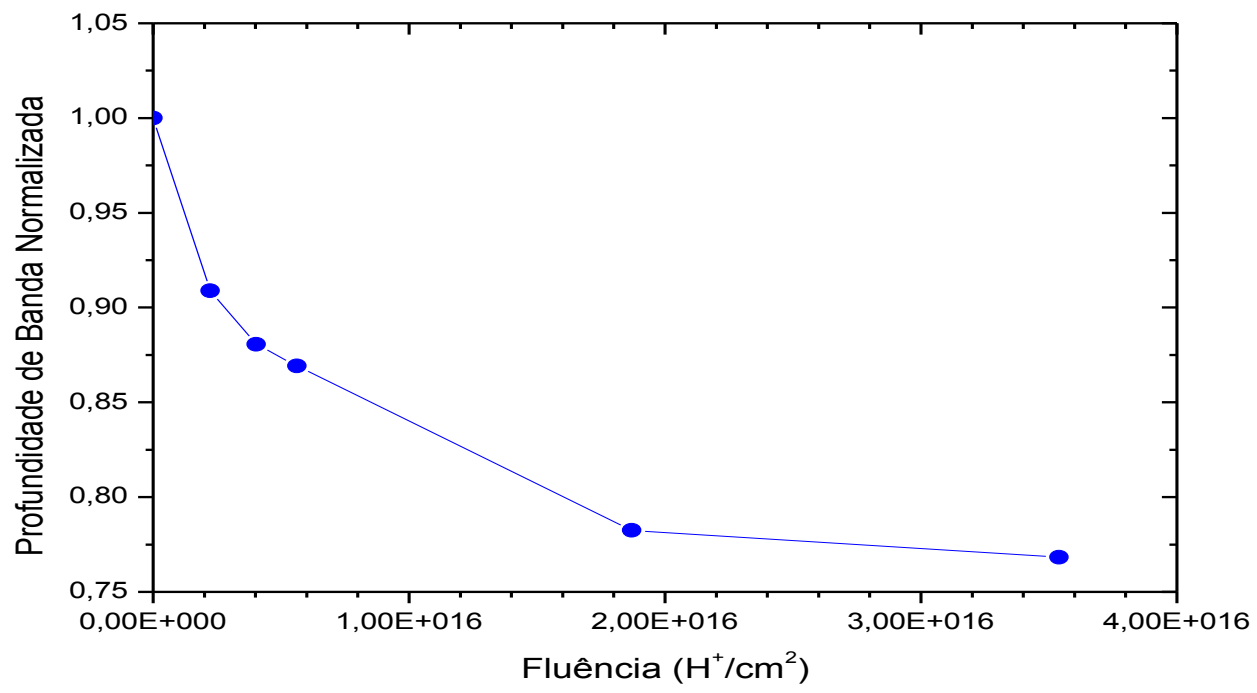

Figura 4.18 - Profundidade de banda em $1 \mu \mathrm{m}$ como função da fluência. 
O último parâmetro espectral estudado foi a inclinação BI. Para uma melhor comparação dos efeitos produzidos pela irradiação com feixe de prótons de 1 $\mathrm{MeV}$, a refletância de todos os espectros foi normalizada a 0,6 micrometros.

Na Figura 4.19 são apresentados os espectros UV-VIS-NIR com refletância normalizadas do meteorito Putinga para diferentes pontos de irradiação, desde o virgem até $3,5 \times 10^{16}$ íns $/ \mathrm{cm}^{2}$.

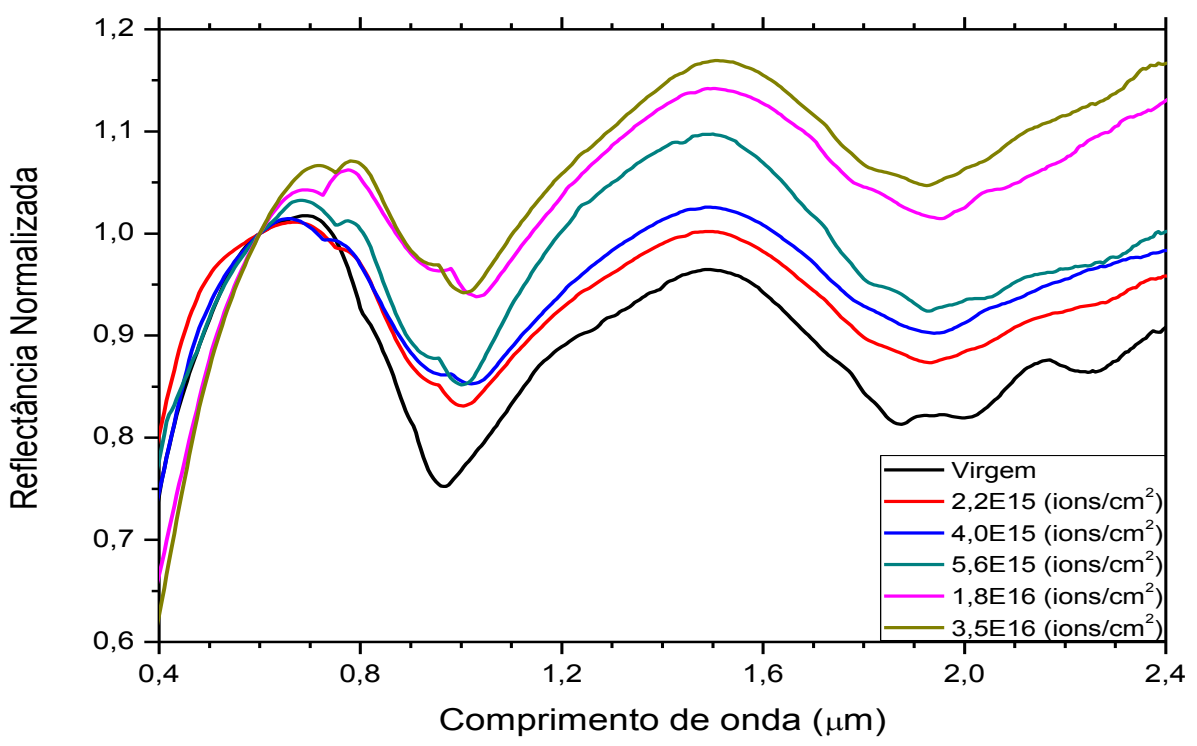

Figura 4.19 - Espectros normalizados a $\lambda=6 \mu \mathrm{m}$ do meteorito Putinga após vários pontos de irradiação.

O principal efeito observado como consequência da irradiação é o "avermelhamento" do espectro (em ingles, "reddening") que pode ser entendido da seguinte forma: i) considere-se, nos espectros normalizados, uma reta que ligue a banda localizada em aproximadamente $0.7 \mu \mathrm{m}$ com o pico em $1.6 \mu \mathrm{m}$ conforme ilustra a Figura 4.18; ii) com o aumento da fluência, a reta vai ficando cada vez mais inclinada. A explicação comumente aceita para esse efeito é que o impacto dos íons sobre a amostra pode causar sputtering preferencial dos átomos de oxigênio $\left(\mathrm{O}^{2-}\right)$. Logo o número de ligações $\mathrm{Fe}^{2+}-\mathrm{O}^{2-}$ é reduzido conforme o tempo de irradiação. O ferro então pode ficar neutro e se depositar nos grãos superficiais na forma de nano-partícula de ferro. O espectro na faixa do visível vai desde o comprimento de onda referente ao azul (lado esquerdo) até o vermelho 
(lado direito). Como a refletância do lado do azul aumenta menos que a vermelha, a aparência do espectro é de avermelhamento.

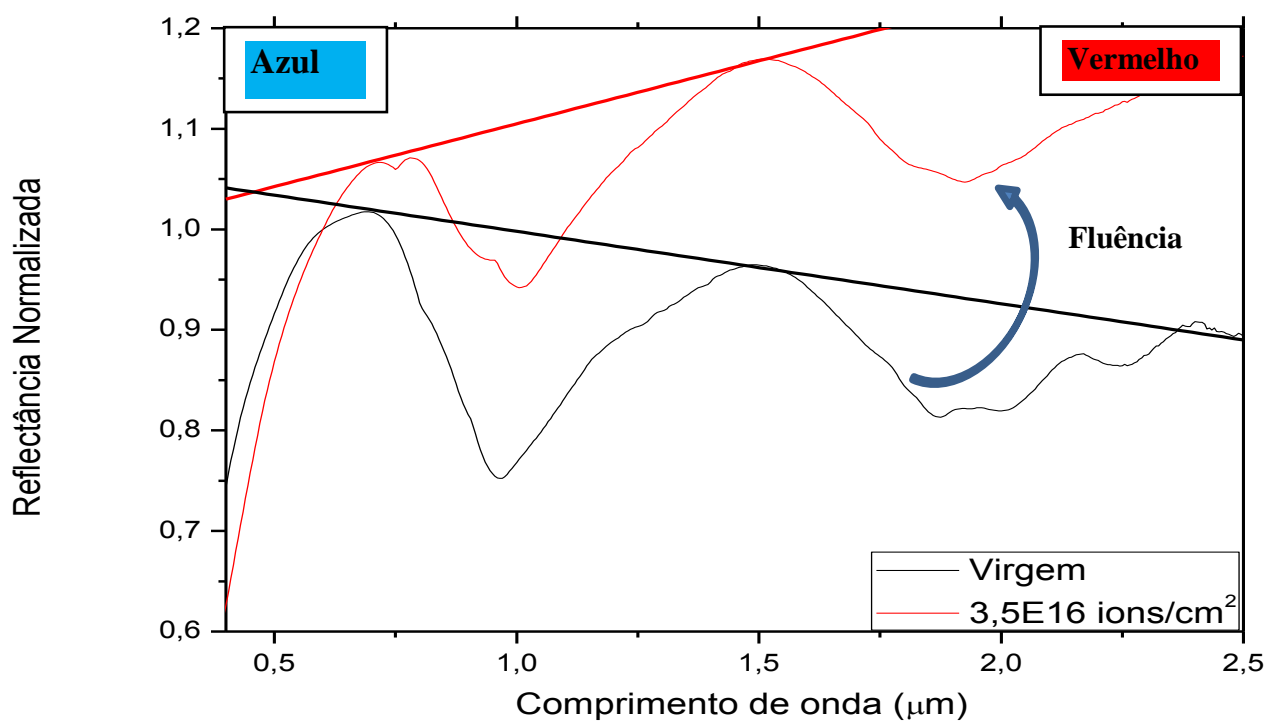

Figura 4.20 - Comparação entre as inclinações BI dos espectros normalizados virgem e adquirido após a última fluência de irradiação.

Para saber se de fato ouve avermelhamento do espectro precisa-se estudar se houve variação da inclinação BI do espectro. A tabela 4.4 mostra a correspondência entre slope e fluência para cada ponto de irradiação. O gráfico desses valores é apresentado na Figura 4.21. O ajuste dos dados obtidos com as funções analíticas revelou que uma função exponencial crescente somada a uma constante reproduzia a relação entre os valores de inclinação e fluência.

Tabela 4.4 - Valores das fluências usadas em cada ponto de irradiação e os respectivos valores do slope.

\begin{tabular}{|c|c|}
\hline Fluência (íons/cm & Inclinação $\left(\boldsymbol{\mu \mathbf { m } ^ { - 1 }}\right)$ \\
\hline 0 & $-0,13$ \\
\hline $2,23 \mathrm{E} 15$ & $-0,023$ \\
\hline $4,04 \mathrm{E} 15$ & $-0,057$ \\
\hline $5,61 \mathrm{E} 15$ & 0,021 \\
\hline $1,87 \mathrm{E} 16$ & 0,067 \\
\hline $3,54 \mathrm{E} 16$ & 0,092 \\
\hline
\end{tabular}




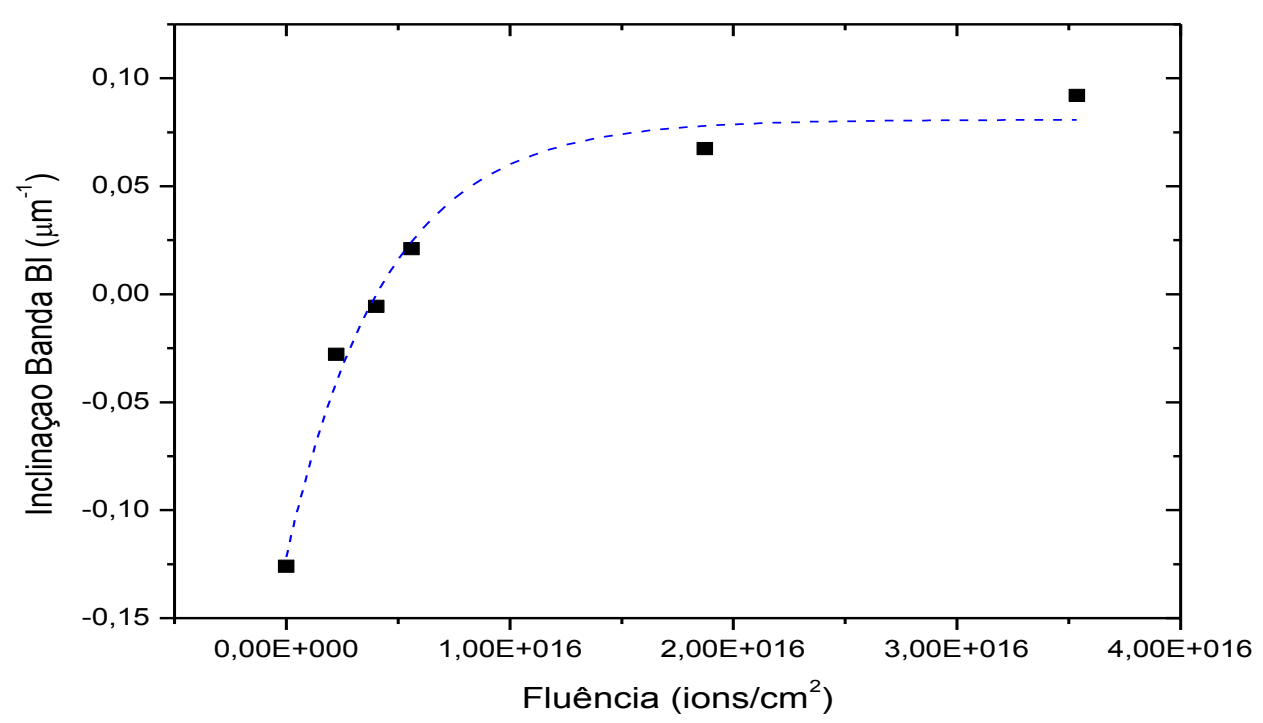

Figura 4.21 - Relação entre os valores da inclinação espectral para cada ponto de irradiação em função do valor da fluência.

Após o ajuste exponencial foi possível obter a seguinte expressão para a variação do Slope (S) como função da fluência (f). O subíndice L corresponde ao tipo do meteorito (LL, L ou H)

$$
S_{L}=S_{0 L}+A_{L} e^{-\sigma_{L} F}
$$

Essa mesma expressão foi utilizada para ajustar os dados relativos aos dois outros meteoritos, mudando apenas os valores numéricos. Nela, $S_{0 L}=$ $\left(8,1 \times 10^{-5} \pm 9,4 \times 10^{-6}\right)$ corresponde à um valor de saturação, ou seja, o valor depois que a irradiação não causasse mais nenhum efeito. $\mathrm{O} \sigma_{\mathrm{L}}=\left(2,2 \times 10^{-14} \pm\right.$ $\left.1,5 \times 10^{-15}\right) \mathrm{cm}^{2}$ pode ser interpretado como sendo a seção de choque de avermelhamento. Ela está relacionada com a rapidez (menores fluências) em tornar o espectro mais avermelhado. Quanto maior o sigma, mais rápido o efeito do SpWe para um dado fluxo do vento solar.

\subsubsection{2}

\section{Meteorito LL: Parambu}

A mesma análise apresentada na seção anterior (meteorito Putinga) foi feita para o meteorito Parambu, um condrito ordinário do subtipo LL. Este meteorito se diferencia do anterior, basicamente, pela quantidade de ferro contida em sua 
estrutura mineral. O objetivo dessa seção é apontar quais diferenças os resultados mostram, em relação aos resultados do Putinga, devido à diferença mineralógica entre os dois.
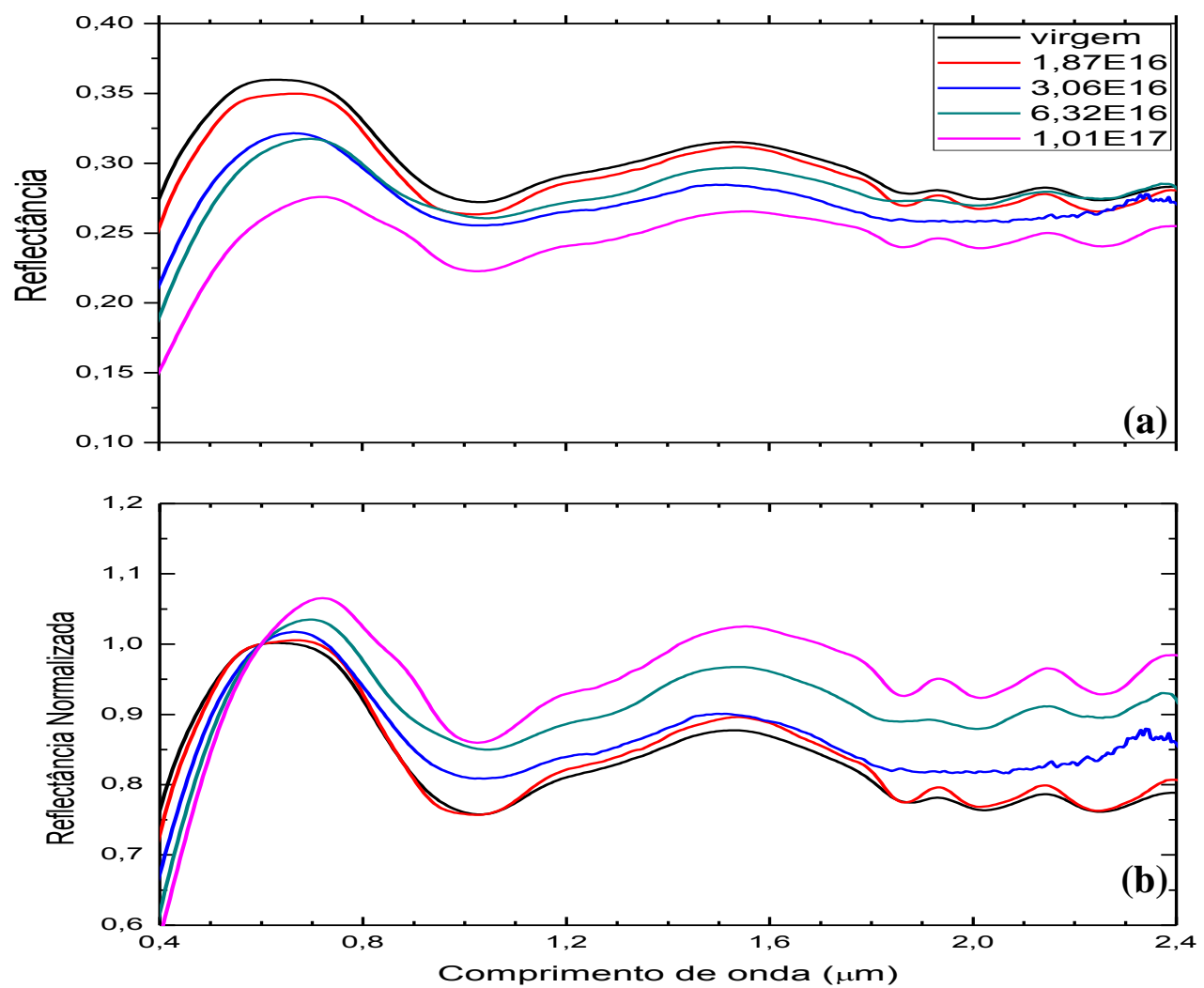

Figura 4.22 - (a) espectros de reflexão do meteorito Parambu, virgem e após quatro pontos de irradiação; (b) os mesmos espectros mas normalizados em $0,6 \mu \mathrm{m}$.

A figura 4.22 mostra (a) os espectros de refletância do meteorito Parambu; e (b) os mesmos espectros com a refletância normalizada em 0,6 $\mu \mathrm{m}$. Em relação à refletância, novamente, o que se observa é uma progressiva diminuição conforme o valor da fluência vai aumentando. A figura 4.23 mostra esse processo. 

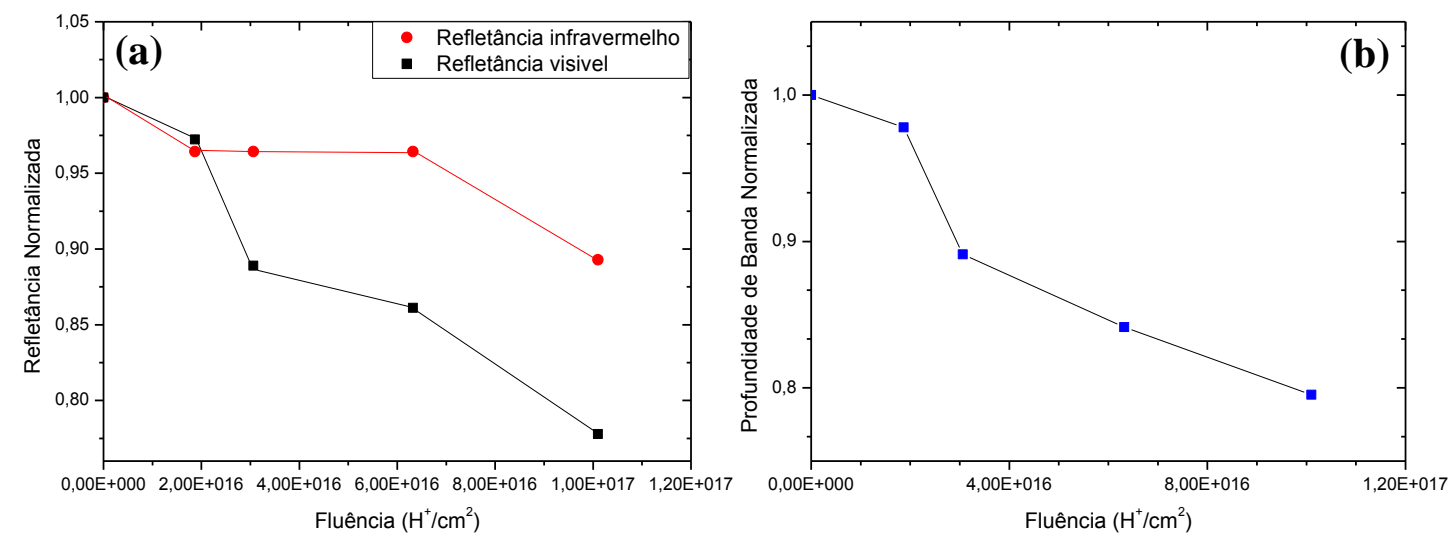

Figura 4.23 - (a) relação entre os albedos na região do visível e do infravermelho como função da fluência; (b) variação da profundidade de banda em $1 \mu \mathrm{m}$ como função da fluência.

Semelhante ao caso do Putinga, o Parambu também experimenta, como consequência da irradiação, diminuição da refletância no visível e da profundidade de banda de $1 \mu \mathrm{m}$. Isso indica que o processo físico que ocorre devido a irradiação por feixe de prótons é o mesmo nos dois casos. A refletância na região do infravermelho próximo quase não se altera.

Em relação à inclinação $\mathrm{BI}$, o que se observa é que, conforme o meteorito vai sendo irradiado, ocorre um aumento progressivo (resultado que, também, é semelhante ao observado no caso do Putinga) da sua inclinação BI (Figura 4.24).

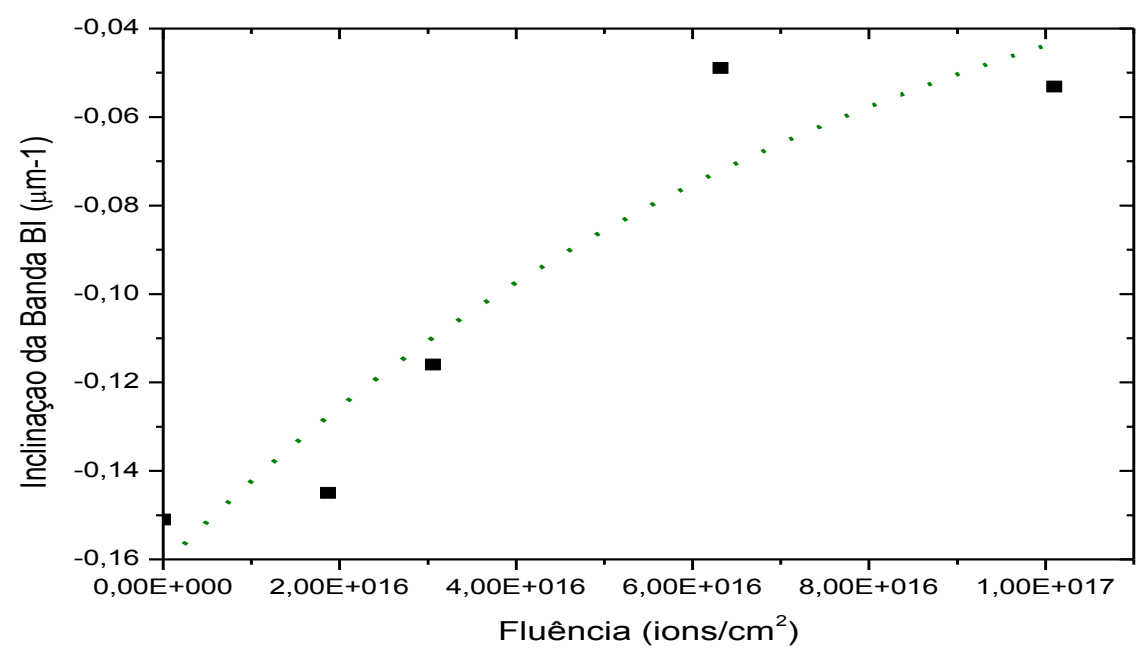

Figura 4.24 - Inclinação BI como função da fluência para o meteorito Parambu.

Para determinar a inclinação BI foi usado o mesmo procedimento citado na seção anterior e ilustrado na figura 4.20. Para o caso do Parambu foi feito o ajuste 
exponencial e a equação obtida tem a mesma forma que a equação 4.1, mudando apenas os valores numéricos. Os valores obtidos foram

$$
S_{0 L L}=\left(7,9 \times 10^{-6} \pm 9,4 \times 10^{-4}\right) \text { e } \sigma_{\mathrm{LL}}=\left(1,2 \times 10^{-15} \pm 8 \times 10^{-16}\right) \mathrm{cm}^{2}
$$

A seção de choque de avermelhamento obtida a partir do gráfico da figura 4.24 é menor do que aquela determinada para o Putinga.

\subsubsection{3}

\section{Meteorito H: Gail}

Finalmente, a análise para o meteorito Gail (subtipo H, maior conteúdo de ferro) é apresentada.

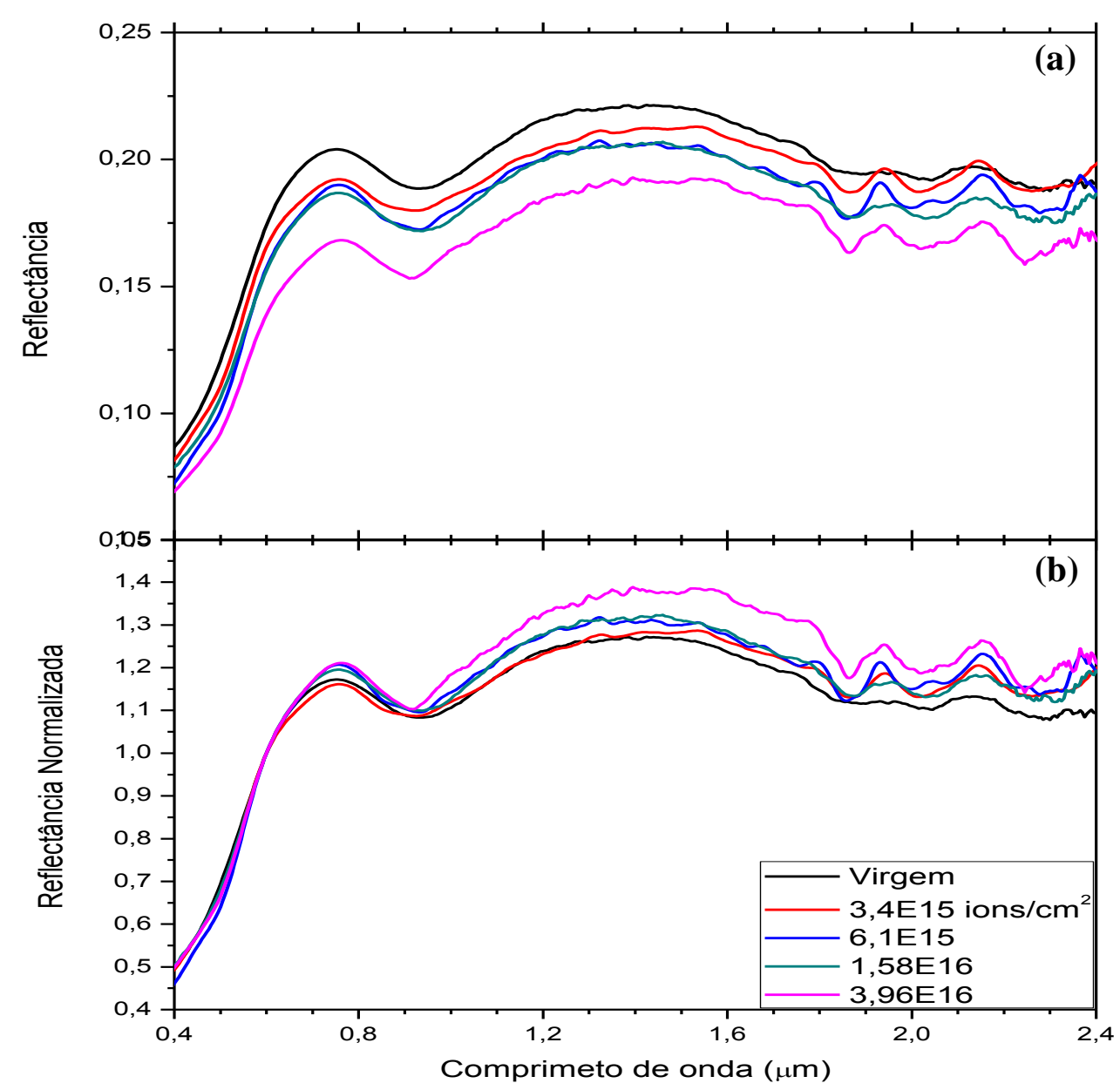

Figura 4.25 - (a) espectros de reflexão do meteorito Gail, virgem e após quatro pontos de irradiação; (b) os mesmos espectros mas com refletância normalizada em 0,6 $\mu \mathrm{m}$.

A Figura 4.25 (a) apresenta os espectros de refletância do meteorito Gail, comparando o espectro virgem com os espectros após cada fluência usada. 
Mesmo espectros, com refletância normalizada, são mostrados na Figura 4.25 (b). Os parâmetros espectrais estudados dos três meteoritos podem ser confrontados. As refletâncias, no visível e no infravermelho, por exemplo, sofrem algumas alterações conforme a Figura 4.26 (a) evidencia.
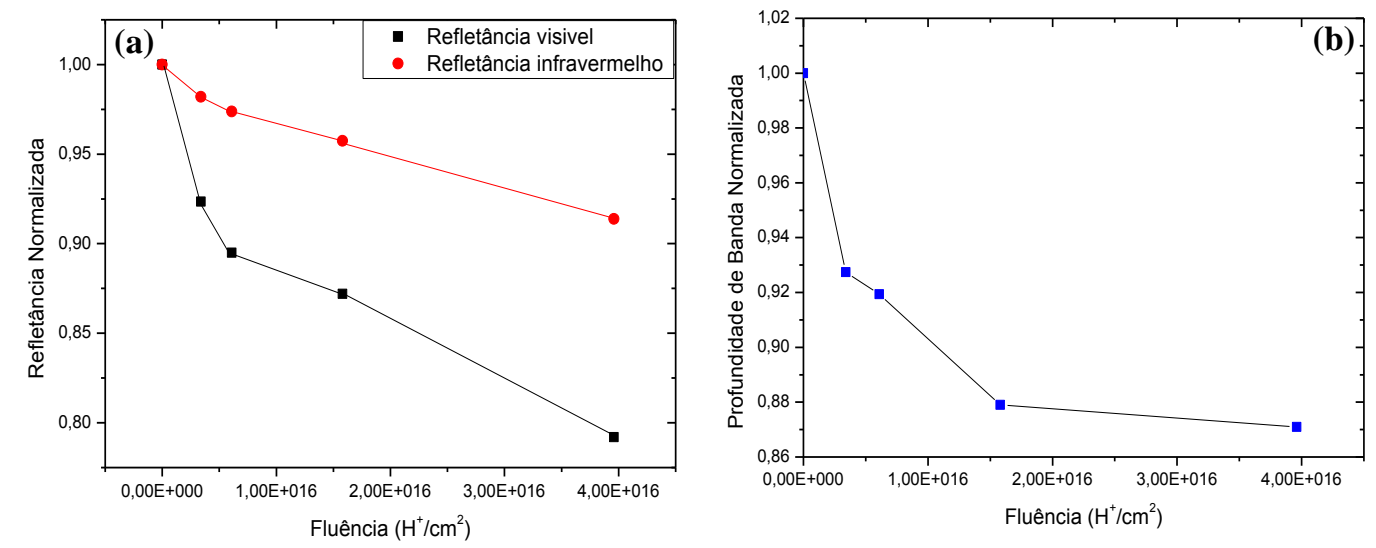

Figura 4.26 - (a) Refletância, visível e infravermelho, como função da fluência; (b) profundidade de banda em $1 \mu \mathrm{m}$ como função da fluência.

Os parâmetros espectrais mostrados na figura 4.26 mostram a mesma tendência de comportamento que as dos meteoritos apresentados nas seções anteriores. No entanto, é fácil notar que as progressivas mudanças que o feixe de prótons causa, são mais expressivas no caso do meteorito Gail, em particular. Tanto a refletância quanto profundidade de banda diminuem, porém a taxa com que isso ocorre é maior. Isto sugere fortemente que a quantidade de ferro da amostra tem influencia no resultado de escurecimento.

O último parâmetro, inclinação da banda, mostra, também, um comportamento semelhante ao visto para os outros dois meteoritos. Essa inclinação sofre aumento conforme a amostra recebe maiores doses de irradiação. A Figura 4.27 mostra o resultado. Porém, no caso do Gail, o valor de saturação é atingido muito rapidamente, quando comparado aos outros dois, mostrando que a porcentagem de ferro maior do Gail produz uma saturação mais rápida. 


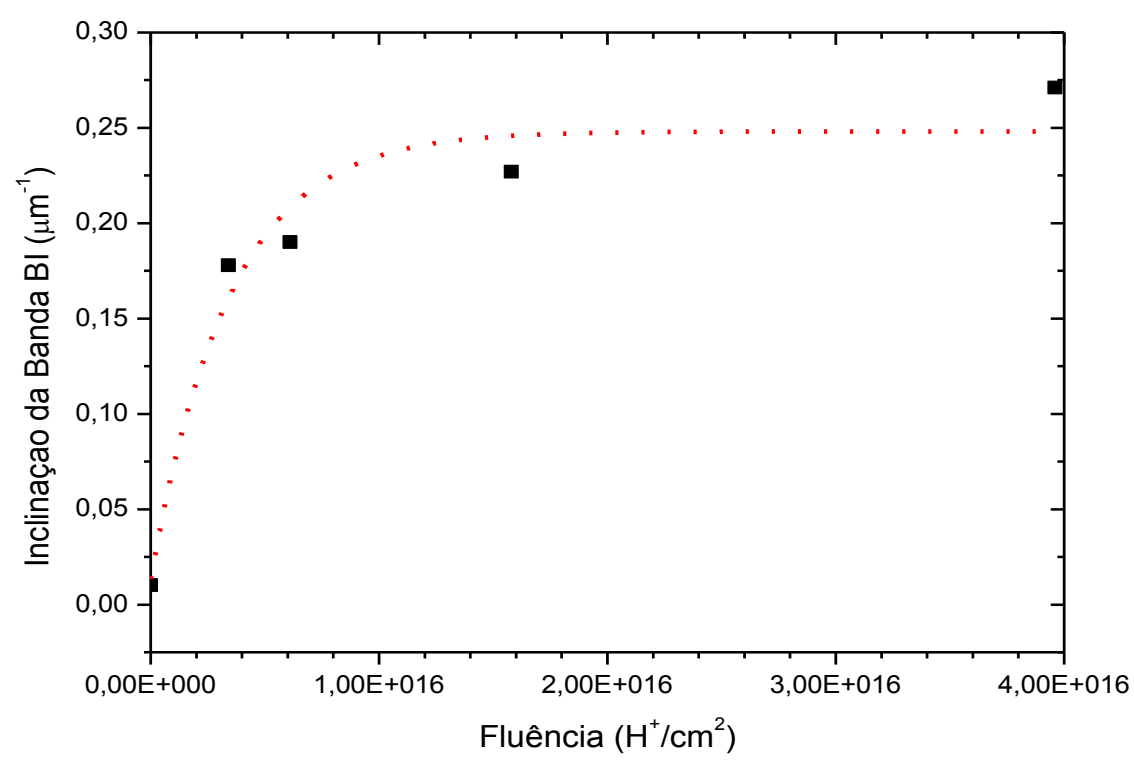

Figura 4.27 - Relação entre a inclinação BI do meteorito Gail e a fluência.

Novamente o ajuste exponencial foi feito e a equação obtida tem a mesma forma que a equação 4.1, mudando apenas os valores numéricos. Os valores obtidos foram

$$
S_{0 H}=\left(2,5 \times 10^{-4} \pm 2,02 \times 10^{-5}\right) \text { e } \sigma_{H}=\left(2,9 \times 10^{-14} \pm 8,8 \times 10^{-16}\right) \mathrm{cm}^{2}
$$

A seção de choque de avermelhamento obtida para o Gail é a maior dentre todas as amostras, conforme mostra a tabela 4.5.

Tabela 4.5 - Comparação entre as seções de choque de avermelhamento obtidas para cada meteorito.

\begin{tabular}{|l|c|c|}
\hline \multicolumn{1}{|c|}{ Meteorito } & Seção de choque $\left(\mathbf{c m}^{2}\right)$ & $\begin{array}{c}\text { Inclinação de } \\
\text { Saturação }\end{array}$ \\
\hline Parambu (LL) & $1,2 \times 10^{-15} \pm 8 \times 10^{-16}$ & $7,9 \times 10^{-6} \pm 9,4 \times 10^{-4}$ \\
\hline Putinga (L) & $2,2 \times 10^{-14} \pm 1,5 \times 10^{-15}$ & $8,1 \times 10^{-5} \pm 9,4 \times 10^{-6}$ \\
\hline Gail (H) & $2,9 \times 10^{-14} \pm 8,8 \times 10^{-16}$ & $2,5 \times 10^{-4} \pm 2,02 \times 10^{-5}$ \\
\hline
\end{tabular}


No capítulo de discussão essa dependência com a quantidade de ferro que a os parâmetros espectrais parecem mostrar será discutida em mais detalhes levando em conta a composição de cada uma delas e a influência da inserção de impurezas na estrutura do material

\subsection{3}

\section{Mudanças espectrais induzidas pela irradiação com nitrogênio}

Uma experiência complementar foi realizada irradiando-se o meteorito Gail (H) com feixe de nitrogênio com energia de 2,0 MeV. O objetivo deste experimento é fazer uma comparação entre os efeitos produzidos pelos feixes de $\mathrm{H}^{+}$e $\mathrm{N}^{+}$. Na Fig. 4.28 são apresentados os espectros de reflexão do meteorito Gail, virgem e após irradiação com $\mathrm{N}^{+}$, bem como os mesmo espectros porém normalizados em $0,6 \mu \mathrm{m}$.
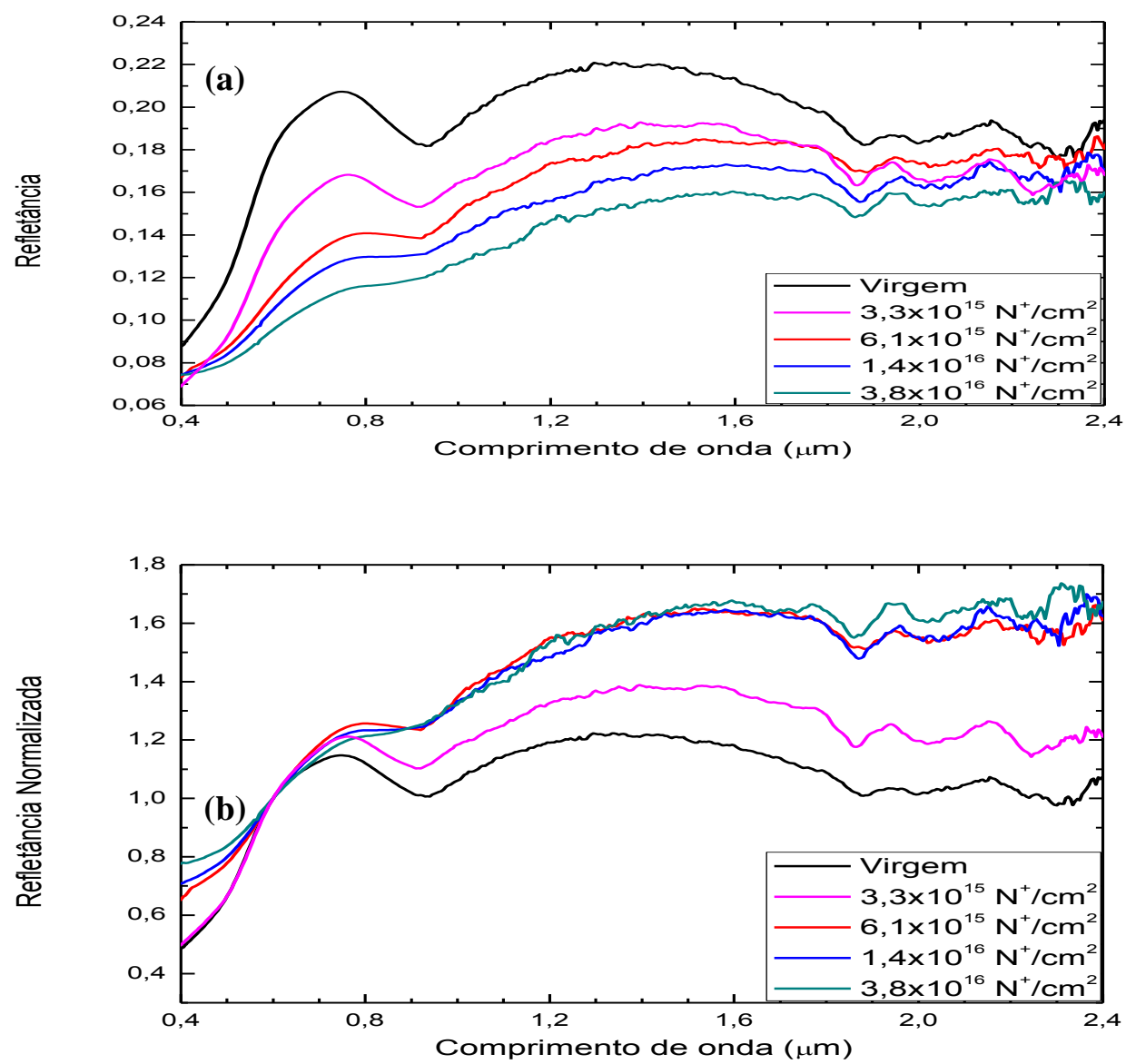

Figura 4.28 - (a) espectros de reflexão do meteorito Gail, virgem e após quatro pontos de irradiação; (b) os mesmos espectros, mas com refletância normalizada em 0,6 $\mu \mathrm{m}$. 
O parâmetro espectral refletância sofreu modificações conforme indica a Fig. 4.29 (a). A refletância na região do visível $(0,7 \mu \mathrm{m})$ sofre progressiva diminuição conforme a irradiação ocorre. A refletância na região do infravermelho não apresenta variações significativas.

A Fig. 4.29 (b) apresenta a inclinação da banda BI como função da fluência para a irradiação com $\mathrm{N}^{+}$. Novamente o ajuste exponencial foi feito e a equação obtida tem a mesma forma que a equação 4.1, mudando apenas os valores numéricos. Os valores obtidos foram

$$
S_{0 H}=\left(6,5 \times 10^{-4} \pm 2,38 \times 10^{-5}\right) \text { e } \sigma_{H}=\left(6,2 \times 10^{-14} \pm 2,2 \times 10^{-16}\right) \mathrm{cm}^{2}
$$
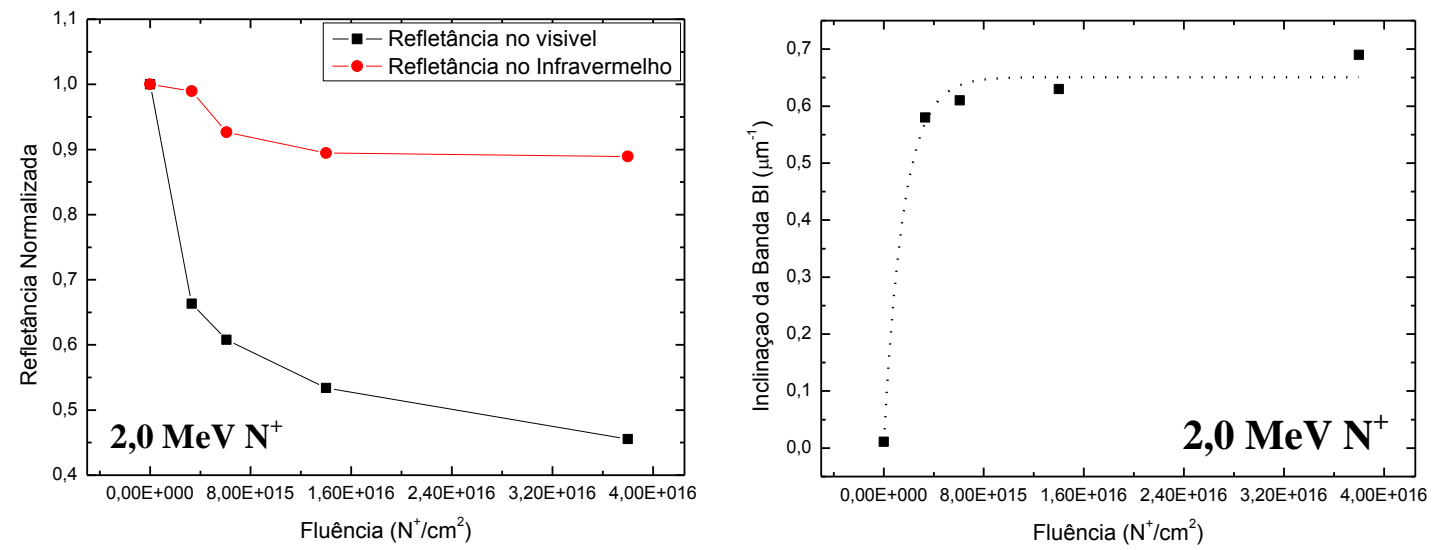

Figura 4.29 - (a) Refletância, visível e infravermelho, como função da fluência; (b) Relação entre a inclinação BI do meteorito Gail e a fluência.

A seção de choque de avermelhamento obtida todas as amostras e todos os feixes utilizados são mostrados na tabela 4.6.

Tabela 4.6 - Comparação entre as seções de choque de avermelhamento obtidas para cada meteorito.

\begin{tabular}{|l|l|c|c|}
\hline Feixe/energia & \multicolumn{1}{|c|}{ Meteorito } & Seção de choque $\left.\mathbf{( c m}^{2}\right)$ & $\begin{array}{c}\text { Inclinação de } \\
\text { Saturação }\end{array}$ \\
\hline $\mathbf{H}^{+} / \mathbf{1 , 0} \mathbf{~ M e V}$ & Parambu (LL) & $1,2 \times 10^{-15} \pm 8 \times 10^{-16}$ & $7,9 \times 10^{-6} \pm 9,4 \times 10^{-4}$ \\
\hline $\mathbf{H}^{+} / \mathbf{1 , 0} \mathbf{M e V}$ & Putinga (L) & $2,2 \times 10^{-14} \pm 1,5 \times 10^{-15}$ & $8,1 \times 10^{-5} \pm 9,4 \times 10^{-6}$ \\
\hline $\mathbf{H}^{+} / \mathbf{1 , 0} \mathbf{M e V}$ & Gail (H) & $2,9 \times 10^{-14} \pm 8,8 \times 10^{-16}$ & $2,5 \times 10^{-4} \pm 2,02 \times 10^{-5}$ \\
\hline $\mathbf{2 , 0} \mathbf{M e V}-\mathbf{N}^{+}$ & Gail (H) & $6,2 \times 10^{-14} \pm 2,2 \times 10^{-16}$ & $6,5 \times 10^{-4} \pm 2,38 \times 10^{-5}$ \\
\hline
\end{tabular}


A forma dos gráficos das Fig. 4.27 e 4.29 (b) é muito semelhante. De fato, a diferença entre eles é apenas em termos de proporções. Observa-se que os valores das inclinações obtidas para o $\mathrm{N}^{+}$, são três vezes o valor das obtidas para $\mathrm{H}^{+}$. Isto pode ser notado dividindo os valores destas inclinações por três. Com isto, dois os gráficos ficam sobrepostos da seguinte forma:

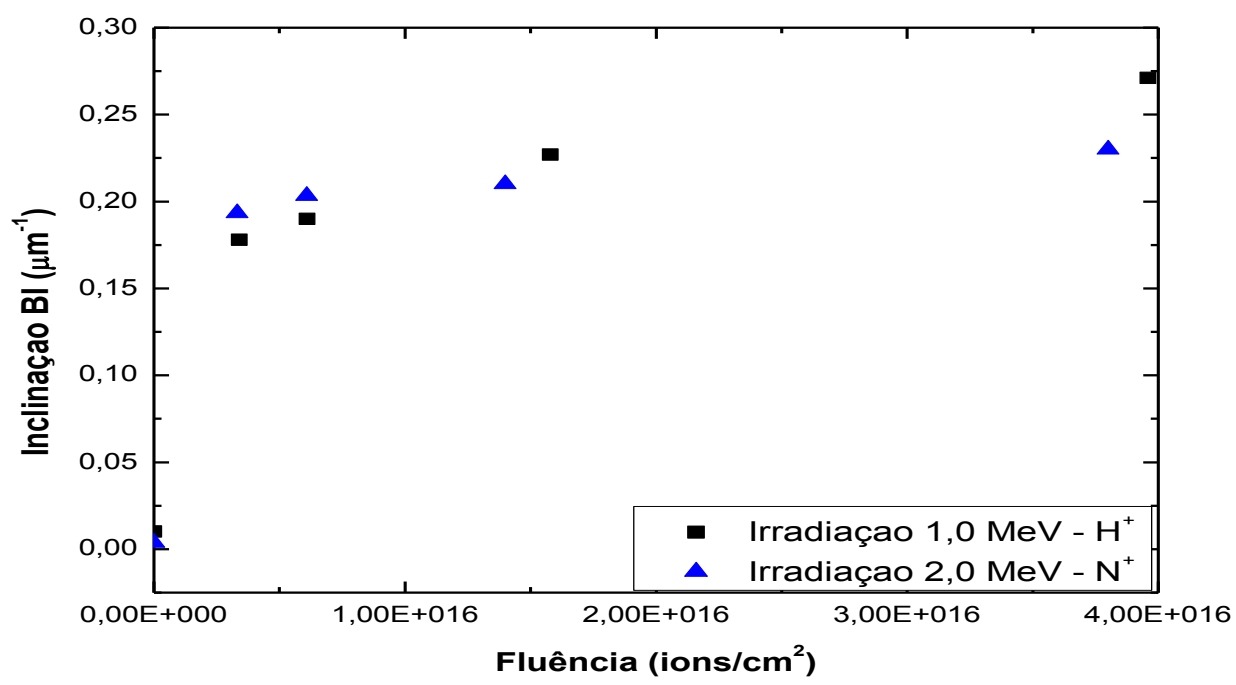

Figura 4.30 - Os valores de inclinação da banda BI obtidos na irradiação por $\mathrm{N}^{+}$formam reescalados (divididos por 3). O resultado é que ele se sobrepõe ao gráfico das inclinações BI obtidos a apartir da irradiação com prótons. 


\section{Discussão}

\section{1}

\section{Variações induzidas na estrutura mineralógica}

Os espectros Raman da grande maioria dos materiais são extremamente sensíveis às variações da estrutura morfológica deles, o que indica que esta sensibilidade deve ser útil na sua caracterização. De acordo com os espectro Raman obtidos, os meteoritos Parambu e Putinga são constituídos, majoritariamente, por olivina e piroxênio, representados pelos picos que foram nomeados de pico 1, pico 2, pico 3 e pico 4. Já o meteorito Gail é constituído majoritariamente por piroxênio.

\section{(i) Picos 1 e 2}

As bandas vibracionais de absorbância mostradas nas Figuras 4.2 e 4.4 são atribuídas à olivina: seus números de onda são $826 \mathrm{~cm}^{-1}$ (pico 1) e $857 \mathrm{~cm}^{-1}$ (pico 2), para o Putinga, e $828 \mathrm{~cm}^{-1}$ (pico 1) e $858 \mathrm{~cm}^{-1}$ (pico 2) para o Parambu. A olivina é um silicato cuja fórmula química é $(\mathrm{Mg}, \mathrm{Fe})_{2} \mathrm{SiO}_{4}$ e cuja estrutura é formada por tetraedros, com o átomo de silício ao centro e quatro átomos de oxigênio nos vértices. Os distintos tetraedros são mantidos juntos por ligações iônicas feitas através dos íons de $\mathrm{Fe}^{2+}$ ou $\mathrm{Mg}^{2+}$ (Strazzulla, 2005), conforme a figura 5.1 (3). Nela são mostrados os tetraedros formados por $\mathrm{SiO}_{4}{ }^{2-}$ que fazem ligação iônica com um cátion de $\mathrm{Fe}^{2+}$ ou $\mathrm{Mg}^{2+}$.

No espectro Raman, o modo vibracional que gera, no espectro Raman, o nomeado pico 1 ocorre devido ao estiramento simétrico da ligação Si-O (Mouri e Enami, 2008). Embora caracterizando a mesma ligação (Si-O), o pico 2 é gerado no modo de vibração de estiramento assimétrico (Mouri e Enami, 2008). Logo, qualquer mudança que venha a ser induzida nesses picos corresponde a alguma 
interferência nesses modos vibracionais. A Figura 5.1 (2) mostra uma representação dos modos vibracionais citados.

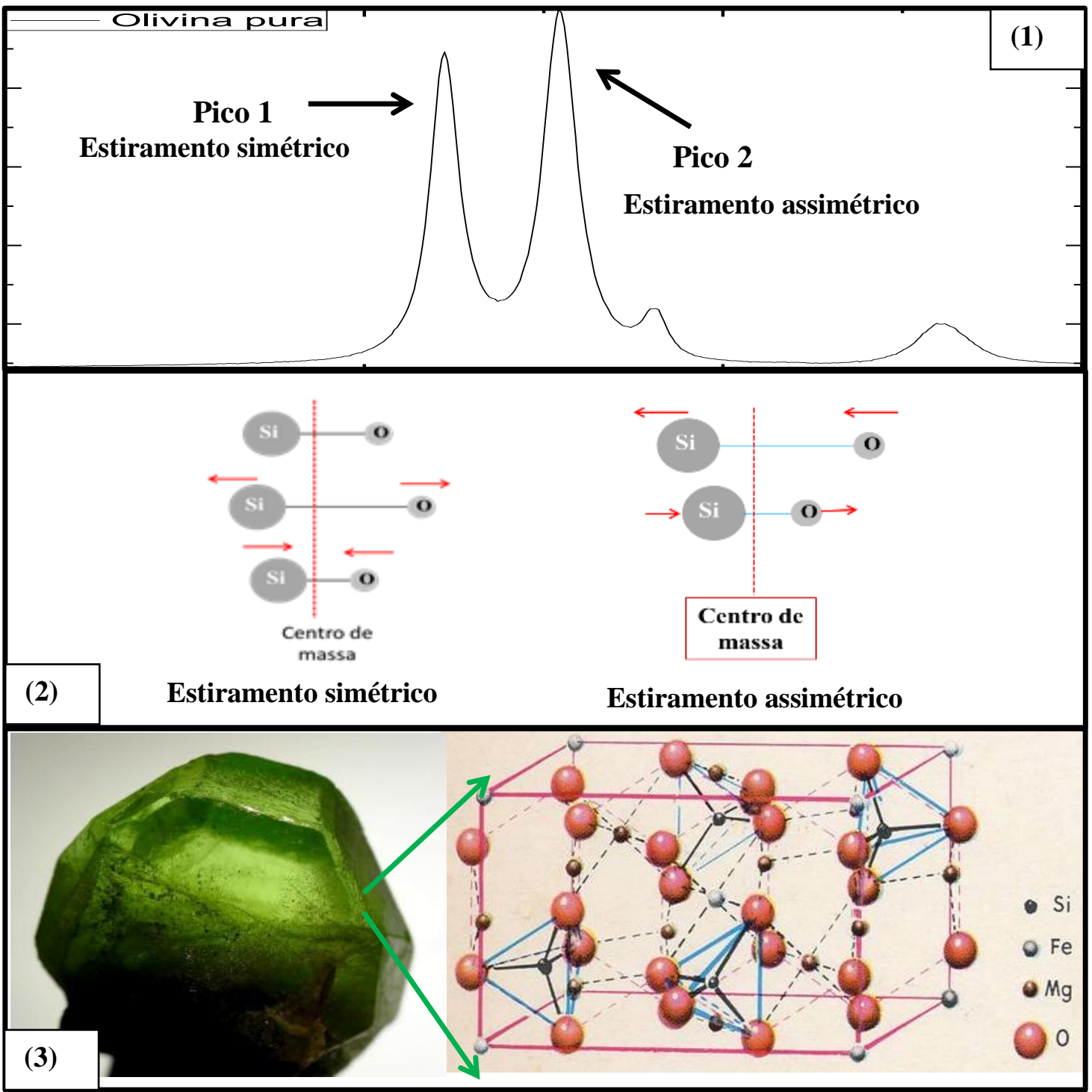

Figura 5.1 - (1) Espectro Raman do meteorito Putinga mostrando os picos 1, 2, 3 e 4; (2) Representação esquemática de modos vibracionais de estiramento simétrico e deflexão da ligação Si-O. (3) Esquerda: imagem de uma olivina terrestre pura; Direita: estrutura do mineral olivina. Os pontos vermelhos representam átomos de oxigênio que se localizam no vértice do tetraedro cujo centro é ocupado por átomos de silício.

Conforme mostrado pelas Figuras 4.8 ((a) e (c)) e 4.9 ((a) e (c)), a irradiação por feixe de prótons de $1 \mathrm{MeV}$ induziu algumas alterações no material, com 
consequentes variações nos números de onda, $\mathrm{Xc}$, de ambas as bandas. As mudanças observadas foram um leve deslocamento de seu valor inicial para energias menores. Uma explicação possível para essa observação é a formação de nanopartículas de ferro neutro, já mencionada no capítulo 2 , e que é considerada consenso na comunidade como forma de explicar os efeitos do SpWe. Yang at. al. (2016) irradiaram a olivina por laser e estudam os efeitos produzidos via espectroscopia Raman; observaram que os picos 1 e 2 tinham o mesmo comportamento: deslocamento progressivo do número de onda para valores menores. Eles atribuíram este efeito a um processo de revestimento dos grãos de olivina pelas nanopartículas de ferro; a formação deste revestimento foi analisada por microscopia eletrônica de transmissão. Outra observação importante feita a partir dos resultados apresentados nas Figuras 4.8 e 4.9, (b) e (d) é que as larguras a meia altura destes mesmos picos apresenta leve aumento como consequência da irradiação. Isto se deve, no caso da olivina, à amorfização da estrutura mineral da amostra. Yang et. al (2016) também observaram que a estrutura cristalina da olivina passaram a ter, em sua superfície, uma camada amorfa. Tal resultado concorda com o proposto por Strazzulla et. al. (2005) que afirma que um dos efeitos do SpWe é a amorfização da amostra.

Uma das principais propostas do presente trabalho é verificar se a quantidade de ferro contido em cada amostra influencia nos efeitos da irradiação observados por Espectroscopia Raman (e por espectroscopia UV-VIS-NIR que será discutida mais a frente). É sempre importante lembrar que as três amostras estudadas (Parambu, Putinga e Gail) são meteoritos que pertencem ao mesmo grupo taxonômico (condritos ordinários) e que a característica que diferencia sua subclassificação (como LL, L ou H) é a abundância relativa do ferro em suas estruturas. De fato, o gráfico da variação do pico 1 para o Parambu (5.2 (a)) mostra que o deslocamento do seu número de onda ocorre com uma taxa mais lenta do que a do Putinga (5.2 (b)). 

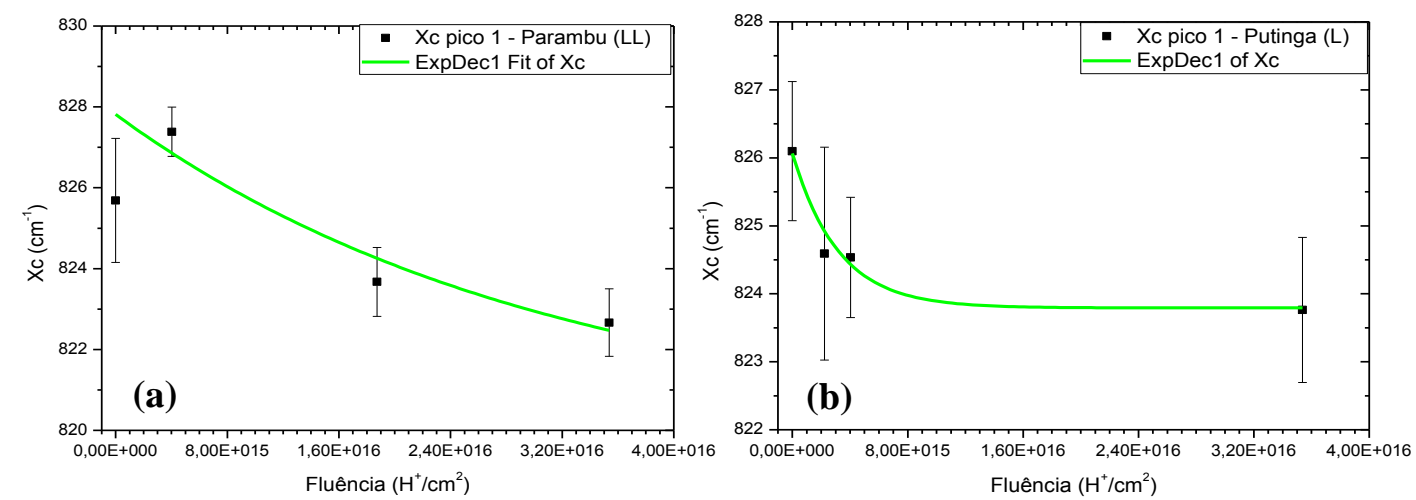

Figura 5.2 - Ajuste exponencial feito dos números de onda $X_{c}$ observados em função da fluência $F$ de irradiação. Lado esquerdo (a): valores $X_{c}$ do meteorito Parambu; lado direito (b): $X_{c}$ do meteorito Putinga.

A Figura 5.2 apresenta o ajuste exponencial feito para os dois gráficos. No ajuste foi usada uma função do tipo:

$$
\mathbf{X}_{c}=\mathbf{X}_{\mathrm{cf}}+\mathbf{A e}^{-\sigma_{\mathrm{x}} \mathbf{F}}
$$

onde $\boldsymbol{\sigma}_{\mathbf{x}}(\operatorname{com} \mathrm{x}=\mathrm{L}, \mathrm{LL}$ ou $\mathrm{H})$ tem as dimensões de uma seção de choque cujo valor determina a rapidez com que a função $X_{c}(F)$ tende de $X_{c 0}=X_{c f}+A$ para o valor de saturação $X_{\mathrm{cf}}$. Neste trabalho, $\sigma_{\mathrm{x}}$ é definida como seção de choque de deslocamento; seu sentido físico está relacionado com as transformações cristalográficas da amostra como consequência da irradiação. Os valores obtidos para $\boldsymbol{\sigma}_{\mathbf{L L}}$ e $\boldsymbol{\sigma}_{\mathbf{L}}$ foram:

$$
\begin{gathered}
\sigma_{\mathrm{LL}}=3,22 \times 10^{-17} \mathrm{~cm}^{2} \\
\sigma_{\mathrm{L}}=3,14 \times 10^{-16} \mathrm{~cm}^{2}
\end{gathered}
$$

Observa-se que $\boldsymbol{\sigma}_{\mathbf{L}}$ é uma ordem de grandeza maior do que $\boldsymbol{\sigma}_{\mathbf{L L}}$. A diferença básica entre Parambu e Putinga é seu conteúdo (inicial) de ferro: o meteorito Parambu apresenta uma concentração de $18,95 \%$ de ferro em sua composição enquanto o Putinga, 23,3\%. O fato de $\sigma_{\mathrm{L}} \gg \sigma_{\mathrm{LL}}$ indica com clareza que, quanto maior a quantidade de ferro da amostra, maior a taxa de variação do número de onda em direção a valores menores.

A olivina é um cristal formado por diferentes fases que vão desde a forsterite (cuja fórmula química é $\mathrm{Mg}_{2} \mathrm{SiO}_{4}$, ou seja, sem ferro) até a faialite 
( $\mathrm{Fe}_{2} \mathrm{SiO}_{4}$, composto químico com ferro). Uma simulação feita com o programa SRIM $^{16}$ para uma mistura de elementos majoritários das amostras utilizadas forneceu a taxa de sputtering para cada um deles. Os resultados são apresentados na tabela 5.1. No caso dos experimentos dessa tese, conforme a irradiação com feixe de prótons transcorre, os átomos de oxigênio apresentam o maior rendimento (yield) de sputtering isto é tem sputtering preferencial em comparação com os demais elementos. Os átomos de ferro, cujo rendimento (yield) de sputtering é muito menor, vão se aglutinando e formando nanopartículas. Assim, a composição inicial do meteorito Putinga, com quantidade maior de ferro do que o meteorito Parambu, provoca na superfície dele uma maior ocorrência de nanopartículas, que por sua vez, acarreta uma variação mais rápida do número de onda da radiação refletida a medida que que a fluência do feixe de íons aumenta.

Tabela 5.1 - Rendimento de sputtering (Y) dos elementos majoritários contidos nas amostras. Simulação feita no programa SRIM.

\begin{tabular}{|c|c|c|}
\hline Elemento & Y (átomos/ín) & Y normalizado a 100 \\
\hline $\mathbf{O}$ & 0,02630 & 100 \\
\hline $\mathbf{M g}$ & 0,01670 & 63,5 \\
\hline $\mathbf{F e}$ & 0,00471 & 17,9 \\
\hline $\mathbf{S}$ & 0,00454 & 17,2 \\
\hline $\mathbf{N i}$ & 0,00415 & 15,8 \\
\hline $\mathbf{S i}$ & 0,00407 & 15,5 \\
\hline $\mathbf{C a}$ & 0,00789 & 30,0 \\
\hline $\mathbf{C}$ & 0,00242 & 9,2 \\
\hline $\mathbf{A l}$ & 0,00465 & 17,7 \\
\hline
\end{tabular}

16 - O SRIM (The Stopping and Range of Ions in Matter, do inglês) é um programa baseado em Monte Carlo que simula o efeito da interação entre um feixe iônico de certa energia pelo interior de um determinado alvo. Este programa fornece cálculos de informações relevantes para a compreensão dos efeitos da irradiação, como o poder de frenamento nuclear e eletrônico. 


\section{(ii) Picos 3 e 4}

As bandas vibracionais vistas nos espectros apresentados nas Figuras 4.2 (lado direito), 4.4 (lado direito) e 4.6 são os picos nomeados de 3 e 4 . Eles tem valor de número de onda em torno de $681 \mathrm{~cm}^{-1}$ (pico 3) e $1014 \mathrm{~cm}^{-1}$ (pico 4) para o Parambu, $680 \mathrm{~cm}^{-1}$ (pico 3) e $1013 \mathrm{~cm}^{-1}$ (pico 4) para o Putinga e $679 \mathrm{~cm}^{-1}$ (pico 3) e $1006 \mathrm{~cm}^{-1}$ (pico 4) para o Gail. Estes dois picos indicam a presença do grupo mineral piroxênio constituído por um conjunto de 21 minerais. Porém, apesar dessa grande quantidade de espécies mineralógicas, os números de onda obtidos para os três meteoritos indicam que o tipo de piroxênio majoritário contido neles deve ser a diopsita $\left(\mathrm{FeCaMg}\left(\mathrm{SiO}_{3}\right)\right)$. A Figura 5.3 mostra um espectro Raman desse mineral puro. As bandas nomeadas de pico 3 correspondem ao modo de vibração de flexão da ligação $\mathrm{Si}-\mathrm{O}-\mathrm{Si}$; os picos chamados de 4 são característicos da ligação Si-O e originam-se de seu modo vibracional de estiramento (AlbaAldave et. al. 2009).

Assim, as variações observadas nos parâmetros Raman desses dois picos indicam que o feixe de prótons de $1 \mathrm{MeV}$ causa modificações na estrutura da diopsita contida em cada amostra de meteorito.

Em relação às variações nos números de onda, as Figuras $4.8((\mathrm{e})$ e $(\mathrm{g})), 4.9$ ((e) e (g)) e 4.10 ((a) e (b)) mostram que esse parâmetro tem um leve deslocamento para valores menores a medida que a irradiação transcorre. Este mesmo efeito sobre os valores do número de onda foi observado por Huang et. al. (2000) ao estudar as modificações do espectro Raman de diferentes amostras se modifica em função da dopagem por íons de Fe. O que esse trabalho evidenciou foi que tanto o pico 3 quanto o pico 4 deslocam-se para valores menores de número de onda, conforme a dopagem com ferro aumentando. Segundo o artigo, isto ocorre, porque a diopsita é constituída por tetraedros de $\mathrm{Si}_{4}$ que formam uma cadeia. Essas cadeias de tetraedros são conectadas por ligações iônicas com íons de $\mathrm{Mg}$, Fe ou Ca. Ao ser inserido na rede cristalina da diopsita, o Fe pode ocupar o lugar que antes era ocupado por $\mathrm{Mg}$ ou $\mathrm{Ca}$. O novo ocupante, por ser mais pesado e maior, acaba amorfizando a estrutura da diopsita e, por consequência, altera o valor dos modos de vibração que depende, basicamente, da distância intermolecular e da massa dos constituintes da ligação. 


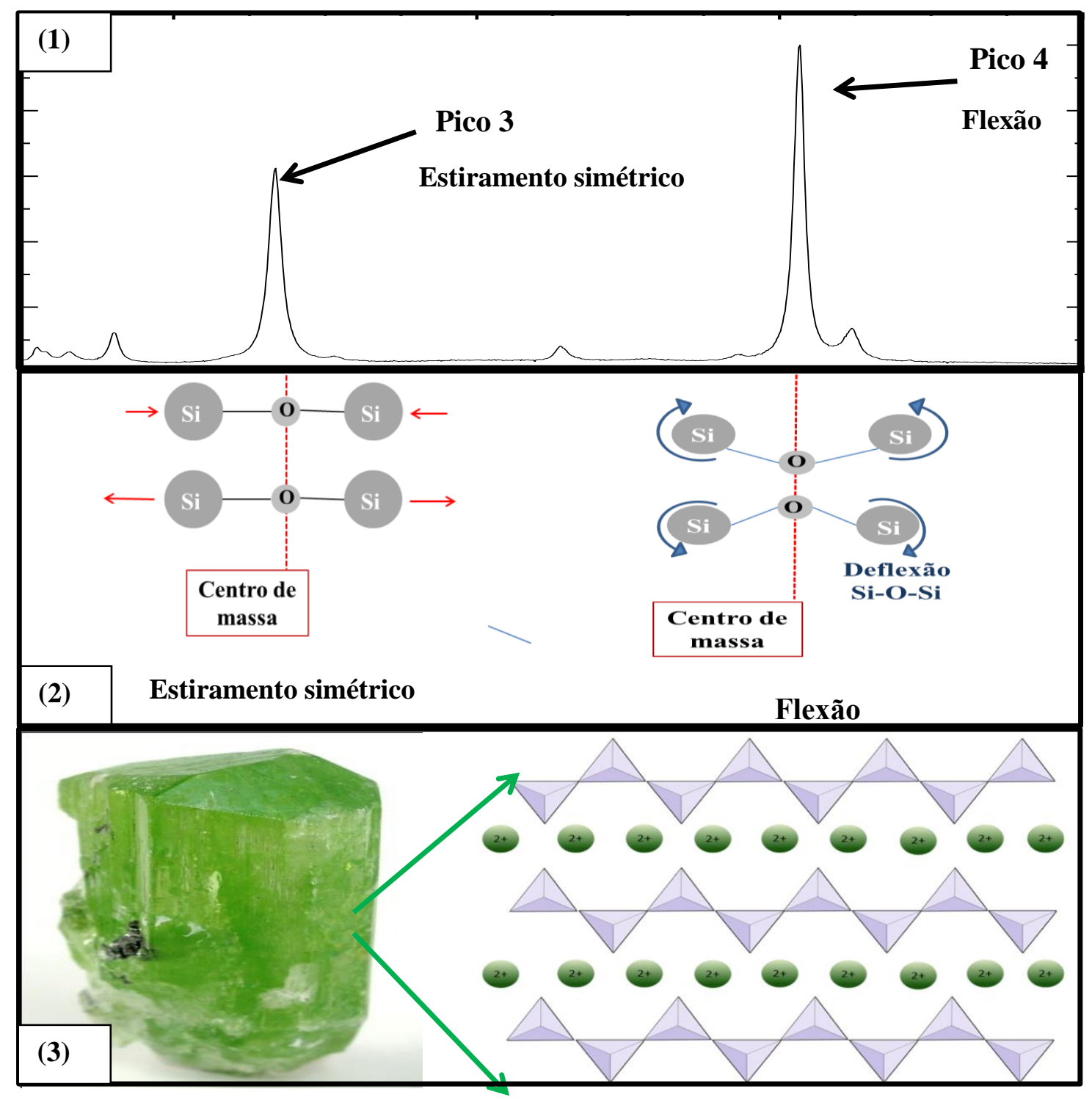

Figura 5.3 - (1) Espectro Raman do mineral diopsita mostrando os picos 3 e 4. (2) Representação esquemática de modos vibracionais de estiramento simétrico e flexão da ligação O-Si-O. (3) Esquerda: imagem de uma diopsita terrestre pura. Direita: estrutura do mineral diopsita. Os tetraedros formam uma cadeia na qual cada tetraedro compartilha um dos átomos de oxigênio com o vizinho. Os pontos verdes representam íons que podem ser $\mathrm{Fe}^{2+}, \mathrm{Mg}^{2+}$ ou $\mathrm{Ca}^{2+}$ que conectam a cadeia de tetraedros.

Nas irradiações feitas no presente trabalho, o impacto do feixe de prótons sobre a amostra pode ter causado sputtering preferencial de átomos de $\mathrm{Mg}$ e $\mathrm{Ca}$ (além dos de oxigênio, como citado para o caso da olivina) da estrutura da diopsita, pois de acordo com a tabela 5.1, os rendimentos de sputtering destes 
elementos são maiores do que a do ferro. Com vacâncias causadas pela irradiação, átomos de ferro remanescentes passam a ocupar esses lugares causando os deslocamentos observados nos números de onda dos modos de vibração. Um resultado que apoia esta hipótese é mostrado na tabela 5.2. Nela são comparados os números de onda dos picos 3 e 4 para cada amostra de meteorito utilizado neste trabalho, antes da irradiação, assim como a concentração relativa de ferro de cada amostra. $\mathrm{O}$ que se observa na tabela é a redução do valor de $\mathrm{X}_{\mathrm{c}}$ de cada pico em função do aumento do conteúdo de ferro.

Tabela 5.2 - Relação entre os valores dos números de onda dos picos 3 e 4 e a porcentagem de Ferro de cada amostra de meteorito.

\begin{tabular}{|l|c|c|c|}
\hline Meteorito & Pico 3 (inicial) & Pico 4 (inicial) & Ferro (\%) \\
\hline Parambu (LL) & $681 \mathrm{~cm}^{-1}$ & $1014 \mathrm{~cm}^{-1}$ & 18,95 \\
\hline Putinga (L) & $680 \mathrm{~cm}^{-1}$ & $1013 \mathrm{~cm}^{-1}$ & 23,30 \\
\hline Gail (H) & $679 \mathrm{~cm}^{-1}$ & $1006 \mathrm{~cm}^{-1}$ & 26,10 \\
\hline
\end{tabular}

Uma análise semelhante àquela feita para o pico 1 , cujos resultados são apresentados na Figura 5.2, foi realizada para os picos 3 e 4 das três amostras de meteorito. Os valores das taxas de variação $(\sigma)$ do parâmetro Xc para estes picos foram obtidos a partir de ajustes feitos nos dados mostrados nas Figuras 4.8 ((e) e (f)) para o Parambu, 4.9 ((e) e (f)) para o Putinga e 4.10 ((a) e (b)) para o Gail. Na Tabela 5.3, os valores obtidos para estas taxas são comparados e relacionados com as respectivas concentrações iniciais de ferro de cada amostra. 
Tabela 5.3 - Comparação entre as seções de choque de deslocamento dos picos 3 e 4 das três amostras de meteorito utilizadas. A abundância relativa inicial de ferro de cada amostra é também apresentada.

\begin{tabular}{|l|c|c|c|}
\hline \multicolumn{1}{|c|}{ Meteorito } & Pico 3 & Pico 4 & Ferro (\%) \\
& $\boldsymbol{\sigma}\left(\mathbf{x} \mathbf{1 0}^{-16} \mathbf{c m}^{\mathbf{2}}\right)$ & $\boldsymbol{\sigma}\left(\mathbf{x} \mathbf{1 0}-\mathbf{1 6} \mathbf{c m}^{\mathbf{2}}\right)$ & \\
\hline Parambu (LL) & $0,13 \pm 0,10$ & $0,89 \pm 0,12$ & 18,95 \\
\hline Putinga (L) & $6,32 \pm 0,4$ & $1,65 \pm 0,50$ & 23,30 \\
\hline Gail (H) & $2,21 \pm 0,5$ & $1,03 \pm 0,21$ & 26,10 \\
\hline
\end{tabular}

Conforme evidencia a Tabela 5.3, as seções de choque de deslocamento correspondentes às bandas 3 e 4 mostram dependência com a concentração de ferro inicial da amostra. O meteorito Parambu é aquele que possuí menor concentração de ferro inicialmente, e é dele a menor taxa de variação de Xc. Putinga e Gail apresentam valores próximos para as taxas de variação de Xc, fato que pode ser explicado pelo valor parecido da concentração de ferro inicial. A Figura 5.4 (b) mostra estas relações. Outra evidência que apoia a proposta da influência da concentração de Fe na posição do pico 3 é apresentada na Figura 5.4 (a): quanto maior ela é, maior o deslocamento total da banda vibracional observado na amostra.

É interessante atentar que a variação do número de onda mostrada por Huang et. al. (2000) é muito pequena em comparação às variações observadas nos espectros Raman adquiridos neste trabalho: de fato, em Huang et. al. (2000), para grandes quantidades de inserção de ferro na estrutura da amostra, o deslocamento do número de onda é quase imperceptível (menor do que $2 \mathrm{~cm}^{-1}$ ). Logo, a presença de maior concentração de ferro nas amostras virgens, por si só, não é um fator decisivo no efeito observado. Este fato reitera que as consequências da exposição dos efeitos do SpWe são relevantes. A irradiação potencializa o 
processo, uma vez que quebra ligações da rede cristalina e gerando a aparição de vacâncias (por meio do processo de sputtering, tabela 5.1) que, por sua vez, podem ser ocupadas pelos átomos de ferro remanescentes. Por exemplo, para o meteorito Gail, a variação do número de onda devido à irradiação é aproximadamente de $10 \mathrm{~cm}^{-1}$, cinco vezes maior do que a observada por Huang et. al. (2000).
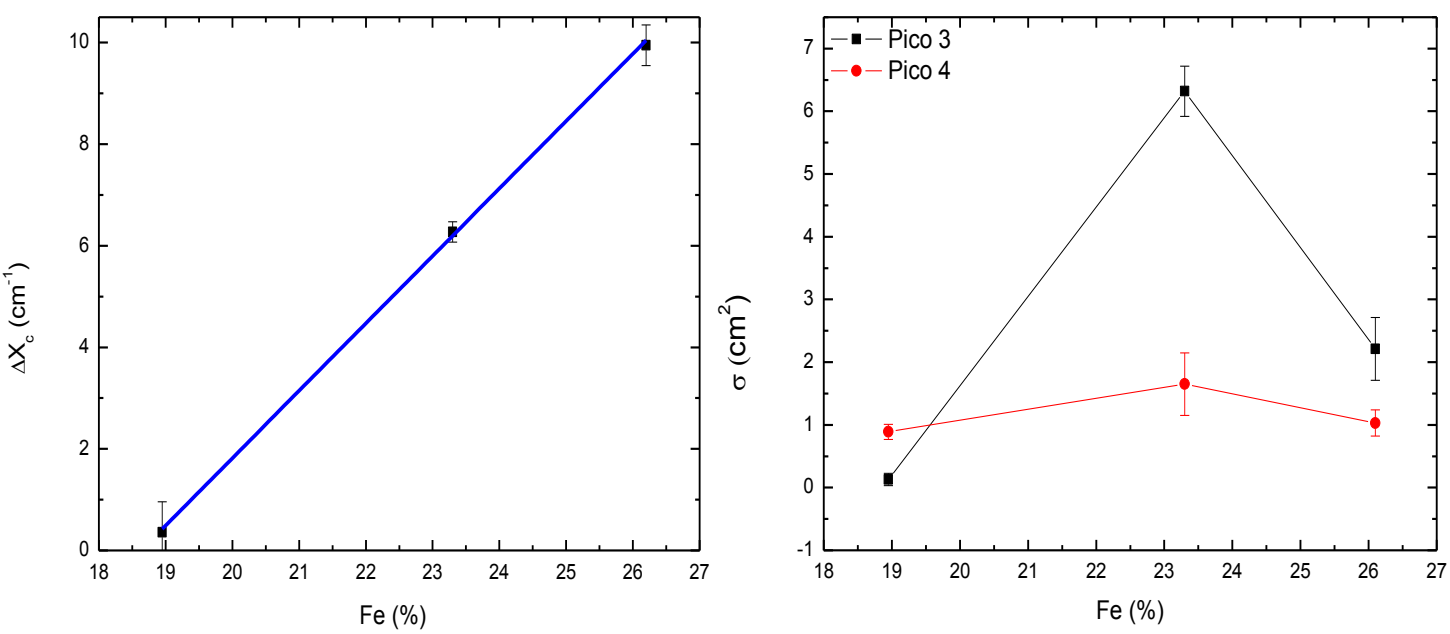

Figura 5.4 - (a) relação entre a variação total do número de onda e (b) das seções de choque de deslocamento, em função da concentração relativa (\%) de ferro de cada amostra de meteorito.

\section{1 .2}

\section{Dissociação química e seções de choque}

Outro parâmetro Raman que fornece informações sobre a amostra é a intensidade da absorbância da banda (altura do pico) ou sua absorbância integrada (área do pico). Na seção 4.1.4 foram apresentados os gráficos que mostram modificações da intensidade em função da fluência da irradiação. A partir dos resultados observa-se que, como consequência da incidência do feixe de íons, ocorre diminuição da área do pico. Isto indica diminuição número de moléculas formando a ligação Si-O na região analisada.

Antes de discutir os resultados apresentados nas Fig. 4.11 e 4.12, é necessário comparar a espessura da região da amostra analisada pela 
espectrometria Raman com as modificações causadas pelo feixe em função da profundidade (d). Esta análise tem que ser feita para verificar se a técnica é sensível às modificações. A Figura 5.5 apresenta a dependência do poder de frenamento, tanto do eletrônico quanto do nuclear, com a profundidade de penetração do feixe em uma amostra de olivina. Este gráfico foi produzido a partir de simulações feitas com o programa SRIM. No mesmo gráfico é também mostrada a atenuação da intensidade do feixe do laser do espectrômetro Raman em função da profundidade de penetração (utilizou-se a equação 3.15 para fazer este cálculo).

A intensidade do laser decai exponencialmente a medida que penetra na matéria. A partir da equação 3.15 é possível obter uma estimativa da profundidade que o feixe do laser consegue analisar a amostra. Para isso, considera-se o valor de profundidade para a qual a intensidade inicial decai para $\mathrm{e}^{-1}=0.368$, cerca de um terço de seu valor inicial, e que ocorre para d igual a:

$$
\mathbf{d}=\frac{1}{2 \alpha}
$$

onde $\alpha$ é o coeficiente de absorção do material. Para olivina, considerando o comprimento de onda do laser do espectrômetro Raman (414 nm),obtem-se d 4,7 $\mu \mathrm{m}$ (valor representado pela linha vertical verde na Figura 5.5). A esta profundidade o poder de frenamento eletrônico é de $120 \mathrm{keV} / \mu \mathrm{m}$ enquanto que o poder de frenamento nuclear é de $0,025 \mathrm{keV} / \mu \mathrm{m}$. A transferência de energia via interação eletrônica é, pois, o processo dominante nesta região. A maior taxa de transferência de energia do feixe de prótons para os átomos e moléculas da amostra ocorre a uma profundidade de $9 \mu \mathrm{m}$. 


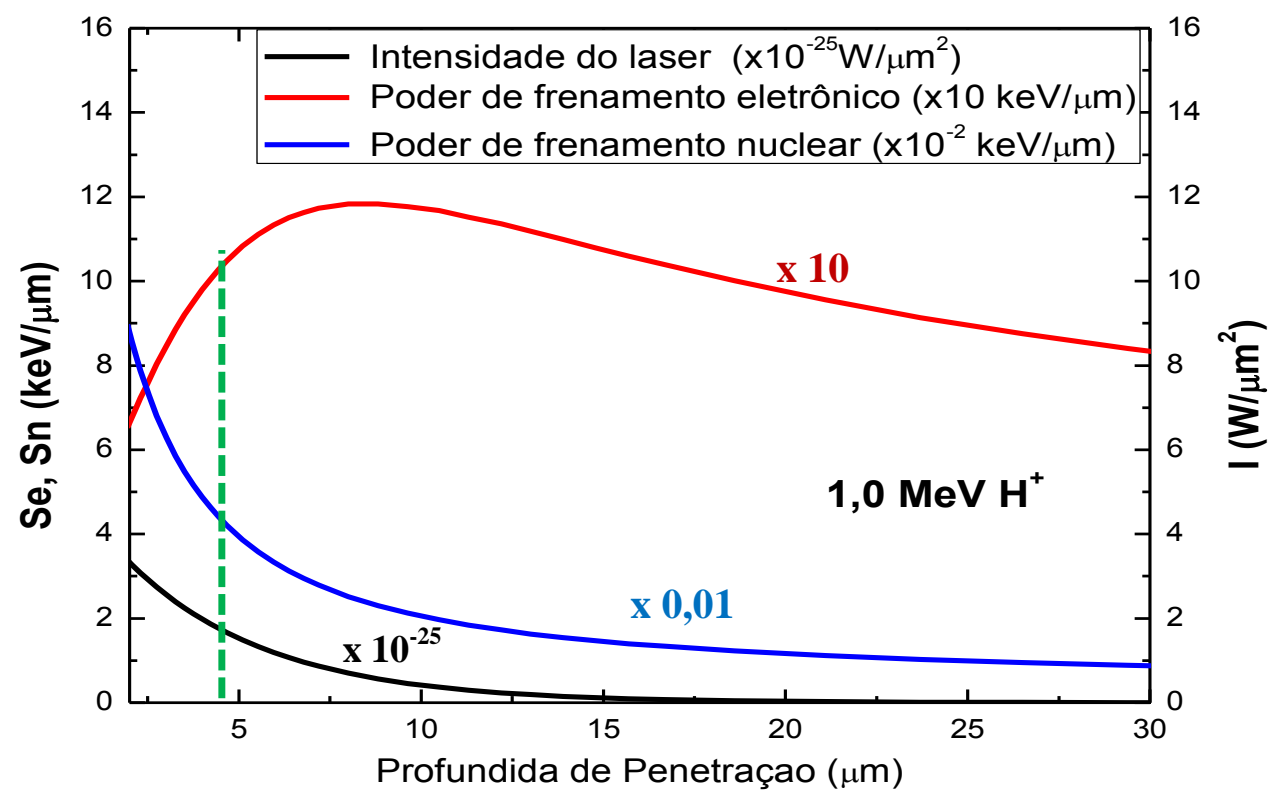

Figura 5.5 - Poder de frenamento eletrônico e nuclear em função da profundidade de penetração na amostra. No mesmo gráfico, intensidade do laser utilizado no espectrômetro Raman em função da profundidade da amostra. As escalas das três curvas foram modificadas para que a comparação fosse possível.

Observa-se pela Figura 5.5 que a análise Raman é de fato sensível à região modificada pelo feixe de íons e que a energia transferida pelo projétil ocorre, majoritariamente, devido à interações com os elétrons das moléculas do alvo. Resta saber de que depende mais a dissociação das moléculas de Si-O: se das ionizações produzidas ou do recuo dos núcleos nas colisões elásticas.

Do ajuste dos dados das absorbâncias Raman em função da fluência foi possível obter os valores de seção de choque de destruição para cada ligação molecular estudada. As Figuras 4.11 (a) e (b) mostram os valores obtidos para os picos 1 e 2 e a comparação entre eles é feita na tabela 4.1. Quando comparados, os valores destas seções de choque são muito próximos. Levando em conta as incertezas, pode-se dizer todas as seções de choque se equivalem. o que pode ser explicado pelo fato de os dois picos (1 e 2) representarem diferentes modos vibracionais de uma mesma ligação, conforme ilustra a Figura 5.1 (2). Desta forma, quando um projétil $\mathrm{H}^{+}$provoca a dissociação da molécula de $\mathrm{Si}-\mathrm{O}$ (quebra a ligação entre $\mathrm{Si}$ e $\mathrm{O}$ ), ambos os modos de vibração (estiramento simétrico e assimétrico de $\mathrm{Si}$-O) são afetados simultaneamente. 
$\mathrm{O}$ raio efetivo $\mathrm{r}$ de destruição das moléculas de $\mathrm{Si}-\mathrm{O}$ pode ser estimado a partir das medidas das seções de choque. O raio efetivo é a distância radial que se inicia no centro do traço (seção 2.3.2, do capítulo 2) formado pela passagem do íon. Ele define uma região dentro da amostra na qual os possíveis fenômenos causado pelo feixe ocorrem (como por exemplo, ionização de átomos e moléculas da amostra). A relação

$$
\sigma_{\mathbf{d}}=\pi \mathbf{r}^{2}
$$

fornece:

$$
\mathbf{r}=\sqrt{\frac{\sigma_{\mathrm{d}}}{\pi}}
$$

Dado que os valores de $\sigma_{\mathrm{d}}$ são muito próximos, a média simples entre eles é usada:

$$
r=\sqrt{\frac{3,4 \times 10^{-16}}{\pi}} \sim(10,4 \pm 0,3) \mathrm{nm}
$$

Os diâmetros médios dos átomos de silício e oxigênio são, respectivamente, 0,26 ̊ e 1,4 $\AA$ (Earles, E. 2015). Considerando a distância entre os átomos, o diâmetro aproximado da molécula $\mathrm{SiO}_{4}$ é de cerca de $3 \AA$ A. Assim, o raio efetivo é centenas de vezes maior que o tamanho da molécula de $\mathrm{SiO}_{4}$, o que mostra que o número de moléculas afetadas é da ordem de uma centena.

Para o caso das bandas 3 e 4, as respectivas seções de choque são maiores. Maior também será o número de moléculas cujas absorbâncias dos modos vibracionais permitem a análise da dissociação molecular. Além disso, como consequência do aumento da seção de choque, o raio efetivo aumenta: utilizando a equação 5.2 para o valor de seção de choque que corresponde à média dos valores obtidos dos dados da Figura 4.12 (tabela 4.2) o raio efetivo para os picos 3 e 4 pode ser calculado. Usando $\sigma_{\mathrm{d}}=6,7 \times 10^{-16} \mathrm{~cm}^{2}$ (o dobro do valor obtido par aos picos 1 e 2) o raio efetivo é: 


$$
r=\sqrt{\frac{6,7 \times 10^{-16}}{\pi}} \sim(14,6 \pm 0,4) \mathrm{nm}
$$

O alcance da interação do feixe de prótons com as moléculas de piroxênio é maior do que quando os mesmos íons interagem com as moléculas que formam a olivina.

Alguns experimentos indicam que a seção de choque de destruição depende apenas do poder de frenamento eletrônico, variando em função deste como uma lei de potência. Em experiências com gelos ${ }^{17}$, os resultados mostram que $\sigma_{d} \sim$ $\left(\mathrm{S}_{\mathrm{e}}\right)^{\mathrm{n}}$ (Barros et. al. (2011)). Na mesma linha de raciocínio, $\sigma_{\mathrm{d}} \sim\left(\mathrm{S}_{\mathrm{e}}\right)^{3 / 2}$ foi encontrado por Andrade et. al. (2013), para irradiação de acido fórmico por feixe de íons pesados, e $\sigma_{\mathrm{d}} \sim\left(\mathrm{S}_{\mathrm{e}}\right)$ por da Costa (2016), para experimento de irradiação de aminoácidos por diferentes feixes na faixa do $\mathrm{MeV}$ realizados em temperatura ambiente. Nos experimentos do presente trabalho foram determinadas as seções de choque de destruição dos minerais: i) olivina, para feixe de prótons de 1,0 $\mathrm{MeV}$, e ii) piroxênio, para feixes de próton de $1,0 \mathrm{MeV} \mathrm{N}^{+}$de 2,0 $\mathrm{MeV}$. Os valores de seção de choque obtidos são apresentados na Figura 5.6 juntamente com os valores de seção de choque de destruição da L-valina (da Costa (2016)). Ambos os experimentos foram realizados à temperatura ambiente. Nos dois experimentos foi encontrado uma relação linear entre $\sigma_{\mathrm{d}}$ e $S_{\mathrm{e}}$. Ambas as retas mostradas na Fig. 5.6 representam uma função do tipo:

$$
\sigma_{\mathrm{d}}=\mathbf{a} \mathbf{S}_{\boldsymbol{e}}
$$

sendo a é uma constante de proporcionalidade que depende do matérial irradiado. Para os dados de minerais o valor obtido para $\mathrm{n}$ é $0,91 \pm 0,17$. Levando em conta as incertezas das medidas pode-se considerar que, para minerais, equação 5.3 continua válida e $\sigma_{\mathrm{d}}$ depende apenas da energia que é transferida do projétil para os átomos da amostra via interações eletrônicas.

\footnotetext{
17 - Experimentos com gelos (temperaturas da ordem de dezenas de Kelvin) simulam a interação de raios cósmicos com amostras compostas de moléculas presentes no ambiente espacial.
} 


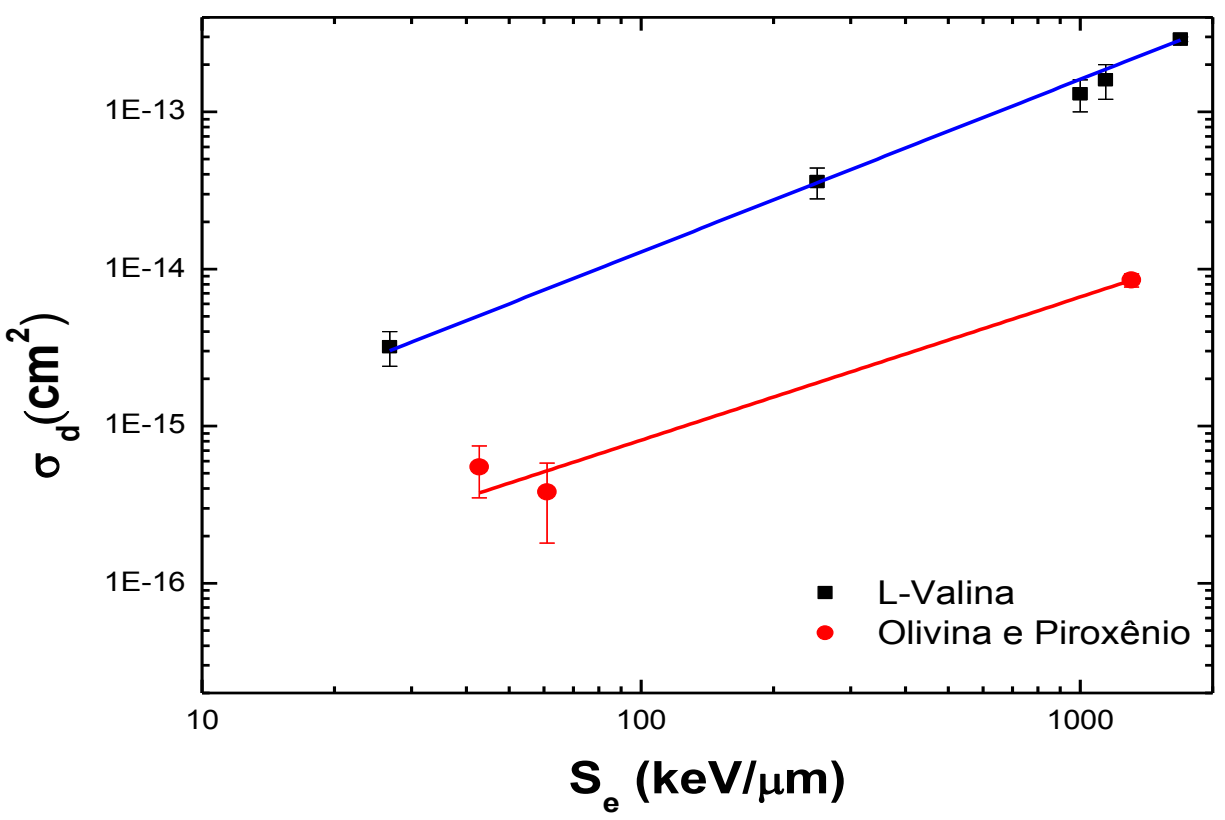

Figura 5.6 - Seção de choque de destruição obtida em experimentos de irradiação do aminoácido L-Valina por diferentes feixes (da Costa, C. A. P. (2016)). As seções de choque de destruição de olivina e piroxênio foram inseridas no mesmo gráfico. As retas tracejadas representam a função $\sigma_{d}$ $=\mathrm{aS}_{\mathrm{e}}$. 


\section{2}

\section{Parâmetros espectrais}

\section{2 .1}

\section{Refletância no visível e profundidade de banda à 1 micrômetro}

Conforme mostrado no capítulo 4, Figuras 4.13, 4.15, 4.17, 4.20 e 4.23, os espectros de refletância das amostras de meteorito são levemente semelhantes entre si e evidenciam uma forte presença do mineral olivina. Isso concorda com os resultados Raman deste trabalho e com dados da literatura que mostram olivina e piroxênio como composição mineral majoritários nas três amostras, sendo a olivina o de maior concentração nos três casos.

Como já escrito, a estrutura mineral da olivina é formada por tetraedros possuindo oxigênio nos quatro vértices e um átomo de silício no centro, tetraedros esses ligados entre si por um íon de $\mathrm{Mg}$ ou de Fe. A banda com comprimento de onda de aproximadamente $1 \mu \mathrm{m}$ (indicada pela seta vermelha na Figura 4.15) é atribuída à presença de ferro ferroso, $\mathrm{Fe}^{2+}$. Dessa forma, qualquer variação observada nas características principais desta banda deve indicar que o $\mathrm{Fe}^{2+}$ foi afetado alguma alteração.

Os resultados obtidos e apresentados no capítulo 4 evidenciam que os parâmetros espectrais de interesse sofreram muitas modificações como consequência da exposição da amostra à irradiação por feixe de prótons com energia de $1 \mathrm{MeV}$. Todas estas mudanças espectrais encontram explicações baseadas na formação de nanopartículas de ferro. Em particular, ficou claro que um dos efeitos desta exposição foi a redução da refletância na região do visível, ocorrida para as três amostras (Figuras 4.15, 4.21 (a) e 4.24 (a)). A explicação mais aceita para esse fenômeno, chamado de escurecimento do espectro, é a de que a formação de nanopartículas de ferro neutro, como produto da irradiação, gera um processo de metalização da superfície. Essa observação concorda com o que é mostrado na seção 5.1 para os resultados da espectroscopia Raman, onde essa mesma formação de uma camada metalizada na superfície da amostra altera os parâmetros Raman, deslocamento Raman. Com relação à profundidade de 
banda à $1 \mu \mathrm{m}$ (ver definição junto à Fig. 4.14), observou-se também uma redução desse parâmetro espectral em função da fluência da irradiação. Essa banda ocorre devido à absorção de radiação pelos orbitais moleculares formados na ligação Fe2+-O2-, os quais apresentam níveis de energia que correspondem à da radiação incidente na faixa de comprimentos de onda entre $0,7 \mu \mathrm{m}$ e $1,5 \mu \mathrm{m}$. Conforme a fluência da irradiação vai aumentando, cada vez mais oxigênio é ejetado da superfície devido ao seu sputtering preferencial e mais nanopartículas de ferro são produzidas. Conclui-se que o número de ligações $\mathrm{Fe}^{2+}-\mathrm{O}^{2-}$ diminui progressivamente. A consequência é a redução da profundidade dessa banda, conforme os resultados mostram (Figura 4.16, 4.21 (a) e 4.24 (b)). Em concordância, Kaluna et. al. (2017) mostram que a formação de nanopartícula de ferro neutro influencia na redução observada para a profundidade de banda BI. Além disso, Loeffler et. al. (2009) evidenciam, via análise XPS (X-ray photoelectron spectroscopy, do inglês), que um dos resultados da irradiação de amostras de olivina pura por feixe de hélio de $4 \mathrm{keV}$ é a diminuição do $\mathrm{Fe}^{2+} \mathrm{e} o$ simultâneo aumento de concentração de ferro metálico.

A influência do conteúdo de ferro de cada amostra nos resultados observados é vista em dois gráficos: i) variação total sofrida pela refletância no Visível $\left(\Delta \mathrm{R}_{\mathrm{vis}}=\right.$ Refletância do espectro virgem - Refletância do espectro após irradiação) e ii) variação total da profundidade de banda em $1 \mu \mathrm{m}(\Delta \mathrm{H}=$ profundidade de banda BI virgem - profundidade de banda BI após a irradiação) em função do conteúdo de Ferro. A Figura 5.7 mostra, nos respectivos gráficos, como estes valores foram obtidos para o meteorito Putinga. 

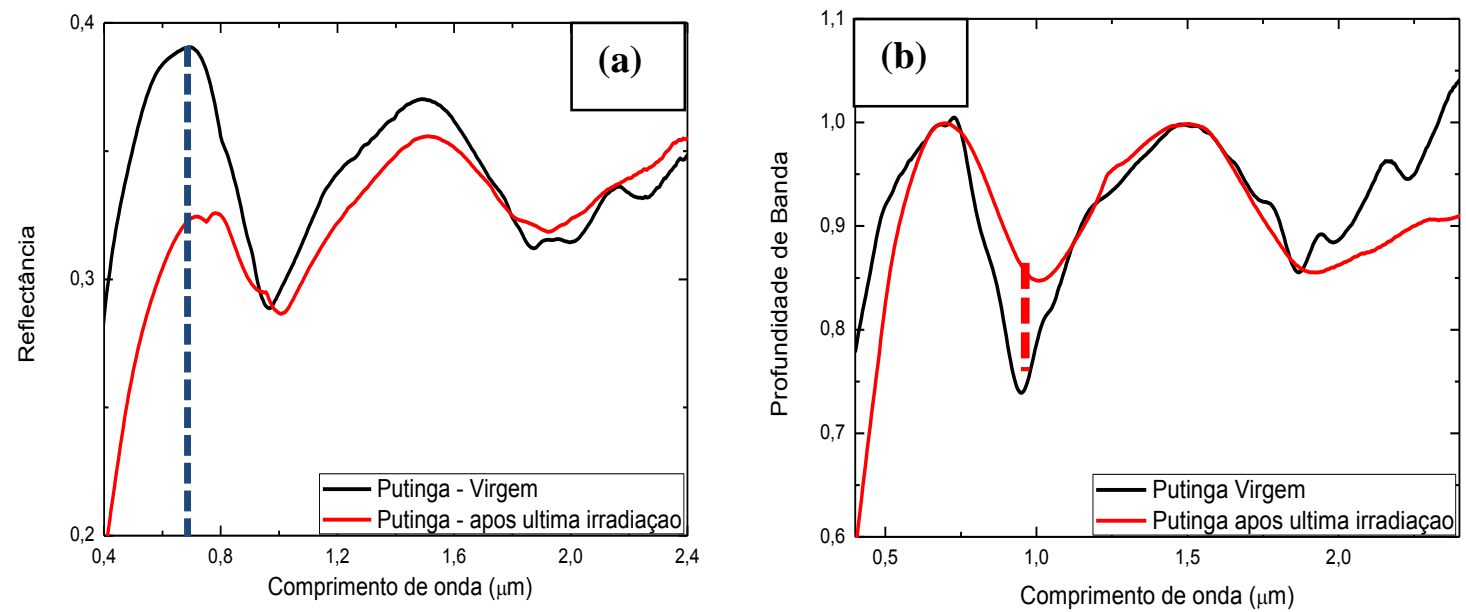

Figura 5.7 - (a) As refletâncias nas faixas do visível e infravermelho nos espectros do meteorito Putinga, virgem e após a última fluência de irradiação. A linha tracejada vertical mostra o comprimento de onda de 0,7 $\mu \mathrm{m}$ para o qual o valor de refletância foi escolhido; (b) As profundidades de banda BI nos espectros do meteorito Putinga, virgem e após o término da irradiação. Foi feita remoção do contínuo. A linha tracejada vertical mostra a diferença de profundidade de banda.

A Figura 5.8 mostra os dois parâmetros citados acima como função da abundância de ferro de cada amostra. O que se observa é que ambos são afetados quando varia a abundância de ferro contida na amostra. No caso da refletância, a explicação mais simples é: como a formação de $\mathrm{Fe} 0$ é tida como responsável por sua redução, então, se a amostra possui uma maior abundância inicial de ferro haverá mais nanopartículas de ferro neutro após a irradiação. Isto potencializa os efeitos de escurecimento. Já no caso da profundidade de banda à 1 micron, a presença de uma abundância maior de ferro adjacente (ou seja, ferro que não participa de uma ligação com oxigênio) pode ser visto como uma contaminação. Seria o equivalente a inserir impurezas na estrutura da amostra, o pode levar a uma reconfiguração de seus orbitais moleculares, afetando a banda tanto em profundidade quanto em largura e posição.

Outro fator a considerar é que, como discutido dos resultados dos espectros Raman, a amostra sofreu um grande grau de amorfização devido ao impacto dos íons $\mathrm{H}^{+}$. Esse processo de reestruturação colabora com as variações observadas podendo ser, na verdade, o fator dominante. O gráfico da variação das seções de 
choque de deslocamento (Fig. 5.4 (b)), que é um indicativo quantitativo da amorfização, como função da abundância de ferro apresenta comportamento semelhante ao observado na Fig. 5.8, fornecendo a mesma explicação física para ambos os fenômenos observados.

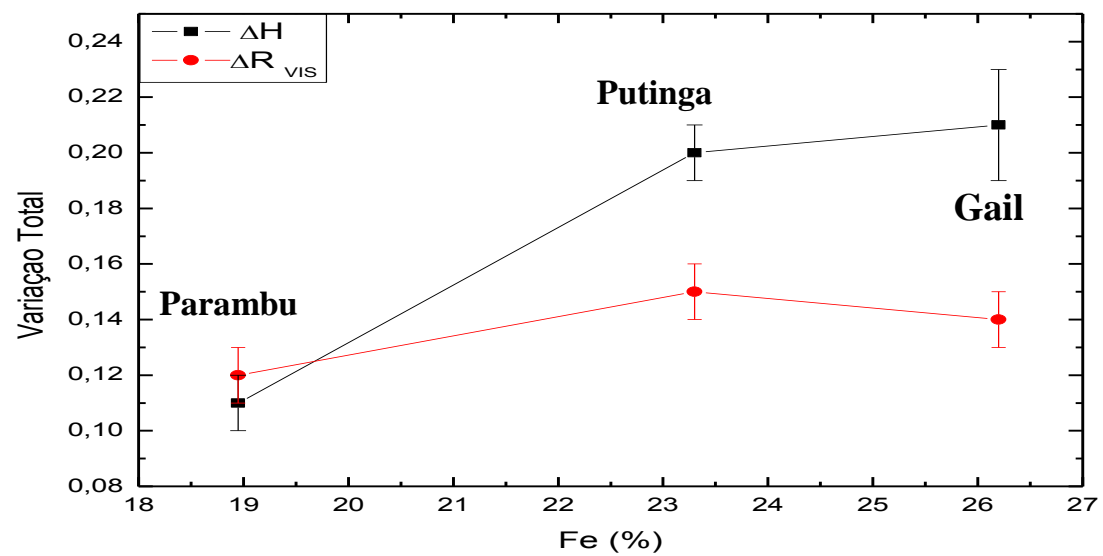

Figura 5.8 - Relação entre a variação total sofrida i) pela profundidade de banda à 1 micron e ii) pela refletância no visível como função da abundância de ferro em cada amostra de meteorito.

\section{2 .2}

\section{Inclinação da banda BI}

O parâmetro mais relevante para o estudo e entendimento dos efeitos produzidos pelo SpWe é a inclinação da banda BI dos espectros UV-VIS-NIR de meteoritos e asteroides. Conforme mostrado na revisão de literatura (capítulo 2) e nos resultados desse trabalho (Figuras 4.21, 4.24 e 4.27), um dos principais produtos da exposição ao $\mathrm{SpWe}$ é o processo de avermelhamento do espectro. Existem duas explicações aceitas para este fenômeno. Uma delas é, novamente, a formação das já bem estabelecidas nanopartículas de ferro neutro, que ao se formarem na superfície da amostra causam o resultado observado (Hapke, 2001), (Strazulla et. al, 2005), (Brunetto et. al, 2013).

A segunda explicação foi proposta por Brunetto e Strazzulla (2005) em um experimento de irradiação de várias amostras de minerais por feixes de $\mathrm{H}^{+} \mathrm{e} \mathrm{Ar}^{+}$. Nesse trabalho, os autores mostram que existe uma forte relação entre o número de deslocamentos nucleares causados pela colisão elástica dos íons utilizados com os núcleos dos constituintes dos átomos da amostra e o processo de 
avermelhamento do espectro. A conclusão é que o deslocamento nuclear é um dos mecanismos físicos que causam avermelhamento da superfície de asteroides. Porém, eles ressaltam que esses efeitos são mais importantes para íons mais pesados ( $\mathrm{Ar}^{+}$, no caso descrito por eles), uma vez que o avermelhamento depende dos poderes de frenamento eletrônico $\left(S_{e}\right)$ e nuclear $\left(S_{n}\right)$; de fato, o $S_{n}$ corresponde a cerca de $50 \%$ da energia transferida). Para os íons $\mathrm{H}^{+}$, a previsão do SRIM é que 99,6\% da transferência de energia ocorram via colisões inelásticas que causam ionização e excitação eletrônica no alvo. Embora a colisão com elétrons não gere diretamente um deslocamento nuclear, ionizações em átomos vizinhos criam forças repulsivas entre estes. Para um poder de frenamento eletrônico suficientemente altos, a amorfização acontece devido às explosões coulombianas que têm lugar no interior do traço. Além disso, a relaxação do sistema eletrônico cria fotos e fônons que criam um pulso térmico (termal spike) capaz de operar transições de fase cristalinas (Iza, P. 2006)

Tabela 5.4 - Comparação entre características dos feixes iônicos utilizados nos experimentos deste trabalho e da literatura. Para cada projétil iônico atravessando a olivina é mostrado: a energia, o poder de frenamento nuclear, o poder de frenamento eletrônico e a penetração. Simulações feitas com o SRIM.

\begin{tabular}{|l|l|c|c|c|c|}
\hline Amostra & Feixe & Energia (keV) & Sn $(\mathbf{k e V} / \boldsymbol{\mu m})$ & Se (keV/ $\boldsymbol{\mu m})$ & Penetração $(\boldsymbol{\mu m})$ \\
\hline Gail & $\mathbf{H}^{+}$ & 1000 & 0,046 & 61,1 & 9,52 \\
\cline { 2 - 6 } & $\mathbf{N}^{+}$ & 2000 & 7,970 & 1308,0 & 1,89 \\
\hline Olivina* & $\mathbf{H}^{+}$ & 200 & 0,121 & 100,0 & 1,80 \\
\cline { 2 - 6 } & $\mathbf{A r}^{2+}$ & 400 & 282,0 & 557,0 & 0,28 \\
\hline
\end{tabular}

* (Brunetto e Strazzulla (2005)

Com o objetivo de verificar o que afirmam Brunetto e Strazzulla (2005), o meteorito Gail foi irradiado por feixe de íons $\mathrm{H}^{+}$com energia de $1000 \mathrm{keV}$ e por $\mathrm{N}^{+}$com energia de $2000 \mathrm{keV}$. Os efeitos de cada feixe são comparados no capítulo 4 (resultados) onde se observa que o feixe de nitrogênio é muito mais eficiente que o de próton no processo de avermelhamento do espectro, sendo cerca de três vezes mais efetivo (Fig.4.30). Na irradiação de uma mistura de olivina e 
piroxênio, os feixes de prótons apresentam o poder de frenamento nuclear $\left(S_{n}\right)$ de $0,046 \mathrm{keV} / \mu \mathrm{m}$ e o eletrônico $\left(\mathrm{S}_{\mathrm{e}}\right)$ de $61,1 \mathrm{keV} / \mu \mathrm{m}$ (tabela 5.4). Dado que $\mathrm{S}_{\mathrm{e}}$ é 3 ordens de grandeza maior do que $S_{n}$, a transferência de energia ocorre, por vasta maioria, através de colisões projétil-elétron (ionização e excitação eletrônica dos átomos da amostra). Já no caso dos íons $\mathrm{N}^{+}, \mathrm{S}_{\mathrm{n}}$ é $11 \mathrm{keV} / \mu \mathrm{m}$ enquanto $\mathrm{S}_{\mathrm{e}}$ é 1308 $\mathrm{keV} / \mu \mathrm{m}$. Comparando os valores de poder de frenamento nuclear e eletrônico para os dois feixes, observa-se que:

$$
\frac{\left(\mathrm{S}_{\mathrm{n}}\right)_{\mathrm{N}}}{\left(\mathrm{S}_{\mathrm{n}}\right)_{\mathrm{H}}} \sim 250 \text { e } \frac{\left(\mathrm{S}_{\mathrm{e}}\right)_{\mathrm{N}}}{\left(\mathrm{S}_{\mathrm{e}}\right)_{\mathrm{H}}} \sim 21,5
$$

Conclui-se que ambos os processos de transferência de energia favorecem uma maior taxa de avermelhamento pelo feixe de $\mathrm{N}^{+}$do que pelo feixe de próton.

Brunetto e Strazzulla (2005) associaram o efeito de avermelhamento como o número de deslocamentos dos átomos da amostra. Para isto, utilizaram o TRIM para calcular o número médio de deslocamentos atômicos causados por cada íon. $\mathrm{O}$ valor de deslocamentos (em deslocamentos/íon) foi multiplicado pelos valores de fluência e assim se obteve o número de deslocamentos por $\mathrm{cm}^{2}$. Considerando o mesmo procedimento, um gráfico da inclinação da banda BI em função do número de deslocamentos foi feito. A Figura 5.9 apresenta o resultado. Observase que existe uma correlação entre a inclinação da banda e o número de deslocamentos para ambos os feixes utilizados, o que corrobora a proposta de Brunetto e strazzulla (2005).

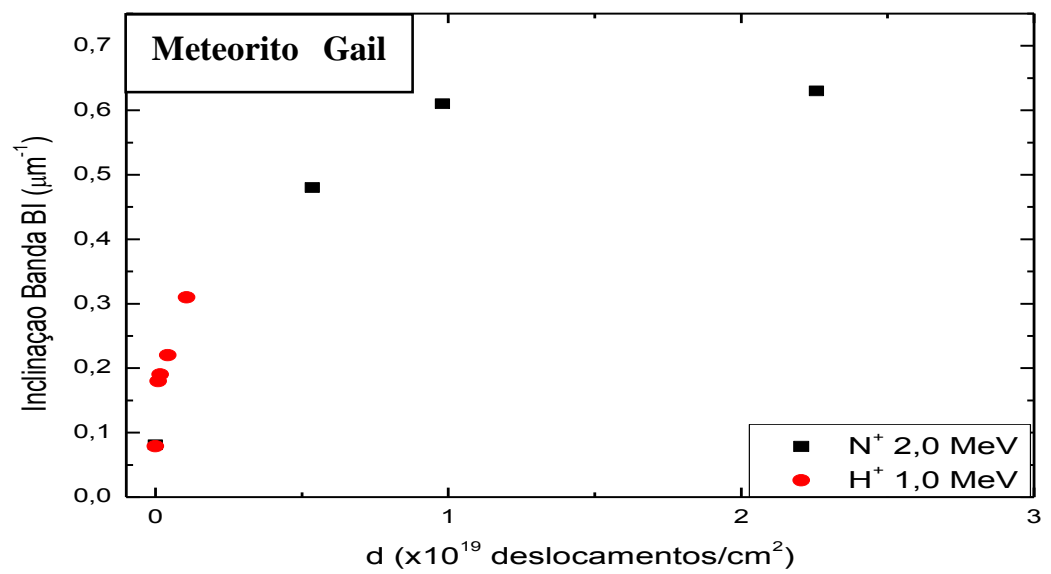


Figura 5.9 - Inclinação da banda BI como função do número de deslocamentos causados pelas colisões nucleares dos íons de $\mathrm{H}^{+}$e $\mathrm{N}^{+}$por unidade de área.

Para calcular o número de deslocamentos atômicos, o código TRIM tem o seguinte protocolo para um feixe de íons que incide sobre uma amostra: i) um dos íons do feixe, de número atômico Z1 e energia $\mathrm{E}$, colide com um átomo da amostra de número atômico Z2; ii) o átomo-alvo atingido pelo projétil inicia uma cascata de recuo no interior do material causando, no caminho, colisões de deslocamento (colisões que retiram o átomo de sua posição inicial), produzindo vacâncias (um buraco é deixado para trás quanto o átomo alvo se desloca para longe de seu local de origem) e colisões de substituição (quando o átomo que atinge outro e toma seu lugar na rede). O TRIM considera como "deslocamento" a soma entre o total de vacâncias produzidas na cascata e o número de colisões de substituição (Ziegler et. al. 1985).

Após a colisão, o íon incidente transferiu parte de sua energia cinética para o átomo alvo: ele tem então energia E1 enquanto o átomo alvo tem E2. Dada configuração estrutural da amostra, o átomo alvo tem previamente especificado certas configurações de energias, que inclui: i) a energia de deslocamento, Ed, que é a energia mínima para que um o átomo alvo possa superar as forças de rede da estrutura das amostras e mover-se uma distância maior que o espaçamento atômico (ou seja, deslocando-se para longe de seu local original); ii) energia de ligação, Eb, do átomo com o restante dos constituintes da rede (esta é a energia que os átomos alvo devem superar para deixar a superfície da amostra, ou seja, para que ocorra sputtering); iii) a energia final (Ef) do átomo em movimento, abaixo da qual o átomo é considerado estacionário. Um deslocamento ocorre se E2 > Ed, ou seja, se o átomo alvo recebe energia suficiente para conseguir sair do local onde está. Para que ocorra uma vacância, é necessário que E1 > Ed e E2 > Ed. Com isso, ambos têm energia suficiente para sair do local e se tornam átomos geradores de cascata. Pode ocorrer, também, que E1 e E2 sejam menores que Ed. Neste caso, os dois átomos envolvidos na colisão não possuem energia suficiente para causar uma vacância. O projétil é considerado um átomo implantado e, junto com o átomo atingido, vibram; a energia E1 + E2 é dissipada na rede como fônons (Ziegler et. al. 1985). 
De fato, os deslocamentos atômicos são uma explicação plausível para o efeito de avermelhamento. Brunetto e Strazzulla (2005) atribuem tal efeito às interações nucleares, pois estas transferem energia através de colisões elásticas que certamente causam amorfização da estrutura da amostra. Apesar de esta descrição ser plausível, a explicação baseada no efeito da formação de vacâncias e deslocamentos atômicos para o avermelhamento do espectro de reflexão ainda é controversa. Loeffler et. al. (2009) afirmam que a real causa do efeito de avermelhamento do espectro é a formação de nanopartículas de ferro neutro (observados via XPS). Os deslocamentos atômicos e vacâncias tem, segundo Loeffler et. al (2009), o papel de ajudar na formação destas nanopartículas pois potencializam os efeitos de sputtering de ferro que, por sua vez, causa o avermelhamento do espectro. O sputtering é proporcional ao quadrado do poder de frenamento eletrônico (Barros et. al. 2011). A irradiação com N+ seria então muito mais eficiente para a formação das nanopartículas, pois a razão entre as taxas de sputtering para os dois feixes utilizados é

$$
\frac{Y_{N}}{Y_{H}} \sim\left(\frac{\left(\mathrm{S}_{\mathrm{e}}\right)_{\mathrm{N}}}{\left(\mathrm{S}_{\mathrm{e}}\right)_{\mathrm{H}}}\right)^{2} \sim 4600
$$

Consequentemente, não se pode descartar a proposta de Loeffler et. al (2009), o que torna difícil entender a causa verdadeira.

\section{2 .3}

\section{Aquecimento no traço e decomposição térmica}

A passagem de um íon pelo interior de um sólido pode causar diversos efeitos, como dissociação química, sputtering, amorfização, etc. Nesta seção serão considerados os efeitos térmicos ${ }^{18}$ causados pela interação íon-sólido e as consequências desta interação serão discutidas. $\mathrm{O}$ apêndice $\mathrm{C}$ apresenta um modelo de aquecimento causado na formação do traço. Para isto utilizou-se a

\footnotetext{
18 - os demais efeitos físicos causados pela interação íon-sólido não serão considerados para esta discussão.
} 
equação de difusão térmica (eq. C.1) com solução para interação entre um íon e uma monocamada do sólido. Esta solução (eq. C.2) representa um pulso térmico que se propaga radialmente no traço. A partir disso, foi possível estimar o valor máximo de temperatura que a passagem do íon pode causar. $\mathrm{O}$ valor obtido para um próton de energia de 1,0 MeV é, aproximadamente, $7000 \mathrm{~K}$.

Para a discussão que segue, considera-se um sólido exposto a tal temperatura e posteriormente resfriado. A questão essencial é saber o que ocorre com o sólido, após este choque térmico. Para um mineral que foi aquecido: i) o que acontece com suas moléculas e estrutura cristalina? e ii) quais outros compostos químicos são formados?

O apêndice B mostra as possíveis espécies químicas podem ser formadas a partir dos componentes majoritários das amostras. Esta informação é obtida por uma simulação teórica feita para determinar a composição de equilíbrio, como função da temperatura, que poderia ser obtida a partir da decomposição térmica de determinados minerais. Os minerais escolhidos foram a faialita (Fig. B.1) e a forsterita (Fig. B.2), ambas sujeitas a variação de temperatura de $0{ }^{\circ} \mathrm{C}$ a $2500{ }^{\circ} \mathrm{C}$.

No caso da forsterita, conforme a temperatura aumenta, o $\mathrm{Mg}_{2} \mathrm{SiO}_{4}$ sofre decomposição química e a quantidade deste composto diminui até quase não restar nada a temperaturas próximas de $2500^{\circ} \mathrm{C}$. Em contrapartida, outros compostos vão sendo formados. Os mais abundantes são o óxido de magnésio e o $\mathrm{MgSiO}_{3}$. A sílica $\left(\mathrm{SiO}_{2}\right)$ também é formada em menor quantidade relativa.

Considerando a decomposição da faialita (Fig. B.1) observa-se que a $\mathrm{Fe}_{2} \mathrm{SiO}_{4}$ também sofre redução química como consequência do aumento da temperatura. Neste caso a diversidade de compostos formados é maior. A principio, a maior parte sofre redução para $\mathrm{FeO}$ e sílica para temperaturas entre $500{ }^{\circ} \mathrm{C}$ e $1000{ }^{\circ} \mathrm{C}$. A partir de $1000{ }^{\circ} \mathrm{C}$, o $\mathrm{FeO}$ sofre redução e inicia-se a formação, em quantidades relativas semelhantes, de maghemita ${ }^{19}\left(\mathrm{Fe}_{2} \mathrm{O}_{3}\right)$ e ferro metálico $\left(\mathrm{Fe}^{0}\right)$. Para temperaturas maiores que $1500{ }^{\circ} \mathrm{C}$ o ferro metálico inicia o

\footnotetext{
19 - A maghemita é um oxido de ferro III semelhante à hematita, diferenciando-se apenas por sua
} estrutura mineral. 
processo de redução química, até não restar nada dele para temperaturas acima de $2000{ }^{\circ} \mathrm{C}$. A maghemita, por sua vez, continua a ser formada e juntamente com ela, há silício metálico, uma liga formada por ferro e silício, silício gasoso e oxido de silício gasoso. Este último contribui para a redução da quantidade de oxigênio contido na amostra. Como visto o ferro metálico, precursor da nanopartículas de ferro neutro, é formado a partir da redução termodinâmica de faialita. No entanto, para regimes de temperatura muito severos, ele também sofre redução ${ }^{20}$ dando origem a outros espécimes químicos.

No fim das contas, para altas temperaturas, a failita se converte em maghemita. Porém, após a interrupção do processo de irradiação a estrutura da amostra tende a dissipar a energia térmica e voltar a resfriar. Assim, inicia-se o processo inverso. Maghemita a $2500^{\circ} \mathrm{C}$ sendo resfriada. A Fig. B.3 mostra que, neste caso, a maghemita se reduziria completamente à hematita, sendo este, ao fim do processo, o composto químico majoritário. Como mostrado a formula da hematita é $\mathrm{Fe}_{2} \mathrm{O}_{3}$, sendo que o $\mathrm{Fe}$ pode estar na forma de ferro férrico $\left(\mathrm{Fe}^{3+}\right)$ ou ferroso $\left(\mathrm{Fe}^{2+}\right)$. Esta informação é muito relevante e será resgatada durante a discussão sobre estruturas de banda da olivina.

\section{2 .4}

\section{As energias de gap}

Independente de qual modelo escolhido para explicar as variações espectrais observadas é o correto, as modificações causadas em um espectro de reflexão são consequência de alterações nas propriedades óticas do material. Com base nisso, procurou-se buscar uma explicação, fundamental do ponto de vista físico que possa ser o elo que falta para conectar ambas as explicações já estabelecidas na literatura para os efeitos de modificação do espectro óptico observados. Propomos, então que tanto as nanopartículas, (ou a formação de óxido de ferro) quanto as modificações cristalográficas resultem em um efeito comum, a variação da energia de gap do material. Como o formalismo do gap ótico descreve de

\footnotetext{
20 - O não favorecimento à formação de nano partículas de ferro neutro é visto para o caso de efeitos térmicos. Isto não implica que estas nanopartículas não podem ser formadas por outros processos causados pelo feixe.
} 
maneira bem estruturada a absorção de radiação pela matéria, ele pode ser invocado para tratar o fenômeno em questão; isto é, propõe-se que ele explique o progressivo avermelhamento e escurecimento do espectro óptico de um mineral irradiado, em termos das mudanças de suas energias de gap.

\subsubsection{1}

\section{Determinação das energias de gap}

Uma maneira de determinar o valor da energia de gap de um dado material, em especial um semicondutor é através da técnica Tauc plot (Tauc, 1966). Ela permite a partir do espectro de absorção ${ }^{21}$ do material, determinar o coeficiente de absorção, $\alpha$, parâmetro que caracteriza a fração da intensidade de luz que um material irá absorver (ou espalhar). A equação de Tauc relaciona a energia de gap com o coeficiente $\alpha$ :

$$
\alpha h v=C\left(h v-E_{g}\right)^{n}
$$

onde $\mathrm{h} v$ é a energia do fóton incidente, Eg a energia de gap e $\mathrm{C}$ uma constante de proporcionalidade. $\mathrm{O}$ expoente, $\mathrm{n}$, pode ter o valor de $1 / 2$ ou 2 para transições diretas e indiretas, respectivamente. Observa-se, pela equação 5.4, que o coeficiente de absorbância de um material está diretamente relacionado com a energia do fóton incidente que sobrou depois que um elétron efetuou uma transição entre as bandas de valência e condução. Assim, quanto maior a energia de gap, menor a absorção. Modificar a energia do gap, Eg, implica em modificar a capacidade de absorver radiação e, consequentemente, alterar as propriedades ópticas e elétricas do material (Nudelman e Mitra, 1969). Como mostra o apêndice $\mathrm{A}$, isto irá depender da função dielétrica do material (eq. A.11) que depende diretamente da densidade de estados das bandas de valência e condução.

Por definição, o coeficiente de absorção pode ser escrito da seguinte forma:

\footnotetext{
${ }^{21}$ - O apêndice A apresenta, de forma sucinta, uma explicação para os espectros de absorção bem como a teoria de Tauc.
} 


$$
\alpha=\frac{4 \pi k}{\lambda}
$$

onde k é o chamado coeficiente de extinção (relacionado com a parte imaginária da constante dielétrica, apêndice A) e $\lambda$ é o comprimento de onda da radiação que interage com o material de interesse.

A refletância, $\mathrm{R}$, de um dado material depende do seu índice de refração, n, e do seu coeficiente de extinção, $\mathrm{k}$, conforme a fórmula abaixo:

$$
\mathbf{R}=\frac{(\mathbf{n}-\mathbf{1})^{2}+\mathbf{k}^{2}}{(\mathbf{n}+\mathbf{1})^{2}+\mathbf{k}^{2}}
$$

Os espectros de reflexão medidos pelo espectrômetro UV-VIS-NIR permitem determinar o valor da refletância, $R$, para cada comprimento de onda da radiação. Pela equação 5.6, qualquer alteração que o material sofra em seu índice de refração ou no coeficiente de extinção irá resultar na variação do valor da refletância. Ou seja, variações observadas no espectro de refletância estão relacionadas com as alterações sofridas pelo coeficiente de absorção, o que segundo a equação 5.4, indica que a energia de gap do material também foi modificada.

Como supracitado, a técnica Tauc Plot $^{22}$ permite determinar a energia de gap a partir de espectros de absorção, que neste trabalho, são de refletância. Nesta metodologia, é preciso primeiro fazer a conversão para um espectro de absorção equivalente. Para isso, é empregada a teoria desenvolvida por Kubelka-Munk, que modela o material como uma camada opaca e espessa,

$$
R_{\infty}=1+\frac{k}{s}-\sqrt{\frac{k}{s}\left(2+\frac{k}{s}\right)}
$$

onde $R_{\infty}$ é a refletância difusa, $k$ é o coeficiente de extinção efetivo e s o coeficiente de espalhamento efetivo. Para a faixa de comprimentos de onda de interesse, s pode ser considerado constante, um fator de escala. Resolvendo a equação 5.7 em k/s, a função de Kukelka-Munk, $f\left(R_{\infty}\right)$, é obtida:

${ }^{22}$ Apêndice A, seção A.3 


$$
\mathbf{f}\left(\mathbf{R}_{\infty}\right)=\frac{\mathbf{k}}{\mathbf{s}}=\frac{\left(1-\mathbf{R}_{\infty}\right)^{2}}{4 \mathbf{R}_{\infty}}
$$

Ela permite calcular o valor de k para cada comprimento de onda a partir de valores de refletância retirados dos espectros. Em seguida, e graças à equação 5.5, pode-se determinar o valor do coeficiente de absorção para cada comprimento de onda. Dito de outra forma, a função de Kubelka-Munk permite obter o coeficiente de absorção, possibilitando que o espectro de absorção possa ser calculado a partir do de reflexão.

A conversão mostrada na figura 5.11 foi feita com o auxílio do programa de análise de espectros Spectragryph ${ }^{23}$ baseado na teoria de Kubelka-Munk (equação 5.8). É importante registrar que o tratamento exposto acima é aproximado. Comparando o espectro da Fig. 5.11 (a) com o da 5.11 (c), observa-se a boa concordância entre os dois em termos de forma (no intervalo entre 0,4 e $2 \mu \mathrm{m}$ ), diferindo apenas em intensidade. Tal concordância valida a aproximação feita. Apesar de não determinar os valores exatos das energias de gap das amostras é possível obter informações relevantes sobre a evolução e variação dessas energias como consequência da exposição a irradiação.
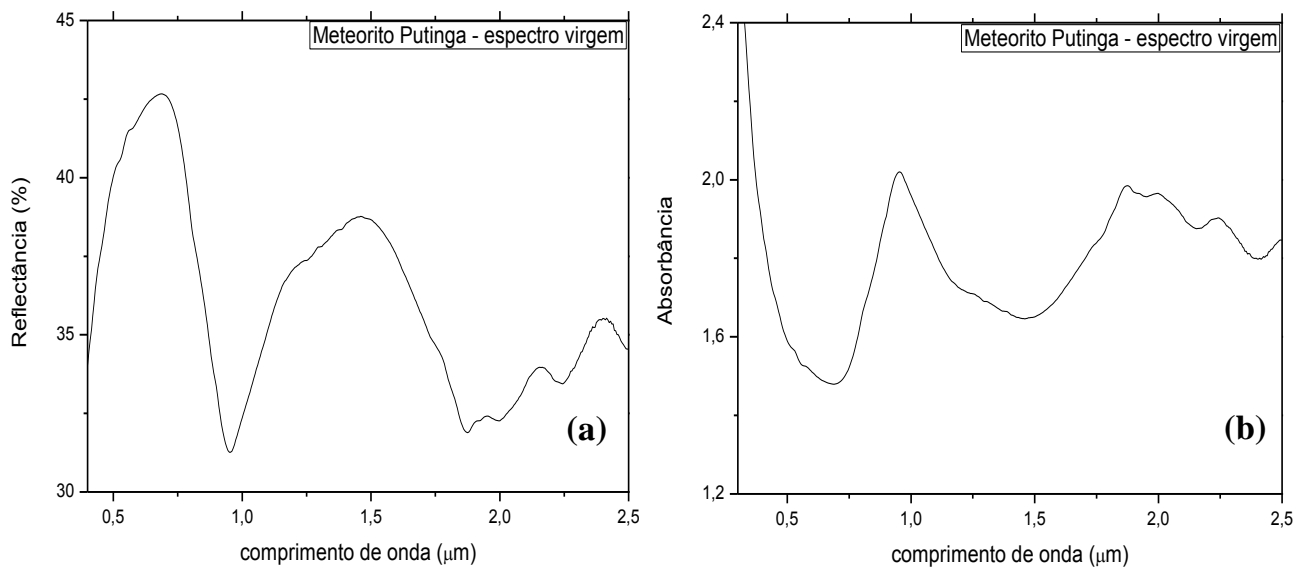

\footnotetext{
23 - É um programa de análise de espectros disponível na internet e aberto para usuários
} individuais. Pode ser encontrado em: https://www.effemm2.de/spectragryph/. 


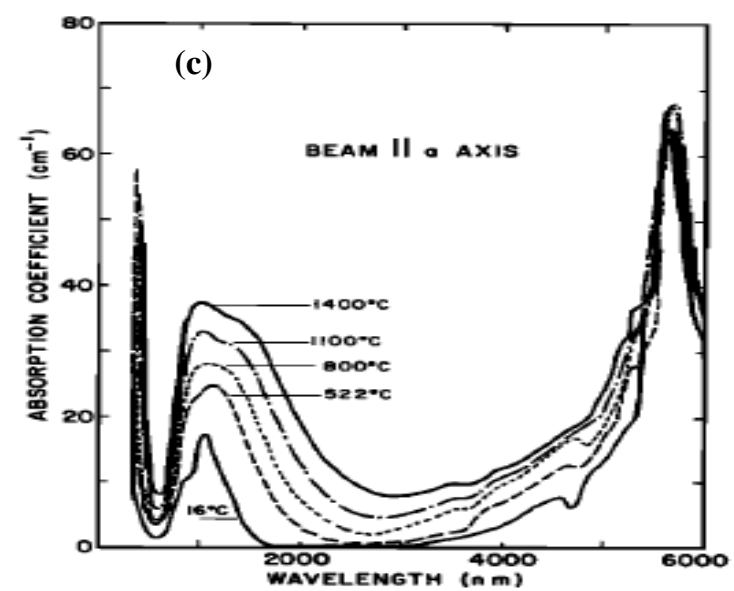

Figura 5.10 - Transformação de um espectro de refletância (a) em um espectro de absorbância (b). Abaixo (c) é mostrado o espectro de absorbância de olivina obtido experimentalmente, Shankland et. at. (1979).

Na Fig. 5.10 (b) pode-se notar uma banda de absorção ${ }^{24}$ entre $0,7 \mu \mathrm{m}$ e 1,2 $\mu \mathrm{m}$, correspondente a uma absorção fundamental (conforme explicado no apêndice A) e, para valores de comprimento de onda menores que $0,5 \mu \mathrm{m}$, uma abrupta absorção de radiação. Este fenômeno é chamado de cauda do espectro ${ }^{25} \mathrm{e}$ corresponde a uma transição pela excitação de um elétron para um nível aceitador que captura o elétron da banda de valência gerando um par elétron buraco. A incidência da radiação, de energia hv, excita o elétron que faz a transição para a banda de condução. Isto causa a abrupta absorção observada (Tauc J.,1966).

A transformação do espectro de reflexão para absorção foi feita para todos os pontos de irradiação das três amostras de meteorito. Comparando o espectro de absorção do meteorito Putinga virgem com o obtido após a irradiação de mais alta fluência (Fig. 5.11), observa-se que a banda de absorção fundamental entre 0,7 $\mu \mathrm{m}$ e 1,2 $\mu \mathrm{m}$ quase não sofre alteração. De fato, a absorbância integrada da banda nos dois casos é quase idêntica, (valendo 0,0338, para o espectro virgem e 0,0342 para o irradiado). Já a cauda da banda, para comprimentos de onda abaixo de 0,5 $\mu \mathrm{m}$ sofre expressivas alterações. O valor do coeficiente de absorção aumenta

\footnotetext{
${ }^{24}$ - Banda gerada pela presença de $\mathrm{Fe}^{2+}$ (seção 5.2.1).

25 - O fenômeno da cauda do espectro não é observado para amostras com alto grau de organização interna. Ela é característica de materiais amorfos ou que possuem impurezas e defeitos.
} 
consideravelmente. Isto significa que a amostra absorve mais radiação nesta faixa de comprimentos de onda após ser modificada pela irradiação. Este resultado é interessante por indicar que as modificações dos parâmetros espectrais (seção 4.2) são resultado de alterações na cauda de absorção e não da banda de absorção fundamental entre $0,7 \mu \mathrm{m}$ e 1,2 $\mu \mathrm{m}$. Ou seja, o feixe está causando modificações na estrutura eletrônica das amostras, mais especificamente, nos níveis de energia de impurezas aceitadoras.

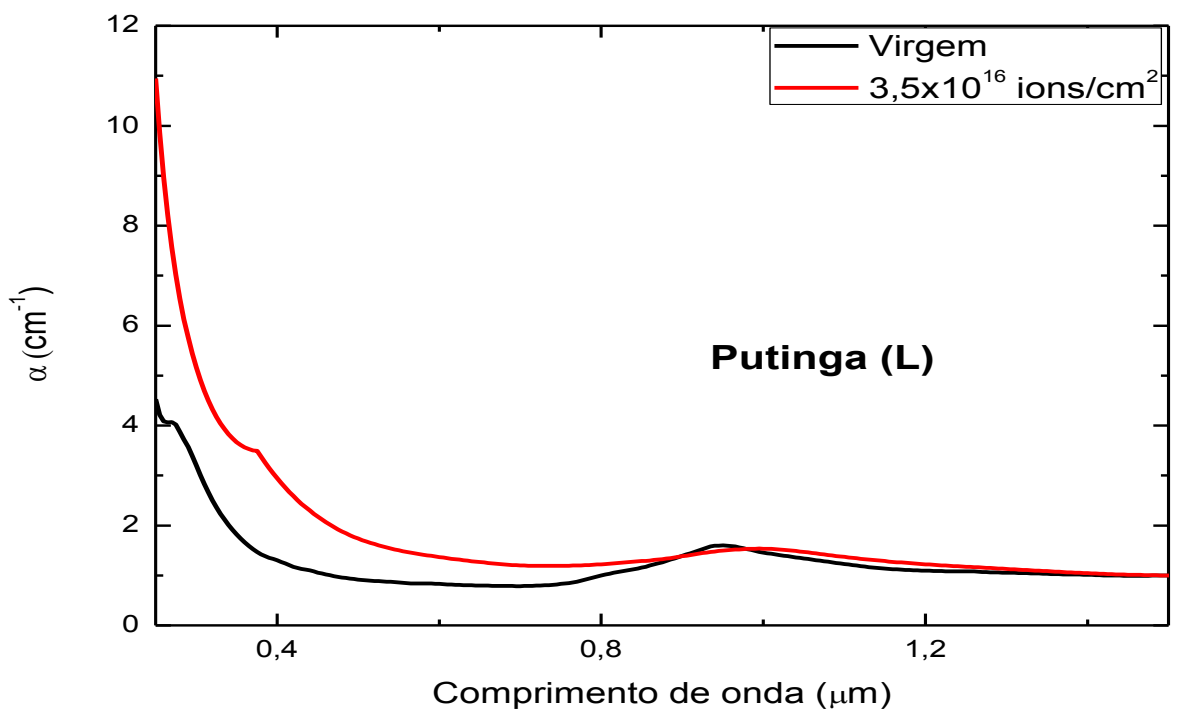

Figura 5.11 - Comparação entre os espectros de absorção do meteorito Putinga, virgem e após a última fluência de irradiação. Ambos foram normalizados a 1,5 $\mu \mathrm{m}$.

Para verificar o valor de energia de gap a que esta transição corresponde é necessário montar um gráfico de $(\alpha \text { hv })^{2}$ em função de $h v$, conforme discutido no apêndice A (seção A.3)

Para cada comprimento de onda, os valores de energia da radiação incidente são determinados através da relação de Planck, $\mathrm{E}=\mathrm{h} v$; a partir dos valores de absorbância (obtidos do gráfico mostrado na Fig. 5.10 (b)), o coeficiente de absorção alfa é calculado graças à equação 5.7. Obtém-se então os gráficos de $(\alpha h v)^{2}$ em função de $h v$, como o mostrado nas Fig. 5.13. Para energias menores que 3,5 eV não ocorre absorção. Porém, para energias maiores que $4 \mathrm{eV}$ ocorre uma absorção de forma abrupta. Isto caracteriza uma borda de absorção (absorption edge, do inglês) conforme predito por Tauc (1966). Para valores superiores a 4,3 eV, o gráfico apresenta um regime linear que pode ser modelado, 
com boa aproximação, pela equação de Tauc (equação 5.4$),(y)^{2}=\mathrm{C}\left(\mathrm{E}_{\mathrm{g}}-\mathrm{hv}\right)$. Extrapolando esta reta encontra-se que $\alpha=\mathrm{y}=0 \mathrm{se} \mathrm{E}_{\mathrm{g}}=\mathrm{h} v_{\mathrm{g}}$ : este é o ponto hv em que a reta tangente a curva intercepta o eixo $h v$, conforme ilustrado pela figura 5.11. A interpretação é que se $\alpha=0$, não há absorção e toda energia do fóton é transmitida ao elétron para transpor o gap.

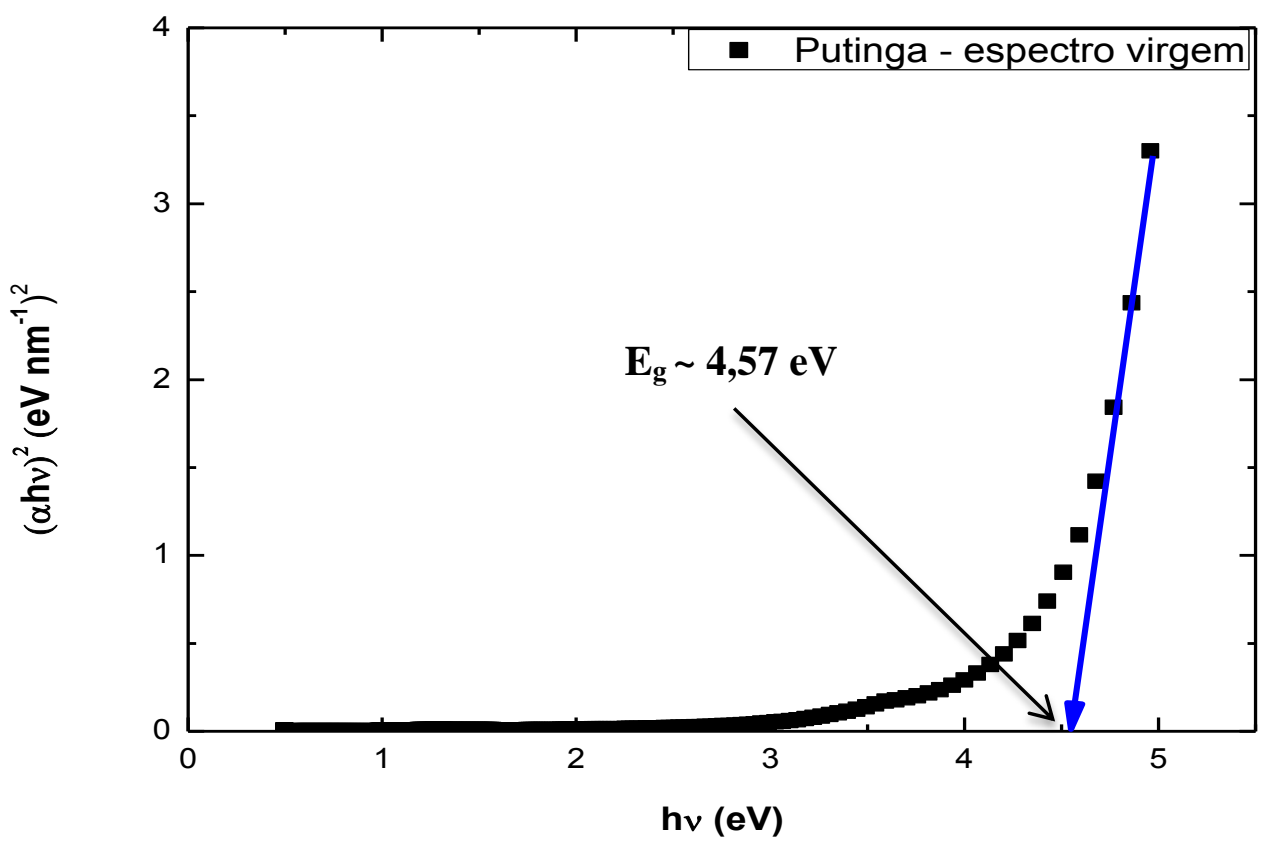

Figura 5.12 - Tauc plot obtido a partir da conversão do espetro de refletância do meteorito Putinga.

As energias de gap para transição direta foram determinadas para os meteoritos expostos a irradiação por feixes de prótons com energia de $1 \mathrm{MeV}$ (Fig. 5.13) e, para o Gail irradiado por $\mathrm{N}^{+}$de 2,0 MeV (Fig. 5.14). 

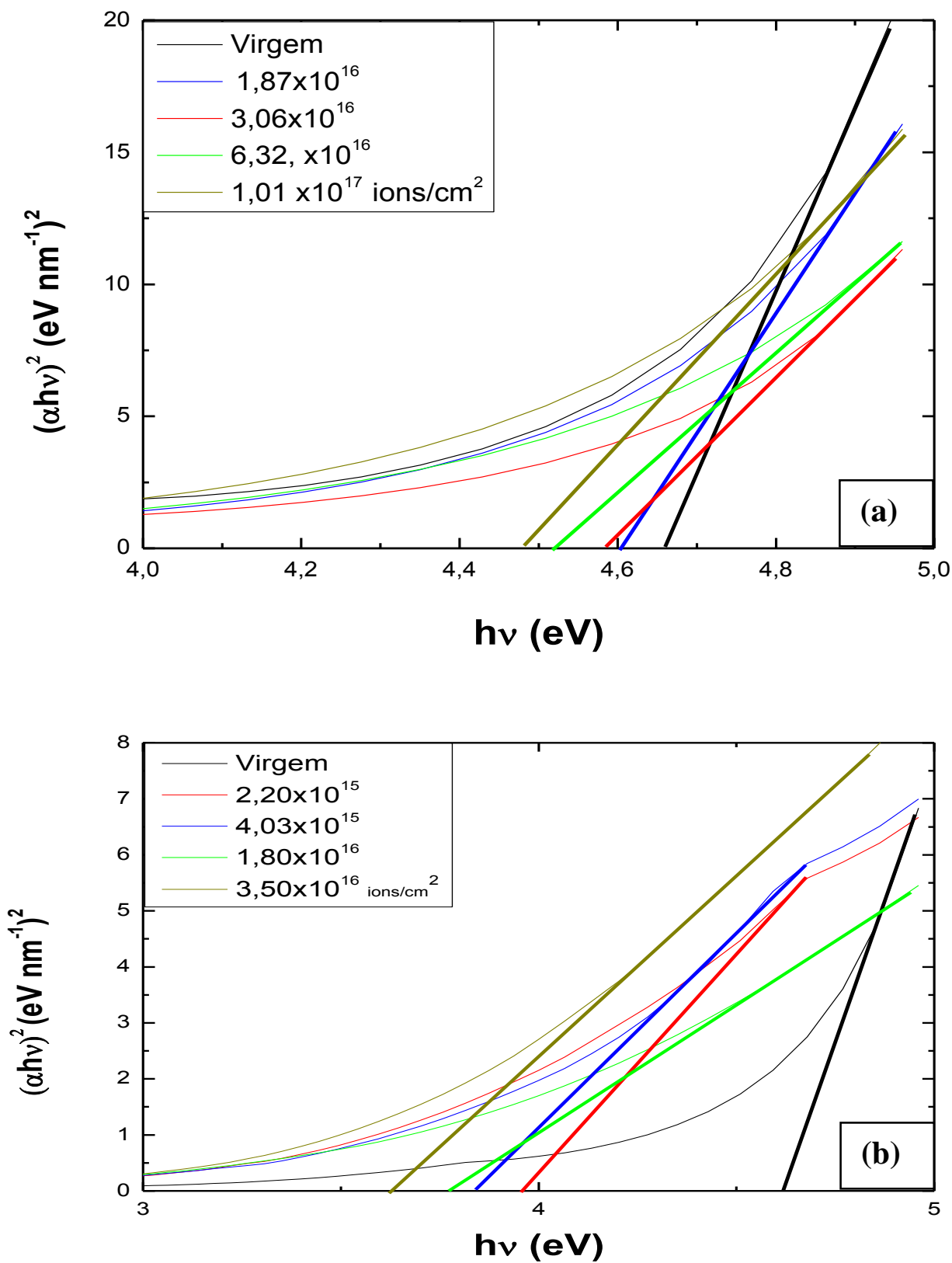

Figura 5.13 - Tauc plot utilizado para determinar as modificações nas energias de gap dos meteoritos (a) Putinga (L) e (b) Parambu (LL). 

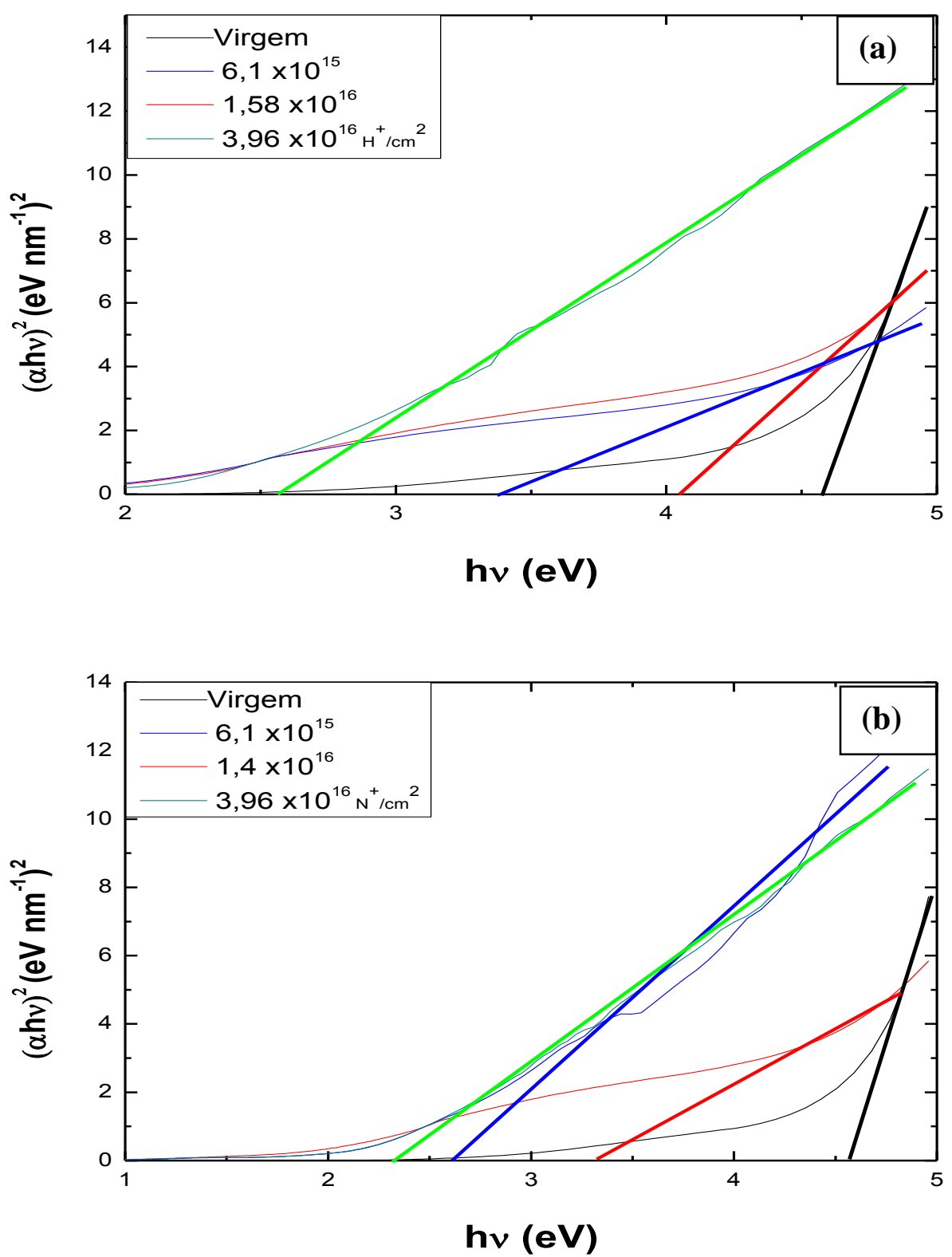

Figura 5.14 - Tauc plot utilizado para determinar as modificações nas energias de gap do meteorito Gail (a) irradiado por $\mathrm{H}^{+}$de $1,0 \mathrm{MeV}$; e (b) irradiado por $\mathrm{N}^{+}$de $2,0 \mathrm{MeV}$.

Mudanças graduais nos espectros de refletância desses meteoritos em função da fluência são evidentes. Variações no espectro significa que alguma propriedade óptica da amostra foi alterada devido à irradiação. E, como visto, as energias de gap são de extrema importância nesse caso, pois o coeficiente de absorção depende diretamente desse valor. A técnica supracitada foi empregada na análise de cada espectro obtido (virgem e após as irradiações) para cada amostra. Os valores correspondentes são apresentados da tabela 5.5. Destes 
valores, gráficos das energias de gap em função da fluência foram confeccionados. Os resultados são apresentados nas Figuras 5.15 e 5.16.

O valor da energia de gap de amostras de olivina pura é estimado, teoricamente por Cococcioni, M. et. al. (2003) e experimentalmente por Jiang e Guo (2004), determinaram 4,2 eV para a faialita, e Morin et. al (1977) mediram 6,4 eV para amostras de forsterita. A média dos valores encontrados neste trabalho para as amostras ainda virgens é $4,61 \mathrm{eV}$, que se encontra dentro da faixa de valores fornecidos pela literatura.

Tabela 5.5 - Valores das fluências usadas em cada ponto de irradiação e os respectivos valores da energia de gap obtidos do espectro.

\begin{tabular}{|c|c|c|c|c|c|c|c|}
\hline \multicolumn{2}{|c|}{ Parambu (LL) } & \multicolumn{2}{|c|}{ Putinga (L) } & \multicolumn{2}{|c|}{$\begin{array}{c}\text { Gail (H) } \\
1,0 \mathrm{MeV}-\mathbf{H}^{+}\end{array}$} & \multicolumn{2}{|c|}{$\begin{array}{c}\text { Gail (H) } \\
2,0 \mathrm{MeV}-\mathrm{N}^{+}\end{array}$} \\
\hline $\begin{array}{r}\text { Fluência } \\
(\text { ions/cm²) }\end{array}$ & $\mathbf{E}_{\mathrm{g}}(\mathbf{e V})$ & $\begin{array}{c}\text { Fluência } \\
(\text { ions/cm²) }\end{array}$ & $\begin{array}{c}\mathbf{E}_{\mathrm{g}} \\
(\mathrm{eV})\end{array}$ & $\begin{array}{r}\text { Fluência } \\
\text { (ions/cm²) }\end{array}$ & $\mathbf{E}_{\mathrm{g}}(\mathbf{e V})$ & $\begin{array}{c}\text { Fluência } \\
\left(\text { ions } / \mathbf{c m}^{2} \text { ) }\right.\end{array}$ & $\mathbf{E}_{\mathrm{g}}(\mathrm{eV})$ \\
\hline 0,0 & 4,65 & 0,0 & 4,57 & 0,0 & 4,72 & 0,0 & 4,52 \\
\hline $1,87 \times 10^{16}$ & 4,60 & $2,20 \times 10^{15}$ & 3,83 & $6,1 \times 10^{15}$ & 4,01 & $3,20 \times 10^{15}$ & 3,31 \\
\hline $3,06 \times 10^{16}$ & 4,57 & $4,03 \times 10^{15}$ & 3,67 & $1,58 \times 10^{16}$ & 3,25 & $6,10 \times 10^{15}$ & 2,61 \\
\hline $6,32 \times 10^{16}$ & 4,50 & $1,80 \times 10^{16}$ & 3,57 & $3,96 \times 10^{16}$ & 2,55 & $1,40 \times 10^{16}$ & 2,2 \\
\hline $1,01 \times 10^{17}$ & 4,45 & $3,50 \times 10^{16}$ & 3,45 & - & - & - & - \\
\hline
\end{tabular}

Nos quatro casos, o que se observa é que, como efeito da irradiação, a energia de gap das amostras diminui progressivamente.

A diminuição da energia de gap leva a um aumento do coeficiente de absorção (evidenciado na Fig. 5.11), o que explica o motivo da diminuição da refletância observado nos espectros (Figuras 4.16, 4.22 e 4.25). Sendo a refletância definida como a razão entre a radiação espalhada pela amostra e a 
radiação incidente, uma diminuição da refletância implica em um aumento de absorbância pela amostra.
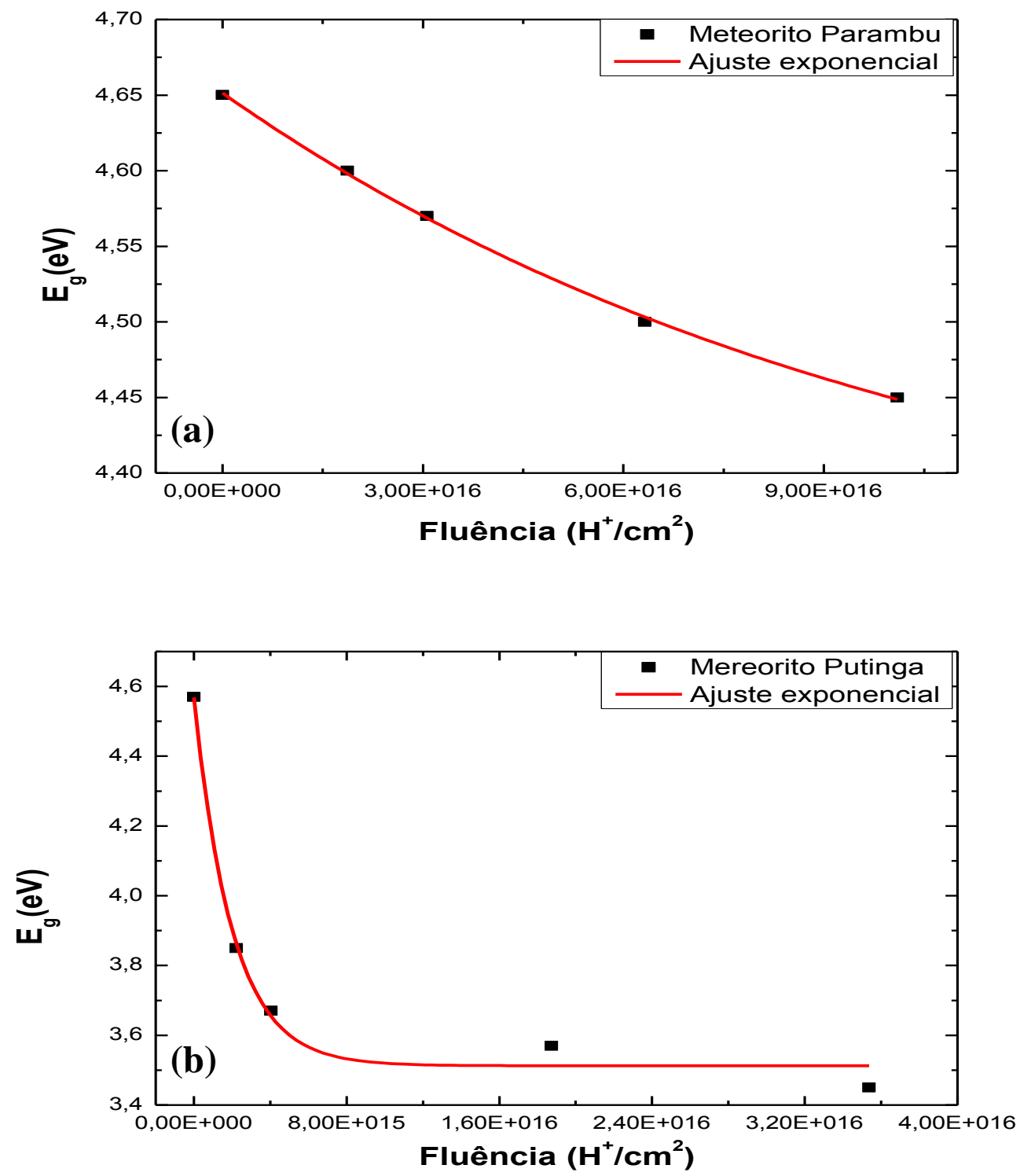

Figura 5.15 - Relação entre os valores obtidos para as energias de gap em função da fluência para os meteoritos (a) Parambu (LL); (b) Putinga (L).

Os fatores que podem levar a modificação da energia de gap de materiais semicondutores são: i) a produção de defeitos na estrutura do material; ii) amorfização; e iii) inserção de impurezas (Sapoval e Hermann, 1988). Em relação à amorfização, Zang et. al (2014) mostra que um dos efeitos da irradiação no mineral mica é a redução progressiva no valor da energia de gap do material. De acordo com os resultados obtidos por espectroscopia Raman (seção 5.1 (i) e (ii)) e 
com a discussão sobre deslocamentos atômicos (seção 5.2.2), as amostra desse trabalho sofreram um alto grau de amorfização.
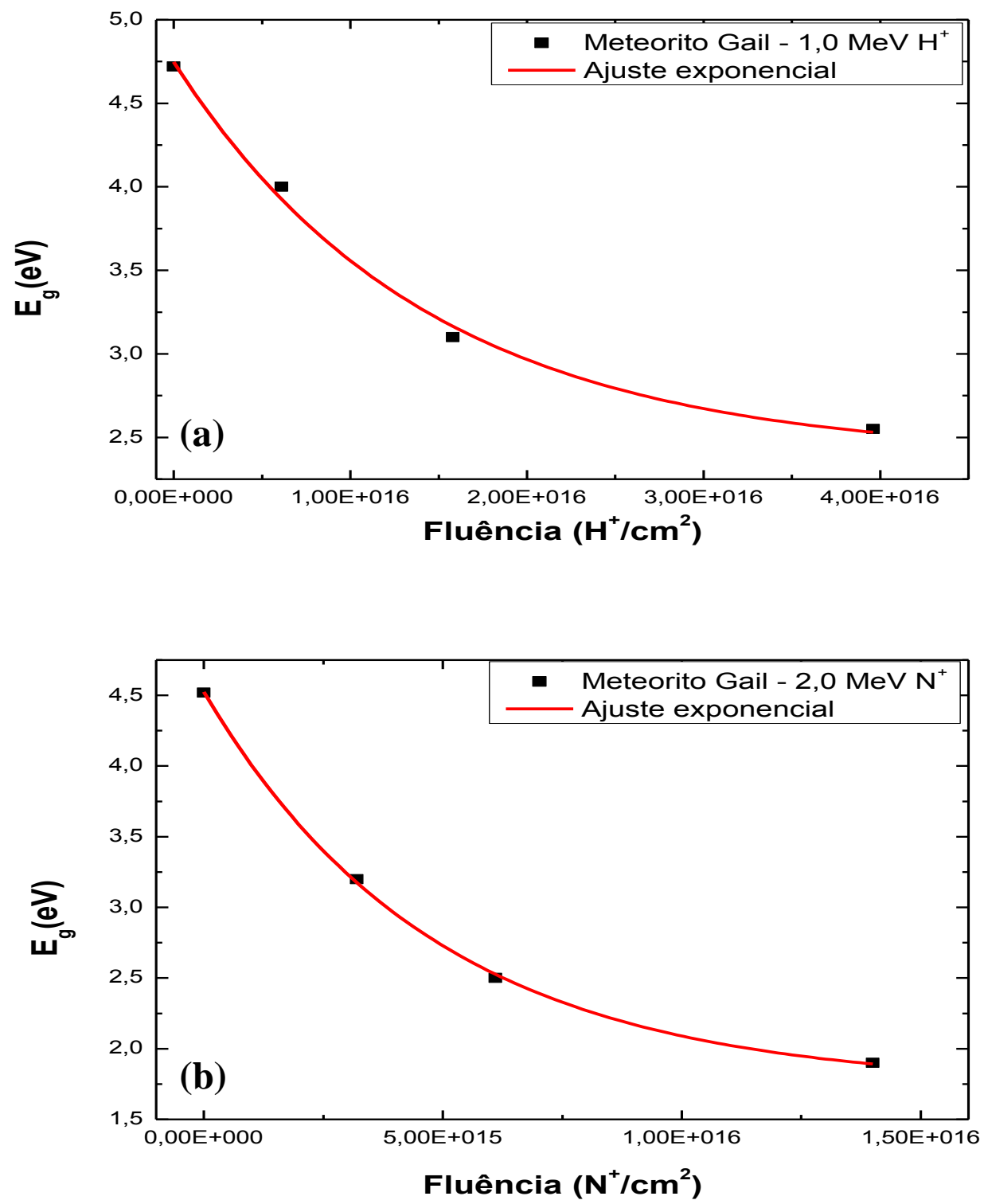

Figura 5.16 - Relação entre os valores obtidos para as energias de gap em função da fluência para o meteorito Gail (H) (a) e (b) irradiado por $\mathrm{N}^{+}$de 2,0 MeV.

Além de relatar efeitos de amorfização, Zang et. al. (2014) mostra que a irradiação cria inúmeros defeitos na estrutura da mica. A produção desses defeitos também contribui para a redução da energia de gap. Segundo Loeffler et. al. (2016), a produção de defeitos pode criar estados de absorção na energia de gap. Esses estados de absorção podem levar a absorção de radiação (dependendo de 
sua frequência). Um dos efeitos observados, na irradiação das amostras de meteoritos desta tese, foi o escurecimento do espectro. Ou seja, o feixe modificou a estrutura cristalográfica da amostra, causando defeitos, cujas consequências o aumento da absorção de radiação e seu escurecimento.

\subsubsection{2}

\section{$\mathrm{Fe}^{3+}$ como responsável pela variação dos parâmetros espectrais}

O terceiro fator que causa variações na energia de gap dos materiais semicondutores é presença de impurezas em sua estrutura. A energia de gap entre as bandas é sensível à inserção de impurezas externas, podendo aumentar ou diminuir de valor segundo a qual átomo é substituído por outro em sua composição elementar (Sapoval e Herman, 1988). Para Shanklar (1968), a mudança de propriedades físico-químicas causada pela introdução de impurezas parece ser o processo dominante em cristais naturais e por isso deve ser analisado com cuidado. O átomo de ferro é uma impureza capaz de causar alterações significativas da energia de gap. Nitsan e Shankland (1975) observaram, por exemplo, que a energia de gap diminui da forterita para a faialita. De fato, a energia de gap da forsterita é 6,4 eV (Morin et. al. 1977) enquanto que para a faialita é de 4,2 eV (Cococcioni, M. et. al. 2003). A forsterita corresponde ao mineral olivina, sem ferro $\left(\mathrm{Mg}_{2} \mathrm{SiO}_{4}\right)$ e a faialita é o mesmo mineral, sem magnésio $\left(\mathrm{Fe}_{2} \mathrm{SiO}_{4}\right)$. De acordo com Shankland (1968) a substituição do magnésio por átomos de ferro na estrutura da olivina tem por consequência a redução da energia de gap. Esta substituição pode ocorrer com facilidade devido à dois fatores: (i) os raios dos átomos de $\mathrm{Mg}$ e Fe são quase iguais (Earles, E. (2015)) e (ii) o rendimento de sputtering do $\mathrm{Mg}$ é 3,5 vezes maior que o do Fe (tabela 5.1). E sendo a remoção de $\mathrm{Mg}$ mais provavel, o ferro pode ocupar a vaga deixada. Badro et. al (2004) confirmam, com base em resultados experimentais, que silicatos que possuem ferro em sua estrutura tendem a apresentar energias de gap menores que os que não o tem. Loeffler et. al. (2016) também verificam que a presença das impurezas $\mathrm{Fe}^{2+}$ e $\mathrm{Fe}^{3+}$ podem afetar o espectro da olivina, pois aumenta sua capacidade de absorção de radiação por gerar um nível de energia aceitador acima da banda de gap, fato esse que já reportado por Shankland (1968). 
Para Morin et. al (1977), o ferro é a impureza eletricamente ativa encontrada nesses materiais.

A discussão apresentada na seção 5.2.3 evidencia que o mineral formado, majoritária mente em processo de aquecimento da faialita é a hematita, cuja estrutura é formada por $\mathrm{Fe}^{2+}$ e $\mathrm{Fe}^{3+}$.

A Fig. 5.17 mostra o diagrama de níveis de energia para forsterita, contendo níveis gerados por defeitos e impurezas.

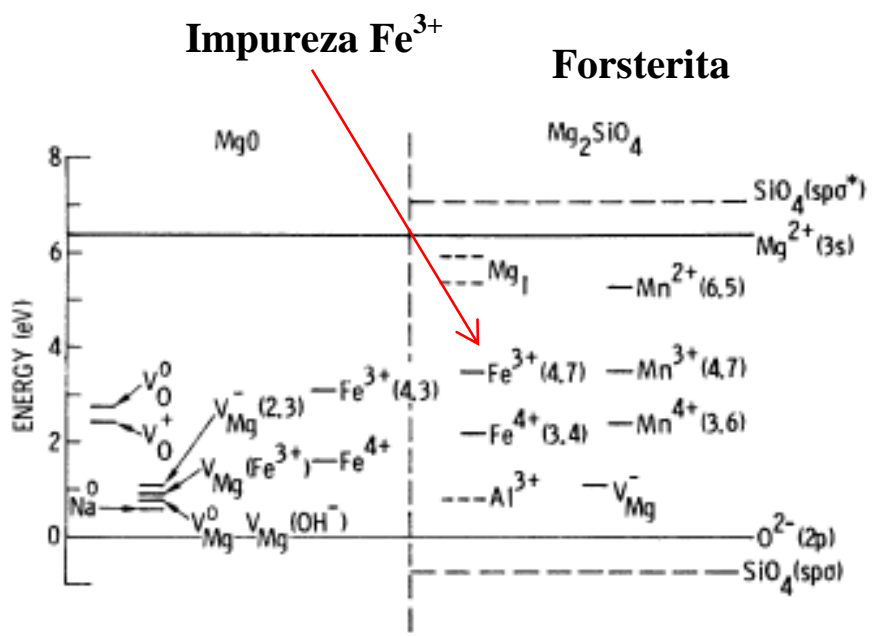

Figura 5.17 - Diagrama de níveis de energia para as bandas de energia de $\mathrm{MgO}$ e de $\mathrm{Mg}_{2} \mathrm{SiO}_{4}$. Os níveis gerados por defeitos e impurezas também são apresentados. Adaptado de Morin et. al. (1977).

Em especial, a presença de $\mathrm{Fe}^{3+}$ introduz, na estrutura de níveis de energia da forsterita, níveis aceitadores profundos que são ionizados através de reações de transferência de carga (Morin et. al. (1977)):

$$
\mathrm{Fe}^{3+} \rightarrow \mathrm{Fe}^{2+}+\mathbf{h}
$$

Os buracos h são gerados logo acima da camada de valência. Eles podem atuar como armadilhas capturando elétrons de átomos adjacentes e contribuindo para a redução da energia de gap do sistema. Em simultâneo, a formação de $\mathrm{Fe}^{2+}$ contribui para alterações na banda de absorção em torno de $1 \mu \mathrm{m}$, tal como a redução de sua profundidade. 
A concentração de buracos, $h$, gerados pela presença do ferro, pode ser calculada pela seguinte expressão:

$$
\mathbf{h}=\mathbf{N}_{\mathbf{v}}\left(\frac{\left[\mathrm{Fe}^{3+}\right]}{\left[\mathrm{Fe}^{2+}\right]}\right) e^{\frac{-\mathbf{E}_{\mathrm{A}}}{\mathrm{kt}}}
$$

onde, na olivina, $\mathrm{h}<<\left[\mathrm{Fe}^{2+}\right], \mathrm{N}_{\mathrm{v}}$ é a densidade de estados na borda da banda de valência e $\frac{\left[\mathrm{Fe}^{3+}\right]}{\left[\mathrm{Fe}^{2+}\right]}$ é a relação entre os níveis aceitadores vazios e cheios cuja energia é $\mathrm{E}_{\mathrm{A}}$.

Pela equação 5.10 observa-se que quanto maior a densidade de estados aceitadores vazios, maior a densidade de buracos. Ou seja, a inserção de ferro, como impureza (especialmente o $\mathrm{Fe}^{3+}$ ) leva a formação de níveis de energia aceitadores intermediários, que podem servir de armadilha para elétrons da banda de valência que fazem a transição para o nível aceitador devido a energia térmica. A consequência é o aumento da absorção observado na Fig. 5.11. Morin et. al. (1977) calcula que o valor da energia entre o nível aceitador gerador pelo $\mathrm{Fe}^{3+} \mathrm{e}$ a banda de valência é de 3,5 eV. Com este valor é possível estimar o comprimeto de onda da radiação, cuja energia seria absorvida, $\lambda=h \mathrm{hc} / 3,5 \sim 390 \mathrm{~nm}$ (h é a constante de Planck e c a velocidade da luz). O valor encontrado é o mesmo para ao qual o aumento abrupto da absorção, na Fig. 5.11, se inicia.

Em conclusão, o ferro é um importante dopante e sua inserção na estrutura de minerais pode levar a redução da energia de gap, uma vez que ele toma o lugar de outros átomos, como o magnésio, por exemplo, e reconfigura a estrutura do mineral. Conforme indicam os resultados, outra informação relevante é que, novamente, a quantidade de ferro inicial de cada amostra influencia as mudanças ópticas observadas. Nos dois gráficos das figuras 5.15 e 5.16 foi possível fazer o ajuste bem sucedido com a função exponencial semelhante à Eq. 5.1:

$$
E_{g}=E_{g f}+A e^{-\sigma_{x} F}
$$

$\mathrm{E}_{\mathrm{g}}$ é a energia de gap à fluência $\mathrm{F}, \mathrm{E}_{\mathrm{gf}}$ a energia de gap final (quando ocorre uma saturação), e $\sigma_{\mathbf{x}}$ uma constante com características de seção de choque que quantifica a rapidez $\mathrm{E}_{\mathrm{g}}(\mathrm{F})$ com que o gráfico chega à saturação $\mathrm{E}_{\mathrm{gf}}$. $\mathrm{O}$ índice $\mathrm{x}$ 
corresponde a cada subtipo de meteorito (LL, $\mathrm{L}$ ou $\mathrm{H}$ ). Os valores de $\boldsymbol{\sigma}_{\mathbf{x}}$ obtidos foram:

$$
\begin{aligned}
& \sigma_{\mathrm{LL}}=9,4 \times 10^{-16} \mathrm{~cm}^{2} \\
& \sigma_{\mathrm{L}}=4,9 \times 10^{-15} \mathrm{~cm}^{2} \\
& \sigma_{\mathrm{H}}=6,9 \times 10^{-15} \mathrm{~cm}^{2}
\end{aligned}
$$

Observa-se que o Parambu, que tem a menor quantidade de ferro em sua estrutura mineral, tem a energia de gap que mais demora a saturar, pois é preciso uma dose maior de irradiação para modifica-la substancialmente. Já os meteoritos Putinga e Gail apresentam valores de $\boldsymbol{\sigma}_{\mathbf{x}}$ muito próximos, consequência da porcentagem de ferro inicial de cada um deles, que também é muito próxima. Em relação à irradiação do Gail por feixe de $\mathrm{N}^{+} \mathrm{o}$ valor obtido para $\sigma_{\mathrm{x}}$ é três vezes maior que o obtido para próton,

$$
\begin{gathered}
\sigma_{\mathrm{H}}\left(2,0 \mathrm{MeV}-\mathrm{N}^{+}\right)=2,1 \times 10^{-14} \mathrm{~cm}^{2} \\
\frac{\sigma_{\mathrm{H}}\left(2,0 \mathrm{MeV}-\mathrm{N}^{+}\right)}{\sigma_{\mathrm{H}}\left(1,0 \mathrm{MeV}-\mathrm{H}^{+}\right)}=\frac{2,1 \times 10^{-14}}{6,9 \times 10^{-15}} \sim 3,04
\end{gathered}
$$

Esta proporção é interessante, pois quando comparados os dois gráfico da variação da inclinação BI do meteorito Gail são comparados, o que se nota é que ao dividir os valores das inclinações obtidas para a irradiação com 2,0 $\mathrm{MeV}$ de $\mathrm{N}^{+}$ por 3 os dois gráficos se sobrepõem (Fig. 4.30). Ou seja, a proporção entre os dois gráficos de inclinação BI é a mesma obtida na razão entre as seções de choque de variação de energia de gap. São remotas as chances disso ser apenas coincidência. A interpretação para esta proporção de três pode ser feita à luz da equação 5.10. O feixe de $\mathrm{N}^{+}$gera três vezes mais níveis aceitadores vazios do que o feixe de prótons. 
Tabela 5.6 - Comparação entre a porcentagem de ferro inicial, valor do número de onda (espectro Raman), seções de choque de deslocamento (tabela 5.3), energia de gap inicial, seções de choque de variação das energias de gap e seção de choque de avermelhamento do espectro de reflexão, obtidas para cada meteorito.

\begin{tabular}{|c|c|c|c|c|c|c|}
\hline Feixe/energia & $\begin{array}{l}\mathrm{Fe} \\
(\%)\end{array}$ & $\begin{array}{c}\mathrm{X}_{\mathrm{c} 0} \text { Pico }^{*} \\
\left(\mathrm{~cm}^{-1}\right)\end{array}$ & $\begin{array}{l}\text { Seção de choque } \\
\text { deslocamento do } \\
\text { pico } 3\left(\times 10^{-16} \mathrm{~cm}^{2}\right)\end{array}$ & $\begin{array}{r}E_{g 0} \\
(e V)\end{array}$ & $\begin{array}{c}\text { Seção de choque } \mathrm{E}_{\mathrm{g}} \\
\left(\mathrm{x}^{-16} \mathrm{~cm}^{2}\right)\end{array}$ & $\begin{array}{l}\text { Seção de choque } \\
\text { avermelhamento } \\
\qquad\left(\mathbf{x 1 0}^{-15} \mathrm{~cm}^{2}\right)\end{array}$ \\
\hline $\mathrm{H}^{+} / 1,0 \mathrm{MeV}$ & 18,95 & 681 & $0,13 \pm 0,02$ & 4,65 & $9,4 \pm 0,2$ & $1,2 \pm 0,8$ \\
\hline $\mathrm{H}^{+} / \mathrm{1,0} \mathrm{MeV}$ & 23,30 & 680 & $6,32 \pm 0,40$ & 4,56 & $49 \pm 12$ & $22 \pm 1,5$ \\
\hline $\mathrm{H}^{+} / 1,0 \mathrm{MeV}$ & & 679 & $2,21 \pm 0,50$ & 4,74 & $69 \pm 16$ & $29 \pm 8,8$ \\
\hline $\mathrm{N}^{+} / 2,0 \mathrm{MeV}$ & 26,10 & - & - & 4,51 & $210 \pm 60$ & $62 \pm 2,2$ \\
\hline
\end{tabular}

*escolheu-se apenas o pico 3 porque a variação sofrida pelos outros picos é semelhante a deste, não sendo necessário colocar todos os valores na tabela para esta discussão.

Em relação à inclinação espectral da banda BI, a Figura 5.18 mostra que a inclinação tende a diminuir com o aumento da energia de gap. Esse parâmetro espectral é pois diretamente influenciado pela energia de gap, em acordo com a discussão feita na presente seção.

A Tabela 5.6 relaciona diferentes parâmetros obtidos neste trabalho com o conteúdo inicial de ferro de cada amostra. O que se observa é que, exceto pela energia de gap inicial, existe uma evidente correlação entre os valores apresentados e o aumento da concentração de ferro. Em especial, observa-se que o valor da seção de choque de deslocamento Raman aumenta junto com a seção de choque energia de gap e com a seção de choque de avermelhamento. Como a seção de choque de deslocamento foi definida como uma quantificação da taxa de amorfização na amostra, então se pode concluir que quanto mais rápida a amorfização de uma das amostras, mais rápida será a diminuição de sua energia de gap e consequentemente, maior será a taxa de avermelhamento do espectro de reflexão. Esta evidência corrobora com a proposta de Brunetto e Strazzulla (2005) que explica o avermelhamento do espectro como consequência da amorfização da estrutura da amostra.

Com base no exposto é possível considerar que a formação de nanopartículas de ferro neutro, observada em diversos experimentos, não é a responsável (ou, pelo menos, não unicamente) pelas modificações observadas nos 
parâmetros espectrais. Aceita esta evidência, obtida através da espectroscopia óptica por reflexão, propomos que dois fatores que causam o avermelhamento e o escurecimento do espectro: i) amorfização da estrutura cristalina e ii) formação de ferro férrico $\left(\mathrm{Fe}^{3+}\right)$, ambos correlacionados com as alteração da energia de gap do material.

Em resumo, o formalismo de gap descrever todas as alterações espectrais observadas. A incidência do feixe de íon causa a amorfização da estrutura, vista por espectroscopia Raman. Em simultâneo, ocorre a formação de $\mathrm{Fe}^{3+}$ (tanto pela incidência direta do feixe, quanto por interações eletrônicas e ainda pelos efeitos de aquecimento térmico que resultam na formação de hematita (seção 5.2.3)). Pela eq. 5.9 o $\mathrm{Fe}^{3+}$ sofre reação de transferência de carga gerando $\mathrm{Fe}^{2+}$ e aumentando a densidade de buracos. A formação de $\mathrm{Fe}^{2+}$ afeta a banda em torno de $1 \mu \mathrm{m}$. A formação de buracos alteram a densidade de estados da banda de condução (Fig. A.3), o que resulta em mudanças na função dielétrica do material (eq. A.11) que passa a absorver mais a radiação com comprimentos de onda abaixo de $0,6 \mu \mathrm{m}$ (Fig. 5.11). A consequência é escurecimento do espectro nesta faixa (Fig. 4.17, 4.23, 4.26 e 4.29). Finalmente, com a amostra absorvendo mais nesta faixa, o espectro de reflexão tende a diminuir sua intensidade, o que leva a um aumento da inclinação da banda. 

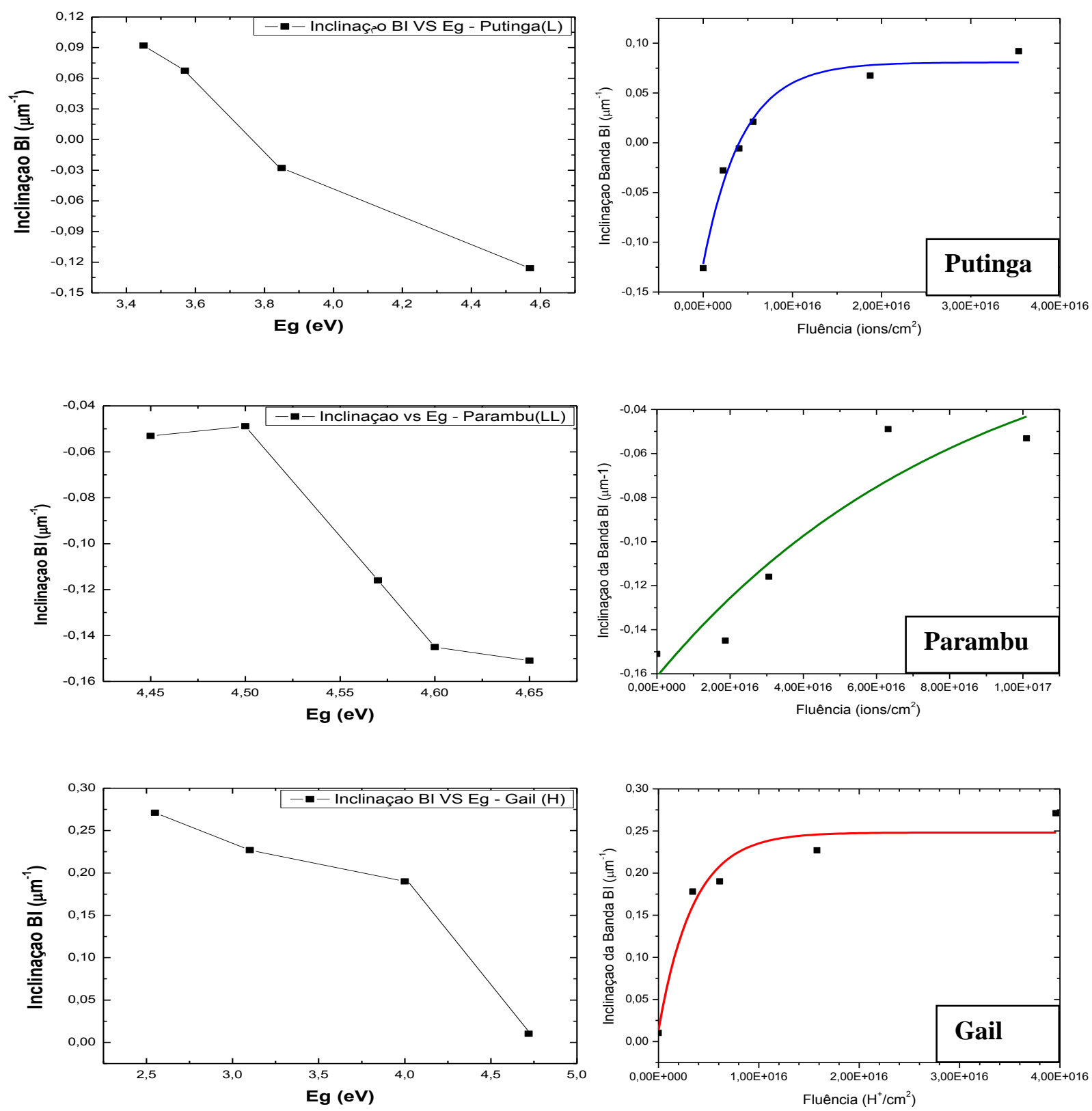

Figura 5.18 - Esquerda: inclinação espectral em função da energia de gap para cada ponto de irradiação; Direita: mesmas inclinações, porém em função da fluência. 


\subsection{6}

\section{A influência do subgrupo químico}

Conforme discutido, a presença de ferro na composição das amostras tem um importante papel nos efeitos da interação de projéteis iônicos com a superfície dos meteoritos estudados.

As três amostras irradiadas pertencem à mesma classificação taxonômica: meteoritos condritos ordinários. Suas composições minerais são bastante semelhantes umas às outras. Isso fica evidente ao observar os resultados obtidos por espectrometrias Raman e UV-VIS-NIR. De fato, os espectros apresentados evidenciam muitas similaridades.

Uma diferença notável entre as três amostras de meteorito é a concentração de ferro na composição elementar deles. Essa diferença gera, inclusive, uma forma de subclassificação taxonômica. Os condritos ordinários do subtipo $\mathrm{H}$ apresentam entre de $25 \%$ a $30 \%$ de ferro em sua composição total. É o caso do Gail que tem cerca de $26 \%$ de ferro, como os do subtipo L tem entre de $20 \%$ a $25 \%$, o Putinga entra nesta subclassificação com aproximadamente 23,3\%. O Parambu, com quase 19\% de ferro em seu conteúdo total, está na subclassificação LL, que compreende uma porcentagem de ferro entre $19 \%$ e $20 \%$.

Uma das questões que este trabalho procura responder é se as características dos membros deste subgrupo taxonômico são correlacionadas com os efeitos da irradiação por feixe de íons.

Se efetivamente o grupo taxonômico tiver correlação com os resultados da irradiação, então é de se esperar que os efeitos de avermelhamento sejam afetados e dependam diretamente da composição da amostra em termos do conteúdo de ferro. A tabela 4.5 exibe as seções de choque de avermelhamento para cada amostra de meteorito. Como esse parâmetro indica a rapidez com que o processo de avermelhamento satura, ele deve ser tanto maior quanto mais ferro a estrutura da amostra apresentar em sua composição. De fato, a Figura 5.19 evidencia que a seção de choque de avermelhamento aumenta linearmente com o conteúdo de ferro. 


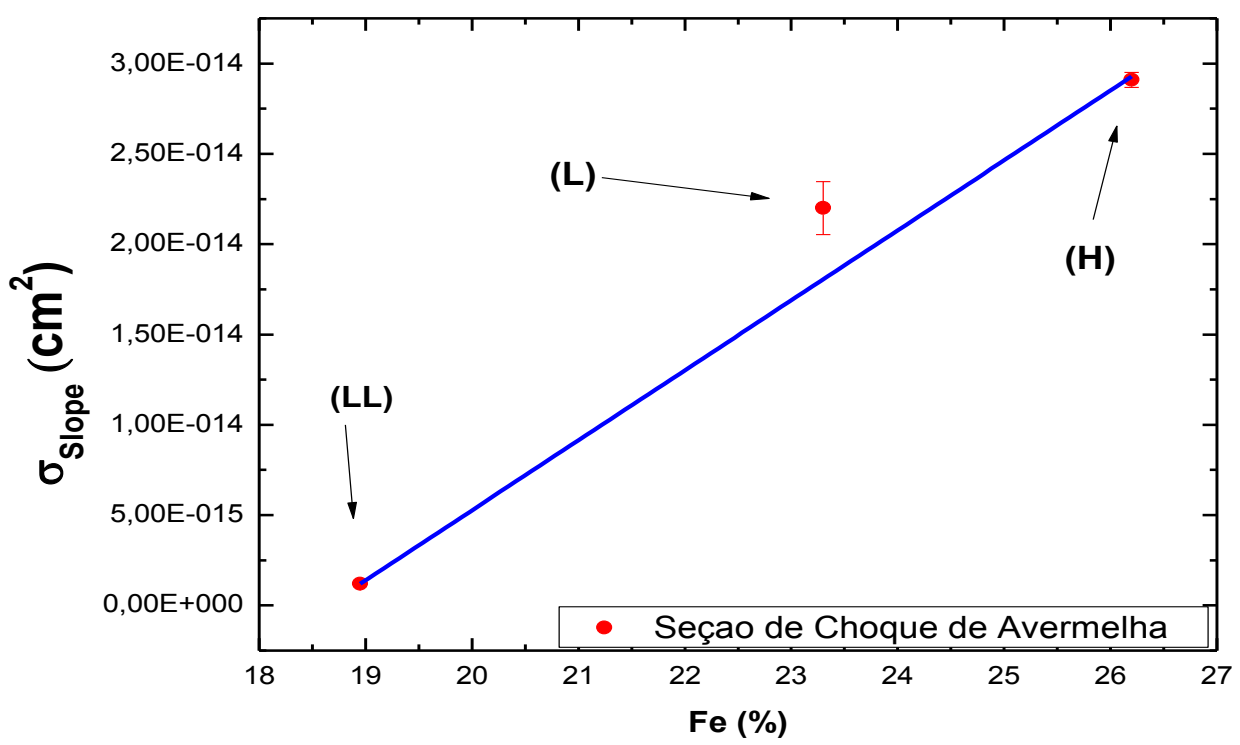

Figura 5.19 - Relação entre a seção de choque de avermelhamento com a porcentagem de Ferro de cada amostra de meteorito.

À proposta de que o avermelhamento seja causado por variações induzidas nas energias de gap do material, acrescentamos que este parâmetro seja, necessariamente, influenciado pelo conteúdo de ferro.

Esta conclusão decorre da análise da relação entre a variação da energia de gap total e o conteúdo de ferro. A Figura 5.20 mostra como a variação da energia de gap total de cada amostra varia em função da concentração inicial de ferro: quanto mais ferro existe na composição do meteorito, maior será a variação sofrida pela energia de gap. Partindo-se do princípio de que o ferro atua como um contaminante (dopante), ele fará (junto com os outros fatores expostos na discussão) com que a energia de gap varie.-Vale ressaltar, uma vez mais, que a dopagem de ferro, sozinha não é o fator mais relevante, uma vez que a tabela 5.2 mostra o meteorito Gail com maior energia de gap. É a irradiação de um material que contem ferro (como dopante em potencial) que provoca os efeitos observados. Isso evidência a importância do estudo dos processos e efeitos da exposição de pequenos corpos do sistema solar à ação do SpWe. 


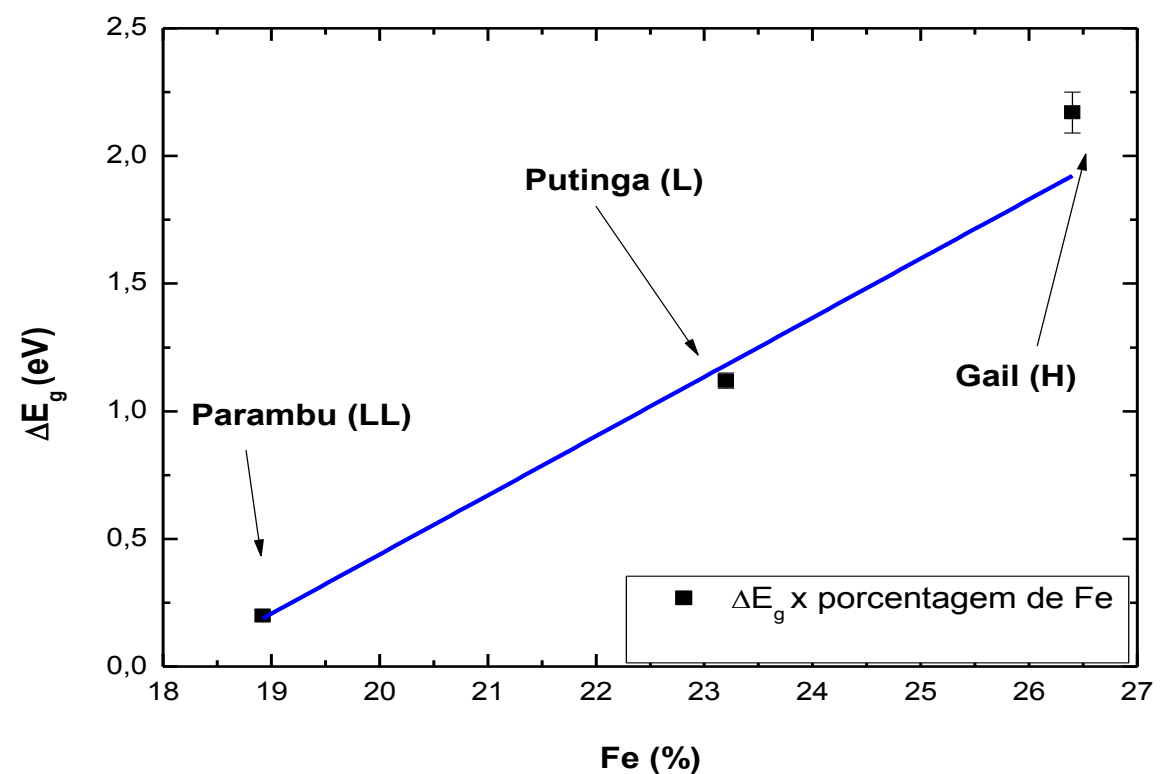

Figura 5.20 - Dependência linear da variação da energia de gap como função do conteúdo de ferro. 
Conclusões e Perspectivas

A espectroscopia Raman permitiu a caracterização mineralógica das amostras, evidenciando que sua composição majoritária é constituída por olivina e piroxênio; a amorfização da estrutura mineral é um dos produtos da exposição à irradiação por feixes de prótons e de íons de nitrogênio. A taxa de amorfização de cada meteorito foi estimada e relacionada com seu conteúdo inicial de ferro. As seções de choque de destruição das ligações Si-O, Si-O-Si e O-Si-O foram determinadas. Uma relação que descreve a variação destas seções de choque como função do poder de frenamento eletrônico para os minerais olivina e piroxênio é proposta; ela é similar a que se obtém em trabalhos de radiólise de gases condensados e de aminoácidos.

A espectroscopia UV-VIS-NIR é uma das técnicas mais importantes para o estudo de minerais e meteoritos. No presente trabalho, ela foi usada para monitorar os efeitos produzidos pela irradiação das amostras. Foram observados efeitos de escurecimento e avermelhamento dos espectros. Na literatura, a formação de nanopartículas de ferro neutro pelo impacto de íons energéticos é tida como a causa da mudança do espectro refletido. A discussão realizada neste trabalho contesta e uma substitui esta hipótese: conclui-se que as variações espectrais observadas ocorrem na cauda de absorção para pequenos comprimentos de onda. A irradiação (ou o intemperismo espacial) causa a formação de hematita e do $\mathrm{Fe}^{3+}$, que atua como uma impureza e possibilita a formação de par elétronburaco ao introduzir um nível aceitador acima da banda de valência e modificando a estrutura de bandas do material. Isto afeta a forma como o material interage com a radiação eletromagnética, pois seu gap ótico é reduzido. Em complemento, evidenciou-se que a amplitude dos efeitos observados varia segundo a concentração inicial de ferro de cada amostra, uma vez que espectros de reflexão de amostras com maior abundância de ferro avermelham-se mais rapidamente devido à maior taxa de formação de $\mathrm{Fe}^{3+}$. Esta proposta mostrou-se coerente na 
explicação dos fenômenos observados e, se confirmada, abre um novo norte no estudo dos efeitos da exposição ao SpWe. Espera-se testar esta proposta com o auxilio de medidas de espectroscopia Mössbauer.

O número de novas perguntas abertas ao fim do presente trabalho não permite que esta tese represente o fim de um ciclo. Ela abre um novo caminho no estudo de amostras de interesse astrofísico no Laboratório Van de Graaff.

Algumas perspectivas são:

1. Repetir a irradiação com amostras mais simples, como minerais puros, a fim de se verificar de forma mais contundente alguns dos resultados.

2. Em particular, as medidas por espectroscopia Raman devem ser refeitas com um número maior de pontos analisados - isso permite obter um espectro médio mais representativo da amostra.

3. É necessário desenvolver uma técnica experimental que permita a obtenção direta de espectros de absorção UV-VIS-NIR de amostras sólidas (sem a necessidade de conversão de espectros de refletância). Isto facilitaria a análise de propriedades ópticas e elétricas das amostras.

4. Os resultados de refletância UV-VIS-NIR devem ser relacionados a dados observacionais de asteroides para que uma possível correlação seja feita. Esta informação é crucial na identificação do corpo parental da amostra analisada.

5. Uma colaboração do nosso grupo de pesquisa com professores do Departamento de Engenharia Química e de Materiais da PUC-Rio e com pesquisadores do Centro Brasileiro de Pesquisas Físicas muito contribuirá para a compreensão dos processos ocorridos na estrutura das amostras. Em especial, medidas de espectroscopia Mössbauer estão em andamento e auxiliarão no entendimento da origem das modificações observadas nos espectros de reflexão: se as nanopartículas são de ferro metálico ou ferro ferroso; esta técnica é sensível às modificações sofridas pelo ferro na amostra, permitindo quantificar a formação de ferro metálico e óxidos de ferro. 


\section{Referências Bibliográficas}

Andrade D. P. P. et. al (2013). Chemical reactions induced in frozen formic acid by heavy ion cosmic rays. MNRAS 430, 787-796 (2013).

Badro, J., Rueff, J.P., Vanko, G., Monaco, G., Fiquet, G., Guyot, F., 2004. Electronic transitions in perovskite: Possible nonconvecting layers in the lower mantle. Science 305, 383-386.

Barros, H. Crescimento de subóxidos de ti por grid-assisted magnetron sputtering reativo: modificações das propriedades elétricas e ópticas através da inserção de oxigênio. Dissertação de mestradoPós-graduação em Física. . UDESC. Santa Catarina, 2018.

Barua, A. G. Boruah, B. R. Bhattacharyya, S. Baruah, G, D. Spectroscopic investigation of the Dergaon meteorite with reference to $10 \mu \mathrm{m}$ and $20 \mu \mathrm{m}$ bands. Pramana Jor. of Phy. 60: 47-52, 2003.

Blitz, J. P. Modern Techniques in Applied Molecular Spectroscopy, Tec in Anal. Chem. Series. 1998, 185-219

Bonal, L. BouroT-denise, M. Qurico, E. Montagnac, G. Lewin, E. Organic matter and metamorphic history of $\mathrm{CO}$ chondrites. Geochimica et Cosmochimica Acta. 71: 1605-1623, 2007.

Bonal, L. Qurico, E. Bourot-Denise, M. Montagnac, G. Determination of the petrologic type of $\mathrm{CV3}$ chondrites by Raman spectroscopy of included organic matter. Geochi and Cosmochi. Atc. 70: 1849-1863, 2005.

Brodholt, J.P., Helffrich, G., Trampert, J., 2007. Chemical versus thermal heterogeneity in the lower mantle: The most likely role of anelasticity. Earth Planet. Sci. Lett. 262, 429-437.

Brunetto, R. et al., 2006. Space weathering of silicates simulated by nanosecond pulse UV excimer laser. Icarus 180, 546-554.

Brunetto, R. et al., 2007b. Optical characterization of laser ablated silicates. Icarus 191, 381-393.

Brunetto, R. et al., 2015. Asteroid surface alteration by space weathering processes. In: Asteroids IV, in press. 
Brunetto, R. Lantz, C. Ledu, D. Baklouti, D. BaruccI, M. A. Beck, P. Delauche, L. Dionnet, Z. Dumas, P. Duprat, J. Engrand, C. Jamme, F. Oudayer, P. Quirico, E. Sandt, C. Dartois, E. Ion irradiation of Allende meteorite probed by visible, IR, and Raman spectroscopies. Icarus. 237: 278-292, 2014.

Brunetto, R., and Strazzulla, G., 2005. Elastic collisions in ion irradiation experiments: a mechanism for space weathering of silicates. Icarus 179, 265273.

Cassidy W., B. Hapke, (1975) Effects of darkening processes on surfaces of airless bodies. Icarus 25, 371 .

Chapman, C.R., 1996. S-type asteroids, ordinary chondrites, and space weathering: The evidence from Galileo's fly-by of Gaspra and Ida. Meteorit. Planet. Sci. 31, 699-725.

Clark, B.E. et al., 2002. Asteroid Space Weathering and Regolith Evolution. Asteroids III. University of Arizona Press, pp. 585-599.

Cococcioni, M. et. al. Structural, electronic, and magnetic properties of Fe2SiO4 fayalite: Comparison of LDA and GGA results. Physical Review B Vol. 67, 2003.

Collado, V. M. Farenzena, L.S. Ponciano, C. da Silevira, E. F. e Wien, K. Ion desorption from frozen $\mathrm{H}_{2} \mathrm{O}$ irradiated by $\mathrm{MeV}$ heavy ions. Surface Science. Vol. 569, 2004, Pages 149-162.

da Costa C. A. P. (2016). Radiólise de valina por íons de MeV analisada por espectroscopia no infravermelho. Dissertação de mestrado. Rio de Janeiro: PUC-Rio, Departamento de Física, 2016.

Davis E. and Mott N., Conduction in non-crystalline systems V. Conductivity, optical absorption and photoconductivity in amorphous semiconductors. The Philosophical Magazine. Volume 22, 2006 - Issue 179.

de Barros A. L. F., Bordalo V., Seperuelo Duarte E., da Silveira E. F., Domaracka A., Rothard H., Boduch P., 2011a, A\&A, 531, 15.

Dukes, C.A., Baragiola, R.A., McFadden, L.A., 1999. Surface modificationof olivine by H+ and He+ bombardment. J. Geophys. Res. 104, 1865-1872. 
Džimbeg-Malčić V, Barbarić-Miko čević Ž, Itrić K. Kubelka-Munk theory in describing optical properties of paper (I). Tehnički Vjesnik/Technical Gazette. 2011:18(1):117-124.

E. A. Davis and N. F. Mott, Philos. Mag., 22903 (1970)

Earles, E. Physical Geology: Silicates Minerals. 2015. Disponível em: $<$ https://opentextbc.ca/geology/chapter/2-4-silicate-minerals/> Acesso em: 05/06/2019.

Fulvio, D., Brunetto, R., Vernazza, P., and Strazzulla, G.: Space weathering of Vesta and V-type asteroids: new irradiation experiments on HED meteorites, A\&A 537, L11, 2012.

Gaffey M. J. (2010) Space weathering and the interpretation of asteroidreflectance spectra. Icarus, 209, 564-574.

Gaffey, M. J. \& Gilbert, S. L. (1998). “Asteroid 6 Hebe: The probable parent body of the H-Type ordinary chondrites and the IIE iron meteorites". Meteoritics and Planetary Science 33:1281-1295.

Gargaud M, et al (2011) Encyclopaedia of Astrobiology. Springer.

Hapke, B. Darkening of silicate rock powders by solar wind sputtering. Moon 7, $342(1973)$

Hapke, B., 2001. Space weathering from Mercury to the asteroid belt. J. Geophys. Res. 106 (E5), 10039-10073.

Hiroi, T. et al., 2011. Space weathering of ordinary chondrite parent bodies, its impact on the method of distinguishing H, L, and LL types, and implications for Itokawa samples returned by the Hayabusa mission. Lunar Planet. Sci. 42, p. 1264.

Hutchison, R. Meteorites: a petrologic, chemical and isotopic synthesis. $2^{\mathrm{a}} \mathrm{Ed}$. Cambridge planetary science series. 506 páginas, 2004.

Iza P. 2006. Extensão do modelo de traço nuclear para descrever a dessorção iônica. Aplicação aos agregados de água. Tese de doutorado. Rio de janeiro: PUC-Rio, Departamento de Física, 2006. 
Jiang X. and Guo, G. Electronic structure, magnetism, and optical properties of Fe2SiO4 fayalite at ambientand high pressures: A GGA+U study. Physical Review B Vol. 69, 2004.

Kanuchova, Z. et al., 2010. Space weathering of asteroidal surfaces. Influence on the UV-Vis spectra. Astron. Astrophys. 517, 1-10. A60.

KITTEL, C., McEuen, P., e McEuen, P., "Introduction to Solid State Physics", 2004; vol. 8th editio, p. 704.

Kolesov B. A. and Geiger C. A. A Raman spectroscopic study of Fe-Mg olivines. Phys Chem Minerals (2004) 31: 142 - 154.

Kumar et al Band gap determination in thick films from reflectance measurements.

Lazzarin,M., Marchi, S., Barucci,M.A., Di Martino, M., Barbieri, C., 2004.Visible and near-infrared spectroscopic investigation of near-Earth objectsat ESO: First results. Icarus 169, 373-384.

Loeffler, M. J., Dukes, C. A., and Baragiola, R. A.: Irradiation of olivine by 4 keV He+: Simulation of space weathering by the solar wind, J. Geophys. Res. 114, E03003, 2009.

Loeffler, M. J., Dukes, C. A., Christoffersen, R. and Baragiola, R. A. (2016), Space weathering of silicates simulated by successive laser irradiation: In situ reflectance measurements of $\mathrm{Fog}_{90}, \mathrm{Fog9}_{+}$, and $\mathrm{SiO}_{2}$. Meteorit Planet Sci, 51: 261-275.

Loyalka, S. K. \& Riggs, C. A. Inverse Problem in Diffuse Reflectance Spectroscopy: Accuracy of the Kubelka-Munk Equations. Appl. Spectrosc. 49, 1107-1110 (1995).

McCord, T.B., Adams, J.B., Johnson, T.V., 1970. Asteroid Vesta: Spectral reflectivity and compositional implications. Science 168, 1445-1447.

Meteoritical Bulletin. Iniciativa: The Meteoritical Society. Disponível em: <http://www.lpi.usra.edu/meteor/metbull.php> Acesso: 24 de Mar. de 2019.

Morin, F. J. Oliver, J. R. and Housley, R. M. Eletrical properties of forsterite. $\mathbf{M g}_{2} \mathrm{SiO}_{4}$. Physical Review. Vol. 16. 1977. 
Murphy, A. B. Band-gap determination from diffuse reflectance measurements of semiconductor films, and application to photoelectrochemical water-splitting. Sol. Energy Mater. Sol. Cells 91, 13261337 (2007).

Noguchi, T. et al., 2014. Space weathered rims found on the surfaces of the Itokawa dust particles. Meteorit. Planet. Sci. 49, 188-214.

Noguchi, T., et al. 2014. Space weathered rims found on the surfaces of the Itokawa dust particles. Meteoritics and Planetary Science 49, 188-214

Pieters, C.M., Fischer, E.M., Rode, O.D., Basu, A., 1993. Optical effects of space weathering on lunar soils and the role of the finest fraction. J. Geophys. Res. 98, 20817-20824.

Pieters, C.M., Taylor, L.A., Noble, S.K., Keller, L.P., Hapke, B., Morris,R.V., Allen, C.C., McKay, D.S.,Wentworth, S., 2000. Space weatheringon airless bodies: Resolving a mystery with lunar samples. Meteorit.Planet. Sci. 35, 1101-1107.

Prawer, S. et. al. 1995. Ion-bean modification of fullerene. PhysRevB. 52, $841-$ 850 .

Rai, V. N. Mukherjee, C. and Jain, B. Optical properties (UV-Vis and FTIR) of gamma irradiated polymethyl methacrylate (PMMA). Researchgate. Outubro de 2016.

Roine, A HSC-Chemistry for Windows. Outokumpu Research Oy, Pori, Finland (2006).

Rubin, A. E. Mineralogy of meteorite groups. Meteoritics and Planetary Science. 32: 1-247, 1996.

Strazzulla, G. et. al. Spectral alteration of the Meteorite Epinal (H5) induced by heavy ion irradiation: a simulation of space weathering effects on nearEarth asteroids. Icarus. 174: 31-35, 2004.

SZE, S. M., e Kwok, K., "Physics of Semiconductor Devices"; 1; John wiley \& sons: 2006 , p. 832.

Tauc J. (F. Abeles ed.), Optical Properties of Solids, North-Holland (1972). 
Tauc, J. Grigorovici, R. Vancu, A. Optical properties and electronic structure of amorphous germanium, Phys. Status Solidi 15. 627-637 (1966).

Torrent, J. \& Barrón, V. Diffuse reflectance spectroscopy of iron oxides. Encycl. Surf. Colloid Sci. 1438-1446 (2002).

Toulemnod, M. Weber, W. Li, G. Shutthanandan, V. Kluth P. Yang, T. Wang, Y. e Zhang, Y. Synergy of nuclear and electronic energy losses in ion-irradiation processes: The case of vitreous silicon dioxide. PHYSICAL REVIEW B Vol. 83, 2011.

Vernazza, P. et al., 2009. Solar wind as the origin of rapid reddening of asteroid surfaces. Nature 458, 993-995.

Vernazza, P., Brunetto, R., Strazzulla, G., Fulchignoni, M., Rochette, P., MeyerVernet, N., and Zouganelis, I.: Asteroid colors: a novel tool for magnetic field detection? The case of Vesta, A\&A 451, L43, 2006.

Viezbicke, Brian D., Patel, Shane, Davis, Benjamin E. \& Birnie, Dunbar P. (2015). Evaluation of the Tauc Method for Optical Absorption Edge Determination: ZnO Thin Films as a Model System. Physica Status Solidi, B 252(8), 1700-1710.

Wang, A. Kuebler, K. Jolliff, B. Haskins, L. A. Mineralogy of a Martian meteorite as determined by Raman spectroscopy. J. Raman Spectrosc. 35: 504-514, 2004.

Weber, I. Bottger, U. Pavlov, S. G. Jessberger, E. K. Hubers, H. Mineralogical and Raman spectroscopy studies of natural olivines exposed to different planetary environments. Planetary and Space Science, 2014.

Wells B. Bandgap measurements of nonspecular materials using a bifurcated fiber optic method of diffuse reflectance. Tese de Doutorado - Departamento Of Physics, Oregon State University, 2015.

WESTPHAL, A. J. et al. Evidence for interstellar origin of seven dust particles collected by the Stardust spacecraft. Science. 345, 786, 2014.

Williams, et. al., 1990. Structural and electronic properties of Fe2SiO4fayalite at ultrahigh pressures: Amorphization and gap closure. J. Geophys. Res. 95, 21549-21563. 
Yamada, M., et. al. 1999. Simulation of space weathering of planet-forming materials: Nanosecond pulse laser irradiationand proton implantation on olivine and pyroxene samples. Earth PlanetsSpace 51, 1255-1265.

Ziegler J. F., Biersack J. and Littmark U. The Stopping and Range of Ions in Matter, Pergamon Press (1985).

Ziegler, J. F. The Stopping and Range of Ions in Matter. Disponível em: <http://www.srim.org/SRIM/SRIMPICS/HESTOPPING.htm> Acesso em: 15/03/2019.

Zongwei Xu, et. al. 2018. Topic Review: Application of Raman Spectroscopy Characterization in Micro/Nano-machining. Micromachines 2018, 9, 361.

Zucolotto, M. E. Fonseca, A. C. Antonello, L. L. Decifrando os meteoritos. $1^{\text {a }}$ Ed. Rio de Janeiro: UFRJ, Museu Nacional. 160 p. Série de livros: 52. 2013.

P. Vernazza, R. Brunetto, G. Strazzulla, M. Fulchignoni, P. Rochette, N. MeyerVernet, and I. Zouganelis, 2006. Asteroid colors: a novel tool for magnetic field detection? The case of Vesta. Astronomy and Astrophysics, 451:43-46.

Clark, B. Hapke, B. Pieters, C. Britt, D, 2002 Asteroid Space Weathering and Regolith Evolution. Asteroids III, p.585-599. 


\section{Apêndice A - Absorção no UV-VIS e Teoria de Tauc}

\section{A.1 Luz e matéria}

Para compreender e interpretar espectros de absorção e reflexão é necessário entender como a radiação interage com a matéria. $O$ índice de refração, ñ, é uma grandeza que especifica como um material responde ao interagir com radiação eletromagnética. Esta grandeza é representada por um número complexo:

$$
\widetilde{\mathbf{n}}=\mathbf{n}+\mathbf{i k}
$$

onde n e k são, respectivamente, as partes real e imaginária do índice de refração complexo. k é chamado, também, de coeficiente de extinção. Para entender o significado de cada um deles considere uma onda eletromagnética plana propagando-se na direção z,

$$
\mathbf{E}=\mathbf{E}_{\mathbf{0}} \mathbf{e}^{\mathbf{i}(\tilde{k} \mathbf{k}-v \mathbf{t})}
$$

$\mathrm{Na}$ equação (A.2) $\mathrm{E}_{0}$ é amplitude da onda eletromagnética, $\tilde{\mathrm{k}}$, é o vetor de onda complexo e $v$ a frequência. Utilizando a equação fundamental para onda eletromagnética, $\mathrm{c}=\lambda v$, e a relação entre o vetor de onda e do índice de refração, $\tilde{\mathrm{k}}=\tilde{\mathrm{n}} \mathrm{v} / \mathrm{c}$, na equação A.2, obtemos:

$$
\begin{gathered}
E=E_{0} e^{i(\tilde{k} z-v t)}=E_{0} e^{i\left((n+i k) \frac{v}{c} \mathbf{z}-v t\right)}= \\
=E_{0} e^{-\frac{i}{2} \alpha z} e^{i(k z-v t)}
\end{gathered}
$$

onde definimos

$$
\alpha=\frac{2 \mathbf{k}}{\lambda}
$$

o coeficiente de absorção da radiação. Para entender seu papel considere a intensidade da onda representada pela equação A.3,

$$
\mathbf{I} \propto \mathbf{E}^{*} \mathbf{E} \propto \mathbf{e}^{-2 \alpha z}
$$


Ou seja, $\alpha$ é responsável pela atenuação da intensidade da radiação durante sua passagem pelo interior do material. Pela equação A.4 observamos que o coeficiente $\alpha$ esta relacionado com a parte imaginária de A.1.

O índice de refração pode, também, ser relacionado com as propriedades dielétricas do material. Esta relação é feita pela fórmula de Maxwell:

$$
\widetilde{\mathbf{n}}=\sqrt{\varepsilon \mu}
$$

na qual $\mu$ é a permissividade magnética e $\varepsilon$ a função dielétrica (fornece as informações a respeito das propriedades óticas do material), que é representada por um valor complexo:

$$
\widetilde{\varepsilon}=\varepsilon_{1}+i \varepsilon_{2}
$$

Para o caso particular de um sólido não magnético $(\mu=1)$ a equação A.5 se reduz a

$$
\widetilde{\mathbf{n}}=\sqrt{\widetilde{\boldsymbol{\varepsilon}}}
$$

com este resultado,

$$
\begin{gathered}
\varepsilon_{1}=n^{2}-\mathbf{k}^{2} \\
\varepsilon_{2}=2 n k
\end{gathered}
$$

A parte imaginária da função dielétrica esta diretamente relacionada com a propriedade do meio de absorver radiação. Esta relação será de grande importância na compreensão da teoria de Tauc.

\section{A.2 Absorção UV-VIS e teoria de bandas}

A teoria de bandas fornece uma explicação bem aceita para as características elétricas e ópticas dos materiais. $\mathrm{O}$ fundamento central dessa teoria é o seguinte. 
Na Figura A.1 (a) é ilustrado o conjunto de níveis de energia dos elétrons de um átomo. Se $\mathrm{N}$ desses átomos formam um agregado, as funções de onda de seus elétrons geram $\mathrm{N}$ orbitais moleculares, separados em níveis de energia desdobrados, como mostrado na figura A.1 (b). Considerando que $\mathrm{N}$ aumente muito, para que o agregado se transforme em um sólido macroscópico, o número de subníveis contido no mesmo conjunto também aumentará. Para um sólido que contenha $10^{23}$ átomos/mol, o resultado é a formação de uma banda contínua (Figura A.1 (c)). Existem regiões de níveis permitidas, chamadas bandas, onde os elétrons podem ocupar qualquer nível de energia. Mas existem também as regiões entre as bandas, chamadas de lacunas ou gaps, constituídas por faixas de energias proibidas aos elétrons. Estes podem, entretanto "saltar" de uma banda para outra, desde que seja fornecida ao sistema uma energia superior à energia de gap.

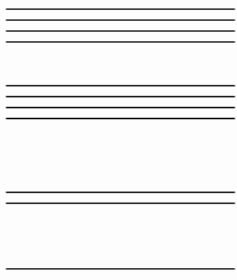

(b)

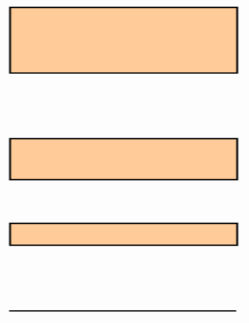

(c)

Figura A.1- Bandas de energia em um sólido. (a) átomo isolado; (b) sistema de alguns átomos; (c) um mol de átomos.

A estrutura de bandas de energia é única para cada sólido e funciona como uma impressão digital do sistema. Essas bandas são responsáveis pelas características elétricas e ópticas do material: elas determinam a maneira como o sólido interage com a radiação eletromagnética (Sapoval e Herman, 1988). Por esse motivo, para descrever corretamente a formação de um espectro de reflexão é necessário conhecer as características dessas bandas de energia. . A banda de gap é extremamente importante, pois determina a mínima energia necessária para que os elétrons da banda de valência sejam excitados para a banda de condução. Estas energias podem corresponder à energias no comprimento de onda do UV-VisívelNIR. 
A uma temperatura de $0 \mathrm{~K}$ todos os níveis de energia da banda de valência estão ocupados. Consequentemente, todos os níveis de energia da banda de condução se encontram vazios. Para temperaturas mais altas, temperatura ambiente, por exemplo, a energia térmica fornecida aos elétrons da banda de valência pode ser suficiente para que um elétron vença a barreira do gap indo para a banda de condução deixando para trás uma vacância chamada de buraco. Este buraco é percebido pelo restante da rede como uma carga positiva e participa do processo, pois afeta o restante dos elétrons da banda de valência.

A radiação eletromagnética pode ser absorvida por um sólido semicondutor por diferentes mecanismos: absorção Inter bandas (também chamada de absorção fundamental), absorção por níveis de impurezas, etc. Uma absorção fundamental ocorre quando a energia da radiação $(h v)$ incidente corresponde à energia de gap. Assim, quando o sólido absorve este fóton, ele recebe energia suficiente para que um elétron possa vencer a barreira de gap. Este tipo de processo gera e um espectro de absorção uma banda, conforme mostra a figura A.2.

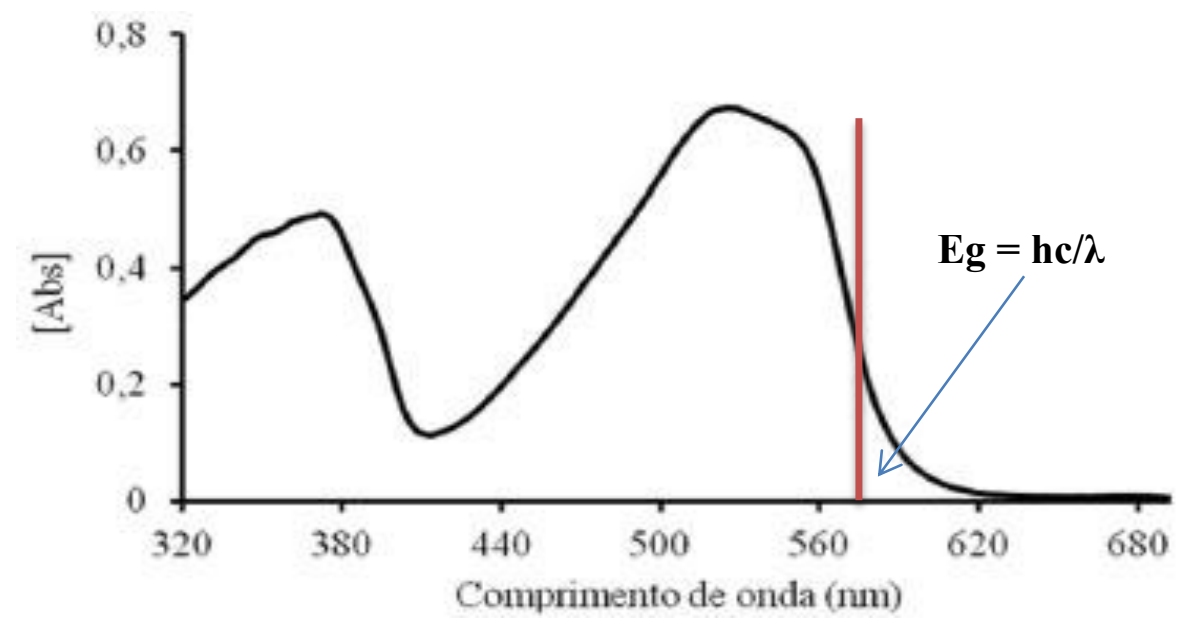

Figura A.2 - Exemplo de um espectro de absorção. Fonte: Adaptado de http://quimicanova.sbq.org.br/imagebank/images/v40n7a15-fig01.jpg

Na Fig. A.2 é apresentando um exemplo de espectro de absorção, típico para absorções fundamentais, com duas bandas bem definidas. A variação o valor da absorção em função do comprimento de onda, indo no sentido decrescente deste, mostra um aumento abrupto a partir de $620 \mathrm{~nm}$. Este aumento abrupto é conhecido como borda de absorção (absorption edge, do inglês). O edge é utilizado para a determinação da energia de gap do material. Como o aumento 
ocorre a uma alta taxa, tornando complicado saber o valor exato do comprimento de onda para o qual ocorreu uma absorção fundamental, convencionou-se traçar uma reta vertical que passe pelo ponto de inflexão da curva de absorção. O valor de comprimento de onda para o qual esta reta intercepta o eixo horizontal é usado para calcular a energia de gap através da equação mostrada na Fig. A.2.

\section{A.2.1 Absorção por níveis de impureza}

Existem algumas maneiras de alterar a energia de gap de um material. Entre elas estão a formação de defeitos na rede cristalina e a inserção de dopantes. A inserção de impureza pode causar modificações na estrutura do sólido de tal forma que a configuração de suas bandas de energia é afetada. Tanto os defeitos quanto as impurezas podem atuar na formação de níveis de energia permitidos na banda proibida atuando como armadinha para elétrons livres.

Se a impureza se caracterizar por possuir mais elétrons na camada de valência do que os átomos da matriz original, então um ou mais elétrons são fornecidos a rede. A consequência é a formação de níveis de energia logo abaixo da banda de condução. Estados criados dessa maneira são chamados doadores. Semicondutores com este tipo de impureza são denominador tipo $\mathrm{n}$.

Quando a impureza se caracteriza pelo déficit de um ou mais elétrons $n$ camada de valência, em comparação com os demais átomos da rede matriz, então esta impureza se comportará como aceitadora. O nível permitido formado na banda proibida estará logo acima da banda de valência, facilitando a passagem de elétrons desta para a impureza aceitadora. A consequência é o aumento da densidade de buracos. Semicondutores como estas características são denominados de tipo $\mathrm{p}$.

A Fig. A.3 mostra a representação do diagrama de energia do semicondutor para cada caso. A inserção de impurezas cria uma nova densidade de estados no nível de energia dos doadores abaixo da banda de condução e de aceitadores acima da banda de valência, alterando a densidade eletrônica de ambas as bandas e modificando as propriedades elétricas no material. 

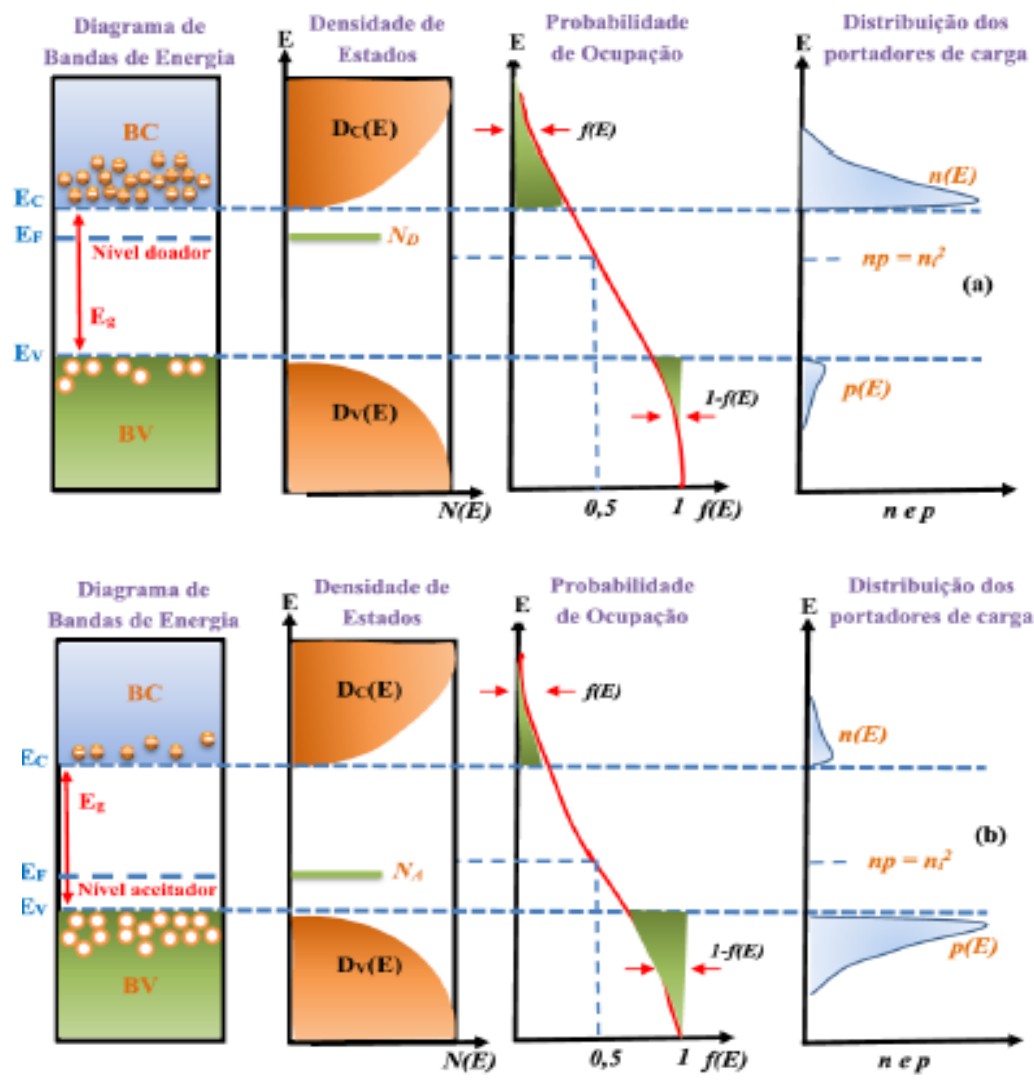

Figura A.3 - Esquema representando: diagrama de energia, densidade de estados, distribuição de Fermi-Dirac e concentração de portadores de carga de semicondutores (a) tipo $\mathrm{n}$ e (b) tipo $\mathrm{p}$. Adaptado de Barros (2018).

\section{A.3 Teoria de Tauc}

A Fig. A.2 mostra uma banda de absorção que é consequência de uma absorção fundamental. Entretanto, dependendo da configuração da estrutura cristalina do sólido, da presença de impurezas e etc., os espectros podem apresentar características que não condizem com uma banda de absorção típica. Tauc (1966) observou, em seu estudo com germâbio, que em regiões próximas de transições de bordas fundamentais podem estar ocorrendo outras transições, diretas ou indiretas (Fig.A.4), que resultaria em uma cauda de alta absorção no espectro conforme mostra a Fig. A.5. 


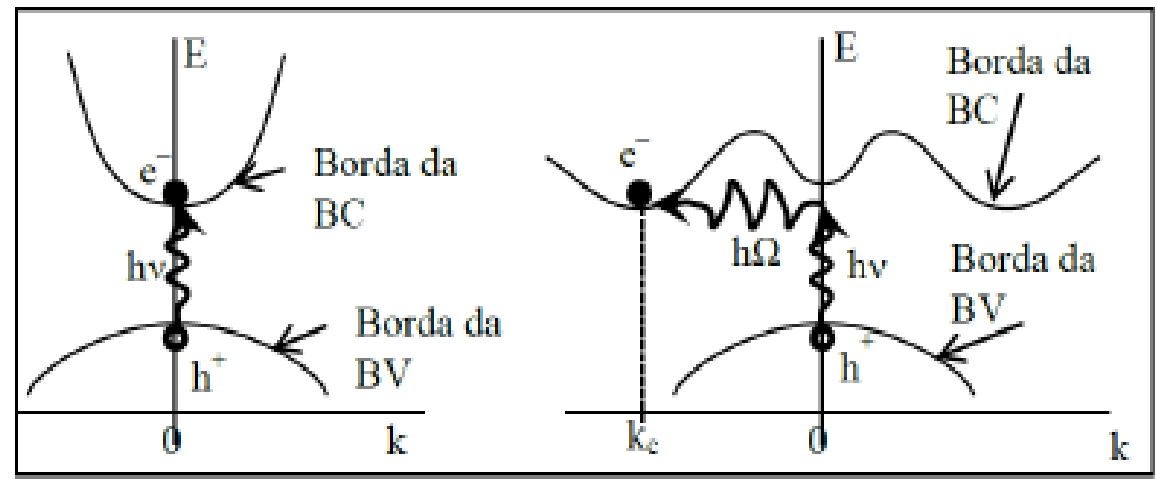

Figura A.4 - Esquema representando transições diretas (esquerda) e indiretas (direita) ocorrendo entre a banda de valência e a banda de condução em uma região próxima da borda fundamental. Adaptado de Barros (2018).

A Fig. A.4 mostra o exemplo de uma transição direta e outra indireta. Quando um fóton de energia hv é absorvido por um sólido, se sua energia for maior ou igual a $E_{g}$ o elétron salta da banda de valência diretamente para a banda de condução. Neste caso, o mínimo da banda de condução e o máximo da banda de valência estão associados a um mesmo momento da rede cristalina. Quando o mínimo da banda de valência e o máximo da banda de condução estão associados a valores diferentes do momento do cristal, o elétron, ao saltar para a banda de condução, cria um fônon de energia $h \Omega$ na rede (Fig. A.4 direita) (Kittel, 2006). Este tipo de transição é dita indireta.

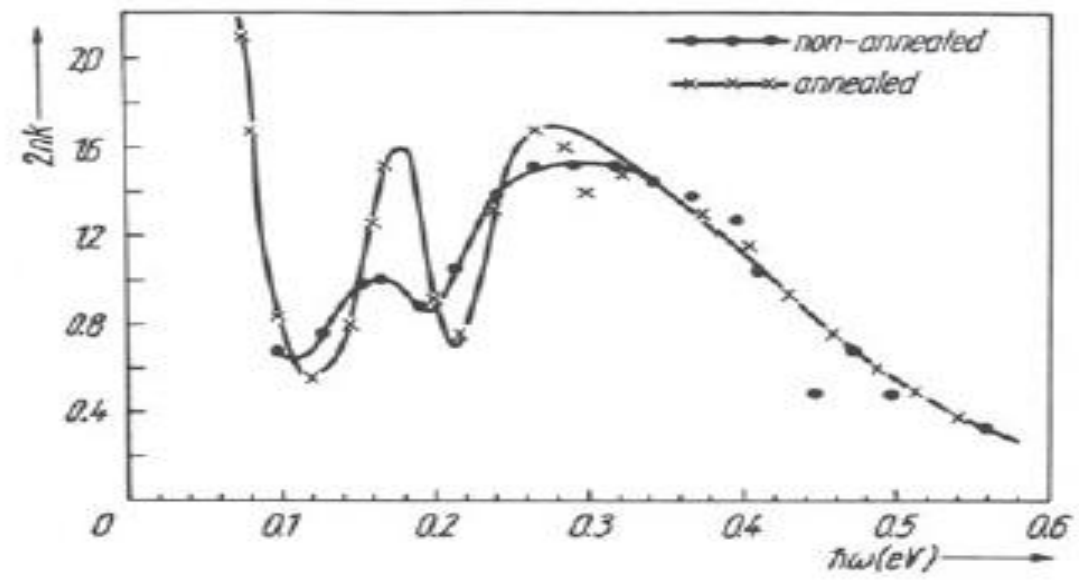

Figura A.5 - Função dielétrica como função da energia do fóton incidente sobre uma amostra de Ge. Entre 0,22 eV e 0,12 eV há uma banda de absorção de uma transição fundamental. Para energias menores que $0,1 \mathrm{eV}$ uma cauda mostra que a absorção, nesta região aumenta rapidamente. Tauc (1966). 
Observando a Fig. A.5 observam-se duas bandas de absorção consequência de transições fundamentais entra banda de valência e de condução. Entretanto, para energias menores que $0,1 \mathrm{eV}$ o valor da absorção aumenta muito rapidamente. Este aumento abrupto é chamado de cauda de absorção (absorption tail, do inglês). Tauc (1966) argumenta que esta cauda é causada por defeitos e impurezas na estrutura do Ge que geram níveis de energia aceitadores. Um nível aceitador captura um elétron da banda de valência. A incidência da radiação de energia hv excita o elétron gerando um par elétron buraco. Isto causa a abrupta absorção observada Tauc (1966). O espectro de Ge cristalino não mostra cauda de absorção. Tauc, então, percebeu que a cauda poderia ser modelada, com excelente aproximadamente, pela expressão:

$$
h v \varepsilon^{1 / 2} \sim\left(h v-E_{g}\right)
$$

que representa uma reta tangente à cauda de absorção.

A fim de verificar sua relação, Tauc fez um gráfico de $h v \varepsilon^{1 / 2}$ como função de hv, e obteve o seguinte resultado:

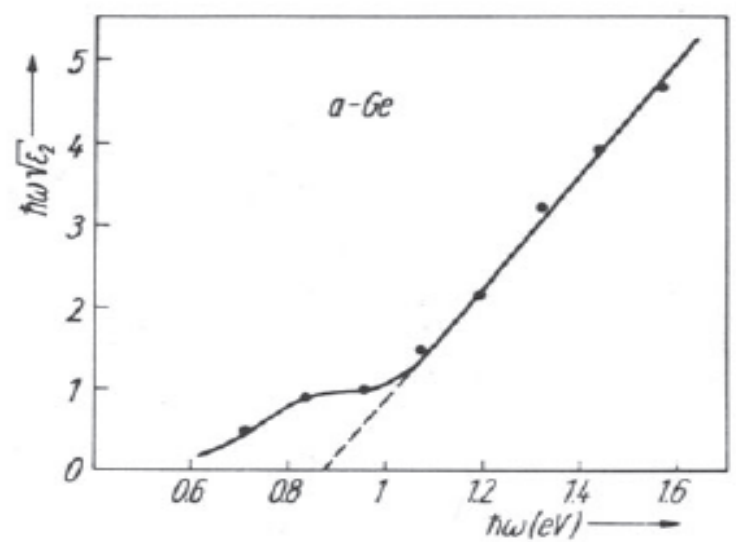

Figura A.6 - Gráfico de $h v \varepsilon^{1 / 2}$ como função de hv. O gráfico apresenta um regime linear que ao ser extrapolado fornece o valor da energia de gap do material. Tauc (1966).

A Fig. A.6 mostra o gráfico de $h v \varepsilon^{1 / 2}$ como função de hv. Em uma região acima de 1,0 eV o gráfico toma uma forma linear que é modelado pela equação A.9. Extrapolar este regime linear em direção ao eixo da energia fornece o valor da energia de gap do material. 
Tauc forneceu um tratamento formal para o problema calculando a parte imaginária da função dielétrica:

$$
\varepsilon_{2}(v)=\left(\frac{2 \pi \mathrm{e}}{\mathrm{mv}}\right)^{2} \frac{1}{\mathrm{v}} \sum_{\mathrm{if}}\left|\mathbf{P}_{\mathrm{if}}\right|^{2} \delta\left(E_{\mathrm{f}}-\mathrm{E}_{\mathrm{i}}-\mathbf{h v}\right)
$$

Onde a some é feita sobre todos os estados i,f em um volume V. $\mathrm{P}_{\text {if }}$ é a matriz de elementos entre as funções de onda dos estados inicial e final das banda de valência e condução. Os elementos de matriz são calculados através da combinação linear com as funções de Bloch que representam funções de onda das bandas de valência e condição para cristais. Após os cálculos a equação A.10 toma a forma

$$
\varepsilon_{2}(v)=\left(\frac{2 \pi \mathrm{e}}{\mathrm{mv}}\right)^{2} \frac{2}{(2 \pi)^{3}}\left|P_{\mathrm{if}}\right|^{2} \int \mathrm{dE} \mathrm{g}_{\mathrm{c}}(\mathrm{E}) \mathrm{g}_{\mathrm{v}}(\mathrm{hv}-\mathrm{E})
$$

onde $g_{c}$ e $g_{v}$ são as densidades de estado das banda de condução e valência, respectivamente. Por fim, Tau usa o argumento de que se as energias são medidas no extremo da banda valem as relações

$$
g_{v}(E)=E_{p}^{1 / 2}, g_{c}(E)=E_{n}^{1 / 2} e E_{n}+E_{p}=h v-E_{g}
$$

Onde o sub índice $\mathrm{n}$ representa o número de níveis aceitadores e o sub índice p o de buracos. Aplicando os valores acima na equação A.11 obtém-se a equação A.9. Posteriormente os resultados de Tauc foram generalizados para comtemplar transições diretas e indiretas. A relação resultante ficou conhecida como função de Tauc:

$$
\alpha h v=C\left(h v-E_{g}\right)^{a}
$$

O expoente, a, vale $1 / 2$ para transições diretas ou 2 para transições indiretas. O gráfico de $(\alpha h v)^{\text {a }}$ como função de hv ficou conhecido como Tauc plot e é utilizando em diversas áreas para determinação das energias de gap de diferentes materiais. 


\section{Apêndice B - Equilíbrio termodinâmico}

Com o objetivo de entender quais as possíveis espécies químicas poderiam ser formadas a partir dos componentes majoritários das amostras, foi feita uma simulação para determinar a composição de equilíbrio, como função da temperatura, que poderia ser obtida a partir da decomposição térmica de determinados minerais. Esta simulação foi feita pelo professor Rodrigo F. M. de Souza do Departamento de Engenharia Química e de Materiais (DEQM/PUCRio).

Esta simulação considera um recipiente fechado contendo o material a ser reduzido. Para cada valor de temperatura, a simulação informa em quais compostos o material original pode ser decomposto, bem como as respectivas abundancias relativas entre eles. A simulação é realizada utilizando-se o programa HSC Chemistry ( Roine A., 2006) que dispõem de um banco de dados contendo valores de grandezas termodinâmicas (entropia, entalpia e capacidade térmica) para um grande número de compostos químicos, o que permite calcular a composição de equilíbrio para cada valor de temperatura.

Os minerais usados na simulação de decomposição térmica foram: fayalita (Fig. B.1), forsterita (Fig. B.2), hematita (Fig. B.3) e sulfato de ferro III (Fig. B.4). Estes dados são de grande ajuda na interpretação dos resultados obtidos nesta tese. Em especial, na discussão sobre o avermelhamento do espectro UV-VIS-NIR. 


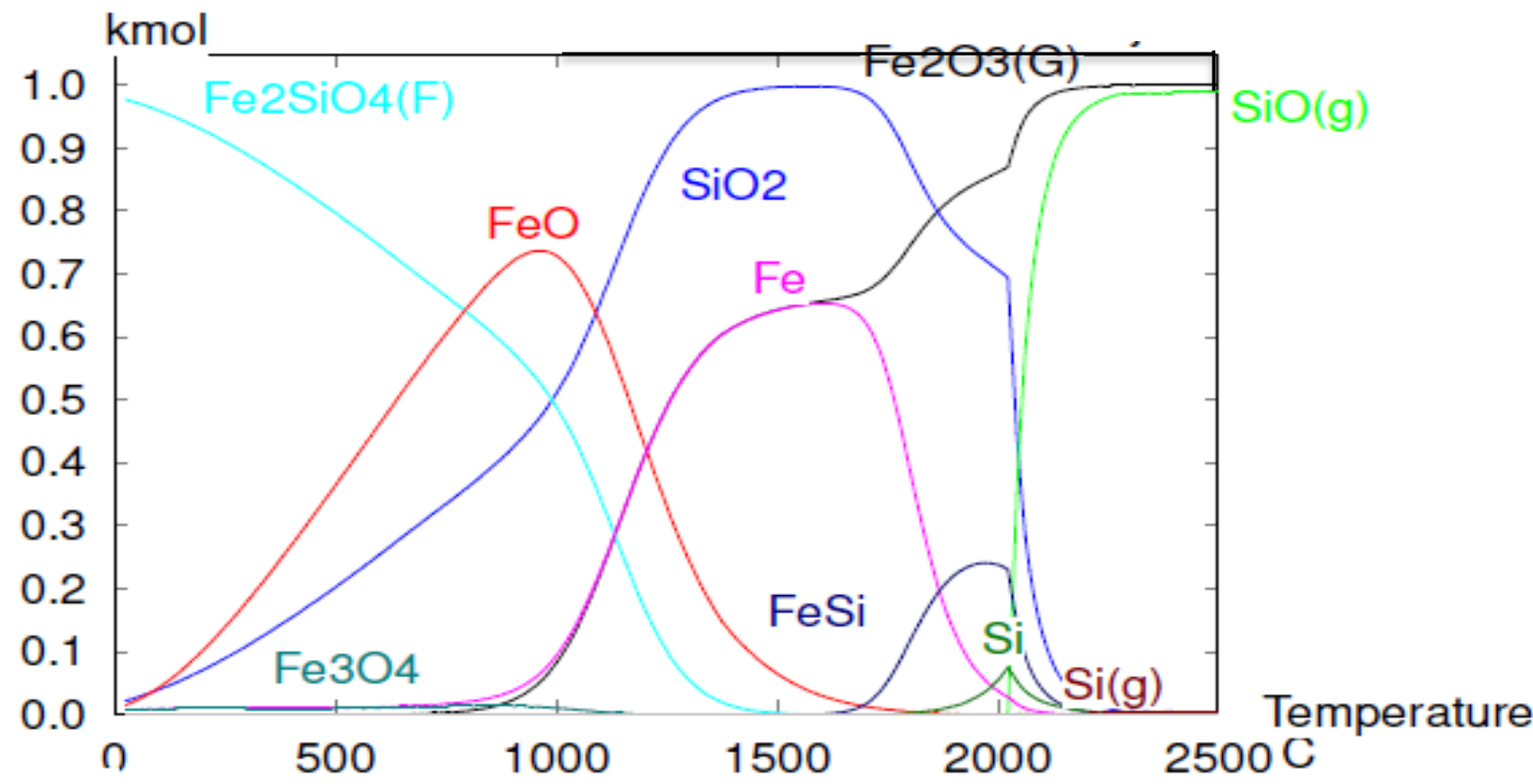

Figura B.1 - Decomposição térmica de $\mathrm{Fe}_{2} \mathrm{SiO}_{4}$ e as composições de equilíbrio formadas em função da temperatura.

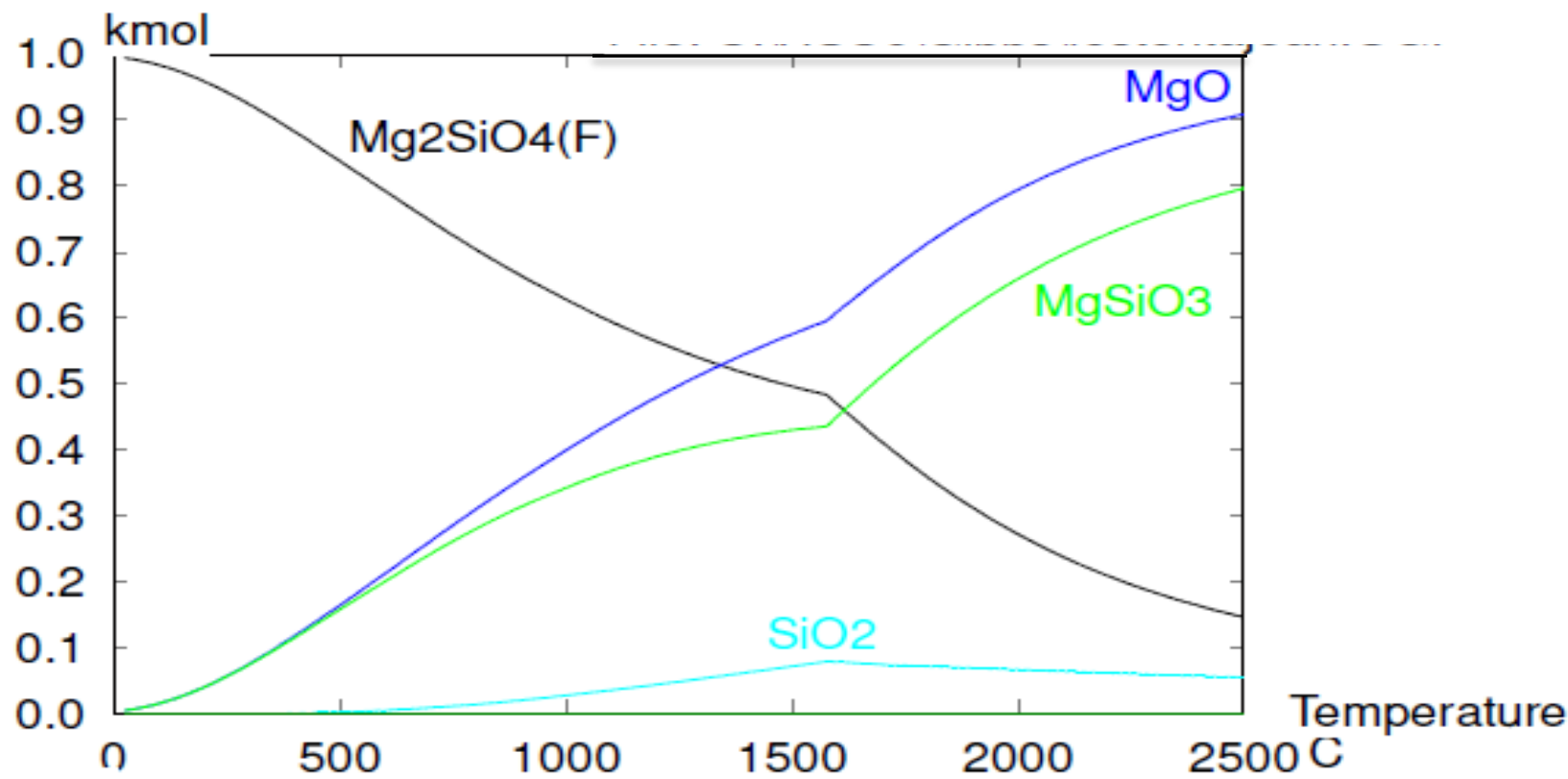

Figura B.2 - Decomposição térmica de $\mathrm{Mg}_{2} \mathrm{SiO}_{4}$ e as composições de equilíbrio formadas em função da temperatura. 


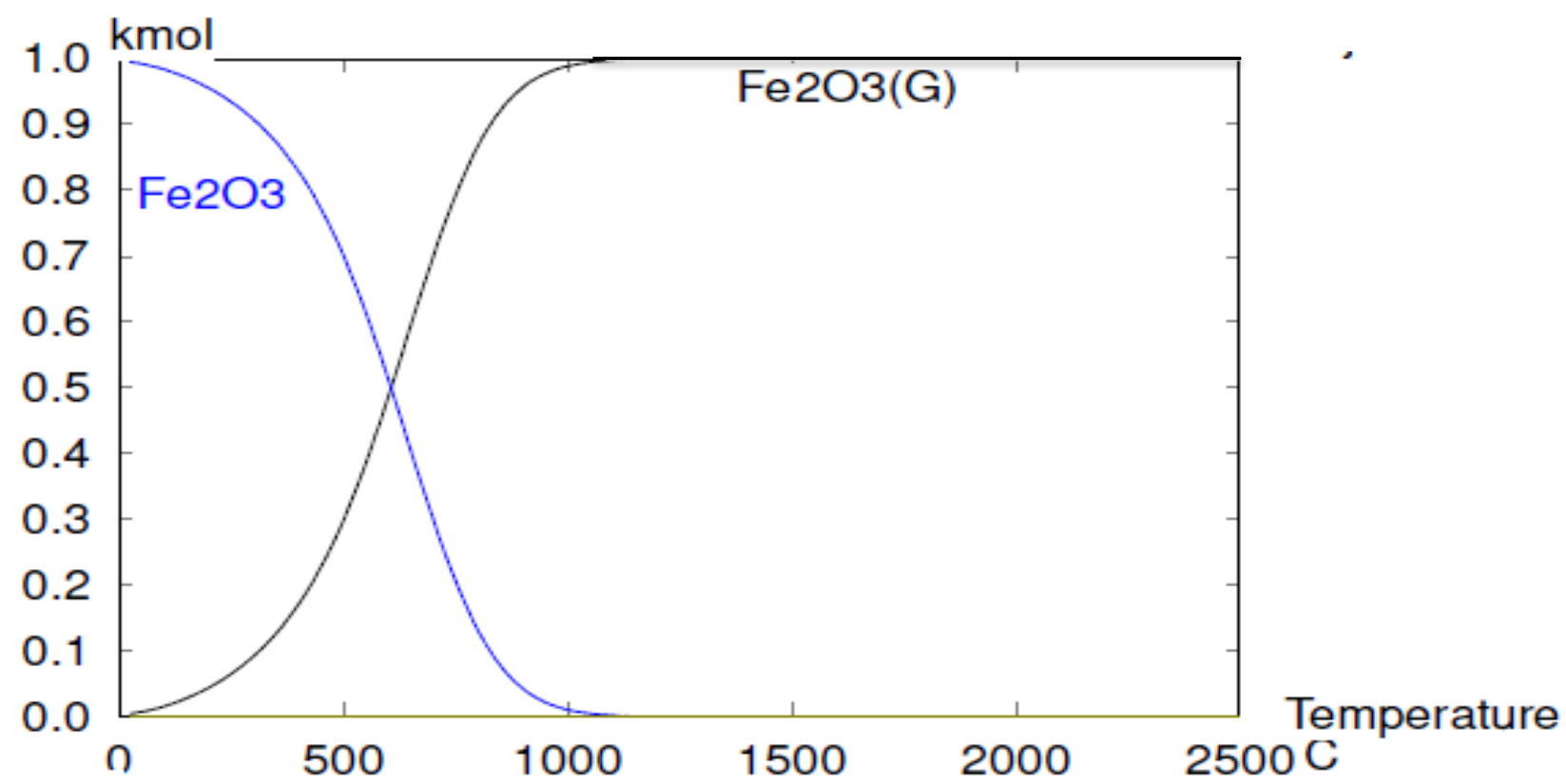

Figura B.3 - Decomposição térmica de $\mathrm{Fe}_{2} \mathrm{O}_{3}$ e as composições de equilíbrio formadas em função da temperatura.

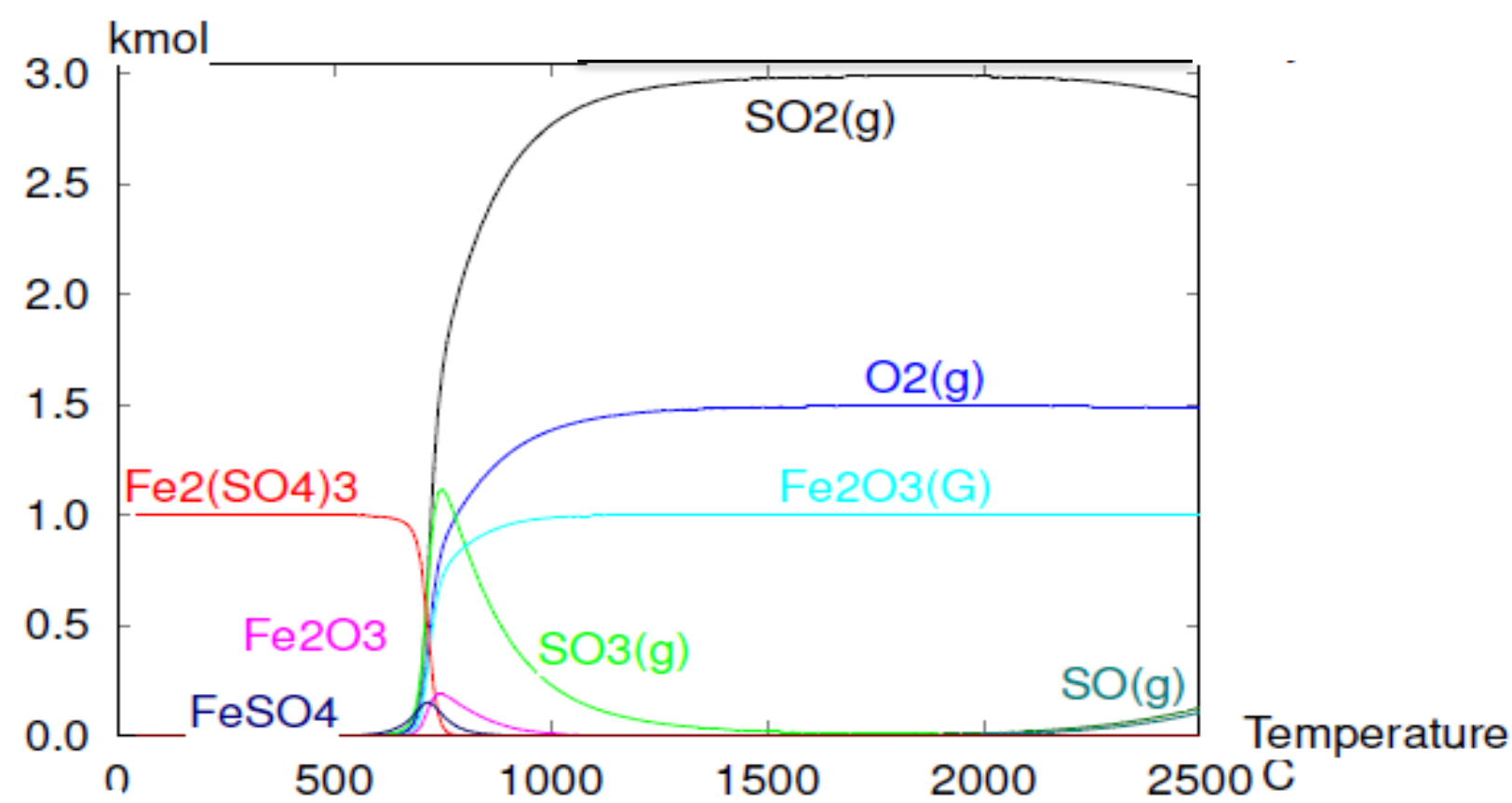

Figura B.4 - Decomposição térmica de $\mathrm{Fe}_{2}\left(\mathrm{SO}_{4}\right)_{3}$ e as composições de equilíbrio formadas em função da temperatura. 


\section{Apêndice C - Modelo de aquecimento térmico no traço}

Em um sólido o fluxo de calor pode ser determinado pela equação de difusão térmica sem fontes de calor:

$$
\frac{\partial T}{\partial t}=\frac{k}{\rho c} \nabla T
$$

Onde $\mathrm{k}$ corresponde a condutividade térmica do material, $\rho$ é a densidade e c a capacidade térmica (Collado et al., 2004).

Uma das soluções possíveis para a equação C.1 pode ser obtida para um meio infinito no qual um projétil rápido atravessa uma monocamada. A solução da equação de fluxo de calor para simetria cilíndrica é (Collado et. al., 2004):

$$
\Delta T=\frac{S \rho c}{4 \pi k t} e^{-\frac{\rho c r^{2}}{4 k t}}
$$

Onde S é o poder de frenamento e r o raio efetivo de interação do feixe. A solução acima corresponde a um pulso térmico propagando-se radialmente no interior do traço. Ele depende da taxa de energia depositada pelo feixe no sólido. A velocidade do pulso pode ser determinada por:

$$
\mathbf{v}=\sqrt{\frac{\mathbf{k}}{\rho \mathrm{ct}}}
$$

Para determinar o instante de tempo no qual a temperatura do pulso térmico é máxima deriva-se a equação C.2 e iguala-se a zero. O restado é o instante $t_{\text {max }}=\frac{\rho c r^{2}}{4 k}$. Para olivina a condutividade térmica vale $2,78 \mathrm{~W} / \mathrm{m}^{\circ} \mathrm{C}$ e o calor especifico $1320 \mathrm{~J} / \mathrm{kgK}$. A densidade é $4,2 \mathrm{~g} / \mathrm{cm}^{3}$. O raio efetivo fora obtidos pela equação 5.2. Utilizando estes valores encontra-se um $t_{\max }=13,8$ ps. Substituindo todos estes valores na equação C.2 estima-se que a temperatura máxima do pulso é de aproximadamente $7000 \mathrm{~K}$. 


\section{Apêndice D - Classificação dos meteoritos}

Os meteoritos recebem o nome do local onde caem ou onde são encontrados. Todos os meteoritos identificados são registrados no Meteoritical Bulletin Database (http://www.lpi.usra.edu/meteor/metbull.php) da The Meteoretical Society (http://meteoriticalsociety.org/).

Os critérios adotados para a classificação de meteoritos nem sempre foram os mesmos. Atualmente, a classificação dos meteoritos segue a proposta de Krot et al. (2005), que tem por objetivo reunir os meteoritos em grupos de origem similar e com histórico de formação parecido, na tentativa de relacioná-los a possíveis corpos parentais.

A classificação mais básica dos meteoritos é feita considerando-se a concentração de ferro e silicatos. Assim, os meteoritos são, inicialmente, divididos em três tipos: rochoso (formados majoritariamente de silicatos), metálicos (basicamente liga ferroníquel) e mistos (silicato e ferro-níquel em proporções equivalentes) [Zucolotto et. al. 2013]. Esses três tipos são ainda divididos em classes, que podem ser subdivididas em grupos.

A principal divisão feita no sistema proposto por Krot é em dois tipos: os condritos e os não condritos. Os condritos são meteoritos rochosos que nunca experimentaram processo de diferenciação planetária ${ }^{26}$, sendo considerados amostras primordiais de matéria do sistema solar. O constituinte que dá nome aos condritos são os côndrulos (grânulos, pequenos esferóides), que podem ser definidos neste contexto como "objetos que foram totalmente ou parcialmente formados antes ou durante o período de acreção que levou a formação dos condritos" [Hutchison, 2004]. Os côndrulos são pequenos corpos quasi-esféricos, formados principalmente de silicatos, com tamanho que varia entre $1 \mu \mathrm{m}$ e $5 \mathrm{~cm}$. Na classificação dos condritos os parâmetros principais são sua composição química, a distribuição de abundâncias isotópicas do oxigênio, do nitrogênio e do carbono, assim como o estado de oxidação dos elementos constituintes do meteorito (ou seja, a especiação química). Os não condritos, como o nome diz, são meteoritos que não possuem côndrulos. Sua origem se deve a corpos inicialmente do tipo condrito mas que sofreram algum grau de processo ígneo que alterou suas características primordiais. A tabela 2.1 mostra as sub-divisões de ambos os tipos: condritos e não condritos.

26 - Processo pelo qual uma mistura se separa em várias fases com diferentes composições químicas. No caso de planetas a diferenciação ocorre devido a ação da gravidade. A mistura formada devido a acreção se separa em camadas, sendo o núcleo formando pelos mais densos (ferro-níquel), um manto rico em silicatos e uma crosta. Os gases formam a atmosfera se a gravidade do planeta for suficiente para mantê-la. 
Tabela D.1 - Classificação química dos meteoritos. Adaptado de Carvalho et al. (2011)

\begin{tabular}{|c|c|c|c|c|c|c|c|c|c|}
\hline \multicolumn{5}{|l|}{ CONDRITOS } & \multicolumn{5}{|c|}{ NÃO CONDRITOS } \\
\hline \multirow{2}{*}{$\begin{array}{l}\text { Carbonáceos } \\
\text { CI-Ivuna }\end{array}$} & \multirow{2}{*}{$\begin{array}{l}\text { Ordinários } \\
\mathrm{H}\end{array}$} & \multirow{2}{*}{$\begin{array}{l}\text { Enstatitos } \\
\text { EH }\end{array}$} & \multirow[b]{2}{*}{ R-Rumuruti } & \multirow[b]{2}{*}{ K-Kakangari } & \multirow{2}{*}{$\begin{array}{l}\text { Primitivos } \\
\text { Pétreos }\end{array}$} & \multicolumn{4}{|l|}{ Diferenciados } \\
\hline & & & & & & Acondritos & \multicolumn{2}{|c|}{ Férreos-Pétreos } & \multirow{2}{*}{$\begin{array}{l}\text { Férreos } \\
\text { IAB }\end{array}$} \\
\hline CM-Mighei & $\mathrm{L}$ & EL & & & Acapulcoitos & Angritos & Mesossideritos & Palasitos & \\
\hline CO-ORNANS & LL & & & & Lodranitos & Aubritos & & Grupo Principal & IC \\
\hline CV-VIGARANO & & & & & Winonaitos & Brachinitos & & EagleStation & IIAB \\
\hline CK-Karoonda & & & & & & Ureleitos & & Piroxenitos & $\mathrm{DC}$ \\
\hline$\overline{\text { CR-Renazzo }}$ & & & & & Férreos & Howarditos & & & IID \\
\hline CB-Bencubbin & & & & & $\mathrm{IAB}$ & Eucritos & & & IIE \\
\hline \multirow[t]{7}{*}{ CH-ALH85005 } & & & & & IIICD & Diogenitos & & & IIF \\
\hline & & & & & & $\begin{array}{l}\text { SHERGOTITO } \\
\text { S }\end{array}$ & & & IIIAB \\
\hline & & & & & & Nakhalitos & & & IIICD \\
\hline & & & & & & Chassignitos & & & IIIE \\
\hline & & & & & & Ortopiroxenitos & & & IIIF \\
\hline & & & & & & Lunares & & & IVA \\
\hline & & & & & & & & & IVB \\
\hline
\end{tabular}




\section{Condritos}

Os condritos são subdivididos em cinco classes: Carbonáceos, Ordinário, Enstatitos, Rumirutitos e Kakangaritos.

1. Carbonáceos: apresentam oito grupos CI, CM, CO, CV, CK, CR, CB e $\mathbf{C H}$, sendo a primeira letra $(\mathrm{C})$ referente a carbonáceo e a segunda representa o nome do meteorito típico que dá nome ao grupo. (I) Ivuna; (M) Mighei; (O) Ornans; (V) Vigarano; (K) Karoonda; (R) Renazzo; (B) Bencubbin e (H) ALH85005.

2. Ordinários: o conteúdo de ferro total nesses meteoritos é usado como critério para sua subdivisão em três grupos: $\mathbf{H}$ (High), de $25 \%$ a $30 \% ; \mathbf{L}$ (Low), de 20\% a 25\%; e LL (Low-Low) de 19\% a 20\% de ferro em massa do total da massa da amostra do meteorito analisado.

3. Enstatitos: como os ordinários, os enstatitos são subdivididos segundo o teor de ferro. O EH (High), com aproximadamente $30 \%$ de ferro e o EL (Low) com $25 \%$ ou menos.

4. Os semelhantes ao meteorito Rumuruti.

5. Os semelhantes ao meteorito Kakangari.

As duas últimas classes designam meteoritos anômalos, que apesar de apresentarem algumas características de outros grupos condríticos, diferem por alguns aspectos que não permitem alocá-los em uma das três classes acima.

\section{Não condritos}

Os meteoritos não condritos são subdivididos de acordo com o grau de fusão a que foram submetidos. São divididos nos tipos primitivos e diferenciados.

1. Primitivos: não sofreram diferenciação completa, sendo apenas parcialmente fundidos apresentando características mineralógicas próximas das dos condritos. São subdivididos em dois grupos. Os pétreos que são denominados Acapulcoítos, Lodranitos e Winonaitos, e os Férreos (IAB e IIICD).

\section{Diferenciados:}


a) Acondrítos: sofreram diferenciação completa e apresentam muito pouco conteúdo metálico em sua composição.

b) Pétreos-férreos: são subdivididos em pallasitos, que foram formados na interface entre o núcleo interno e o manto inferior de corpos parentais diferenciados, e em mesosideritos formados por fusão durante o impacto de diferentes corpos parentais.

c) Férreos: são divididos em 13 grupos quimicamente distintos, designados por uma sigla composta por um número romano de I a IV seguido por uma ou duas letras, de A a G.

Os meteoritos são depositados nos Museus de História Natural de diversos países. Merecem destaque as Coleções do Smithsonion Institution (http://geogallery.si.edu/index.php/en/meteorites/all), Museum of London (http://www.nhm.ac.uk/nature-online/space/meteorites-dust), Muséum National d'Histoire Naturelle (http://www.mnhn.fr/fr). No Brasil, os meteoritos estão guardados no Museu Nacional da Quinta da Boa Vista, Rio de Janeiro (http://www.meteoritos.museunacional.ufrj.br). O mais famoso dos meteoritos caídos no Brasil é o Bendegó [Carvalho et al. 2011]. A Coleção do Museu Nacional é mantida por doações e por permutas. 